Artículo especial

Este artículo completo solo se encuentra disponible en versión electrónica: www.revespcardiol.org

\title{
Guía ESC 2015 sobre el tratamiento de pacientes con arritmias ventriculares y prevención de la muerte súbita cardiaca
}

\section{Grupo de Trabajo de la Sociedad Europea de Cardiología (ESC) para el tratamiento de pacientes con arritmias ventriculares y prevención de la muerte súbita cardiaca}

\author{
Avalada por: Association for European Paediatric and Congenital Cardiology (AEPC) \\ Autores/Miembros del Grupo de Trabajo: Silvia G. Priori* (coordinador) (Italia), \\ Carina Blomström-Lundqvist* (coordinador) (Suecia), Andrea Mazzantia (Italia), Nico Blom ${ }^{\mathrm{b}}$ \\ (Países Bajos), Martin Borggrefe (Alemania), John Camm (Reino Unido), Perry Mark Elliott (Reino Unido), \\ Donna Fitzsimons (Reino Unido), Robert Hatala (Eslovaquia), Gerhard Hindricks (Alemania), \\ Paulus Kirchhof (Reino Unido/Alemania), Keld Kjeldsen (Dinamarca), Karl-Heinz Kuck (Alemania), \\ Antonio Hernández-Madrid (España), Nikolaos Nikolaou (Grecia), Tone M. Norekvål (Noruega), \\ Christian Spaulding (Francia) y Dirk J. Van Veldhuisen (Países Bajos)
}

\begin{abstract}
Revisores del documento: Philippe Kolh (coordinador de revisión del CGPC) (Bélgica), Gregory Y.H. Lip (coordinador de revisión del CGPC) (Reino Unido), Stefan Agewall (Noruega), Gonzalo Barón-Esquivias (España), Giuseppe Boriani (Italia), Werner Budts (Bélgica), Héctor Bueno (España), Davide Capodanno (Italia), Scipione Carerj (Italia), María G. Crespo-Leiro (España), Martin Czerny (Suiza), Christi Deaton (Reino Unido), Dobromir Dobrev (Alemania), Cetin Erol (Turquía), Maurizio Galderisi (Italia), Bulent Gorenek (Turquía), Thomas Kriebel (Alemania), Pier Lambiase (Reino Unido), Patrizio Lancellotti (Bélgica), Deirdre A. Lane (UK), Irene Lang (Austria), Athanasios J. Manolis (Grecia), Joao Morais (Portugal), Javier Moreno (España), Massimo F. Piepoli (Italia), Frans H. Rutten (Países Bajos), Beata Sredniawa (Polonia), José L. Zamorano (España) y Faiez Zannad (Francia)
\end{abstract}

aCoordinador, filiación incluida en el apéndice

${ }^{\circ}$ En representación de la Association for European Paediatric and Congenital Cardiology (AEPC)

VÉASE CONTENIDO RELACIONADO:

http://dx.doi.org/10.1016/j.recesp.2015.12.006, Rev Esp Cardiol.2016;69:94-101.

\begin{abstract}
*Autores para correspondencia:
Department of Molecular Medicine University of Pavia, Cardiology \& Molecular Cardiology, IRCCS Fondazione Salvatore Maugeri, Via Salvatore Maugeri 10/10A, IT-27100 Pavia, Italia. Correo electrónico: silvia.priori@fsm.it (S. Giuliana Priori).

Department of Cardiology, Institution of Medical Science, Uppsala University, SE-751 85 Uppsala, Suecia.

Correo electrónico: carina.blomstrom.lundqvist@akademiska.se (C. Blomström-Lundqvist).

Los miembros del Comité de la ESC para la Elaboración de GPC y los revisores del documento representantes de las sociedades nacionales de cardiología aparecen listados en el apéndice.

Entidades de la ESC que han participado en el desarrollo de este documento:

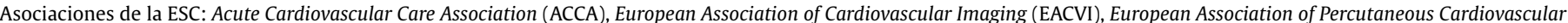
Interventions (EAPCI), European Heart Rhythm Association (EHRA) y Heart Failure Association (HFA)

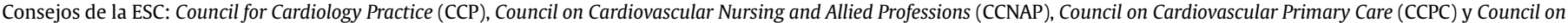
Hypertension.

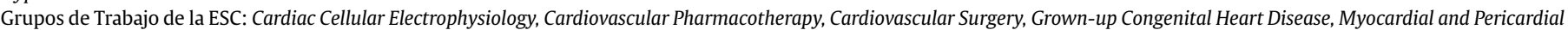
Diseases, Pulmonary Circulation and Right Ventricular Function, Thrombosis y Valvular Heart Disease.

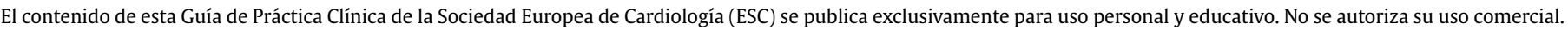

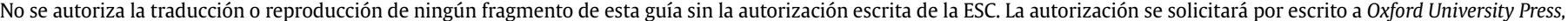
editorial de European Heart Journal y representante autorizado de la ESC para gestionar tales permisos.

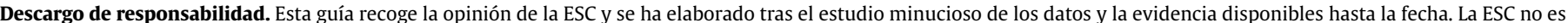

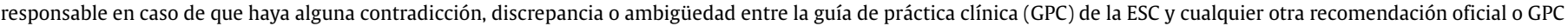

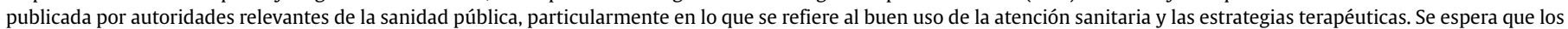

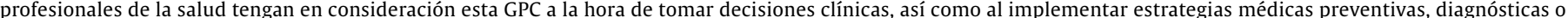

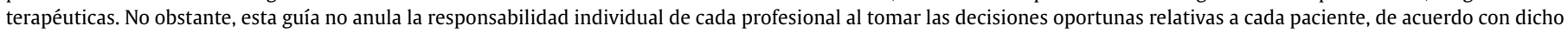

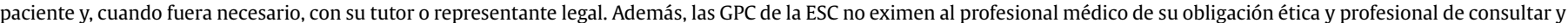

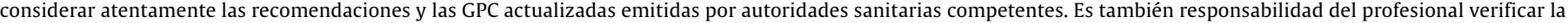
normativa y la legislación sobre fármacos y dispositivos médicos a la hora de prescribirlos.
\end{abstract}

Se puede consultar las declaraciones de conflicto de intereses de los expertos participantes en el desarrollo de esta guía en la página web de la ESC: www.escardio.org/guidelines

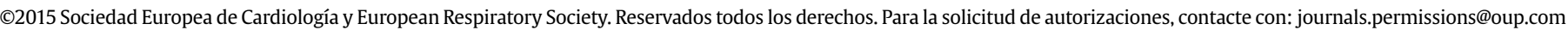

Palabras clave:

Síndrome coronario agudo • Terapia de resincronización cardiaca • Miocardiopatía • Enfermedad cardiaca congénita • Desfibrilador • Guías • Insuficiencia cardiaca • Desfibrilador automático implantable • Infarto de miocardio • Reanimación • Cardiopatía isquémica estable • Muerte súbita cardiaca $\bullet$ Taquicardia $•$ Enfermedad cardiaca valvular $•$ Arritmia ventricular 


\section{TABLA DE CONTENIDOS}

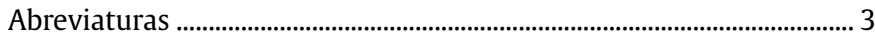

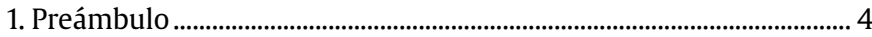

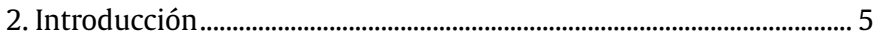

2.1. Estructura de la guía........................................................................ 5

3. Definiciones, epidemiología y perspectivas de futuro para la prevención de la muerte súbita cardiaca..................................... 5

3.1. Epidemiología de la muerte súbita cardiaca ................................. 5

3.1.1. Causas de muerte súbita cardiaca en diferentes grupos de edad ...................................................................... 5

3.2. Autopsia y autopsia molecular de víctimas de muerte

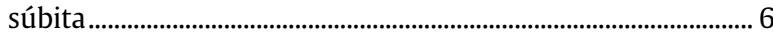

3.3. Predicción de riesgos de muerte súbita cardiaca ........................ 7

3.3.1. Individuos sin enfermedad cardiaca conocida ................ 7

3.3.2. Pacientes con cardiopatía isquémica .................................. 7

3.3.3. Pacientes con enfermedades arritmogénicas hereditarias 7

3.4. Prevención de la muerte súbita cardiaca en situaciones especiales

3.4.1. Cribado de la población general respecto al riesgo de muerte súbita cardiaca.

3.4.2. Cribado de familiares de víctimas de muerte súbita... 8

3.4.3. Cribado de pacientes con arritmias ventriculares documentadas o supuestas ..................................................... 9

3.4.3.1. Historia clínica .............................................................. 9

3.4.3.2. Evaluación no invasiva e invasiva.......................... 9

4. Terapias para arritmias ventriculares ....................................................... 11

4.1. Tratamiento de la enfermedad cardiaca subyacente ............... 11

4.2. Farmacoterapia para la arritmia ventricular

y la prevención de la muerte súbita cardiaca ............................ 11

4.2.1. Tratamiento general ............................................................... 11

4.2.2. Fármacos antiarrítmicos .................................................... 12

4.2.2.1. Bloqueadores beta ....................................................... 14

4.2.2.2. Amiodarona................................................................... 14

4.2.2.3. Sotalol/d-sotalol...................................................... 14

4.2.2.4. Tratamientos combinados.................................... 14

4.2.3. Pacientes portadores de desfibrilador automático..... 15

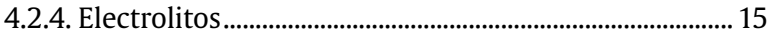

4.2.5. Terapia con otros fármacos.................................................... 15

4.3. Terapia con dispositivos .............................................................. 15

4.3.1. Desfibrilador automático implantable............................. 15

4.3.1.1. Prevención secundaria de la muerte súbita cardiaca y la taquicardia ventricular ................... 15

4.3.2. Desfibrilador automático implantable subcutáneo.... 16

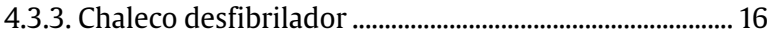

4.3.4. Acceso público a la desfibrilación ...................................... 17

4.4. Tratamiento agudo de las arritmias ventriculares sostenidas... 17

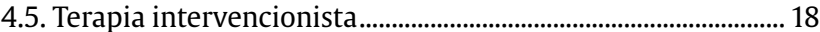

4.5.1. Ablación con catéter

4.5.1.1. Pacientes con enfermedad cardiaca relacionada con cicatrices....................................... 18

4.5.1.2. Pacientes sin enfermedad cardiaca estructural manifiesta

4.5.2. Cirugía antiarrítmica 19

4.6. Impacto psicosocial del tratamiento con desfibrilador automático implantable . .20

5. Tratamiento de las arritmias ventriculares y prevención de la muerte súbita cardiaca en la cardiopatía isquémica.................20

5.1. Síndromes coronarios agudos ..................................................2

5.1.1. Arritmias ventriculares asociadas a síndromes coronarios agudos. .20

5.1.2. Prevención y tratamiento de la muerte súbita cardiaca asociada a síndromes coronarios agudos: fase prehospitalaria
5.1.3. Prevención de la muerte súbita cardiaca asociada a síndromes coronarios agudos: fase hospitalaria ...... 21

5.1.3.1. Arritmias ventriculares en síndromes coronarios agudos .22

5.1.3.2. Uso de fármacos antiarrítmicos en síndromes coronarios agudos: consideraciones generales .22

5.1.3.3. Pacientes con síndromes coronarios agudos y sin arritmias ventriculares....................................22

5.1.3.4. Extrasístoles ventriculares.......................................22

5.1.3.5. Taquicardia ventricular y fibrilación ventricular sostenidas

5.1.3.6. Ablación por catéter de taquicardia ventricular sostenida recurrente, fibrilación ventricular recurrente y tormentas eléctricas.........................22

5.1.3.7. Dispositivos de asistencia circulatoria................22

5.1.3.8. Bradicardia y bloqueo del corazón .......................23

5.1.4. Valor pronóstico de la fibrilación ventricular precoz.......23

5.2. Periodo precoz tras un infarto de miocardio ..............................23

5.2.1. Estratificación de riesgos de muerte súbita cardiaca.. 23

5.2.2. Momento para colocar el desfibrilador automático implantable después de un infarto de miocardio: valoración de la disfunción del ventrículo izquierdo antes y después del alta ...................................23

5.3. Cardiopatía isquémica estable después de un infarto de miocardio con fracción de eyección conservada .................23

5.3.1. Estratificación de riesgos .....................................................23

5.3.2. Recomendaciones para una estrategia óptima ............. 24

5.3.3. Uso de fármacos antiarrítmicos............................................ 24

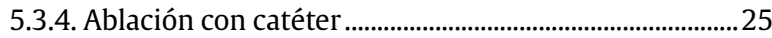

6. Terapias para pacientes con disfunción del ventrículo izquierdo con o sin insuficiencia cardiaca ...............................................2.

6.1. Prevención primaria de la muerte súbita cardiaca....................25

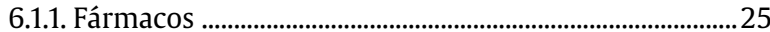

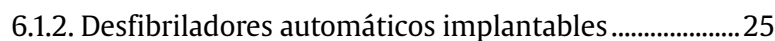

6.1.3. Desfibriladores automáticos implantables en pacientes en clase funcional IV de la New York Heart Association en lista de espera para trasplante cardiaco .26

6.1.4. Terapia de resincronización cardiaca.................................26

6.1.4.1. Insuficiencia cardiaca con fracción de eyección del ventrículo izquierdo reducida en clase III de la New York Heart Association/clase IV ambulatoria. 26

6.1.4.2. Insuficiencia cardiaca con fracción de eyección ventricular izquierda reducida pero con síntomas leves (clase II de la New York Heart Association) ....................................................... 28

6.2. Extrasístoles ventriculares en pacientes con enfermedad cardiaca estructural/disfunción del ventrículo izquierdo ....28

6.3. Taquicardia ventricular sostenida ...............................................28

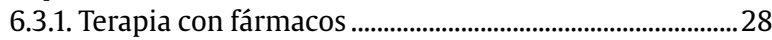

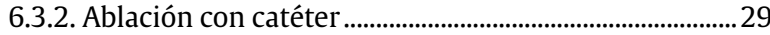

6.3.2.1. Pacientes con disfunción del ventrículo izquierdo...................................................................229

6.3.2.2. Taquicardia por reentrada rama-rama ..............29

6.3.3. Desfibrilador automático implantable ..............................29

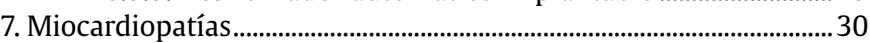

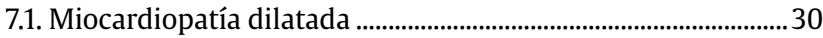

7.1.1. Definiciones, epidemiología y datos de supervivencia....30

7.1.2. Enfoque de la estratificación de riesgos

y del tratamiento .30

7.1.2.1. Estudios con desfibrilador automático implantable en la miocardiopatía dilatada........30

7.1.2.2. Prevención primaria ................................................... 31

7.1.2.3. Prevención secundaria............................................... 31 
7.1.2.4. Mortalidad por causas específicas ..........................31

7.1.2.5. Tratamiento de la arritmia ventricular en la miocardiopatía dilatada................................ 31

7.1.2.6. Ablación de la taquicardia ventricular................ 31

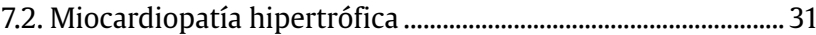

7.2.1. Definiciones, epidemiología y datos de supervivencia... 31

7.2.2. Enfoque de la estratificación de riesgos

y del tratamiento .32

7.2.3. Arritmias ventriculares en la miocardiopatía hipertrófica .. .32

7.2.4. Enfoque de la estratificación de riesgos y del tratamiento de pacientes adultos

7.2.5. Enfoque de la estratificación de riesgos y del tratamiento de pacientes pediátricos .........32

7.2.6. Prevención de la muerte súbita cardiaca.........................32 7.2.6.1. Fármacos y consejos sobre el estilo de vida.....32 7.2.6.2. Desfibriladores automáticos implantables......33

7.3. Miocardiopatía arritmogénica del ventrículo derecho............33

7.3.1. Definiciones, epidemiología y supervivencia..................33

7.3.2. Enfoque de la estratificación de riesgos y del tratamiento . .33

7.3.3. Arritmias ventriculares en la miocardiopatía arritmogénica del ventrículo derecho...............................33 7.3.3.1. Tratamiento de la arritmia ventricular................34 7.3.3.2. Restricción del ejercicio.........................................34 7.3.3.3. Desfibriladores automáticos implantables......34

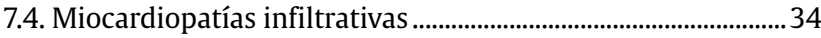

7.4.1. Amiloidosis cardiaca................................................................. 34

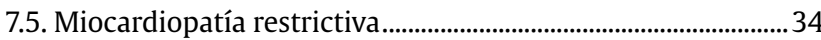

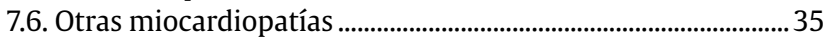

7.6.1. Ventrículo izquierdo no compactado................................... 35

7.6.2. Miocardiopatía chagásica....................................................... 35

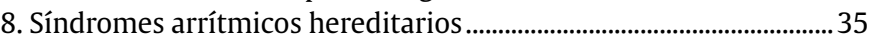

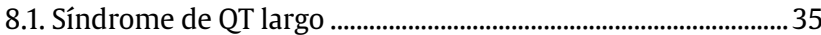

8.1.1. Definiciones y epidemiología ................................................ 35

8.1.2. Enfoque de la estratificación de riesgos

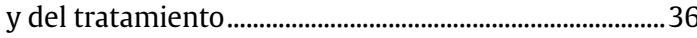

8.2. Síndrome de QT corto .......................................................................36

8.2.1. Definiciones y epidemiología..............................................36

8.2.2. Enfoque de la estratificación de riesgos

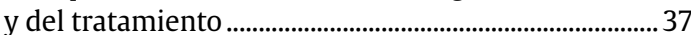

8.3. Síndrome de Brugada ...................................................................... 37

8.3.1. Definiciones y epidemiología............................................. 37

8.3.2. Enfoque de la estratificación de riesgos y del tratamiento ................................................................... 37

8.4. Taquicardia ventricular polimórfica catecolaminérgica ........38

8.4.1. Definiciones y epidemiología.................................................38

8.4.2. Enfoque de la estratificación de riesgos y del tratamiento.

8.5. Síndrome de repolarización precoz..............................................39

8.5.1. Definiciones y epidemiología...............................................39

9. Arritmias pediátricas y enfermedad cardiaca congénita...................39

9.1. Tratamiento de las arritmias ventriculares en niños con corazón estructuralmente normal. . .39

9.2. Muerte súbita cardiaca y arritmias ventriculares en pacientes con enfermedad cardiaca congénita....................40

9.3. Terapia con desfibrilador automático implantable en pacientes pediátricos .. .41

10. Taquicardias ventriculares y fibrilación ventricular

en corazones estructuralmente normales............................................. 41

10.1. Taquicardia ventricular del tracto de salida ................................. 41

10.1.1. Taquicardias del tracto de salida del ventrículo derecho

10.1.2. Taquicardias del tracto de salida del ventrículo izquierdo

10.1.3. Taquicardias ventriculares de las cúspides aórticas.... 42
10.1.4. Taquicardias ventriculares epicárdicas del tracto de salida

10.1.5. Otras (incluidas las arterias pulmonares) .....................42

10.2. Taquicardias ventriculares de origen misceláneo....................43

10.2.1. Taquicardia ventricular izquierda idiopática ................43

10.2.2. Taquicardia ventricular de los músculos papilares .... 43

10.2.3. Taquicardia ventricular de los anillos (mitral

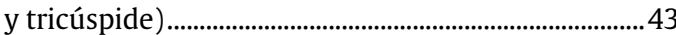

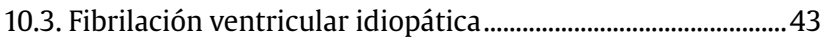

10.4. Torsade de pointes con acoplamiento corto .................................4

11. Enfermedades cardiacas inflamatorias, reumáticas y valvulares... 44

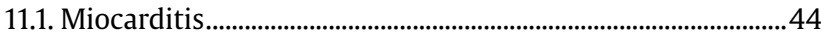

11.1.1. Miocarditis aguda y fulminante ........................................ 45

11.1.2. Miocarditis que da lugar a miocardiopatía inflamatoria

11.2. Endocarditis .................................................................................... 46

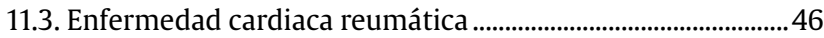

11.4. Pericarditis ........................................................................................ 46

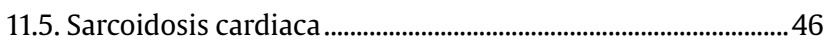

11.6. Enfermedad cardiaca valvular ...........................................................4 46

12. Riesgo arrítmico en poblaciones seleccionadas ..................................4

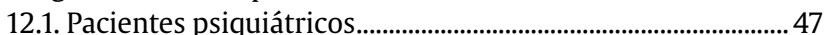

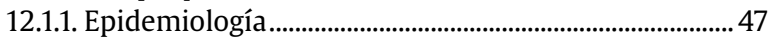

12.1.2. Diagnóstico ............................................................................ 47

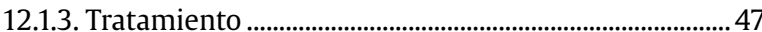

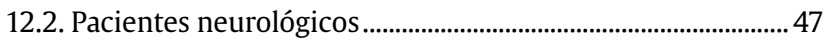

12.2.1. Muerte súbita inexplicable en la epilepsia .................... 47

12.2.2. Trastornos neuromusculares ...............................................4 48

12.3. Pacientes gestantes........................................................................... 49

12.3.1. Arritmias no relacionadas con miocardiopatía periparto 49 12.3.1.1. Epidemiología............................................................ 50

12.3.1.2. Diagnóstico ................................................................. 50

12.3.1.3. Tratamiento ............................................................ 50

12.3.2. Arritmias relacionadas con miocardiopatía periparto .

.50

12.4. Apnea obstructiva del sueño .......................................................50

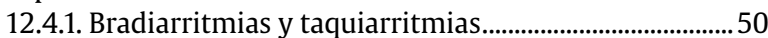

12.4.1.1. Epidemiología............................................................ 51

12.4.1.2. Diagnóstico .............................................................. 51

12.4.1.3. Tratamiento ................................................................ 51

12.5. Proarritmia relacionada con fármacos ...................................... 51

12.5.1. Interacción fármaco-sustrato debida a sustrato de enfermedad subyacente............................... 51

12.5.2. Interacción fármaco-fármaco debida a fármacos específicos y combinaciones ....................... 51

12.5.3. Riesgo proarrítmico de fármacos antiarrítmicos ....... 51

12.5.4. Proarritmia debida a factores desencadenantes ........52

12.6. Muerte súbita cardiaca después de un trasplante cardiaco.. 52

12.7. Muerte súbita cardiaca de atletas...............................................52

12.8. Síndrome de Wolff-Parkinson-White ..........................................54

12.9. Prevención de la muerte súbita cardiaca de ancianos..........54

12.10. Aspectos de la etapa final de la vida........................................54

13. Lagunas en la evidencia..............................................................................5

14. Mensajes sobre lo que se debe y lo que no se debe hacer ...............55

15. Anexo web ................................................................................................ 56

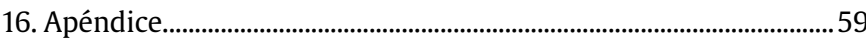

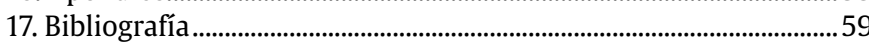

\section{Abreviaturas}

ARA-II: antagonistas del receptor de la angiotensina II ARM: antagonista de los receptores de mineralocorticoides $\mathrm{AV}$ : arritmia ventricular 
AV: auriculoventricular

BRDH: bloqueo de la rama derecha del haz de His

BRIH: bloqueo de la rama izquierda del haz de His

CI: cardiopatía isquémica

DAI: desfibrilador automático implantable

ECC: enfermedad cardiaca congénita

ECG: electrocardiograma

ECG-SP: electrocardiograma de señal promediada

EEF: estudio electrofisiológico

ESC: Sociedad Europea de Cardiología

EV: extrasístole ventricular

EVP: estimulación ventricular programada

FA: fibrilación auricular

FEVI: fracción de eyección del ventrículo izquierdo

FV: fibrilación ventricular

GWAS: estudio de asociación del genoma completo

HR: hazard ratio

i.v.: intravenoso

IMCEST: infarto de miocardio con elevación del segmento ST

IMSEST: infarto de miocardio sin elevación del segmento ST

IC: insuficiencia cardiaca

ICFEc: insuficiencia cardiaca con fracción de eyección conservada

ICFEr: insuficiencia cardiaca con fracción de eyección reducida

IECA: inhibidores de la enzima de conversión de la angiotensina

LMNA: lamina A/C

MAVD: miocardiopatía arritmogénica del ventrículo derecho

MCD: miocardiopatía dilatada

$\mathrm{MCH}$ : miocardiopatía hipertrófica

MSC: muerte súbita cardiaca

NYHA: New York Heart Association

OR: odds ratio

QTc: QT corregido

RMC: resonancia magnética cardiaca

RR: riesgo relativo

SCA: síndrome coronario agudo

SPECT: tomografía computarizada por emisión monofotónica

SQTC: síndrome del QT corto

SQTL: síndrome del QT largo

SQTL1: síndrome del QT largo de tipo 1

SQTL2: síndrome del QT largo de tipo 2

SQTL3: síndrome del QT largo de tipo 3

TC: tomografía computarizada

TdP: torsade de pointes

TRC: terapia de resincronización cardiaca

TRC-D: terapia de resincronización cardiaca con desfibrilador

TRC-M: terapia de resincronización cardiaca con marcapasos

TS: tracto de salida

TSVD: tracto de salida del ventrículo derecho

TSVI: tracto de salida del ventrículo izquierdo

TV: taquicardia ventricular

TVNS: taquicardia ventricular no sostenida

TVPC: taquicardia ventricular polimórfica catecolaminérgica

VD: ventrículo derecho

VI: ventrículo izquierdo

WPW: Wolff-Parkinson-White

\section{PREÁMBULO}

Las Guías de Práctica Clínica (GPC) tienen como objetivo reunir y evaluar toda la evidencia relevante disponible durante el proceso de elaboración sobre un tema particular para ayudar a los médicos a seleccionar la mejor estrategia posible de tratamiento para un paciente en particular, que sufre una enfermedad determinada, teniendo en cuenta no solo el resultado final, sino también sopesando los riesgos y los beneficios de un procedimiento diagnóstico o terapéutico concreto. Las GPC y las recomendaciones deben ayudar a los profesionales de la salud en la toma de decisiones clínicas en su ejercicio diario. No obstante, la decisión final sobre un paciente concreto la debe tomar el médico responsable de su cuidado, en consulta con el propio paciente 0 , cuando proceda, con la persona responsable de sus cuidados.

En los últimos años, la Sociedad Europea de Cardiologia (ESC), además de otras sociedades y organizaciones científicas, ha publicado gran número de GPC. Debido al impacto de las GPC, se han establecido criterios de calidad para su elaboración de modo que todas las decisiones se presenten de forma clara y transparente al usuario. Se puede encontrar las recomendaciones de la ESC para la elaboración y publicación de GPC en la sección de guías de la página web de la ESC (http://www.escardio.org/Guidelines-\&-Education/Clinical-PracticeGuidelines/Guidelines-development/Writing-ESC-Guidelines). Las GPC de la ESC representan la postura oficial de la ESC sobre un tema particular y se actualizan con regularidad.

Los miembros de este Grupo de Trabajo fueron seleccionados por la ESC en representación de los profesionales de la salud dedicados a los cuidados médicos de la patología tratada en el presente documento. Los expertos seleccionados realizaron una revisión exhaustiva de la evidencia publicada sobre el manejo de una entidad concreta (incluidos el diagnóstico, el tratamiento, la prevención y la rehabilitación) según las normas establecidas por el Comité de la ESC para la elaboración de GPC. Además, llevaron a cabo la evaluación crítica de los procedimientos diagnósticos y terapéuticos, incluida la valoración de la razón riesgo/beneficio. Cuando se dispone de datos, se incluye también una estimación de los resultados sanitarios para grandes grupos de población. Se valoraron el nivel de evidencia y la fuerza de la recomendación de una opción terapéutica particular de acuerdo con escalas predefinidas, tal como se indica en las tablas 1 y 2.

Los miembros del Grupo de Trabajo y los revisores del documento han declarado por escrito cualquier relación que se pueda considerar conflicto de intereses real o potencial. Estas declaraciones escritas han sido archivadas y están disponibles en la página web de la ESC (http://www.escardio.org/guidelines). Durante el periodo de redacción, se notificaron a la ESC y se actualizaron las modificaciones en las relaciones que se pudieran considerar conflictos de intereses. El informe del Grupo de Trabajo fue financiado en su totalidad por la ESC y se desarrolló sin ninguna participación de la industria.

El Comité para la elaboración de GPC de la ESC supervisa y coordina la preparación de nuevas GPC elaboradas por los Grupos de Trabajo, grupos de expertos o paneles de consenso. El Comité es responsable también del proceso de aprobación de las GPC. El Comité de la ESC y expertos externos revisan exhaustivamente el documento, tras lo cual es aprobado por todos los miembros del Grupo de Trabajo. Por último, el documento final es aprobado por el Comité de la ESC para su publicación en European Heart Journal. La elaboración de la presente GPC se realizó tras la meticulosa evaluación del conocimiento científico y médico y de la evidencia disponible hasta la fecha de su redacción.

La tarea de elaboración de GPC incluye no solo la integración de la investigacion más reciente, sino también la creación de herramientas educativas y programas de implementación de las recomendaciones. Para su implementación, se desarrollan ediciones de bolsillo, resúmenes en diapositivas y tarjetas, folletos con mensajes clave y versiones electrónicas para aplicaciones digitales (smartphones, etc.). Estas versiones son resumidas y, por lo tanto, en caso de necesidad, se debe consultar la versión completa disponible gratuitamente en las páginas web de la ESC. Se recomienda a las sociedades nacionales que forman parte de la ESC suscribir, traducir e implementar las GPC de la ESC. Los programas de implementación son necesarios porque se ha demostrado que la aplicación de las recomendaciones clínicas influye favorablemente en los resultados clínicos. 
Tabla 1

Clases de recomendación

\begin{tabular}{|c|c|c|}
\hline Grados de recomendación & Definición & Expresiones propuestas \\
\hline Clase I & $\begin{array}{l}\text { Evidencia y/o acuerdo general en que un determinado procedimiento diagnóstico/tratamiento } \\
\text { es beneficioso, útil y efectivo }\end{array}$ & Se recomienda/está indicado \\
\hline Clase II & Evidencia conflictiva y/o divergencia de opinión acerca de la utilidad/eficacia del tratamiento & \\
\hline Clase IIa & El peso de la evidencia/opinión está a favor de la utilidad/eficacia & Se debe considerar \\
\hline Clase IIb & La utilidad/eficacia está menos establecida por la evidencia/opinión & Se puede recomendar \\
\hline Clase III & $\begin{array}{l}\text { Evidencia o acuerdo general en que el tratamiento no es útil/efectivo y en algunos casos puede } \\
\text { ser perjudicial }\end{array}$ & No se recomienda \\
\hline
\end{tabular}

Tabla 2

Niveles de evidencia

\begin{tabular}{|ll|}
\hline Nivel de evidencia A & $\begin{array}{l}\text { Datos procedentes de múltiples ensayos clínicos } \\
\text { aleatorizados o metanálisis }\end{array}$ \\
\hline Nivel de evidencia B & $\begin{array}{l}\text { Datos procedentes de un único ensayo clínico } \\
\text { aleatorizado o de grandes estudios no aleatorizados }\end{array}$ \\
\hline Nivel de evidencia C & $\begin{array}{l}\text { Consenso de opinión de expertos y/o pequeños } \\
\text { estudios, estudios retrospectivos, registros }\end{array}$ \\
\hline
\end{tabular}

Asimismo es necesario realizar encuestas y registros para verificar si la práctica clínica en la vida real se corresponde con las recomendaciones de las guías y de esta forma se completa el ciclo entre la investigación clinica, la elaboración de las guías y su implementación en la práctica clínica.

Se recomienda a los profesionales de la salud que tengan en consideración la presente guía de la ESC en la toma de decisiones clínicas en su ejercicio diario, así como en la determinación y la implementación de estrategias preventivas, diagnósticas y terapéuticas; no obstante, la decisión final sobre el cuidado de un paciente concreto, en consulta con dicho paciente y, si fuera necesario, con su representante legal, debe tomarla el médico responsable de su cuidado. Además, es responsabilidad del profesional de la salud comprobar la normativa aplicable a fármacos y dispositivos médicos antes de su prescripción.

\section{INTRODUCCIÓN}

El presente documento se ha concebido como actualización europea de las Guías de 2006 del American College of Cardiology (ACC)/ American Heart Association (AHA)/ESC para el tratamiento de pacientes con arritmias ventriculares y la prevención de la muerte súbita cardiaca (MSC) ${ }^{1}$. A la luz de los muy recientes documentos de consenso para el tratamiento de pacientes con arritmias ventriculares emitidos por las principales sociedades internacionales sobre ritmo cardiaco ${ }^{2,3}$, el Comité de Guías de la ESC decidió enfocar el contenido de este documento en la prevención de la MSC. La actualización es oportuna, si se consideran los nuevos conocimientos sobre la historia natural de enfermedades que predisponen a la MSC y la finalización de importantes estudios que tendrán impacto en las estrategias de tratamiento para la insuficiencia cardiaca (IC) que incluyen terapias tanto con fármacos como con dispositivos.

\subsection{Estructura de la guía}

El documento se divide en secciones que cubren temas específicos. Se debe adaptar el esquema de evaluación de riesgos y el tratamiento ofrecidos teniendo en consideración las comorbilidades, la limitación de la esperanza de vida, el impacto en la calidad de vida y otras circunstancias.

Mientras preparaba esta actualización, el Comité revisó las recomendaciones más recientes sobre cada tema y modificó la clase o la solidez de las recomendaciones considerando si los nuevos resultados de ensayos aleatorizados, los metanálisis o la evidencia clínica requerirían un cambio. Se tuvo especial cuidado en mantener la coherencia en el uso del lenguaje con las guías existentes. Ocasionalmente, sin embargo, se hicieron cambios en la redacción para hacer que algunas de las recomendaciones originales estuviesen más adaptadas al usuario y fuesen más precisas.

El Comité estaba compuesto por médicos y profesionales de la salud, asociados expertos en las áreas de MSC y prevención, arritmias ventriculares complejas, electrofisiología intervencionista, cardiopatía isquémica (CI), IC y miocardiopatía, cardiología pediátrica y arritmias, terapia con dispositivos, cuidados cardiovasculares, genética cardiovascular y enfermería. Se identificó a expertos en diferentes subespecialidades de cardiología con la ayuda de los grupos de trabajo relacionados de la ESC.

Todos los miembros del Comité de Redacción aprobaron las recomendaciones de la guía. Setenta y cuatro revisores realizaron la revisión del documento por pares. Se realizó un extenso examen de la literatura que condujo a la incorporación de 810 referencias. Las guías revisadas relacionadas con la prevención de la MSC se enumeran en la tabla 1 del anexo $w e b^{3-13}$.

\section{DEFINICIONES, EPIDEMIOLOGÍA Y PERSPECTIVAS DE FUTURO PARA LA PREVENCIÓN DE LA MUERTE SÚBITA CARDIACA}

Las definiciones utilizadas para muerte súbita, parada cardiaca abortada, fibrilación ventricular (FV) idiopática y prevención de la muerte súbita se detallan en la tabla 3.

\subsection{Epidemiología de la muerte súbita cardiaca}

En los últimos 20 años, la mortalidad cardiovascular ha disminuido en los países más desarrollados ${ }^{19}$ en respuesta a la adopción de medidas preventivas para reducir la carga de $\mathrm{CI}$ e IC. A pesar de estos resultados esperanzadores, las enfermedades cardiovasculares causan en todo el mundo aproximadamente 17 millones de muertes al año, de las que aproximadamente un $25 \%$ corresponde a $\mathrm{MSC}^{20}$. El riesgo de MSC es mayor para los varones que para las mujeres y aumenta con la edad debido a la mayor prevalencia de $\mathrm{Cl}$ a edad avanzada $^{21}$. Por consiguiente, se estima que la tasa de MSC varía de 1,40/100.000 personas-año (intervalo de confianza del 95\% [IC95\%], $0,95-1,98$ ) entre las mujeres a $6,68 / 100.000$ personas-año (IC95\%, $6,24-7,14)$ entre los varones ${ }^{21}$. La MSC de individuos más jóvenes tiene una incidencia estimada de $0,46-3,7$ episodios/100.000 personasaño $0^{22,23}$, lo que corresponde a una estimación aproximada de 1.100 9.000 muertes en Europa y 800-6.200 muertes en Estados Unidos cada año ${ }^{24}$.

\subsubsection{Causas de muerte súbita cardiaca en diferentes grupos de edad}

Las enfermedades cardiacas asociadas a MSC difieren entre las personas jóvenes y las de más edad. En los jóvenes, predominan las 
Tabla 3

Definiciones de términos empleados habitualmente

\begin{tabular}{|c|c|c|}
\hline Término & Definición & Ref \\
\hline Muerte súbita & $\begin{array}{l}\text { Suceso fatal no traumático e inesperado que se produce en la primera hora tras la aparición de síntomas en un sujeto } \\
\text { aparentemente sano. Si no se presencia la muerte, la definición se aplica cuando la víctima estaba en buen estado de salud } \\
24 \mathrm{~h} \text { antes del evento }\end{array}$ & 1 \\
\hline SMSInex y MSII & Muerte súbita sin causa aparente ni autopsia realizada a un adulto (SMSInex) o un niño de edad < 1 año (MSII) & 14 \\
\hline \multirow[t]{4}{*}{ MSC } & Se usa el término cuando: & \\
\hline & - Afección cardiaca congénita o adquirida potencialmente fatal conocida en vida o & \\
\hline & - Autopsia que identifica una anomalía cardiaca o vascular como causa probable del evento o & \\
\hline & $\begin{array}{l}\text { - Causas extracardiacas obvias no identificadas mediante examen post mortem, de modo que la probable causa de muerte } \\
\text { es un evento arrítmico }\end{array}$ & $1,14,15$ \\
\hline SMSA y SMSI & $\begin{array}{l}\text { Tanto la autopsia como los estudios toxicológicos son inconcluyentes, el corazón es estructuralmente normal al examen } \\
\text { macroscópico e histológico y se excluyen etiologías no cardiacas en adultos (SMSA) y niños (SMSI) }\end{array}$ & 16 \\
\hline Parada cardiaca abortada & $\begin{array}{l}\text { Parada circulatoria inesperada que se produce en la primera hora tras la aparición de los síntomas agudos y se revierte } \\
\text { mediante maniobras de reanimación eficaces (como desfibrilación) }\end{array}$ & - \\
\hline Fibrilación ventricular idiopática & Las investigaciones clínicas son negativas en un paciente que sobrevive a un episodio de fibrilación ventricular & 17,18 \\
\hline Prevención primaria de la MSC & $\begin{array}{l}\text { Terapias para reducir el riesgo de MSC de individuos en riesgo de MSC pero que aún no han sufrido una parada cardiaca } \\
\text { abortada o arritmias de riesgo vital }\end{array}$ & - \\
\hline Prevención secundaria de la MSC & $\begin{array}{l}\text { Terapias para reducir el riesgo de MSC de pacientes que ya han sufrido una parada cardiaca abortada o arritmias de riesgo } \\
\text { vital }\end{array}$ & 1 \\
\hline
\end{tabular}

MSC: muerte súbita cardiaca; MSII: muerte súbita inexplicable en la infancia; Ref: referencias; SMSA: síndrome de muerte súbita arrítmica; SMSI: síndrome de muerte súbita infantil; SMSInex: síndrome de muerte súbita inexplicable.

canalopatías y las miocardiopatías (tabla 2 del anexo web) ${ }^{21,25-48}$, miocarditis y abuso de sustancias ${ }^{49}$, mientras que en poblaciones de más edad predominan las enfermedades degenerativas crónicas ( $\mathrm{Cl}$, cardiopatías valvulares e IC). Varios retos socavan la identificación de la causa de la MSC en ambos grupos de edad: las víctimas de más edad, por ejemplo, pueden sufrir múltiples afecciones cardiovasculares crónicas, de tal forma que resulta difícil determinar qué contribuyó más a la MSC. En personas más jóvenes, la causa de la MSC puede ser difícil de precisar incluso tras la autopsia, ya que algunas afecciones -como las canalopatías heredadas o las arritmias inducidas por fármacos- que están desprovistas de anormalidades estructurales son relevantes desde el punto de vista epidemiológico en este grupo de edad.

Indicaciones de autopsia y autopsia molecular para víctimas de muerte súbita

\begin{tabular}{|c|c|c|c|}
\hline Recomendaciones & Clase $^{\mathrm{a}}$ & Nivel $^{\mathrm{b}}$ & $\operatorname{Ref}^{c}$ \\
\hline $\begin{array}{l}\text { Se recomienda una autopsia para investigar las } \\
\text { causas de la muerte súbita y determinar si la } \\
\text { MSC es secundaria a mecanismos arrítmicos o no } \\
\text { arrítmicos (p. ej., rotura de un aneurisma aórtico) }\end{array}$ & I & C & 17 \\
\hline $\begin{array}{l}\text { Siempre que se realice una autopsia, se } \\
\text { recomienda un examen histológico estándar del } \\
\text { corazón que debería incluir bloques marcados } \\
\text { de miocardio mapeados de cortes transversales } \\
\text { representativos de ambos ventrículos }\end{array}$ & I & C & 17 \\
\hline $\begin{array}{l}\text { Se recomienda el análisis de sangre y otros } \\
\text { fluidos corporales adecuadamente recogidos para } \\
\text { toxicología y patología molecular de toda víctima } \\
\text { de muerte súbita inexplicable }\end{array}$ & I & C & 17 \\
\hline $\begin{array}{l}\text { Se debería considerar el análisis post mortem } \\
\text { dirigido de genes potencialmente causantes de } \\
\text { enfermedad de toda víctima de muerte súbita } \\
\text { con sospecha de canalopatía o miocardiopatía } \\
\text { hereditaria específica }\end{array}$ & IIa & C & $17,50,51$ \\
\hline
\end{tabular}

MSC: muerte súbita cardiaca.

${ }^{a}$ Clase de recomendación.

${ }^{b}$ Nivel de evidencia.

'Referencias que respaldan las recomendaciones.

\subsection{Autopsia y autopsia molecular de víctimas de muerte súbita}

La identificación de la causa de una muerte inesperada permite a la familia entender parcialmente y racionalizar la tragedia, lo que facilita el proceso de aceptación y permite saber si el riesgo de muerte súbita puede extenderse a los miembros de la familia. Por consiguiente, parece razonable someter a todas las víctimas de muerte súbita no explicable a un examen post mortem por expertos para investigar si se habría de sospechar causa cardiaca. Aunque la CI causa una gran proporción de muertes súbitas, especialmente de mayores de 40 años, habría que considerar otras causas como los trastornos genéticos que afecten a la integridad del músculo cardiaco (véase la sección 7) o su función eléctrica (véase la sección 8). Cada vez que se identifica una enfermedad hereditaria en un individuo fallecido, los familiares de la víctima pueden tener riesgo de hallarse afectados y de morir repentinamente a menos que se haga un diagnóstico a tiempo y se tomen medidas preventivas.

Por desgracia, incluso cuando se realiza una autopsia, entre un 2 y un $54 \%^{48}$ de las muertes súbitas permanecen sin explicar (tabla 2 del anexo $w e b)$ : este amplio margen de valores probablemente se deba a la heterogeneidad de los protocolos de autopsia. Para promover una norma común para la autopsia, se han desarrollado guías centradas en este tema con el fin de definir los protocolos para el examen del corazón y la toma de muestras histológicas, así como para la toxicología y la investigación molecular ${ }^{17,50}$. En general, una autopsia apropiadamente realizada debe proporcionar respuestas a las siguientes cuestiones: a) si la muerte es atribuible a una enfermedad cardiaca; b) de estar presente, la naturaleza de dicha enfermedad cardiaca; c) si el mecanismo de la muerte era arrítmico; $d$ ) si hay evidencia de una enfermedad cardiaca que se pueda heredar y, por lo tanto, requiera rastreo y asesoramiento de los familiares, y e) la posibilidad de consumo de fármacos tóxicos o ilegales u otras causas de muerte no natural.

Un examen histológico estándar del corazón debería incluir bloques marcados mapeados de cortes transversales del miocardio representativos de ambos ventrículos. Animamos a los patólogos a ponerse en contacto con centros especializados y enviarles el corazón 
para su examen. El patólogo debe realizar un examen macroscópico estándar del corazón que incluya una sección apical transversal y recoger tejidos, sangre y otros fluidos para toxicología y patología molecular antes de fijar el corazón en formalina. Además, se anima a recoger y almacenar muestras biológicas para la extracción de ADN con objeto de poder realizar una autopsia «molecular»" ${ }^{17}$. La autopsia molecular es un complemento importante de la autopsia estándar, ya que permite el diagnóstico post mortem de la presencia de canalopatías que pueden explicar un $15-25 \%$ de los casos de síndrome de muerte súbita arrítmica ${ }^{17}$. El valor del diagnóstico post mortem de una víctima de MSC reside en la ampliación del cribado genético a los miembros de la familia de las víctimas de síndrome de muerte súbita arrítmica o síndrome de muerte súbita infantil. Recientes documentos de consenso de expertos para el diagnóstico y el tratamiento de arritmias hereditarias indican que habría que considerar el uso de una autopsia molecular dirigida/pruebas genéticas post mortem para las víctimas de MSC cuando se sospeche de canalopatías. Se apoya esta recomendación y se remite a los lectores interesados a los documentos de consenso más recientes sobre este tema ${ }^{14,52}$.

\subsection{Predicción de riesgos de muerte súbita cardiaca}

La predicción de la MSC es la piedra filosofal de la arritmología, y los intentos de proporcionar indicadores fiables de MSC han impulsado una de las áreas más activas de investigación en la arritmología durante las últimas décadas ${ }^{53}$. Actualmente está claro que la propensión a morir repentinamente se origina como una "tormenta perfecta»: interacción de un sustrato vulnerable (cambios genéticos o adquiridos en las propiedades eléctricas o mecánicas del corazón) con múltiples factores transitorios que participan en el desencadenamiento del suceso mortal. En la sección siguiente se proporciona una breve revisión de la escasez de esquemas de estratificación de riesgo de MSC para sujetos normales, pacientes con $\mathrm{CI}$ y pacientes con canalopatías y miocardiopatías.

\subsubsection{Individuos sin enfermedad cardiaca conocida}

Aproximadamente un $50 \%$ de las paradas cardiacas se producen en individuos sin una enfermedad cardiaca conocida, pero la mayoría padece $\mathrm{Cl}$ oculta ${ }^{54}$. Como consecuencia, el enfoque más eficaz para prevenir la MSC en la población general reside en la cuantificación del riesgo individual de sufrir CI según gráficos de puntuación de riesgo, seguida del control de factores de riesgo tales como el colesterol total en suero, la glucosa, la presión sanguínea, el consumo de tabaco y el índice de masa corporal ${ }^{55}$. Aproximadamente un $40 \%$ de la reducción observada en la MSC es consecuencia directa de una reducción de la CI y otras afecciones cardiacas ${ }^{56}$.

Varios estudios ${ }^{57-61}$ han aportado evidencia de que hay una predisposición genética a morir repentinamente. El grupo de investigación liderado por X. Jouven fue uno de los primeros en investigar el valor predictivo de la recurrencia familiar de muerte súbita. Los autores demostraron, en el estudio de París publicado en $1999^{57}$, que un antecedente parental de muerte súbita tenía un riesgo relativo (RR) de muerte súbita de 1,89 , que aumentaba a 9,44 en quienes tenían 2 antecedentes parentales de muerte súbita $(\mathrm{p}=0,01)$. Al mismo tiempo, Friedlander et $\mathrm{al}^{58}$ confirmaron, en un estudio de cohortes basado en casuística del estudio de Framingham, un incremento de casi el 50\% ( $R R=1,46$; IC95\%, 1,23-1,72) en la probabilidad de muerte súbita en presencia de antecedente familiar de MSC. En 2006, Dekker et $\mathrm{a}^{59}$ mostraron que la muerte súbita familiar se produce significativamente con mayor frecuencia en individuos reanimados de una FV primaria que en controles (odds ratio [OR] = 2,72; IC95\%, 1,84-4,03). La consistencia impactante de estos resultados apunta a que la predisposición a morir repentinamente está escrita en los genes, incluso en ausencia de una enfermedad mendeliana, y anima a que las investiga- ciones moleculares identifiquen marcadores de ADN para predecir la MSC en la población general.

Entre los estudios que han buscado polimorfismos de un solo nucleótido que predispongan a MSC, son relevantes los resultados de 2 estudios de asociación de genoma completo (GWAS): el estudio AGNES $^{61}$, que incluyó a pacientes con un primer infarto de miocardio y FV y los comparó con una cohorte de pacientes con un primer infarto de miocardio sin FV. Solo un polimorfismo de un único nucleótido localizado en el locus 21q21 alcanzó significación de genoma completo $\left(\mathrm{OR}=1,78\right.$; IC95\%, 1,47-2,13; $\left.\mathrm{p}=3,36 \times 10^{-10}\right)$. Este polimorfismo de un solo nucleótido común (el $47 \%$ de frecuencia del alelo) está en una región intergénica y el gen más próximo, CXADR (a 98kb de distancia), codifica un receptor viral implicado en la miocarditis viral. El segundo GWAS ${ }^{62}$ es un estudio muy extenso que identificó una fuerte señal en el locus 2q24.2, que contiene 3 genes con función desconocida que se expresan todos ellos en el corazón. Este locus aumenta el riesgo de MSC en 1,92 (IC95\%, 1,57-2,34). El estudio, sin embargo, no reprodujo los resultados del estudio AGNES, lo que levantó sospechas de que el tamaño o el diseño de este tuvieran limitaciones. Estos datos genéticos aún no se aplican en clínica, pero muestran que la genética puede llegar a ser un enfoque prometedor para cuantificar el riesgo de MSC en un momento precoz de la vida. La disponibilidad de nuevas tecnologías que permitan una genotipificación más rápida y más barata puede proporcionar pronto datos sobre poblaciones muy extensas y suministrar el poder estadístico necesario para estas investigaciones.

\subsubsection{Pacientes con cardiopatía isquémica}

Durante más de 2 décadas, los investigadores de todo el mundo han concebido una amplia gama de «indicadores» para la MSC en el marco de la CI. Se han propuesto varios marcadores no invasivos de riesgo de MSC para pacientes con isquemia miocárdica, entre otros, la estimulación ventricular programada (EVP), los potenciales tardíos, la variabilidad del ritmo cardiaco, la sensibilidad barorrefleja, la dispersión del intervalo QT, la microalternancia de la onda T y la turbulencia del ritmo cardiaco. Sin embargo, a pesar de los prometedores resultados de los estudios iniciales, ninguno de estos "predictores» ha influido en la práctica clínica. Como consecuencia de ello, el único indicador que ha mostrado de manera constante asociación con mayor riesgo de muerte súbita en el marco del infarto de miocardio y la disfunción del ventrículo izquierdo (VI) es la fracción de eyección del VI (FEVI $)^{63,64}$. Esta variable se ha utilizado durante más de una década para indicar el uso de desfibrilador automático implantable (DAI) para la prevención primaria de la MSC, frecuentemente en combinación con la clase funcional de la New York Heart Association (NYHA). A pesar de que la FEVI no es un parámetro clínico exacto y altamente reproducible, aún se emplea para seleccionar a pacientes para implante de DAI en prevención primaria de la MSC.

Entre las variables emergentes que parecen prometedoras para predecir la MSC, se encuentran indicadores bioquímicos tales como el péptido natriurético tipo B (BNP) y la prohormona $\mathrm{N}$-terminal del BNP (NT-proBNP), que han mostrado resultados alentadores en las investigaciones preliminares ${ }^{65,66}$.

\subsubsection{Pacientes con enfermedades arritmogénicas hereditarias}

La disponibilidad de esquemas de estratificación de riesgo es altamente heterogénea entre las diferentes canalopatías y miocardiopatías: por ejemplo, aunque la duración del intervalo QT corregido (QTc) es un indicador fiable de riesgo de eventos cardiacos en el síndrome del QT largo (SQTL ${ }^{67}$ y la hipertrofia septal predice que se producirá como resultado miocardiopatía hipertrófica $(\mathrm{MCH})^{68}$, en otras enfermedades como el síndrome de Brugada o el síndrome del QT corto (SQTC), las medidas de estratificación de riesgo no son sólidas, lo que deja dudas sobre cómo abordar el uso profiláctico del DAI. Hasta ahora, se puede 
usar la información genética para guiar la estratificación de riesgos solo en unas cuantas enfermedades, tales como el SQTL y la miocardiopatía dilatada (MCD) por mutaciones del gen de la lamina $\mathrm{A} / \mathrm{C}^{69-71}$.

\subsection{Prevención de la muerte súbita cardiaca en situaciones especiales}

\subsubsection{Cribado de la población general respecto al riesgo de muerte súbita cardiaca}

La vigilancia con respecto a signos electrocardiográficos (ECG) y ecocardiográficos de enfermedades arritmogénicas hereditarias parece ser una parte importante de la práctica clínica y puede contribuir a la identificación precoz de pacientes con riesgo de MSC. Actualmente, no está claro si dicho enfoque cuidadoso debería ampliarse al cribado masivo de poblaciones con riesgo de muerte súbita. Italia y Japón han utilizado sistemas de cribado por ECG, que pueden identificar a pacientes asintomáticos con enfermedades arritmogénicas hereditarias ${ }^{72-74}$. Aunque hay consenso entre los expertos de Europa y Estados Unidos que apoyan el cribado en atletas previo a la participación (un enfoque respaldado por el Comité Olímpico Internacional $)^{75-77}$, un estudio reciente ha mostrado que no hubo cambios en las tasas de incidencia de MSC entre los atletas de competición tras la utilización de programas de cribado en Israel ${ }^{78}$.

De modo similar, no hay datos claros que respalden el beneficio de los programas de cribado amplio de la población general. Narain et al ${ }^{79}$ hicieron un cribado de 12.000 personas sanas no seleccionadas de 14-35 años de edad. El cribado se realizó con un coste de 35 libras esterlinas por individuo y consistía en un cuestionario de salud, ECG de 12 derivaciones y consulta con un cardiólogo. Se sometió a las personas con anormalidades a un ecocardiograma transtorácico el mismo día o se los derivó para una evaluación más amplia. Aunque el cribado identificó solo a unos cuantos pacientes con canalopatías o miocardiopatías hereditarias (4/12.000), los autores concluyeron que el coste que supone identificar a individuos con mayor riesgo de MSC de todos modos respaldaba un programa de cribado en masa.

Está claro que la valoración de coste-beneficios del cribado de la población por ECG está influida en gran medida por el coste de identificación de un solo individuo afectado. El sistema nacional de salud italiano no ha determinado dicho coste, a pesar de que hay un programa de cribado universal en vigor durante los últimos 35 años, y variará dependiendo de la organización regional de salud. La estimación de costes en Estados Unidos para el cribado de atletas varía entre 300 millones y 2.000 millones de dólares al año según Kaltman et al ${ }^{80}$.

En general, no se puede hacer recomendaciones para el cribado de poblaciones en este momento, ya que no se han establecido las consecuencias de las estrategias de cribado que detectan un número aún sin definir de "falsos positivos" y dejan de lado un porcentaje desconocido de casos afectados ("falsos negativos»). Esta incapacidad para derivar una recomendación de la evidencia obtenida de los programas de cribado existentes ilustra la necesidad de trabajar más para recoger datos cuantitativos sobre el perfil de coste-beneficios de la realización de cribado por ECG en diferentes poblaciones y en diferentes sistemas y situaciones de salud. Por el contrario, considerando el mayor riesgo de arritmias y el empeoramiento de enfermedades estructurales o genéticas de individuos expuestos a ejercicio físico intenso ${ }^{81,82}$, respaldamos las recomendaciones existentes para el cribado de atletas previo a la participación deportiva. En Europa hay consenso en que se debe realizar a esta población una evaluación clínica, una elaboración de la historia personal o familiar y un ECG basal de 12 derivaciones (véase la sección 12.7).

\subsubsection{Cribado de familiares de víctimas de muerte súbita}

Se establece el diagnóstico de un trastorno arritmogénico hereditario en hasta un $50 \%{ }^{83}$ de las familias con una víctima de síndrome de muerte súbita arrítmica, especialmente canalopatías (p. ej., SQTL, sín- drome de Brugada y taquicardia ventricular polimórfica catecolaminérgica [TVPC]) y ocasionalmente formas sutiles de miocardiopatía (MCH y miocardiopatía arritmogénica del ventrículo derecho [MAVD] en particular) o hipercolesterolemia familiar. Como consecuencia de estos hallazgos, cuando no se dispone de la autopsia de la víctima (es decir, síndrome de muerte súbita inexplicable o muerte súbita inexplicable en la infancia) o el examen post mortem no consigue detectar anormalidades estructurales y los resultados de la toxicología son normales (es decir, síndrome de muerte súbita arrítmica o síndrome de muerte súbita infantil), se debe informar a los familiares en primer grado de la víctima del riesgo potencial de que les ocurran eventos similares y deben someterse a evaluación cardiaca. El antecedente familiar de síndrome de muerte súbita inexplicable prematuro recurrente o cardiopatía hereditaria representa una "bandera roja» que hace que se recomiende firmemente la evaluación familiar.

El cribado familiar de los familiares en primer grado de víctimas de muerte súbita es una intervención importante para identificar a individuos que se encuentran en situación de riesgo, aconsejar sobre el tratamiento disponible y prevenir adecuadamente la muerte súbita $^{14,84}$. Actualmente solo se criba a un $40 \%$ de los familiares ${ }^{85}$, en parte debido a la falta de una infraestructura de cribado adecuada, pero también debido a la ansiedad y la angustia asociadas a la experiencia personal de una arritmia de riesgo vital o el fallecimiento reciente de un familiar por una afección cardiaca hereditaria ${ }^{86,87}$. Habría que evaluar las necesidades psicosociales de estos pacientes y sus familias y se debería seguir un enfoque multidisciplinario en centros especializados, como se ha recomendado recientemente ${ }^{14,84,88}$. Se ha demostrado el valor de este enfoque ${ }^{89,90}$.

Se han propuesto diversos protocolos para el cribado de los familiares de víctimas de muerte súbita ${ }^{14,91}$. Estos protocolos siguen normalmente un enfoque por etapas, comenzando con investigaciones de menor coste y mayor rendimiento y pasando a posteriores exámenes basados tanto en los hallazgos iniciales como en la historia fami$\operatorname{liar}^{91}$. Siempre que se sospeche un diagnóstico basado en la presencia de anormalidades estructurales o eléctricas, se debe seguir el procedimiento estándar para el diagnóstico de la enfermedad sospechada.

Una elaboración precisa de la historia es la primera etapa para alcanzar el diagnóstico post mortem, previamente a la exploración activa de los familiares. Cuando la víctima es joven, debe centrarse en miocardiopatías y canalopatías. Se recomienda la evaluación de síntomas cardiacos premonitorios (incluidos el síncope y la «epilepsia»), junto con una exploración exhaustiva de las circunstancias de la muerte y la recogida de investigaciones clínicas cardiacas ante mortem. Cuando la víctima es de edad > 40 años, se debe valorar la presencia de factores de riesgo de $\mathrm{CI}$ (p. ej., si es fumador activo o pasivo, dislipoproteinemia, hipertensión o diabetes mellitus). Además, se debe crear una genealogía completa de 3 generaciones que registre todas las muertes súbitas y las cardiopatías ${ }^{14}$. Se debe realizar esfuerzos por recuperar los expedientes médicos antiguos o los exámenes post mortem. Se debe dar prioridad para la evaluación a los familiares con síntomas que indiquen afección cardiaca, tales como síncope, palpitaciones o dolor torácico.

En la tabla 4 se ilustra la evaluación fundamental recomendada de un pariente en primer grado de una víctima de muerte súbita. En ausencia de un diagnóstico en la familia, se debe hacer un cribado de los niños de corta edad al menos con un ECG basal y un ecocardiograma.

Dado que muchas enfermedades arritmogénicas hereditarias se caracterizan por penetrancia relacionada con la edad y expresión incompleta, se debería hacer un seguimiento de los individuos más jóvenes a intervalos regulares. Se puede librar de los cuidados a los adultos asintomáticos y totalmente desarrollados, a menos que aparezcan síntomas o se disponga de nueva información de la familia.

Cuando se sospeche una enfermedad arritmogénica hereditaria, las muestras de ADN de la víctima son la mejor fuente de información cuando se lleva a cabo una autopsia molecular. Si hay un resultado positivo, se debe ofrecer a los familiares la oportunidad de someterse a 
Tabla 4

Abordaje diagnóstico para familiares de víctimas de síndrome de muerte súbita inexplicable o síndrome de muerte súbita arrítmica

\begin{tabular}{|c|c|}
\hline Abordaje & Acción* \\
\hline Anamnesis y examen físico & $\begin{array}{l}\text { - Historia clínica personal } \\
\text { • Historia familiar centrada en enfermedades o muertes súbitas cardiacas }\end{array}$ \\
\hline ECG & $\begin{array}{l}\text { - ECG basal de } 12 \text { derivaciones con derivaciones estándar y precordiales altas } \\
\text { - ECG ambulatorio de } 24 \text { horas } \\
\text { - Prueba de estrés en ejercicio } \\
\text { - ECG de señal promediada } \\
\text { - Prueba de provocación con ajmalina/flecainida (cuando se sospeche síndrome de Brugada) }\end{array}$ \\
\hline Imagen cardiaca & - Ecocardiografía bidimensional y/o RMC (con o sin contraste) \\
\hline Estudios genéticos & $\begin{array}{l}\text { - Estudios moleculares dirigidos y asesoramiento genético si hay sospecha clínica de una enfermedad específica } \\
\text { - Derivación a un centro terciario especializado en la evaluación de la genética de las arritmias }\end{array}$ \\
\hline
\end{tabular}

ECG: electrocardiograma; RMC: resonancia magnética cardiaca.

*Las recomendaciones de esta tabla se basan en el consenso de este panel de expertos, no en datos basados en la evidencia.

un cribado genético predictivo en forma de cascada. Se debe incluir el "derecho a no saber" y la posibilidad de declinar el cribado molecular en cualquier comunicación previa a la información con los familiares.

En ausencia de muestras biológicas de la persona fallecida, se puede considerar el cribado molecular dirigido de los familiares en primer grado cuando haya sospecha de una enfermedad hereditaria en los miembros de la familia. Por el contrario, no se debería realizar un cribado genético de un gran panel de genes en familiares con síndrome de muerte súbita inexplicable o síndrome de muerte súbita arrítmica sin pistas clínicas de una enfermedad específica tras la evaluación clínica. Esto es especialmente cierto en casos de síndrome de muerte súbita infantil, donde la autopsia molecular identifica una menor carga de enfermedad de los canales iónicos en comparación con síndrome de muerte súbita arrítmica, y la enfermedad genética esporádica como causa de muerte súbita puede ser más frecuente.

\subsubsection{Cribado de pacientes con arritmias ventriculares documentadas o supuestas}

\subsubsection{Historia clínica}

Las palpitaciones (o sensación de latidos cardiacos rápidos repentinos), el presíncope y el síncope son los 3 síntomas más importantes que requieren la elaboración de una historia clínica concienzuda y posiblemente más estudios para descartar una relación con las arritmias ventriculares. Las palpitaciones relacionadas con taquicardia ventricular (TV) tienen normalmente un patrón repentino de aparición/desaparición y pueden ir asociadas a presíncope o síncope. Los episodios de colapso repentino con pérdida de conciencia sin premonición alguna deben levantar la sospecha de bradiarritmias o arritmias ventriculares. Un síncope que tiene lugar durante un ejercicio extenuante, estando sentado o en supinación siempre debe levantar la sospecha de una causa cardiaca, mientras que otros eventos situacionales pueden indicar síncope vasovagal o hipotensión postural ${ }^{92}$. También puede haber síntomas relacionados con cardiopatías estructurales subyacentes, tales como malestar torácico, disnea y fatiga, y habría que buscarlos. En la evaluación de pacientes con sospecha de arritmias ventriculares, se debe incluir indagaciones a fondo acerca de un antecedente familiar de MSC y fármacos que incluyan las dosificaciones utilizadas. Un antecedente familiar de MSC es un potente predictor independiente de susceptibilidad a arritmias ventriculares y $\mathrm{MSC}^{57,58}$. Aunque el examen físico raramente es revelador, a veces puede dar valiosas pistas.

\subsubsection{Evaluación no invasiva e invasiva}

Un ECG estándar de 12 derivaciones en reposo puede revelar signos de trastornos heredados asociados a arritmias ventriculares y
Evaluación no invasiva de pacientes con arritmias ventriculares sospechadas o conocidas

Recomendaciones $\quad$ Clase $^{\mathrm{a}}$ Nivel $^{\mathrm{b}}$ Ref $^{\mathrm{c}}$

ECG de 12 derivaciones en reposo

Se recomienda ECG de 12 derivaciones en reposo para todo paciente evaluado por arritmia ventricular

Monitorización por ECG

Se recomienda ECG ambulatorio para detectar y diagnosticar arritmias. Se recomienda ECG de 12 derivaciones ambulatorio para evaluar cambios en el intervalo QT o el ST

Se recomiendan registradores de eventos cardiacos cuando los síntomas son esporádicos para establecer si los causan arritmias transitorias

Se recomiendan registradores de asa implantables cuando síntomas como un síncope sean esporádicos y se los sospeche relacionados con arritmias o no se pueda establecer correlación síntoma-ritmo mediante técnicas diagnósticas convencionales

Se recomienda ECG-SP para mejorar el diagnóstico de la MAVD en pacientes con arritmia ventricular o en riesgo de sufrir arritmia ventricular de riesgo vital

\section{Estudios de estrés en ejercicio}

Se recomienda realizar estudios de estrés en ejercicio a pacientes adultos con arritmia ventricular y probabilidad de tener $\mathrm{CI}$ intermedia o superior por la edad y los síntomas para provocar cambios isquémicos o arritmia ventricular

Se recomienda realizar estudios de estrés en ejercicio a pacientes con arritmia ventricular inducida por el ejercicio sospechada o conocida, como una TVPC, para alcanzar un diagnóstico y definir el pronóstico

Se debe considerar la realización de estudios de estrés en ejercicio para evaluar la respuesta a la terapia médica o ablativa de pacientes con arritmia ventricular inducida por el ejercicio conocida

\section{Imagen}

Se recomienda ecocardiografía para determinar la función del VI y detectar enfermedad cardiaca estructural de todo paciente con arritmia ventricular sospechada o conocida

Se recomienda ecocardiografía para determinar la función del VI y el VD y detectar enfermedad cardiaca estructural de pacientes con alto riesgo de arritmia ventricular grave o MSC, como los que tienen miocardiopatías dilatadas, hipertróficas o del VD, supervivientes a infarto de miocardio o familiares de pacientes con trastornos hereditarios asociados a MSC
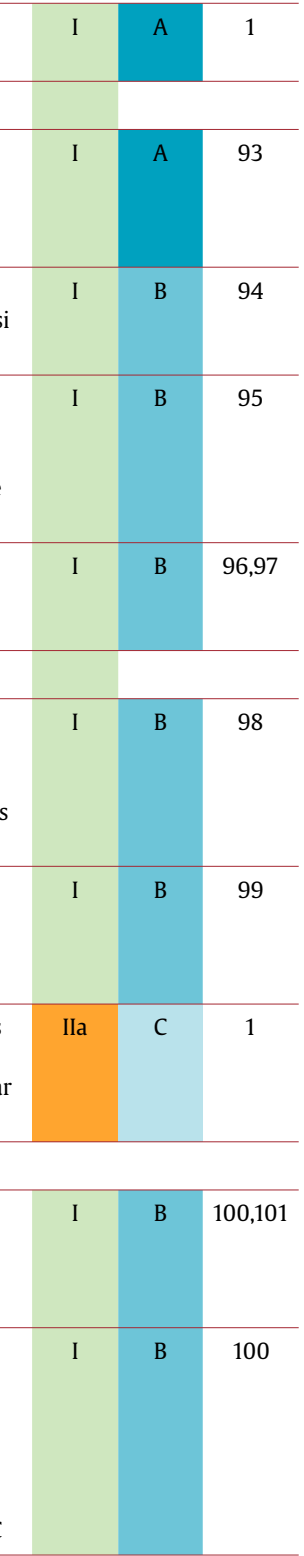
Evaluación no invasiva de pacientes con arritmias ventriculares sospechadas o conocidas (continuación)

\begin{tabular}{lccc}
\hline Recomendaciones & Clase $^{\mathrm{a}}$ & Nivel $^{\mathrm{b}}$ & Ref $^{\mathrm{c}}$ \\
\hline $\begin{array}{l}\text { Se recomiendan pruebas de ejercicio más imagen } \\
\text { (ecocardiografía con estrés en ejercicio o perfusión }\end{array}$ & $\mathrm{I}$ & $\mathrm{B}$ & 102 \\
$\begin{array}{l}\text { nuclear, SPECT) para detectar isquemia silente en } \\
\text { pacientes con arritmia ventricular y probabilidad de } \\
\text { tener CI intermedia por edad o síntomas, en los que } \\
\text { un ECG es menos fiable (uso de digoxina, hipertrofia } \\
\text { del VI, depresión del segmento ST }>1 \text { mm en reposo, } \\
\text { síndrome de WPW o BRIH) }\end{array}$ & & \\
\hline $\begin{array}{l}\text { Se recomienda la modalidad de estudios de estrés } \\
\text { farmacológico más imagen para detectar isquemia } \\
\text { silente en pacientes con arritmia ventricular y } \\
\text { probabilidad de tener CI intermedia por edad o } \\
\text { síntomas que son físicamente incapaces de realizar una } \\
\text { prueba de ejercicio limitada por los síntomas }\end{array}$ & & & \\
\hline $\begin{array}{l}\text { Se debe considerar la RMC o la TC para pacientes con } \\
\text { arritmia ventricular cuando la ecocardiografía no } \\
\text { proporcione una determinación precisa de la función } \\
\text { del VI y el VD y/o cambios estructurales }\end{array}$ & B & & \\
\hline
\end{tabular}

BRIH: bloqueo de la rama izquierda del haz de His; CI: cardiopatía isquémica; ECG: electrocardiograma; ECG-SP: ECG de señal promediada; MAVD: miocardiopatía arritmogénica del ventrículo derecho; MSC: muerte súbita cardiaca; RMC: resonancia magnética cardiaca; SPECT: tomografía computarizada por emisión monofotónica; TC: tomografía computarizada; TVPC: taquicardia ventricular polimórfica catecolaminérgica; VD: ventrículo derecho; VI: ventrículo izquierdo; WPW: WolffParkinson-White.

aClase de recomendación.

bNivel de evidencia.

'Referencias que respaldan las recomendaciones.

Evaluación invasiva de pacientes con arritmias ventriculares sospechadas o conocidas

\begin{tabular}{lccc}
\hline Recomendaciones & Clase $^{\mathrm{a}}$ & Nivel $^{\mathrm{b}}$ & Ref $^{\mathrm{c}}$ \\
\hline Angiografía coronaria & & & \\
\hline $\begin{array}{l}\text { Se debe considerar la angiografía coronaria para } \\
\text { establecer o excluir una Cl obstructiva significativa }\end{array}$ & Ila & C & 104 \\
$\begin{array}{l}\text { para pacientes con arritmia ventricular de riesgo } \\
\text { vital o supervivientes a MSC que tienen probabilidad } \\
\text { de Cl intermedia o superior por edad y síntomas }\end{array}$ & & & \\
\hline
\end{tabular}

\section{Estudio electrofisiológico}

\begin{tabular}{|c|c|c|c|}
\hline $\begin{array}{l}\text { Se recomienda estudio electrofisiológico de } \\
\text { pacientes con } \mathrm{CI} \text {, para la evaluación diagnóstica } \\
\text { de pacientes con infarto de miocardio antiguo y } \\
\text { síntomas que indican taquiarritmias ventriculares, } \\
\text { como palpitaciones, presíncope y síncope }\end{array}$ & I & B & 105 \\
\hline $\begin{array}{l}\text { Se recomienda estudio electrofisiológico de } \\
\text { pacientes con síncope cuando se sospechen } \\
\text { bradiarritmias o taquiarritmias por los síntomas } \\
\text { (como palpitaciones) o los resultados de una } \\
\text { valoración no invasiva, especialmente en pacientes } \\
\text { con enfermedad cardiaca estructural }\end{array}$ & I & C & 106 \\
\hline $\begin{array}{l}\text { Se puede considerar el estudio electrofisiológico } \\
\text { para el diagnóstico diferencial entre MAVD } \\
\text { y taquicardia benigna del TSVD o sarcoidosis }\end{array}$ & IIb & B & 107 \\
\hline
\end{tabular}

CI: cardiopatía isquémica; MAVD: miocardiopatía arritmogénica del ventrículo derecho; MSC: muerte súbita cardiaca; TSVD: tracto de salida del ventrículo derecho.

aClase de recomendación.

bNivel de evidencia.

'Referencias que respaldan las recomendaciones.

MSC, tales como canalopatías (SQTL, SQTC, síndrome de Brugada, TVPC) y miocardiopatías (MAVD y MCH). Otros parámetros de ECG que permiten sospechar enfermedad estructural subyacente son el bloqueo de las ramas del haz de His, el bloqueo auriculoventricular (BAV), la hipertrofia ventricular y las ondas Q compatibles con $\mathrm{CI}$ o miocardiopatía infiltrativa. Las alteraciones electrolíticas y los efectos de diversos fármacos pueden dar lugar a anormalidades de la repolarización o prolongación del QRS.

El ECG en condiciones de ejercicio se aplica más habitualmente para detectar isquemia silente en pacientes adultos con arritmias ventriculares. Se informó de TV no sostenida inducida por el ejercicio en casi un $4 \%$ de los adultos asintomáticos de mediana edad y no se asoció con un mayor riesgo de mortalidad total ${ }^{108}$. Las pruebas de ejercicio en alteraciones del ritmo de dependencia adrenérgica, incluidas las TV monomórficas y las TV polimórficas, como la TVPC, son útiles con fines diagnósticos y para evaluar la respuesta al tratamiento. Las pruebas de ejercicio para pacientes con arritmias ventriculares de riesgo vital pueden asociarse a arritmias que requieren cardioversión, fármacos intravenosos (i.v.) o reanimación, pero aún pueden estar indicadas, ya que es mejor exponer las arritmias y evaluar el riesgo en circunstancias controladas. Se debe realizarlas cuando haya disponibilidad inmediata de equipo de reanimación y personal entrenado.

Las técnicas de registro ambulatorio continuo o intermitente pueden ayudar a relacionar síntomas con la presencia de la arritmia. También se puede detectar episodios de isquemia miocárdica silente. Es apropiado un registro de Holter continuo de $24-48$ h siempre que se sepa o se sospeche que la arritmia se produce al menos una vez al día. Para episodios esporádicos, son más útiles los registradores de eventos convencionales, ya que pueden registrar durante largos periodos. Los dispositivos subcutáneos implantables que monitorizan continuamente el ritmo cardiaco y registran eventos en un marco temporal medido en años pueden registrar al activarlos el paciente o automáticamente según criterios preespecificados. Pueden resultar muy útiles en el diagnóstico de taquiarritmias y bradiarritmias graves en pacientes con síntomas de riesgo vital tales como el síncope. Los nuevos registradores de asa «inyectables» no requieren preparaciones quirúrgicas convencionales.

El ECG de señal promediada (ECG-SP) mejora la razón señal/ruido de un ECG de superficie, de tal forma que se puede identificar las señales de baja amplitud (a escala de microvoltios), referidas como "potenciales tardíos", al final del complejo QRS. Los potenciales tardíos indican regiones de miocardio anormal con conducción lenta, una anormalidad de sustrato que puede permitir taquiarritmias ventriculares reentrantes. Se recomienda el ECG-SP para el diagnóstico diferencial de cardiopatías estructurales como la MAVD en pacientes con arritmias ventriculares.

La ecocardiografía es la técnica de imagen usada más comúnmente, ya que, en comparación con la resonancia magnética cardiaca (RMC) y la tomografía computarizada (TC) cardiaca, es barata y de fácil disponibilidad y proporciona un diagnóstico preciso de trastornos cardiacos miocárdicos, valvulares y congénitos asociados a arritmias ventriculares y MSC ${ }^{109}$. Además, se puede hacer una evaluación de la función sistólica del VI y del movimiento de la pared regional en la mayoría de los pacientes. Por lo tanto, la ecocardiografía está indicada para pacientes con arritmias ventriculares y sospecha de cardiopatía estructural y para el subgrupo de pacientes en alto riesgo de arritmias ventriculares graves o MSC, como los que tienen MCH, MCD o miocardiopatía del ventrículo derecho (VD), los supervivientes a un infarto de miocardio o los familiares de pacientes con trastornos heredados asociados a MSC. La combinación de la ecocardiografía con ejercicio o estrés farmacológico (comúnmente conocida como «eco de estrés») es aplicable a un grupo de pacientes seleccionados con sospecha de arritmias ventriculares desencadenadas por isquemia incapaces de hacer ejercicio o con anormalidades en el ECG en reposo que limitan la precisión de este para la detección de isquemia.

Los avances en la RMC han hecho posible la evaluación tanto de la estructura como de la función del corazón. La excelente resolución de imagen obtenida con las técnicas actuales permite la cuantificación precisa de los volúmenes de las cámaras, la masa del VI y la función ventricular. Esto tiene particular valor para pacientes con 
sospecha de MAVD, en quienes la RMC proporciona una excelente valoración del tamaño, la función y el movimiento de la pared regional del VD.

La TC permite una cuantificación precisa de los volúmenes, la FEVI y la masa del VI, con resultados comparables a los de la RMC, pero además proporciona imágenes segmentarias de las arterias coronarias a partir de las cuales se puede cuantificar el grado de calcificación. Se puede usar la TC cardiaca para pacientes seleccionados en quienes no sea factible evaluar las estructuras cardiacas con ecocardiografía y no esté disponible la RMC. Se puede detectar un origen anómalo de las arterias coronarias por TC u otras técnicas de imagen.

La TC por emisión monofotónica (SPECT) con perfusión miocárdica en ejercicio o con agentes farmacológicos es aplicable a un grupo de pacientes seleccionados con sospecha de arritmias ventriculares desencadenadas por isquemia incapaces de realizar ejercicio o con anormalidades en el ECG en reposo que limitan la precisión de este para la detección de isquemia. La cuantificación precisa de la FEVI es posible con angiografía con radionúclidos sincronizada (escáner de adquisición de sincronización múltiple) y puede ser de ayuda en pacientes para quienes no se dispone de esta medición con ecocardiografía.

La angiografía coronaria tiene un importante papel diagnóstico para determinar o excluir $\mathrm{Cl}$ obstructiva significativa en pacientes con arritmias ventriculares de riesgo vital o supervivientes a MSC.

Se ha utilizado un estudio electrofisiológico (EEF) con EVP para documentar la inducibilidad de TV, guiar la ablación, valorar los riesgos de TV recurrente o de MSC, evaluar la pérdida de conciencia de pacientes seleccionados son sospecha de que las arritmias son una causa y valorar las indicaciones de tratamiento con DAI. El rendimiento del EEF varía fundamentalmente con el tipo y la gravedad de la cardiopatía subyacente, la presencia o ausencia de TV espontánea, un tratamiento concomitante con fármacos, el protocolo de estimulación y el sitio de estimulación. Se observan los mayores índices de inducción y la mayor reproducibilidad en pacientes después de un infarto de miocardio, y en este documento se dan recomendaciones para su uso en casos seleccionados.

Para evaluar a pacientes con arritmias ventriculares, la mayoría de los centros emplean 8 estímulos ventriculares con duraciones de ciclo de conducción de entre 600 y $400 \mathrm{~ms}$ en el ápex del VD, a un umbral 2 veces el diastólico y una duración de pulso de $0,5-2 \mathrm{~ms}$, que suministran de uno a 3 extraestímulos ventriculares basales. Se puede repetir esta prueba durante una infusión de isoproterenol ${ }^{110}$. Se aumenta la prematuridad de los extraestímulos hasta que se alcanza la refractariedad o la inducción de taquiarritmia ventricular sostenida. Dado que es más probable que la estimulación ventricular prematura con un intervalo de acoplamiento muy corto induzca FV en oposición a TV monomórfica, puede ser razonable limitar la prematuridad de los extraestímulos a un mínimo de $180 \mathrm{~ms}$ cuando se estudie a pacientes para quienes solo se consideraría la TV monomórfica sostenida inducible como criterio de valoración positivo. Se puede repetir el EEF en el tracto de salida del VD (TSVD) o en el VI.

Se puede usar el EEF para documentar la causa arrítmica del síncope y se debería utilizar para complementar un chequeo completo del síncope. Es muy útil en pacientes con CI y disfunción del VI. Se puede usar el EEF para documentar o provocar bradiarritmias o BAV cuando otras exploraciones no hayan podido proporcionar información concluyente. El rendimiento diagnóstico varía mucho con las poblaciones de pacientes seleccionados ${ }^{111} \mathrm{y}$ es bajo en ausencia de cardiopatía estructural o cuando el ECG es normal. En pacientes con síncope, bloqueo de rama y FEVI reducida (<45\%), se puede inducir TV durante el EEF en hasta un $42 \%$ de los casos. En pacientes con síncope y bloqueo de rama, es común que el EEF dé un resultado falso negativo ${ }^{112}$. El EEF puede provocar respuestas taquiarrítmicas no específicas en pacientes con función del VI conservada que no tienen cardiopatía estructural.
En las secciones 7 y 8 se discute la utilidad del EEF para determinar el pronóstico y guiar el tratamiento para pacientes con miocardiopatías y síndromes de arritmia primaria heredados. Resumiendo, el EEF podría tener un papel para pacientes con MAVD ${ }^{113,14}$ o MCD ${ }^{115}$, aunque no contribuye a identificar a los pacientes de alto riesgo en la $\mathrm{MCH}$ (NYHA II $)^{116}$. Entre las canalopatías, el EEF no está indicado para el SQTL ${ }^{117}$, la TVPC ${ }^{14}$ y el SQTC ${ }^{118,119}$, aunque se debate su utilidad en el síndrome de Brugada ${ }^{120}$.

En pacientes con cardiopatía estructural y, en particular, con disfunción significativa del VI, el síncope es una mala señal. La TV no sostenida (TVNS) en la monitorización con Holter, el síncope y la cardiopatía estructural son muy sensibles para predecir TV inducible. El síncope asociado a enfermedad cardiaca y FE reducida tiene gran recurrencia y altas tasas de mortalidad ${ }^{121}$ incluso cuando los resultados del EEF son negativos. El EEF es útil en pacientes con disfunción del VI debida a un infarto de miocardio previo (FEVI $<40 \%$ ), pero no es sensible para pacientes con miocardiopatía no isquémica. La inducción de TV polimórfica o FV, especialmente con técnicas de estimulación agresivas, no es específica. En la $\mathrm{Cl}$, el rendimiento diagnóstico puede alcanzar el $50 \%$.

La figura 1 ilustra el proceso diagnóstico propuesto para pacientes que sobreviven a una parada cardiaca abortada, mientras que el tratamiento de la parada cardiaca en el marco de condiciones específicas se describe en las secciones 5-12. La tabla 3 del anexo web presenta la nomenclatura adoptada al hacer referencia a las arritmias ventriculares en todo este documento ${ }^{122}$. En la tabla 4 del anexo web se detallan los estudios que pueden revelar hallazgos específicos de enfermedad.

\section{TERAPIAS PARA ARRITMIAS VENTRICULARES}

\subsection{Tratamiento de la enfermedad cardiaca subyacente}

Un aspecto fundamental del éxito en el tratamiento de las arritmias ventriculares y la prevención de la MSC es el tratamiento efectivo de las enfermedades subyacentes y las comorbilidades. Se debe evitar el empeoramiento agudo y el deterioro progresivo de estas afecciones. También se debe controlar comorbilidades que puedan estimular el inicio o contribuir al desarrollo de un sustrato que sostenga la arritmia ventricular. El tratamiento de la enfermedad cardiaca ha cambiado considerablemente desde que se llevaron a cabo los ensayos iniciales de fármacos antiarrítmicos y el DAI. Como no se prevé que esos estudios vayan a repetirse, hay que extrapolar las implicaciones terapéuticas de las pruebas originales al contexto moderno. No obstante, se debe optimizar el tratamiento actualizado de la enfermedad cardiovascular subyacente (las guías de la ESC relevantes se pueden consultar en: http://www.escardio.org/Guidelines\&-Education/Clinical-Practice-Guidelines/listing).

\subsection{Farmacoterapia para la arritmia ventricular y la prevención de la muerte súbita cardiaca}

\subsubsection{Tratamiento general}

La selección de una terapia apropiada para el tratamiento de la arritmia ventricular y la prevención de la MSC se centra en la arritmia, las afecciones médicas asociadas que pueden contribuir a la arritmia o exacerbarla, el riesgo impuesto por la arritmia y los aspectos de riesgos-beneficios de la terapia potencial. El tratamiento de una arritmia manifiesta puede incluir la interrupción de fármacos proarrítmicos perjudiciales (véase la sección 12.5) y la terapia antiarrítmica apropiada con fármacos, dispositivos implantables, ablación o cirugía. Para recomendaciones específicas sobre farmacoterapia, véase el texto y las tablas de recomendaciones para las diversas indicaciones detalladas en secciones posteriores de esta guía. 


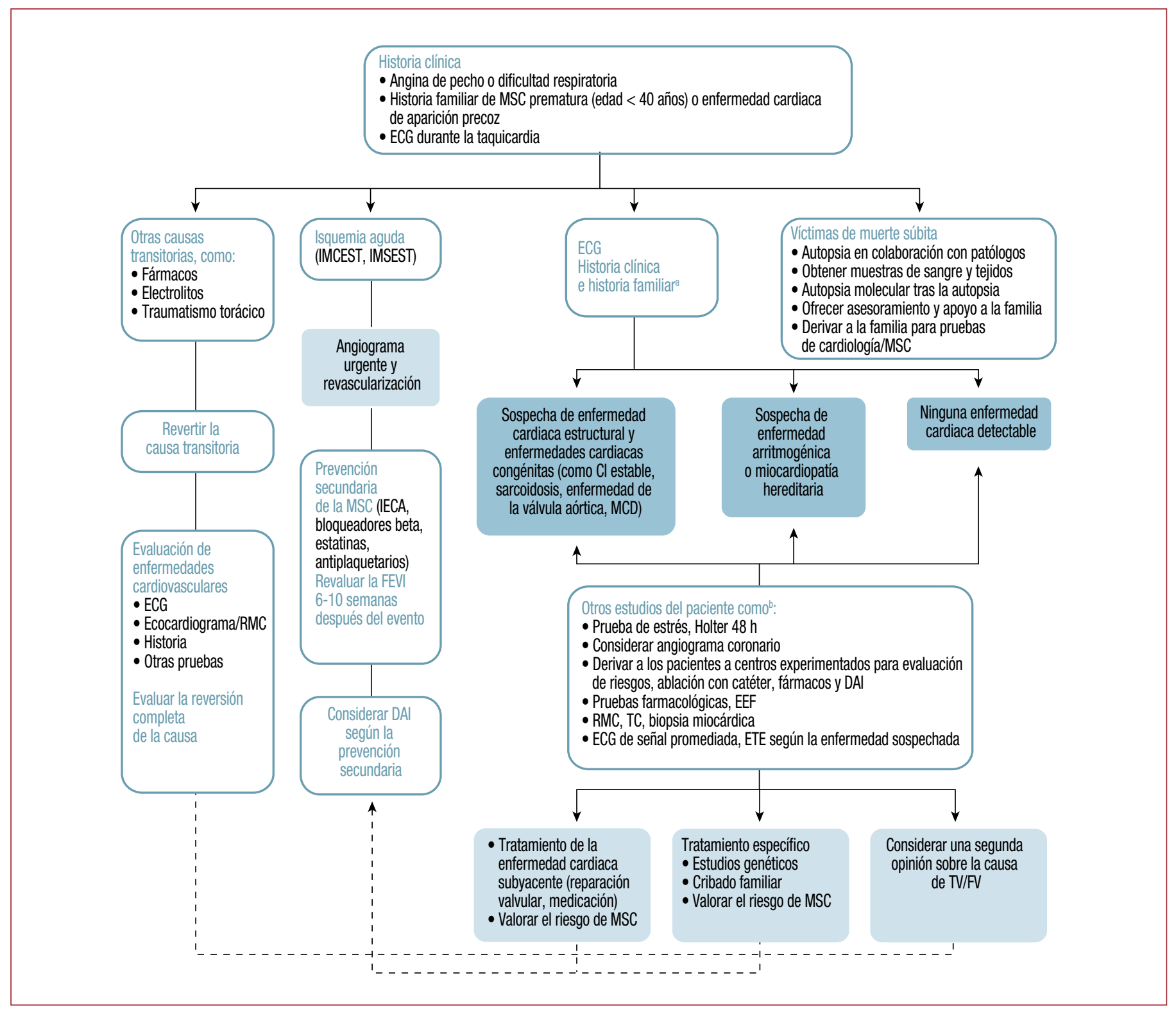

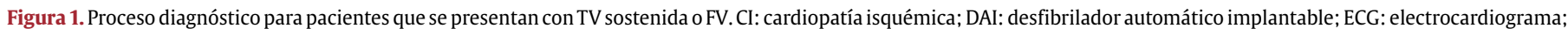

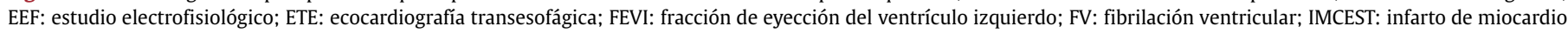

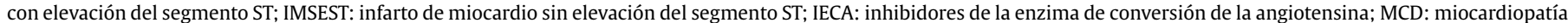
dilatada; MSC: muerte súbita cardiaca; RMC: resonancia magnética cardiaca; TC: tomografía computarizada; TV: taquicardia ventricular.

aHistoria clínica de dolor torácico, disnea y síntomas asociados a ciertas afecciones cardiacas y el árbol familiar.

bLa necesidad de más pruebas y evaluaciones estará guiada por la valoración inicial y la sospecha de enfermedades cardiovasculares.

\subsubsection{Fármacos antiarrítmicos}

A excepción de los bloqueadores beta, los fármacos antiarrítmicos actualmente disponibles no se han mostrado en ensayos clínicos aleatorizados efectivos en el tratamiento primario de pacientes con arritmia ventricular de riesgo vital o en la prevención de la MSC. Estudios ocasionales con amiodarona han mostrado resultados positivos, pero este no es un hallazgo consistente ${ }^{123,124}$. Como norma general, los agentes antiarrítmicos pueden ser efectivos como terapia adjunta en el tratamiento de pacientes propensos a arritmias en circunstancias específicas. Debido a los potenciales efectos adversos de los fármacos antiarrítmicos, hay que usarlos con precaución. Esta sección proporciona una revisión de la farmacoterapia para las arritmias ventriculares para prevenir la TV recurrente (tabla 5).
Cada fármaco tiene un potencial significativo de causar efectos adversos, incluida la proarritmia. Muchos fármacos cardiacos y no cardiacos comercializados inducen bradicardia sinusal y BAV, algunos alteran la conducción del sistema His-Purkinje y producen BAV o bloqueo de las ramas del haz de His, mientras que otros prolongan la repolarización ventricular y el intervalo QT. Por lo tanto, los fármacos antiarrítmicos podrían precipitar taquiarritmias ventriculares de riesgo vital, de modo similar (pero con mayor prevalencia) a algunos fármacos no cardiovasculares, que también pueden prolongar el intervalo QT o ralentizar la conducción intraventricular ${ }^{125,126}$.

Es un hecho relevante para el cardiólogo que los fármacos antiarrítmicos de la clase IA (p. ej., quinidina y disopiramida) que bloquean la corriente de sodio también bloquean el componente rápido de la corriente de potasio rectificadora tardía, por lo que pueden prolongar 
Tabla 5

Fármacos antiarrítmicos disponibles para el tratamiento de las arritmias ventriculares en la mayoría de los países europeos

\begin{tabular}{|c|c|c|c|c|}
\hline $\begin{array}{l}\text { Fármacos } \\
\text { antiarrítmicos (clase } \\
\text { de Vaughan Williams) }\end{array}$ & $\begin{array}{l}\text { Dosis oral } \\
(\mathrm{mg} / \text { día })^{\mathrm{a}}\end{array}$ & $\begin{array}{l}\text { Efectos adversos comunes } \\
\text { o importantes }\end{array}$ & Indicaciones & Contraindicaciones cardiacas y advertencias \\
\hline Amiodarona (III) & $200-400$ & $\begin{array}{l}\text { Fibrosis pulmonar, hipotiroidismo } \\
\text { e hipertiroidismo, neuropatías, } \\
\text { depósitos corneales, } \\
\text { fotosensibilidad, decoloración } \\
\text { cutánea, hepatotoxicidad, } \\
\text { bradicardia sinusal, prolongación } \\
\text { del QT y TdP ocasional }\end{array}$ & TV, FV & $\begin{array}{l}\text { Afecciones y tratamientos concomitantes asociados a prolongación del } \\
\text { intervalo QT; SQTL hereditario; bradicardia sinusal (excepto en parada } \\
\text { cardiaca); enfermedad del nódulo sinusal (a menos que haya marcapasos); } \\
\text { alteraciones de la conducción AV graves (a menos que haya marcapasos); } \\
\text { IC descompensada o miocardiopatía }\end{array}$ \\
\hline Bloqueadores beta (II) & Diversas & $\begin{array}{l}\text { Broncospasmo, hipotensión, } \\
\text { bradicardia sinusal, BAV, fatiga, } \\
\text { depresión, disfunciones sexuales }\end{array}$ & EV, TV, SQTL & $\begin{array}{l}\text { Bradicardia sinusal y enfermedad del nódulo sinusal graves (a menos que } \\
\text { haya marcapasos); alteraciones de la conducción AV (a menos que haya } \\
\text { marcapasos); fase aguda del infarto de miocardio (evitar si hay bradicardia, } \\
\text { hipotensión o insuficiencia del VI); IC descompensada; angina de Prinzmetal }\end{array}$ \\
\hline Disopiramida (IA) & $250-750$ & $\begin{array}{l}\text { Inotropo negativo, prolongación } \\
\text { del QRS, BAV, proarritmia (flutter } \\
\text { auricular, TV monomórfica, TdP } \\
\text { ocasional), efectos anticolinérgicos }\end{array}$ & TV, EV & $\begin{array}{l}\text { Enfermedad del nódulo sinusal grave (a menos que haya marcapasos); } \\
\text { alteraciones de la conducción AV graves (a menos que haya marcapasos); } \\
\text { alteraciones de la conducción intraventricular graves; infarto de miocardio } \\
\text { previo; CI; IC; FEVI reducida; hipotensión }\end{array}$ \\
\hline Flecainida (IC) & $200-400$ & $\begin{array}{l}\text { Inotropo negativo, ensanchamiento } \\
\text { del QRS, BAV, bradicardia sinusal, } \\
\text { proarritmia (flutter auricular, TV } \\
\text { monomórfica, TdP ocasional), } \\
\text { mayor incidencia de muerte } \\
\text { tras infarto de miocardio }\end{array}$ & EV, TV & $\begin{array}{l}\text { Disfunción del nódulo sinusal (a menos que haya marcapasos); fibrilación/ } \\
\text { flutter auricular (sin uso concomitante de agentes que producen BAV); } \\
\text { alteraciones de la conducción AV graves (a menos que haya marcapasos); } \\
\text { alteraciones de la conducción intraventricular graves; infarto de } \\
\text { miocardio previo; CI; IC; FEVI reducida; enfermedad cardiaca valvular } \\
\text { hemodinámicamente significativa; síndrome de Brugada; SQTL hereditario } \\
\text { (distinto de SQTL3); tratamientos concomitantes asociados a prolongación } \\
\text { del intervalo QT }\end{array}$ \\
\hline Mexiletina (IB) & $450-900$ & $\begin{array}{l}\text { Temblor, disartria, mareos, malestar } \\
\text { gastrointestinal, hipotensión, } \\
\text { bradicardia sinusal }\end{array}$ & TV, SQTL3 & $\begin{array}{l}\text { Disfunción del nódulo sinusal (a menos que haya marcapasos); alteraciones } \\
\text { de la conducción AV graves (a menos que haya marcapasos); IC grave; FEVI } \\
\text { reducida; SQTL hereditario (distinto de SQTL3); tratamientos concomitantes } \\
\text { asociados a prolongación del intervalo QT }\end{array}$ \\
\hline Procainamida (IA) & $1.000-4.000$ & $\begin{array}{l}\text { Erupción cutánea, mialgia, } \\
\text { vasculitis, hipotensión, lupus, } \\
\text { agranulocitosis, bradicardia, } \\
\text { prolongación del QT, TdP }\end{array}$ & TV & $\begin{array}{l}\text { Enfermedad del nódulo sinusal grave (a menos que haya marcapasos); } \\
\text { alteraciones de la conducción AV graves (a menos que haya marcapasos); } \\
\text { alteraciones de la conducción intraventricular graves; infarto de miocardio } \\
\text { previo; CI; IC; hipotensión; FEVI reducida, síndrome de Brugada }\end{array}$ \\
\hline Propafenona (IC) & $450-900$ & $\begin{array}{l}\text { Inotropo negativo, malestar } \\
\text { gastrointestinal, prolongación } \\
\text { del QRS, BAV, bradicardia sinusal, } \\
\text { proarritmia (flutter auricular, TV } \\
\text { monomórfica, TdP ocasional) }\end{array}$ & $\mathrm{EV}, \mathrm{TV}$ & $\begin{array}{l}\text { Bradicardia sinusal y disfunción del nódulo sinusal graves (a menos que haya } \\
\text { marcapasos); fibrilación/flutter auricular (sin uso concomitante de agentes } \\
\text { que producen BAV); alteraciones de la conducción AV graves (a menos que } \\
\text { haya marcapasos); alteraciones de la conducción intraventricular graves; } \\
\text { infarto de miocardio previo; CI; IC; FEVI reducida; enfermedad cardiaca } \\
\text { valvular hemodinámicamente significativa; síndrome de Brugada; SQTL } \\
\text { hereditario (distinto de SQTL3); tratamientos concomitantes asociados } \\
\text { a prolongación del intervalo QT }\end{array}$ \\
\hline Quinidina & $600-1.600$ & $\begin{array}{l}\text { Náuseas, diarrea, alteraciones } \\
\text { auditivas y visuales, confusión, } \\
\text { hipotensión, trombocitopenia, } \\
\text { anemia hemolítica, anafilaxia, } \\
\text { prolongación de QRS y QT, TdP }\end{array}$ & $\begin{array}{l}\text { TV, FV, SQTC, } \\
\text { síndrome de } \\
\text { Brugada }\end{array}$ & $\begin{array}{l}\text { Enfermedad del nódulo sinusal grave (a menos que haya marcapasos); } \\
\text { alteraciones de la conducción AV graves (a menos que haya marcapasos); } \\
\text { alteraciones de la conducción intraventricular graves; infarto de miocardio } \\
\text { previo; CI; IC; FEVI reducida; hipotensión; síndrome del QT largo hereditario; } \\
\text { tratamientos concomitantes asociados a prolongación del intervalo QT }\end{array}$ \\
\hline Ranolazina (IB) & $750-2.000$ & $\begin{array}{l}\text { Mareos, náuseas, estreñimiento, } \\
\text { hipotensión, malestar } \\
\text { gastrointestinal, dolor de cabeza, } \\
\text { erupción cutánea, bradicardia } \\
\text { sinusal, prolongación del QT }\end{array}$ & SQTL3 $^{\mathrm{b}}$ & $\begin{array}{l}\text { Bradicardia sinusal y enfermedad del nódulo sinusal graves; IC grave; } \\
\text { síndrome del QT largo hereditario (distinto de SQTL3); tratamientos } \\
\text { concomitantes asociados a prolongación del intervalo QT }\end{array}$ \\
\hline Sotalol (III) & $160-320$ & $\begin{array}{l}\text { Igual que otros bloqueadores beta } \\
\text { y TdP }\end{array}$ & TV, $(\text { MAVD) })^{c}$ & $\begin{array}{l}\text { Bradicardia sinusal y enfermedad del nódulo sinusal graves (a menos que } \\
\text { haya marcapasos); alteraciones de la conducción AV (a menos que haya } \\
\text { marcapasos); IC grave; angina de Prinzmetal; SQTL hereditario; tratamientos } \\
\text { concomitantes asociados a prolongación del intervalo QT }\end{array}$ \\
\hline Verapamilo (IV) & $120-480$ & $\begin{array}{l}\text { Inotropo negativo (especialmente } \\
\text { en pacientes con FEVI reducida), } \\
\text { erupción cutánea, malestar } \\
\text { gastrointestinal, hipotensión, } \\
\text { bradicardia sinusal, BAV, TV }\end{array}$ & $\begin{array}{l}\text { Taquicardia } \\
\text { fascicular } \\
\text { del VI }\end{array}$ & $\begin{array}{l}\text { Bradicardia sinusal y enfermedad del nódulo sinusal graves (a menos } \\
\text { que haya marcapasos); alteraciones de la conducción AV graves } \\
\text { (a menos que haya marcapasos); fase aguda del infarto de miocardio (evitar } \\
\text { si hay bradicardia, hipotensión, insuficiencia del ventrículo izquierdo); IC; } \\
\text { FEVI significativamente reducida; flutter o fibrilación auricular asociados } \\
\text { a vías accesorias (p. ej., síndrome de WPW) }\end{array}$ \\
\hline
\end{tabular}

AV: auriculoventricular; BAV: bloqueo auriculoventricular; CI: cardiopatía isquémica; EV: extrasístole ventricular; FA: fibrilación auricular; FEVI: fracción de eyección del ventrículo izquierdo; FV: fibrilación ventricular; IC: insuficiencia cardiaca; MAVD: miocardiopatía arritmogénica del ventrículo derecho; SQTC: síndrome del QT corto; SQTL: síndrome del QT largo; SQTL3: síndrome del QT largo tipo 3; TdP: torsade de pointes; TV: taquicardia ventricular; VI: ventrículo izquierdo; WPW: Wolff-Parkinson-White. ${ }^{a}$ En esta tabla se citan las dosis de fármacos para adultos.

bLa ranolazina solo está aprobada para el tratamiento de la angina estable crónica. Obsérvese que se puede usar otras dosis en condiciones especiales.

'El sotalol se indicó para la MAVD, pero se ha cuestionado su uso. 
el intervalo QT. Por esta razón, se ha advertido sobre el uso de los bloqueadores de los canales de sodio en pacientes con medicación prolongadora de QT o afectados de SQTL transmitido genéticamente. Recientemente, sin embargo, se ha demostrado que algunos bloqueadores de las corrientes de sodio (predominantemente de la clase IB, como la mexiletina, y de la clase IC, como la flecainida) inhiben activamente tanto el pico de la corriente de sodio como el componente tardío de la corriente de sodio. Al hacerlo, estos agentes pueden inducir un acortamiento del intervalo QT en pacientes con SQTL de tipo 3 (SQTL3), ya que esta forma está causada por mutaciones que aumentan la corriente de sodio tardía ${ }^{127}$. Por esta razón, se puede considerar que estos fármacos acortan el intervalo QT en pacientes con SQTL3 (véase la sección 8.1). Aún se desconoce si la prolongación del QT inducida por fármacos y otras variantes genéticas del SQTL también responden a los bloqueadores de la corriente de sodio tardía con acortamiento del intervalo QT.

Recientemente, un estudio alemán que utilizó un enfoque de vigilancia activa describió una incidencia bruta de SQTL inducido por fármacos que conducía a torsade de pointes (TdP) de 3,2/millón/año ${ }^{128}$. Una vez se aprecia que una arritmia ventricular puede deberse a terapia con fármacos «antiarrítmicos», se debería interrumpir las posibles terapias perjudiciales y llevar a cabo la monitorización por ECG de seguimiento apropiada.

A la luz de los resultados del ensayo de supresión de arritmia cardiaca (CAST) ${ }^{129}$, que mostraban una tasa de mortalidad o parada cardiaca no mortal excesiva (7,7\%) entre los pacientes de infarto de miocardio tratados con encainida o flecainida, en comparación con los pacientes tratados con placebo (3,0\%), se ha contraindicado el uso de bloqueadores de los canales de sodio de clase IC tras infarto de miocardio. Se ha ampliado la contraindicación a otros agentes antiarrítmicos de clase I, ya que al usarlos para reducir la carga arrítmica de pacientes posinfartados, aunque no aumenten la mortalidad, no consiguen reducirla (para referencias y discusión de los resultados, veáse la sección 5).

El uso de fármacos para los síndromes de arritmia primaria heredada (SQTL, SQTC, síndrome de Brugada) y las miocardiopatías es una indicación fuera de lo aprobado.

\subsubsection{Bloqueadores beta}

El mecanismo de eficacia antiarrítmica de los bloqueadores beta incluye el bloqueo competitivo de los receptores betaadrenérgicos de los mecanismos de desencadenamiento simpático, la ralentización del ritmo sinusal y posiblemente la inhibición del exceso de liberación de calcio por el canal de los receptores de rianodina.

Los bloqueadores beta son eficaces para suprimir los latidos ventriculares ectópicos y la arritmia, así como para reducir la MSC en un espectro de trastornos cardiacos en pacientes con y sin IC. Los bloqueadores beta son agentes antiarrítmicos eficaces y generalmente seguros que se puede considerar pilares de la terapia con fármacos antiarrítmicos. Recientemente, sin embargo, un estudio de registro en 34.661 pacientes con infarto de miocardio con (IMCEST) o sin elevación del segmento ST (IMSEST) encontró que, en pacientes con 2 o más factores de riesgo de shock (p. ej., edad > 70 años, ritmo cardiaco $>110 \mathrm{lpm}$, presión arterial sistólica < $120 \mathrm{mmHg}$ ), el riesgo de shock o muerte estaba significativamente aumentado en los tratados con bloqueadores beta (IMSEST, OR = 1,23; IC95\%, 1,08-1,40; p = 0,0016; IMCEST, OR = 1,30; IC95\%, 1,03-1,63; p = 0,025) ${ }^{130}$.

En general, los bloqueadores beta son la terapia de primera línea para el tratamiento de la arritmia ventricular y la prevención de la MSC.

\subsubsection{Amiodarona}

La amiodarona tiene un amplio espectro de acción, que incluye el bloqueo de las corrientes despolarizantes de sodio y de los canales de potasio que conducen corrientes repolarizantes; estas acciones pueden inhibir o finalizar las arritmias ventriculares al influir en el automatismo y la reentrada.

El estudio Sudden Cardiac Death in Heart Failure Trial (SCD-HeFT) ${ }^{64}$ mostró ausencia de beneficio en supervivencia con el tratamiento con amiodarona frente a placebo para pacientes con FEVI $\leq 35 \%$. Sin embargo, a diferencia de los bloqueadores de los canales de sodio $^{131}$, la amiodarona se puede usar sin aumentar la mortalidad de los pacientes con $\mathrm{IC}^{132}$.

Un metanálisis que incluyó a 8.522 pacientes posinfartados o con IC sistólica aleatorizados a amiodarona o placebo/control mostró que, por cada 1.000 pacientes tratados con amiodarona, se evitaban 5 muertes por cualquier causa, 24 muertes cardiovasculares y 26 muertes súbitas ${ }^{133}$. La reducción absoluta del riesgo de muerte por cualquier causa del 1,5\% no alcanzó la significación estadística.

La administración crónica de amiodarona se asocia con interacciones complejas de fármacos y multitud de efectos colaterales extracardiacos que afectan al tiroides, la piel y ocasionalmente los pulmones y el hígado. Es necesaria la monitorización regular de la función pulmonar, hepática y tiroidea. Como norma general, a mayor duración de la terapia y mayor dosis de amiodarona, mayor probabilidad de que los efectos colaterales adversos requieran la interrupción del fármaco. En comparación con placebo, el 10\% de los pacientes aleatorizados a amiodarona interrumpieron la terapia ${ }^{133}$.

\subsubsection{Sotalol/d-sotalol}

El sotalol racémico, un rápido inhibidor de la corriente de potasio rectificadora retardada con propiedades de bloqueo beta, es eficaz para suprimir la arritmia ventricular. El sotalol se puede usar con seguridad en pacientes con $\mathrm{CI}^{134,135}$, a menos que tengan IC. Por ejemplo, en un estudio de 146 pacientes con arritmias ventriculares sostenidas y DAI, el sotalol redujo significativamente la incidencia de recidivas de taquiarritmias ventriculares sostenidas en comparación con la ausencia de tratamiento con fármacos antiarrítmicos, pero no mejoró la supervivencia ${ }^{136}$.

Además, un estudio de d-sotalol, un rápido inhibidor puro de la corriente de potasio rectificadora retardada, en 3.121 pacientes con disfunción del VI tras infarto de miocardio se detuvo prematuramente debido a la mayor tasa de mortalidad en el grupo tratado con d-sotalol $(R R=1,65 ;$ IC95\%, 1,15-2,36; p = 0,006), probablemente a causa de proarritmias ventriculares, aunque se documentaron muy pocos casos de $\mathrm{TdP}^{137}$. Por lo tanto, no se debería usar sotalol en esos pacientes a menos que se haya implantado un DAI. El uso de dosis antiarrítmicas de sotalol requiere una cuidadosa monitorización por ECG, especialmente en pacientes con bajo índice de masa corporal o función renal alterada.

\subsubsection{Tratamientos combinados}

Escasean los datos que guíen los tratamientos combinados con fármacos antiarrítmicos, y dichas combinaciones deberían quedar reservadas para pacientes en quienes se han intentado otros tratamientos antiarrítmicos (incluidas monoterapias con diferentes agentes, el tratamiento con amiodarona y la ablación con catéter) sin una supresión satisfactoria de los episodios arrítmicos. En pacientes con TV frecuente, se han usado combinaciones de bloqueadores de los canales de sodio y bloqueadores de los canales de potasio (p. ej., mexiletina y sotalol o amiodarona y flecainida/propafenona), normalmente en pacientes con recurrencias de TV frecuentes que tienen un desfibrilador. El tratamiento con bloqueadores beta en combinación con amiodarona reduce el número de choques del DAI; sin embargo, los efectos colaterales pueden dar como resultado la interrupción de los fármacos en un número significativo de pacientes ${ }^{138}$. Se ha combinado la ranolazina con otros agentes antiarrítmicos para suprimir la TV en casos por lo demás refractarios a fármacos ${ }^{139}$. Es necesaria una cuida- 
dosa monitorización del ECG y de la función cardiaca para detectar el deterioro de la función del VI o signos de proarritmia en tales pacientes.

\subsubsection{Pacientes portadores de desfibrilador automático}

Muchos pacientes provistos de un desfibrilador automático toman bloqueadores beta para minimizar las terapias tanto apropiadas como inapropiadas del DAI. Los pacientes con choques del desfibrilador automático recurrentes pueden beneficiarse cambiando a sotalol para suprimir las arritmias auriculares y ventriculares ${ }^{140}$. Sin embargo, se debería evitar el sotalol a pacientes con función del VI muy reducida. Dado que muchos de tales pacientes también tienen mala función renal, la combinación más efectiva de amiodarona y bloqueadores beta puede preferirse frente al sotalol ${ }^{138}$.

El tratamiento con fármacos antiarrítmicos nunca ha mostrado claramente que reduzca la muerte súbita arrítmica de los pacientes que ya han sufrido una arritmia ventricular potencialmente mortal. Sin embargo, tanto en pacientes posinfartados como en pacientes con IC, la amiodarona reduce la aparición de esas arritmias ${ }^{123,124,133}$ y se da por hecho que el fármaco sí ofrece alguna protección contra arritmias ventriculares graves a quienes ya han sufrido tales eventos. Sin embargo, la reducción de la muerte arrítmica no parece conllevar una reducción en la mortalidad total y los eventos adversos asociados a la amiodarona reducen aún más el beneficio del tratamiento. No obstante, la amiodarona, especialmente junto con bloqueadores beta, reduce significativamente las intervenciones del DAI a los pacientes portadores $^{138}$.

Para los pacientes con DAI y fibrilación auricular (FA) paroxística o crónica con ritmos rápidos y choques inapropiados, es esencial el control de la rápida respuesta ventricular a la taquiarritmia auricular, y se puede usar con cuidado un tratamiento combinado con un bloqueador beta o un bloqueador de los canales de calcio no dihidropiridínicos. Si resulta ineficaz, la amiodarona puede ser de ayuda. Puede ser necesaria la ablación del nódulo auriculoventricular (NAV) si el tratamiento farmacológico o la ablación de la FA en casos seleccionados no son eficaces.

\subsubsection{Electrolitos}

La administración de potasio para restaurar la concentración normal en sangre puede influir favorablemente en el sustrato implicado en la arritmia ventricular. La administración de magnesio puede ayudar específicamente a suprimir las arritmias por TdP.

Las alteraciones electrolíticas son comunes en pacientes con IC, en particular los que usan dosis altas de diuréticos ahorradores de potasio. Recientemente, un estudio de base de datos que incluyó a 38.689 pacientes con infarto de miocardio mostró el más bajo riesgo de FV, parada cardiaca o muerte con concentraciones de potasio de $3,5-4,5 \mathrm{mmol} / \mathbf{1}^{141}$

\subsubsection{Terapia con otros fármacos}

En el ventrículo se produce un remodelado adverso tras un infarto de miocardio o en relación con una miocardiopatía no isquémica. Estos cambios estructurales, así como las alteraciones asociadas de los canales iónicos, pueden exacerbar el potencial de arritmia ventricular. Varios fármacos, como los inhibidores de la enzima de conversión de la angiotensina (IECA), los antagonistas del receptor de la angiotensina II (ARA-II) y los antagonistas de los receptores de mineralocorticoides (MRA), mejoran el remodelado inverso y reducen las tasas de MSC ${ }^{142,143}$. Además, los anticoagulantes y los antiplaquetarios pueden ser de ayuda para reducir la frecuencia de oclusiones trombóticas coronarias en pacientes de alto riesgo ${ }^{144}$. Además, los hallazgos indican que las estatinas pueden reducir la aparición de arritmia ventricular con riesgo vital en pacientes de alto riesgo ${ }^{145}$.

\subsection{Terapia con dispositivos}

\subsubsection{Desfibrilador automático implantable}

Los desfibriladores implantables se utilizan en pacientes desde hace más de 30 años. El DAI original se implantaba quirúrgicamente y se conectaba a cables o electrodos fijados en los ventrículos mediante una toracotomía. Esto aún es necesario ocasionalmente, pero la mayoría de los dispositivos emplean electrodos transvenosos predominantemente insertados en el corazón derecho tanto para estimulación cardiaca (cámara única o doble y univentricular o biventricular) como para desfibrilación mediante bobinas intracavitarias en el corazón derecho o la carcasa del desfibrilador implantado. La mayoría de las pruebas clínicas que respaldan el uso del DAI se han realizado mediante DAI transvenosos. Los primeros pacientes en recibir desfibriladores eran supervivientes a una FV o parada cardiaca abortada. Estudios posteriores demostraron beneficio de la terapia mediante desfibrilador para los pacientes con riesgo de muerte súbita. La terapia con DAI previene la muerte súbita y prolonga la vida de los pacientes con alto riesgo de muerte súbita arrítmica siempre que el paciente no sufra otras afecciones que limiten la esperanza de vida a $<1-2$ años ${ }^{146}$. Los estudios a largo plazo han demostrado la eficacia de los DAI ${ }^{147}$ y los desfibriladores con terapia de resincronización cardiaca (TRC-D) $)^{148}$ en seguimientos medios de 8 y 7 años respectivamente.

Por otra parte, los desfibriladores pueden dar complicaciones, como choques inapropiados, que son especialmente frecuentes en niños ${ }^{149}$. Un reciente estudio de más de 3.000 pacientes con DAI o TRC-D encontró una incidencia acumulada de eventos adversos en 12 años del 20\% (IC95\%, 18-22) por choques inapropiados, del 6\% (IC95\%, 5-8) por infección relacionada con el dispositivo y del $17 \%$ (IC95\%, 14-21) por fallo de los electrodos ${ }^{150}$.

A pesar de las indicaciones de terapia con DAI para pacientes posinfartados con FE reducida, firmemente respaldadas por datos basados en la evidencia, en varios países las guías distan claramente de la práctica clínica. Un factor que limita el uso de DAI es su alto coste inicial.

4.3.1.1. Prevención secundaria de la muerte súbita cardiaca y la taquicardia ventricular

DAI para la prevención secundaria de la muerte súbita cardiaca y la taquicardia ventricular

\begin{tabular}{|c|c|c|c|}
\hline Recomendaciones & Clase $^{\mathrm{a}}$ & Nivel $^{\mathrm{b}}$ & $\operatorname{Ref}^{c}$ \\
\hline $\begin{array}{l}\text { Se recomienda implantar DAI a pacientes con } \\
\text { FV documentada o TV hemodinámicamente no } \\
\text { tolerada en ausencia de causas reversibles o en las } \\
48 \text { h siguientes a un infarto de miocardio que están } \\
\text { recibiendo terapia médica óptima crónica y tienen } \\
\text { una esperanza razonable de supervivencia con buen } \\
\text { estado funcional > } 1 \text { año }\end{array}$ & I & A & $151-154$ \\
\hline $\begin{array}{l}\text { Se debe considerar la implantación de DAI a } \\
\text { pacientes con TV sostenida recurrente (no en las } \\
48 \text { h siguientes a un infarto de miocardio) que } \\
\text { están recibiendo terapia médica óptima crónica y } \\
\text { tienen FEVI normal y una esperanza razonable de } \\
\text { supervivencia con buen estado funcional > } 1 \text { año }\end{array}$ & IIa & C & $\begin{array}{c}\text { Este } \\
\text { panel de } \\
\text { expertos }\end{array}$ \\
\hline $\begin{array}{l}\text { Para pacientes con FV/TV e indicación de DAI, se } \\
\text { puede considerar la amiodarona cuando no se } \\
\text { disponga de DAI, este esté contraindicado por } \\
\text { razones médicas concurrentes o el paciente lo } \\
\text { rechace }\end{array}$ & IIb & C & 155,156 \\
\hline
\end{tabular}

DAI: desfibrilador automático implantable; FEVI: fracción de eyección del ventrículo izquierdo; FV: fibrilación ventricular; MSC: muerte súbita cardiaca; TV: taquicardia ventricular.

aClase de recomendación.

bNivel de evidencia.

'Referencias que respaldan las recomendaciones. 
Se han llevado a cabo 3 ensayos clínicos en pacientes que habían sufrido una parada cardiaca o una arritmia ventricular con riesgo vital (arritmia ventricular hemodinámicamente inestable o TV sincopal), el AVID ${ }^{153}$, el CIDS $^{151}$ y el CASH ${ }^{152}$, que compararon el tratamiento con DAI frente a terapia con fármacos antiarrítmicos, predominantemente amiodarona. Los resultados de los 3 ensayos coinciden, aunque solo uno mostró una reducción estadísticamente significativa de la tasa de mortalidad total; el DAI redujo las tasas de mortalidad arrítmica tanto en el ensayo AVID como en el CASH. Un metanálisis de los 3 ensayos demostró que la terapia con DAI se asociaba a una reducción del $50 \%$ (IC95\%, 0,37-0,67; $\mathrm{p}=0,0001$ ) en la mortalidad arrítmica y del $28 \%$ (IC95\%, 0,60-0,87; p = 0,006) en la mortalidad total (tabla 5 del anexo $w e b)^{154}$. Un análisis de los resultados del ensayo AVID demostró claramente que el beneficio quedaba confinado primariamente a pacientes con FEVI del $20-34 \%{ }^{153}$. La terapia es moderadamente coste-efectiva y las guías para el uso de DAI en prevención secundaria tienen aceptación general desde hace años. No hay evidencia de ensayos recientes que indique que haya que cambiar sustancialmente las recomendaciones previas.

\subsubsection{Desfibrilador automático implantable subcutáneo}

Desfibrilador automático implantable subcutáneo

\begin{tabular}{lcccc}
\hline Recomendaciones & Clase $^{\mathrm{a}}$ & Nivel $^{\mathrm{b}}$ & Ref $^{\mathrm{c}}$ \\
\hline $\begin{array}{l}\text { Se debe considerar los desfibriladores subcutáneos } \\
\text { como alternativa a los transvenosos para pacientes } \\
\text { con indicación de DAI cuando no se necesite terapia } \\
\text { de estimulación antibradicardia, resincronización } \\
\text { cardiaca o estimulación antitaquicardia }\end{array}$ & Ila & C & 157,158 \\
\hline $\begin{array}{l}\text { Se puede considerar el DAI subcutáneo como una } \\
\text { alternativa útil al sistema de DAI transvenoso } \\
\text { cuando el acceso venoso sea difícil, tras la retirada } \\
\text { de un DAI transvenoso por infecciones o para } \\
\text { pacientes jóvenes con necesidad de terapia con DAI } \\
\text { a largo plazo }\end{array}$ & & & & \\
\hline
\end{tabular}

DAI: desfibrilador automático implantable.

aClase de recomendación.

bNivel de evidencia.

'Referencias que respaldan las recomendaciones.

Los problemas con el acceso al corazón a través del sistema vascular y los problemas recurrentes con los electrodos transvenosos motivaron el desarrollo de un desfibrilador subcutáneo con un sistema de electrodos que se coloca por completo subcutáneamente, fuera de la cavidad torácica. El sistema consiste en 3 electrodos: la carcasa del DAI, un electrodo distal sobre el electrodo o cable de desfibrilación y un electrodo proximal localizado a aproximadamente $8 \mathrm{~cm}$ de la punta del electrodo de desfibrilación. Entre la punta y el electrodo proximal, hay una bobina para desfibrilación contra la carcasa del desfibrilador. El electrodo se posiciona de modo tal que la parte distal del mismo se sitúa en el borde paraesternal izquierdo y el generador sobre el quinto espacio intercostal entre las líneas anterior izquierda y axilar media. La configuración precisa usada por el dispositivo para la detección de la señal cardiaca, puede ser determinada mediante programación. El dispositivo es capaz de desfibrilar a la mayoría de los pacientes con una energía de $80 \mathrm{~J}^{159}$.

Los datos disponibles apuntan a que los desfibriladores subcutáneos son eficaces en la prevención de la muerte súbita. Actualmente se carece de datos sobre la tolerabilidad y la seguridad a largo plazo del tratamiento, pero se están recogiendo. En uno de los estudios más amplios, se sometió a 330 pacientes -304 de los cuales fueron implantados con éxito- a pruebas de desfibrilación con éxito, con un seguimiento de una media de 11 meses $^{157}$. No hubo fallos de las derivaciones o complicaciones asociadas a la colocación de los electrodos. Todos los eventos inducidos finalizaron con éxito y 118 de las
119 taquiarritmias ventriculares espontáneas que se produjeron en 21 pacientes finalizaron gracias al dispositivo y uno remitió espontáneamente durante la carga del dispositivo. Un $13 \%$ de los pacientes recibieron un choque inapropiado debido en gran parte a taquicardia supraventricular o sobredetección de ondas T, lo que también se ha descrito en los grupos de pacientes más jóvenes ${ }^{160}$. Un reciente registro del mundo real de 472 pacientes registró 317 episodios espontáneos en 85 pacientes durante un seguimiento medio de 18 meses. De estos, 169 (53\%) recibieron terapia para TV o FV y solo 1 paciente murió por FV recurrente y bradicardia grave ${ }^{161}$. Los estudios sobre DAI subcutáneo se resumen en la tabla 6 del anexo $w_{e b} b^{157-165}$.

El dispositivo subcutáneo no es adecuado para pacientes que requieren estimulación antibradicardia, a menos que esta necesidad se restrinja al periodo inmediatamente posterior a la aplicación de un choque (el dispositivo puede aplicar estimulación transcutánea durante $30 \mathrm{~s}$ tras el choque). Los pacientes que necesitan TRC tampoco son adecuados para tratamiento con DAI subcutáneo. De modo similar, el DAI subcutáneo no es apropiado para pacientes que sufren taquiarritmia que pueda finalizarse fácilmente mediante estimulación antitaquicardia. El dispositivo puede ser útil cuando es difícil el acceso venoso, en pacientes jóvenes que se enfrentan a toda una vida de terapia con el dispositivo y pacientes con riesgo particular de bacteriemia (p. ej., con un sistema de DAI transvenoso actual o reciente). Aunque la categoría general de prevención primaria de la MSC debería ser adecuada para terapia con DAI subcutáneo, no se han realizado en esta población estudios a gran escala y a largo plazo, y el rendimiento del dispositivo a largo plazo aún no está totalmente claro. Por ejemplo, estudios individuales han presentado una tasa de choques inapropiados y complicaciones que requieren reintervención ${ }^{160}$ superior a la media: aún queda por determinar si estos resultados pertenecen a una curva de aprendizaje o al mayor riesgo de choques inapropiados de las poblaciones seleccionadas. Un reciente metanálisis de 852 pacientes demostró que no hubo fallos de electrodos, que se remplazaron los dispositivos por necesidad de estimulación del VD a solo 3 pacientes y que la tasa de choques inapropiados fue $<5 \%$ en el último cuartil de inclusión ${ }^{166}$. Actualmente están en marcha ensayos prospectivos aleatorizados para comparar la eficacia y las complicaciones del DAI subcutáneo frente al DAI convencional ${ }^{158}$.

\subsubsection{Chaleco desfibrilador}

\section{Chaleco desfibrilador}

\begin{tabular}{lcccc}
\hline Recomendaciones & Clase $^{\mathrm{a}}$ & Nivel $^{\mathrm{b}}$ & Ref $^{\mathrm{c}}$ \\
\hline $\begin{array}{l}\text { Se puede considerar el ChD para pacientes adultos } \\
\text { con mala función sistólica del VI que tienen riesgo } \\
\text { de muerte súbita arrítmica durante un periodo }\end{array}$ & IIb & C & 167,168 \\
$\begin{array}{l}\text { limitado pero no son candidatos a desfibrilador } \\
\text { implantable (p. ej., transición a trasplante, transición } \\
\text { a implante transvenoso, miocardiopatía periparto, } \\
\text { miocarditis activa y arritmias en la fase precoz tras } \\
\text { un infarto de miocardio) }\end{array}$ & & & \\
& & & \\
\hline
\end{tabular}

ChD: chaleco desfibrilador; VI: ventrículo izquierdo.

aClase de recomendación.

bNivel de evidencia.

'Referencias que respaldan las recomendaciones.

Se ha visto que un desfibrilador externo (más electrodos y placas de electrodos) unido a un chaleco portátil identifica e interrumpe eficazmente la $\mathrm{TV}$ y la $\mathrm{FV}^{168}$. No hay ningún ensayo clínico prospectivo aleatorizado que haya evaluado este dispositivo, pero existen muchos informes de casos, series de casos y registros (mantenidos por el fabricante o independientemente) que han descrito el uso eficaz del chaleco desfibrilador en una proporción relativamente pequeña de pacientes con riesgo de arritmias ventriculares potencialmente fatales. Por ejemplo, Chung et al ${ }^{169}$ vieron que se producían 80 episodios 
de TV o FV sostenida en 59 de 3.569 (1,7\%) pacientes portadores de chaleco desfibrilador. El primer choque fue eficaz en 76 de 76 (100\%) pacientes con TV o FV con pérdida de conciencia y 79 de $80(99 \%)$ con cualquier TV o FV. Más recientemente, Epstein et al ${ }^{170}$ comunicaron que 133 de 8.453 (1,6\%) pacientes recibieron choques apropiados y se reanimó de una arritmia ventricular al $91 \%$. Por lo tanto, este dispositivo puede salvar la vida de pacientes vulnerables, pero su eficacia no se ha validado. En pacientes con FEVI alterada transitoriamente, se puede usar el chaleco desfibrilador hasta haber recuperado suficientemente la función del VI, tras entidades tales como infarto de miocardio, miocardiopatía posparto y miocarditis o intervenciones como revascularización asociada a disfunción transitoria del $\mathrm{VI}^{171}$. De modo similar, los pacientes con antecedente de arritmia ventricular con riesgo vital, en riesgo de padecerla o programados para trasplante de corazón pueden estar protegidos temporalmente con el chaleco desfibrilador $^{172}$

\subsubsection{Acceso público a la desfibrilación}

\section{Acceso público a la desfibrilación}

\begin{tabular}{|c|c|c|c|}
\hline Recomendaciones & Clase $^{\mathrm{a}}$ & Nivel $^{\mathrm{b}}$ & $\operatorname{Ref}^{c}$ \\
\hline $\begin{array}{l}\text { Se recomienda establecer el acceso público a la } \\
\text { desfibrilación en lugares donde la parada cardiaca } \\
\text { sea relativamente común y se disponga de un } \\
\text { almacenamiento adecuado (como escuelas, } \\
\text { estadios, grandes estaciones, casinos, etc.) o en } \\
\text { lugares donde no se disponga de ningún otro } \\
\text { acceso a la desfibrilación (como trenes, cruceros, } \\
\text { aviones, etc.) }\end{array}$ & I & B & 173,174 \\
\hline $\begin{array}{l}\text { Se puede considerar la formación en asistencia } \\
\text { circulatoria básica para las familias de pacientes } \\
\text { con alto riesgo de MSC }\end{array}$ & IIb & C & $\begin{array}{c}\text { Este } \\
\text { panel de } \\
\text { expertos }\end{array}$ \\
\hline
\end{tabular}

MSC: muerte súbita cardiaca.

aClase de recomendación.

bNivel de evidencia.

cReferencias que respaldan las recomendaciones.

La mayoría de las paradas cardiacas se producen fuera del hospital ${ }^{175}$. Es mucho más probable que una desfibrilación inmediata, en comparación con una desfibrilación diferida, restaure un ritmo organizado y un gasto cardiaco estable. El acceso público a la desfibrilación, junto con la reanimación cardiopulmonar, se ha demostrado más eficaz que la reanimación cardiopulmonar por sí sola ${ }^{173}$, y el acceso público a la desfibrilación está ahora bien establecido, especialmente en lugares donde son comunes las aglomeraciones y el estrés y en particular donde puede haber una pronta disponibilidad de voluntarios entrenados (p. ej., casinos, aeropuertos, estadios deportivos), incluso cuando el entrenamiento no se extiende a la reanimación cardiopulmonar ${ }^{174}$. Las paradas cardiacas extrahospitalarias se producen más habitualmente ( $70 \%)$ en el hogar, incluso en pacientes más jóvenes ${ }^{176}$, pero se presencian con menos frecuencia, por lo que no se puede prevenirlas mediante desfibriladores domésticos ${ }^{177}$

La implementación de programas de desfibrilador automático externo reduce la mortalidad en lugares públicos donde habitualmente se presencian paradas cardiacas ${ }^{178}$. Las actividades básicas y avanzadas de soporte vital han conducido a crear protocolos para guiar a los respondedores. Estos documentos, publicados por el European Resuscitation Council y el International Consensus on Cardiopulmonary Resuscitation and Emergency Cardiovascular Care ${ }^{179}$, cubren las amplias circunstancias clínicas y consideraciones sobre los mecanismos. Proporcionan una información clara de manejo y se remite al lector a los documentos fuente para obtener detalles. Como guías de manejo, estos documentos se clasifican con nivel de evidencia $C$, pero derivan de una combinación de estudios y opiniones variadas que van del nivel de evidencia A al B o C.

\subsection{Tratamiento agudo de las arritmias ventriculares sostenidas}

Cardioversión o desfibrilación y tratamiento agudo de las arritmias ventriculares sostenidas

\begin{tabular}{lccc}
\hline Recomendaciones & Clase $^{\mathrm{a}}$ & Nivel $^{\mathrm{b}}$ & Ref $^{\mathrm{c}}$ \\
\hline $\begin{array}{l}\text { Se recomienda la cardioversión eléctrica para } \\
\text { pacientes que se presentan con TV sostenida e } \\
\text { inestabilidad hemodinámica }\end{array}$ & I & C & 180 \\
\hline $\begin{array}{l}\text { Para pacientes que se presentan con TV sostenida } \\
\text { hemodinámicamente tolerada en ausencia de } \\
\text { enfermedad cardiaca estructural (p. ej., TSVD } \\
\text { idiopático), se puede considerar la flecainida i.v. } \\
\text { o un bloqueador beta convencional, verapamilo o } \\
\text { amiodarona }\end{array}$ & IIb & C & \\
\end{tabular}

i.v.: intravenoso; TSVD: tracto de salida del ventrículo derecho; TV: taquicardia ventricular.

aClase de recomendación.

bNivel de evidencia.

'Referencias que respaldan las recomendaciones.

Los mecanismos eléctricos más comunes de la parada cardiaca son FV o TV, bradiarritmias, asistolias y disociación electromecánica (actividad eléctrica sin pulso). En general, la supervivencia es mejor para pacientes que se presentan con taquiarritmias ventriculares en comparación con asistolias. En 2010, los miembros del International Liaison Committee on Resuscitation (ILCOR) actualizaron las conclusiones y recomendaciones derivadas de una conferencia de consenso internacional celebrada en Dallas, Texas, en 2010. En el caso de la parada cardiaca, se debería aplicar el algoritmo universal (figura 2).

Aún es debatible si se debe realizar reanimación cardiopulmonar antes de la desfibrilación. En casos de parada cardiaca extrahospitalaria, se debe realizar inmediatamente una reanimación cardiopulmonar con compresión torácica hasta que sea posible la desfibrilación. En casos de parada cardiaca hospitalaria, se debe intentar la desfibrilación inmediata, ya que en ese caso la probabilidad de que la parada cardiaca se deba a taquiarritmia ventricular sostenida es mayor. Se aconseja iniciar la desfibrilación a máxima energía. Los desfibriladores semiautomáticos proporcionan una excelente tecnología para expandir la capacidad de desfibrilación en los hospitales. En pacientes con un DAI, idealmente se debe colocar los parches del desfibrilador en la pared torácica a al menos $8 \mathrm{~cm}$ de la posición del generador. La amiodarona intravenosa puede facilitar la desfibrilación o prevenir las recurrencias agudas de TV o FV. En el documento ILCOR de 2010 se resumen maniobras avanzadas de soporte vital distintas de las relacionadas con medidas eléctricas para la finalización de taquiarritmias ventriculares ${ }^{181}$.

Se debe tratar a los pacientes que se presentan con TV sostenida según los síntomas y la tolerabilidad de la arritmia. Los pacientes que se presentan con TV monomórfica e inestabilidad hemodinámica (TV sincopal) deben someterse a cardioversión directa. A los pacientes hipotensos y a pesar de ello conscientes, se les debe dar una sedación inmediatamente antes de someterlos a cardioversión. Para los pacientes con taquicardia de QRS ancho hemodinámicamente estables, la cardioversión eléctrica debería ser el abordaje de primera línea. Se puede considerar la procainamida o la flecainida intravenosa para quienes no se presentan con IC grave o infarto de miocardio. Se puede considerar la amiodarona intravenosa para pacientes con IC o sospecha de isquemia. La lidocaína intravenosa es solo moderadamente efectiva en pacientes que se presentan con TV monomórfica. Como norma general, se debe registrar un ECG de 12 derivaciones de todos los pacientes con TV sostenida que se presenten en condición hemodinámicamente estable.

Se debe administrar verapamilo o bloqueadores beta por vía intravenosa a los pacientes que se presentan con TV fascicular del VI (morfología de bloqueo de rama derecha del haz de His [BRDH] y desviación del eje a la izquierda) ${ }^{182}$. 


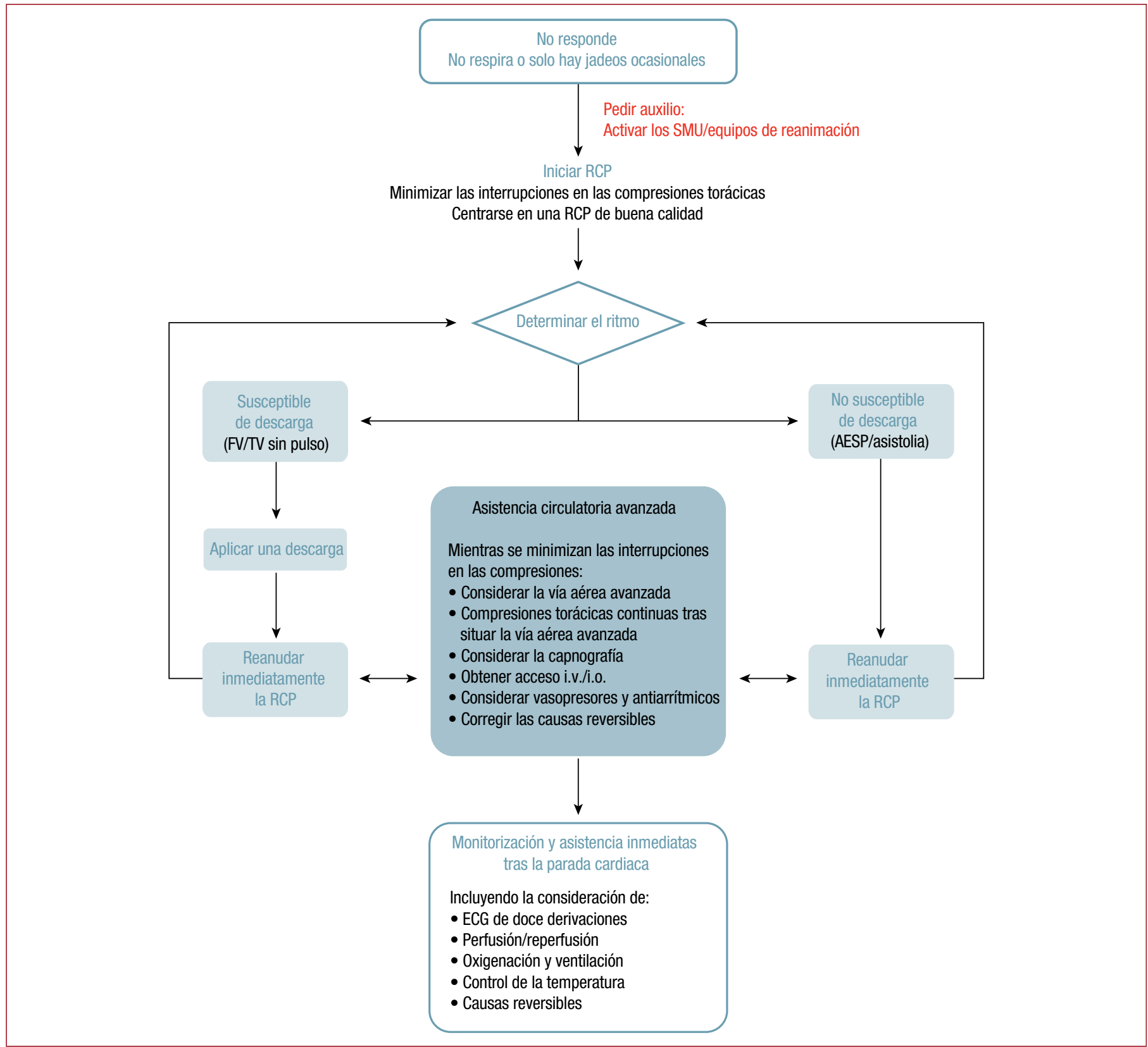

Figura 2. Algoritmo universal de parada cardiaca. AESP: actividad eléctrica sin pulso; ECG: electrocardiograma; SMU: servicios médicos de urgencia; FV: fibrilación ventricular; i.o.: intraóseo; i.v.: intravenoso; RCP: reanimación cardiopulmonar; TV: taquicardia ventricular. Reproducido con permiso de las recomendaciones del ILCOR ${ }^{181}$.

\subsection{Terapia intervencionista}

\subsubsection{Ablación con catéter}

\subsubsection{Pacientes con enfermedad cardiaca relacionada con cicatrices}

La ablación con catéter ha evolucionado hasta convertirse en una importante opción de tratamiento para pacientes con enfermedad cardiaca relacionada con cicatrices que se presentan con TV o FV. Los datos de 2 estudios multicéntricos prospectivos y aleatorizados sobre el resultado en pacientes con $\mathrm{CI}$ demostraron que la ablación de la TV con catéter reduce la probabilidad de posteriores choques del DAI y previene eventos de TV recurrentes ${ }^{187,188}$. Más aún, con frecuencia se emplea la ablación con catéter para controlar la TV incesante o las tormentas eléctricas (es decir, TV/FV recurrentes con frecuentes descargas del DAI apropiadas) y para reducir o prevenir recurrencia de eventos de TV sostenida ${ }^{183,184,187,188}$
Ablación con catéter para el tratamiento de la taquicardia ventricular monomórfica sostenida

\begin{tabular}{lccc}
\hline Recomendaciones & Clase $^{\mathrm{a}}$ & Nivel $^{\mathrm{b}}$ & Ref $^{\mathrm{c}}$ \\
\hline $\begin{array}{l}\text { Se recomienda la ablación con catéter urgente para } \\
\text { pacientes con cardiopatía relacionada con cicatrices } \\
\text { que se presentan con TV incesante o tormenta } \\
\text { eléctrica }\end{array}$ & $\mathrm{I}$ & $\mathrm{B}$ & 183 \\
\hline $\begin{array}{l}\text { Se recomienda la ablación con catéter para } \\
\text { pacientes con cardiopatía isquémica y descargas } \\
\text { de DAI recurrentes debido a TV sostenida }\end{array}$ & $\mathrm{I}$ & $\mathrm{B}$ & $184-186$ \\
\hline $\begin{array}{l}\text { Se debe considerar la ablación con catéter tras un } \\
\text { primer episodio de TV sostenida para pacientes } \\
\text { con cardiopatía isquémica y DAI }\end{array}$ & Ila & B & $184-186$ \\
\hline
\end{tabular}

DAI: desfibrilador automático implantable; TV: taquicardia ventricular.

aClase de recomendación.

${ }^{b}$ Nivel de evidencia.

'Referencias que respaldan las recomendaciones. 
Aunque los DAI pueden finalizar eficazmente la TV en pacientes con miocardiopatía isquémica o no isquémica, no pueden prevenir la recurrencia de la arritmia. Varios estudios han mostrado que los choques del DAI se asocian a mayor mortalidad y alteración de la calidad de vida ${ }^{189,190}$. La terapia con bloqueadores beta en combinación con amiodarona reduce el número de choques del DAI; sin embargo, los efectos colaterales pueden dar lugar a interrupción de los fármacos ${ }^{156}$. En general, el tejido cicatricial es el sustrato en los pacientes que se presentan con TV ${ }^{191}$. La ablación con catéter se dirige al istmo de conducción lenta (istmo crítico) en el circuito de reentrada de la TV. El circuito de reentrada puede abarcar varios centímetros y afectar al endocardio, el mesocardio o el epicardio en una estructura tridimensional compleja ${ }^{192,193}$. La TV relacionada con cicatrices es típicamente monomórfica y se puede inducir múltiples morfologías de TV en el mismo paciente. Se determina la morfología del QRS por el sitio de salida por donde se propagan los frentes de onda de reentrada desde la cicatriz para despolarizar el miocardio ventricular. Por ello, un registro mediante ECG de superficie de 12 derivaciones de la TV clínica puede ayudar en el procedimiento de mapeo y ablación. Para los pacientes con miocardiopatía no isquémica, la morfología del QRS puede identificar a aquellos que probablemente requieran ablación epicárdica ${ }^{194-197}$. Además, la RMC previa al procedimiento puede facilitar la identificación no invasiva del sustrato arrítmico de los pacientes con antecedente de infarto de miocardio ${ }^{198}$ o que se presentan con TV epicárdica ${ }^{199}$.

La TV polimórfica se define como una morfología del QRS en cambio continuo, que frecuentemente se asocia con isquemia miocárdica aguda, canalopatías adquiridas o hereditarias o hipertrofia ventricular. Para algunos de estos pacientes que son refractarios al tratamiento con fármacos, se puede aplicar la ablación con catéter a la TV polimórfica relacionada con las fibras de Purkinje ${ }^{200,201}$.

Se puede usar la imagen no invasiva de la estructura cardiaca, lo cual se realiza mejor por RMC, para planear y guiar los procedimientos de ablación de la $\mathrm{TV}^{198}$. Se puede realizar mapeo y ablación durante una TV en curso (mapeo de activación). Un sistema de mapeo electroanatómico tridimensional puede ayudar a localizar tejido ventricular anormal y permite la ablación con catéter en ritmo sinusal (ablación de sustrato) sin inducción de TV, que se podría mostrar hemodinámicamente inestable. Se puede utilizar un sistema de mapeo sin contacto para pacientes con TV hemodinámicamente inestable. Se puede usar varias técnicas, como la ablación punto por punto en el sitio de salida del circuito de reentrada (descanalización de la cicatriz), la ablación lineal o la ablación de la actividad ventricular anormal local para la homogenización de la cicatriz $^{202-205}$. El mapeo epicárdico y la ablación son necesarios con más frecuencia en pacientes con $\mathrm{MCD}^{206}$ o MAVD ${ }^{207}$ sometidos a ablación de TV. Son complicaciones potenciales de la punción epicárdica y de la ablación epicárdica, el daño en las arterias coronarias o la punción inadvertida de los órganos circundantes, la parálisis del nervio frénico izquierdo o sangrado significativo que dé lugar a taponamiento pericárdico.

Los pacientes con TV relacionada con una cicatriz posmiocárdica tienden a mejor resultado tras la ablación con catéter que los pacientes con TV debida a miocardiopatía no isquémica ${ }^{208}$. Cinco estudios multicéntricos prospectivos han evaluado el papel de la ablación con catéter en el tratamiento de la TV sostenida ${ }^{184-188}$. Aproximadamente un 50\% de los pacientes incluidos en estos estudios tuvieron resultados favorables (es decir, no hubo más recurrencias de TV clínica durante el periodo de seguimiento del estudio), y la ablación con catéter es más efectiva que la terapia con fármacos antiarrítmicos.

En un individuo, se determina la tasa de eficacia de la ablación con catéter para la TV por la extensión de las cicatrices relacionadas con el infarto, representadas como áreas de bajo voltaje en los sistemas de mapeo electroanatómicos ${ }^{209}$, aunque las unidades dedicadas al tratamiento de pacientes mediante ablación con catéter de la TV pueden afectar de manera positiva al resultado ${ }^{210}$. Además, la expe- riencia del equipo y del centro influirá en los resultados, y todos los datos publicados surgen de centros experimentados.

Entre las posibles complicaciones relacionadas con la ablación de la TV con catéter en pacientes con cardiopatía estructural, están el accidente cerebrovascular, los daños valvulares, el taponamiento cardiaco y el BAV. La mortalidad relacionada con el procedimiento varía del 0 al 3\%, y más comúnmente se debe a TV incontrolable cuando falla el procedimiento ${ }^{183-185,187,211}$. Aunque la ablación con catéter es una opción de tratamiento aceptada para una amplia variedad de sustratos de TV, falta evidencia derivada de estudios aleatorizados prospectivos de que la ablación con catéter reduce la mortalidad.

\subsubsection{Pacientes sin enfermedad cardiaca estructural manifiesta}

La TV en pacientes sin enfermedad cardiaca estructural manifiesta emana más habitualmente de los tractos de salida del VD (TSVD) o del VI (TSVI). El ECG de superficie de 12 derivaciones demuestra una morfología de BRIH y eje inferior si la TV surge del TSVD o una morfología de BRIH o BRDH y eje inferior si surge del TSVI. Una actividad desencadenada es el mecanismo fisiopatológico subyacente más común y el abordaje del sitio de activación más precoz durante la ablación con catéter da lugar a una alta tasa de éxito del procedimiento, aunque la tasa de MSC en esta población de pacientes es generalmente baja. Aunque infrecuente, los pacientes pueden presentarse con TV izquierda idiopática que involucra a la red distal de Purkinje. La ablación con catéter es curativa para la mayoría de los pacientes afectados y las complicaciones del procedimiento son raras.

\subsubsection{Cirugía antiarrítmica}

\begin{tabular}{|c|c|c|c|}
\hline Recomendaciones & Clase $^{\mathrm{a}}$ & Nivel $^{\mathrm{b}}$ & $\operatorname{Ref}^{\mathrm{c}}$ \\
\hline $\begin{array}{l}\text { Para pacientes con TV refractaria a la terapia con } \\
\text { fármacos antiarrítmicos tras fallo de la ablación } \\
\text { con catéter por electrofisiólogos experimentados, } \\
\text { se recomienda la ablación quirúrgica guiada } \\
\text { mediante mapeo electrofisiológico preoperatorio } \\
\text { e intraoperatorio realizada en un centro } \\
\text { experimentado }\end{array}$ & I & B & $212-215$ \\
\hline $\begin{array}{l}\text { Para pacientes con TV o FV clínicamente } \\
\text { documentada tras fallo de la ablación con catéter, } \\
\text { se puede considerar la ablación quirúrgica en el } \\
\text { momento de la cirugía cardiaca (bypass o cirugía } \\
\text { valvular) }\end{array}$ & IIb & C & 216,217 \\
\hline
\end{tabular}

FV: fibrilación ventricular; TV: taquicardia ventricular.

${ }^{a}$ Clase de recomendación.

${ }^{b}$ Nivel de evidencia.

'Referencias que respaldan las recomendaciones.

En la era de la ablación con catéter percutánea para el tratamiento de las arritmias ventriculares, el requerimiento de ablación quirúrgica es una rareza. La aneurismectomía del VI anatómicamente guiada se describió por primera vez hace más de 50 años. Los aneurismas de gran tamaño pueden ir acompañados de arritmia ventricular, y la resección guiada por mapa del aneurisma no solo mejora la función del VI, sino que también elimina las arritmias ventriculares. Josephson et $a^{218}$ decribieron por primera vez la resección subendocárdica para el tratamiento de las arritmias ventriculares. Esta técnica se asociaba a morbilidad y mortalidad periprocedimentales significativas (10\%) y, por lo tanto, solo se realizaba en centros quirúrgicos muy especializa$\operatorname{dos}^{212-214,216-219}$. Si los pacientes sobrevivían a la fase posoperatoria inicial, su resultado a largo plazo era excelente. Estudios más recientes han demostrado que el EEF periquirúrgico tras endocardiectomía subtotal y crioablación tiene una tasa de recurrencias de la TV de 
aproximadamente un $10-20 \%$, predominantemente en los primeros 90 días $^{213}$. Por lo tanto, se recomienda el implante precoz de un DAI para los pacientes con TV inducible tras la cirugía ${ }^{213,215,220,221}$. La mayoría de las técnicas quirúrgicas se han convertido en la base para las técnicas de ablación con catéter, incluida una técnica reciente de aislamiento del sustrato 222 .

Resumiendo, la ablación quirúrgica debería realizarse en centros experimentados con mapeo electrofisiológico preoperatorio e intraoperatorio. Se puede considerar para cirugía de la arritmia a los pacientes con TV refractaria a la terapia con fármacos antiarrítmicos o tras una ablación con catéter fallida en un centro de ablación altamente experimentado, en particular si hay aneurisma del VI secundario a infarto de miocardio y se requiere revascularización ${ }^{216-219}$.

\subsection{Impacto psicosocial del tratamiento con desfibrilador automático implantable}

Tratamiento psicosocial tras implante de desfibrilador cardioversor

\begin{tabular}{|c|c|c|c|}
\hline Recomendaciones & Clase $^{\mathrm{a}}$ & Nivel $^{\mathrm{b}}$ & $\operatorname{Ref}^{c}$ \\
\hline $\begin{array}{l}\text { Se recomienda valorar el estado psicológico y el } \\
\text { tratamiento del malestar de los pacientes } \\
\text { con descargas inapropiadas recurrentes }\end{array}$ & I & C & $223-225$ \\
\hline $\begin{array}{l}\text { Se recomienda discutir con todos los pacientes } \\
\text { los inconvenientes para la calidad de vida antes } \\
\text { de implantar un DAI y durante el avance de la } \\
\text { enfermedad }\end{array}$ & I & C & 226,227 \\
\hline
\end{tabular}

DAI: desfibrilador automático implantable.

${ }^{a}$ Clase de recomendación.

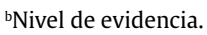

'Referencias que respaldan las recomendaciones.

\section{TRATAMIENTO DE LAS ARRITMIAS VENTRICULARES Y PREVENCIÓN DE LA MUERTE SÚBITA CARDIACA EN LA CARDIOPATÍA ISQUÉMICA}

\subsection{Síndromes coronarios agudos}

\subsubsection{Arritmias ventriculares asociadas a síndromes coronarios agudos}

Pese a la clara reducción de las tasas de MSC gracias a la mejor revascularización y la prevención de la $\mathrm{CI}$ por el cese del consumo de tabaco y el tratamiento con estatinas, el síndrome coronario agudo (SCA) y las arritmias tardías tras un infarto de miocardio siguen siendo una causa común de MSC (véase la sección 3.1). Un número significativo de eventos de MSC se producen en la fase prehospitalaria del SCA, lo que subraya el papel crítico de los programas de cribado para identificar a pacientes de riesgo. La incidencia de arritmias ventriculares en la fase hospitalaria del SCA ha declinado en las últimas décadas, principalmente por las estrategias de revascularización precoces e intensas y la introducción precoz de un tratamiento farmacológico adecuado. Sin embargo, hasta un $6 \%$ de los pacientes con SCA sufren TV o FV en las primeras $48 \mathrm{~h}$ tras la aparición de los síntomas, más frecuentemente durante la reperfusión o antes. Además de una revascularización coronaria rápida y completa, pueden ser necesarias intervenciones no farmacológicas (cardioversión, desfibrilación, estimulación cardiaca y ablación con catéter) y tratamiento farmacológico (fármacos no antiarrítmicos y antiarrítmicos) para controlar las arritmias ventriculares en esta situación.

En la figura 3 se representan las pruebas diagnósticas para pacientes con arritmias ventriculares sostenidas en el contexto de un SCA.

\subsubsection{Prevención y tratamiento de la muerte súbita cardiaca asociada a síndromes coronarios agudos: fase prehospitalaria}

Prevención de la muerte súbita cardiaca asociada a síndrome coronario agudo: fase prehospitalaria

\begin{tabular}{|c|c|c|c|}
\hline Recomendaciones & Clase $^{\mathrm{a}}$ & Nivel $^{\mathrm{b}}$ & $\operatorname{Ref}^{\mathrm{c}}$ \\
\hline $\begin{array}{l}\text { Para pacientes con dolor torácico, se recomienda } \\
\text { reducir los tiempos entre la aparición de los } \\
\text { síntomas y el primer contacto médico y entre el } \\
\text { primer contacto médico y la reperfusión }\end{array}$ & I & A & 244 \\
\hline $\begin{array}{l}\text { Se recomienda que los equipos de ambulancias } \\
\text { estén entrenados y equipados para identificar } \\
\text { el SCA (mediante equipos de registro de ECG y } \\
\text { telemetría según sea necesario) y tratar la parada } \\
\text { cardiaca realizando una asistencia circulatoria } \\
\text { básica y desfibrilación }\end{array}$ & I & B & 178 \\
\hline $\begin{array}{l}\text { Se recomienda que el soporte vital básico y } \\
\text { avanzado se preste siguiendo protocolos de los } \\
\text { algoritmos definidos por el European Resuscitation } \\
\text { Council o los grupos de expertos en reanimación } \\
\text { nacionales o internacionales }\end{array}$ & I & C & 179 \\
\hline $\begin{array}{l}\text { Se recomienda que la atención tras la reanimación } \\
\text { se preste en centros expertos de gran volumen } \\
\text { capaces de ofrecer un tratamiento de cuidados } \\
\text { intensivos multidisciplinario que incluya } \\
\text { intervención coronaria primaria, electrofisiología, } \\
\text { dispositivos de asistencia cardiaca, cirugía cardiaca } \\
\text { y vascular e hipotermia terapéutica }\end{array}$ & I & B & 245,246 \\
\hline $\begin{array}{l}\text { Se debe considerar la creación de redes regionales } \\
\text { para el tratamiento de la parada cardiaca con el fin } \\
\text { de mejorar los resultados }\end{array}$ & IIa & B & 245 \\
\hline
\end{tabular}

ECG: electrocardiograma; SCA: síndrome coronario agudo.

aClase de recomendación.

bNivel de evidencia.

'Referencias que respaldan las recomendaciones. calidad de vida de los receptores de un desfibrilador conservada o mejorada en comparación con la de los controles ${ }^{223,224}$. No obstante, la ansiedad (8-63\%) y la depresión (5-41\%) son comunes en los pacientes con desfibrilador ${ }^{228}$ y son más pronunciadas en pacientes que sufren choques inapropiados o frecuentes (es decir, más de 5 cho-

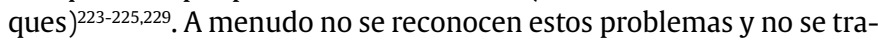
tan en la práctica clínica ${ }^{230,231}$. Aunque el tratamiento inmediato debería eliminar la causa de la activación del dispositivo, el tratamiento del malestar psicológico es una ayuda importante ${ }^{229}$. Los niveles de malestar varían, pero los pacientes pueden presentarse con formas más graves, como trastorno de estrés postraumático ${ }^{232,233}$, que se asocia a choques previos y malestar previo al implante ${ }^{234}$. Los pacientes con DAI y taquiarritmia reciente también pueden mostrar ansiedad por anticiparse al choque ${ }^{235}$. Los pacientes con grandes preocupaciones relacionadas con el DAI antes del implante son más propensos a sufrir problemas tras este, y la depresión puede ser particularmente maligna en esta población ${ }^{236,237}$. Por lo tanto, la valoración y el tratamiento adecuados del malestar psicológico deberían formar parte integral del tratamiento clínico. Todos los pacientes con DAI, en particular los que muestran malestar, requieren ayuda sobre cómo vivir con su dispositivo con objeto de mejorar los resultados ${ }^{238}$.

El implante de un DAI puede afectar a muchas áreas de la vida, como la capacidad para conducir ${ }^{239,240}$, las relaciones íntimas ${ }^{241,242}$, la calidad del sueño ${ }^{226}$, preocupaciones por la imagen corporal (particularmente de las mujeres más jóvenes ${ }^{227}$ y la participación en deportes reglados (en especial niños y adolescentes) ${ }^{243}$. El apoyo de los profesionales de la salud mitiga estas preocupaciones, pero se requiere más estudios para optimizar el progreso del cuidado y desarrollar intervenciones basadas en la evidencia ${ }^{233}$. 
Aunque la mortalidad hospitalaria por IMCEST se ha reducido sustancialmente gracias al uso de la moderna terapia de reperfusión, aún preocupa la mortalidad total a corto plazo. El infarto que se presenta como muerte súbita en las primeras horas tras la aparición de los síntomas actualmente es una de las principales causas de muerte por infarto de miocardio.

\subsubsection{Prevención de la muerte súbita cardiaca asociada a síndromes coronarios agudos: fase hospitalaria}

Prevención y tratamiento de la muerte súbita cardiaca asociada a síndrome coronario agudo: fase hospitalaria. Indicaciones para la revascularización

\begin{tabular}{|c|c|c|c|}
\hline Recomendaciones & Clase $^{\mathrm{a}}$ & Nivel $^{\mathrm{b}}$ & $\operatorname{Ref}^{c}$ \\
\hline $\begin{array}{l}\text { Se recomienda reperfusión urgente de los } \\
\text { pacientes con IMCEST }\end{array}$ & I & A & $247-249$ \\
\hline $\begin{array}{l}\text { Se recomienda la revascularización coronaria } \\
\text { para pacientes con IMSEST o angina inestable } \\
\text { según la guía de la ESC sobre IMSEST }\end{array}$ & I & C & 13,250 \\
\hline $\begin{array}{l}\text { Se recomienda un angiograma coronario, si es } \\
\text { necesario seguido de angioplastia coronaria en } \\
\text { las } 2 \text { h siguientes al ingreso hospitalario para } \\
\text { pacientes con IMSEST de alto riesgo que incluye } \\
\text { las arritmias ventriculares malignas }\end{array}$ & I & C & 13,250 \\
\hline $\begin{array}{l}\text { Se recomienda revascularización coronaria } \\
\text { rápida y completa para tratar la isquemia } \\
\text { miocárdica que podrían tener los pacientes } \\
\text { con TV o FV recurrente }\end{array}$ & I & C & 251,252 \\
\hline $\begin{array}{l}\text { Se recomienda una rápida apertura de los } \\
\text { vasos responsables del infarto para revertir las } \\
\text { alteraciones isquémicas de la conducción AV de } \\
\text { nueva aparición. Esto es particularmente cierto } \\
\text { para el BAV debido a infarto inferior, incluso en } \\
\text { caso de presentación tardía (> } 12 \mathrm{~h} \text { ) }\end{array}$ & I & C & 253 \\
\hline $\begin{array}{l}\text { Se recomienda el ingreso directo en } \\
\text { el laboratorio de hemodinámica de } \\
\text { los supervivientes a parada cardiaca } \\
\text { extrahospitalaria comatosos con criterios } \\
\text { electrocardiográficos de IMCEST } \\
\text { en el ECG posterior a la reanimación }\end{array}$ & I & B & 251,252 \\
\hline $\begin{array}{l}\text { Se debe considerar pasar por una unidad de } \\
\text { cuidados intensivos a los supervivientes a } \\
\text { parada cardiaca extrahospitalaria comatosos } \\
\text { sin criterios electrocardiográficos de elevación } \\
\text { del segmento ST en el ECG posterior a la } \\
\text { reanimación, para excluir causas no coronarias; } \\
\text { en ausencia de una causa no coronaria } \\
\text { obvia, se debe considerar la realización de } \\
\text { un angiograma coronario lo antes posible } \\
\text { (<2 h), particularmente a los pacientes } \\
\text { hemodinámicamente inestables }\end{array}$ & $\begin{array}{l}\text { Ila (para } \\
\text { ambas } \\
\text { recomen- } \\
\text { daciones) }\end{array}$ & B & 251,252 \\
\hline $\begin{array}{l}\text { Se debe considerar implantar un dispositivo de } \\
\text { asistencia ventricular izquierda a los pacientes } \\
\text { hemodinámicamente inestables con TV o FV } \\
\text { recurrente pese a recibir una terapia óptima }\end{array}$ & IIa & B & 254 \\
\hline $\begin{array}{l}\text { Se puede considerar los dispositivos de } \\
\text { asistencia circulatoria y la revascularización } \\
\text { en centros especializados para pacientes con } \\
\text { parada cardiaca refractaria }\end{array}$ & IIb & C & 255,256 \\
\hline
\end{tabular}

AV: auriculoventricular; BAV: bloqueo auriculoventricular; ECG: electrocardiograma; ESC: Sociedad Europea de Cardiología; FV: fibrilación ventricular; IMCEST: infarto de miocardio con elevación del segmento ST; IMSEST: infarto de miocardio sin elevación del segmento ST; MSC: muerte súbita cardiaca; SCA: síndrome coronario agudo; TV: taquicardia ventricular; VI: ventrículo izquierdo.

aClase de recomendación.

bNivel de evidencia.

'Referencias que respaldan las recomendaciones.
Prevención y tratamiento de la muerte súbita cardiaca asociada a síndrome coronario agudo: fase hospitalaria. Desfibrilación/cardioversión/fármacos/ ablación con catéter

\begin{tabular}{|c|c|c|c|}
\hline Recomendaciones & Clase $^{\mathrm{a}}$ & Nivel $^{\mathrm{b}}$ & $\operatorname{Ref}^{c}$ \\
\hline $\begin{array}{l}\text { Se recomienda el tratamiento con bloqueadores } \\
\text { beta para la TV polimórfica recurrente. }\end{array}$ & I & B & 257 \\
\hline $\begin{array}{l}\text { Se recomienda amiodarona intravenosa para el } \\
\text { tratamiento de la TV polimórfica }\end{array}$ & I & C & 258 \\
\hline $\begin{array}{l}\text { Se recomienda cardioversión eléctrica o } \\
\text { desfibrilación inmediata para pacientes con TV } \\
\text { sostenida o FV }\end{array}$ & I & C & 180 \\
\hline $\begin{array}{l}\text { Se recomienda angiografía coronaria urgente, } \\
\text { seguida de revascularización cuando esté } \\
\text { indicado, para pacientes con TV o FV recurrente } \\
\text { si no se puede excluir isquemia miocárdica }\end{array}$ & I & C & 251,252 \\
\hline $\begin{array}{l}\text { Se recomienda corregir los desequilibrios } \\
\text { electrolíticos de los pacientes con TV o FV } \\
\text { recurrente }\end{array}$ & I & C & 179 \\
\hline $\begin{array}{l}\text { Para todo paciente con SCA sin } \\
\text { contraindicaciones, se debe considerar el } \\
\text { tratamiento oral con bloqueadores beta durante } \\
\text { la estancia hospitalaria y continuar con él } \\
\text { después }\end{array}$ & IIa & B & $\begin{array}{l}130,257 \\
259,260\end{array}$ \\
\hline $\begin{array}{l}\text { Para pacientes con TV, FV o tormentas eléctricas } \\
\text { recurrentes a pesar de una revascularización } \\
\text { completa y tratamiento médico óptimo, se } \\
\text { debe considerar la ablación con catéter de } \\
\text { radiofrecuencia en un centro de ablación } \\
\text { especializado, seguida de implante de DAI }\end{array}$ & IIa & C & $261-267$ \\
\hline $\begin{array}{l}\text { Se debe considerar la estimulación rápida } \\
\text { con catéter transvenoso si la TV a menudo } \\
\text { es recurrente pese al uso de fármacos } \\
\text { antiarrítmicos y no es posible la ablación con } \\
\text { catéter }\end{array}$ & Ila & C & \\
\hline $\begin{array}{l}\text { Se puede considerar la lidocaína intravenosa } \\
\text { para el tratamiento de la TV sostenida o la FV } \\
\text { recurrente que no responden a bloqueadores } \\
\text { beta o amiodarona o en presencia de } \\
\text { contraindicaciones para la amiodarona }\end{array}$ & IIb & C & 268 \\
\hline $\begin{array}{l}\text { No se recomienda el tratamiento profiláctico } \\
\text { con fármacos antiarrítmicos (aparte de los } \\
\text { bloqueadores beta) }\end{array}$ & III & B & 269,270 \\
\hline
\end{tabular}

DAI: desfibrilador automático implantable; FV: fibrilación ventricular; MSC: muerte súbita cardiaca; SCA: síndrome coronario agudo; TV: taquicardia ventricular.

aClase de recomendación.

Nivel de evidencia.

'Referencias que respaldan las recomendaciones.

Se han publicado guías de la ESC para el tratamiento del SCA con o sin elevación del segmento ST y revascularización coronaria que facilitan detalladamente toda la información relevante para el diagnóstico del SCA, IMSEST e IMCEST y las recomendaciones para el tratamiento ${ }^{13,250,271}$. Esta sección se centra en el papel específico de la reperfusión y la revascularización para la prevención y el tratamiento de la TV y la FV en pacientes con SCA.

Debido a la implementación de programas de concienciación pública sobre la MSC, se produce ingreso hospitalario de un número cada vez mayor de supervivientes a una parada cardiaca extrahospitalaria. Si hay elevación del segmento ST en el ECG previo a la reanimación o tras la reanimación inicial, se recomienda angiografía y revascularización urgentes, como para todos los pacientes con IMCEST $^{251}$. Sin embargo, la ausencia de elevación del segmento ST no excluye el origen en lesiones coronarias obstructivas o incluso trombóticas, que pueden estar presentes en un 25-58\% de los $\operatorname{casos}^{251,252}$. Dada la gran prevalencia de oclusiones coronarias y las dificultades potenciales en la interpretación del ECG de un pacientes que ha sufrido una parada cardiaca, habría que considerar un angiograma 
Prevención y tratamiento de la muerte súbita cardiaca asociada a síndrome coronario agudo: fase hospitalaria. Control del ritmo/desfibrilador automático implantable

\begin{tabular}{|c|c|c|c|}
\hline Recomendaciones & Clase $^{\mathrm{a}}$ & Nivel $^{\mathrm{b}}$ & $\operatorname{Ref}^{c}$ \\
\hline $\begin{array}{l}\text { Se recomienda la estimulación temporal } \\
\text { transvenosa temporal para pacientes con síntomas } \\
\text { de bradicardia sinusal pese a recibir tratamiento } \\
\text { con medicación cronotrópica positiva }\end{array}$ & I & C & 271 \\
\hline $\begin{array}{l}\text { Se recomienda la estimulación temporal } \\
\text { transvenosa temporal para pacientes con BAV de } \\
\text { alto grado sintomático sin ritmo de escape estable }\end{array}$ & I & C & 271 \\
\hline $\begin{array}{l}\text { Se recomienda angiografía urgente para pacientes } \\
\text { con síntomas de BAV de alto grado que no han } \\
\text { recibido reperfusión }\end{array}$ & I & C & 271 \\
\hline $\begin{array}{l}\text { Se recomienda reprogramar el DAI previamente } \\
\text { implantado para pacientes con terapias con DAI } \\
\text { inapropiadas recurrentes }\end{array}$ & I & C & 272 \\
\hline $\begin{array}{l}\text { Se debe considerar la reprogramación del DAI } \\
\text { previamente implantado para evitar descargas } \\
\text { del DAI innecesarias }\end{array}$ & IIa & C & 272 \\
\hline $\begin{array}{l}\text { Para pacientes seleccionados (revascularización } \\
\text { incompleta }{ }^{\text {}} \text {, disfunción de la FEVI preexistente, } \\
\text { aparición de arritmias más de } 48 \text { h después de la } \\
\text { aparición de SCA, TV polimórfica o FV), se puede } \\
\text { considerar el implante de DAI o el uso temporal } \\
\text { de ChD los primeros } 40 \text { días tras un infarto de } \\
\text { miocardio }\end{array}$ & IIb & C & 170,273 \\
\hline $\begin{array}{l}\text { En general, no está indicado el implante de DAI } \\
\text { en prevención primaria de la MSC antes de } 40 \text { días } \\
\text { tras un infarto de miocardio }\end{array}$ & III & A & 274,275 \\
\hline
\end{tabular}

BAV: bloqueo auriculoventricular; ChD: chaleco desfibrilador; DAI: desfibrilador automático implantable; FEVI: fracción de eyección del ventrículo izquierdo; FV: fibrilación ventricular; MSC: muerte súbita cardiaca; SCA: síndrome coronario agudo; TV: taquicardia ventricular.

aClase de recomendación.

bNivel de evidencia.

'Referencias que respaldan las recomendaciones.

dRevascularización incompleta se refiere a incapacidad para tratar la lesión culpable o presencia de lesiones no causales que no se puede tratar.

coronario para los supervivientes a una parada cardiaca extrahospitalaria después de pasar por un servicio de urgencias o una unidad de cuidados intensivos para excluir causas no cardiacas de la parada ${ }^{276}$.

En el marco del SCA y recurrencia de TV o FV sostenida y hemodinámicamente relevante, la revascularización rápida y eficaz es clave para una mayor prevención de la arritmia y se debería intentar inmediatamente ${ }^{13,250,271}$.

\subsubsection{Arritmias ventriculares en síndromes coronarios agudos}

La isquemia aguda causa inestabilidad eléctrica y arritmias ventriculares en pacientes con SCA ${ }^{266}$. El uso precoz de bloqueadores beta en el marco del SCA reduce la TV/FV y, por lo tanto, está recomendado $^{257,269}$. La corrección de la hipomagnesemia y la hipopotasemia puede ayudar a pacientes seleccionados. La terapia con estatina reduce la mortalidad de los pacientes con $\mathrm{CI}$, mayormente por prevención de eventos coronarios recurrentes, de modo que es parte de la medicación recomendada habitualmente ${ }^{250,271}$.

\subsubsection{Uso de fármacos antiarrítmicos en síndromes coronarios agudos: consideraciones generales}

La cardioversión o desfibrilación eléctrica es la intervención de elección para finalizar de manera aguda las arritmias ventriculares de pacientes con $\mathrm{SCA}^{1,271}$. La administración precoz (posiblemente i.v.) de bloqueadores beta puede ayudar a prevenir arritmias recurrentes ${ }^{257,269,271}$. Se debe considerar el tratamiento antiarrítmico con amiodarona solo si los episodios de TV o FV son frecuentes y ya no se pueden controlar mediante cardioversión o desfibrilación eléctrica ${ }^{1,271}$. Se puede considerar la lidocaína i.v. para la TV o la FV sostenida recurrente que no responde a los bloqueadores beta o la amiodarona o en caso de contraindicaciones para la amiodarona. Para pacientes con TV o FV recurrente desencadenada por una extrasístole ventricular (EV) que surge de fibras de Purkinje parcialmente lesionadas, la ablación con catéter es muy efectiva y se debería conside$\operatorname{rar}^{261-265}$ (véase la sección 6.3.2).

\subsubsection{Pacientes con síndromes coronarios agudos y sin arritmias ventriculares}

Se recomienda el tratamiento con bloqueadores beta para prevenir arritmias ventriculares ${ }^{257,271}$. El tratamiento profiláctico con fármacos antiarrítmicos no se ha demostrado beneficioso e incluso puede ser perjudicial, por lo que no está indicado ${ }^{257,269}$.

\subsubsection{Extrasístoles ventriculares}

Con frecuencia se producen EV y TVNS en pacientes con SCA, especialmente durante la angioplastia primaria para el IMCEST (se las conoce como arritmias de reperfusión). Muy raramente tienen relevancia hemodinámica y no requieren tratamiento específico. Una ectopia ventricular prolongada y frecuente puede ser signo de que se necesita nueva revascularización (p. ej., repetición de angiograma/intervención coronaria percutánea $)^{250,271}$. En la TVNS hemodinámicamente relevante, habría que considerar la amiodarona (bolo de $300 \mathrm{mg}$ i.v. $)^{1,271}$.

\subsubsection{Taquicardia ventricular y fibrilación ventricular sostenidas}

La TV sostenida recurrente, sobre todo cuando es polimórfica, y la FV recurrente pueden indicar reperfusión incompleta o recurrencia de isquemia aguda. Habría que considerar, por lo tanto, una angiografía coronaria inmediata ${ }^{250,271}$. Una TV polimórfica recurrente que degenera en FV puede responder a los bloqueadores beta. Además, una sedación profunda puede ser de ayuda para reducir los episodios de TV o FV. Habría que considerar la amiodarona (bolo de 150-300 mg i.v.) para suprimir de manera aguda las arritmias ventriculares hemodinámicamente relevantes y recurrentes. No se recomienda el uso de otros fármacos antiarrítmicos en el SCA (como procainamida, propafenona, ajmalina y flecainida) $)^{1,269,271}$.

\subsubsection{Ablación con catéter de taquicardia ventricular sostenida recurrente, fibrilación ventricular recurrente y tormentas eléctricas}

Para pacientes con TV o FV recurrente a pesar de revascularización completa y tratamiento médico óptimo, habría que considerar la ablación con catéter. Los episodios de FV recurrentes pueden ser desencadenados por EV que surgen de fibras de Purkinje parcialmente lesionadas o de miocardio ventricular lesionado por isquemia o reperfusión. En casi todos los casos, se puede acceder al sustrato desde el endocardio. El mapeo preciso con catéter y la ablación eficaz de los extrasístoles que originan la TV o la FV o del sustrato miocárdico que sostiene la TV o la FV es un procedimiento complejo y exigente. Por lo tanto, habría que considerar la derivación precoz de los pacientes que se presentan con tormentas de TV o FV a centros de ablación especializados ${ }^{261-265}$.

\subsubsection{Dispositivos de asistencia circulatoria}

Para casos seleccionados con TV o FV recurrente no abordable según las recomendaciones de tratamiento mencionadas, habría que considerar el implante de dispositivos de asistencia del VI para la estabilización hemodinámica. Dichas intervenciones también pueden generar ventanas temporales que permitan intervenciones coronarias 
en el shock cardiogénico debido a TV o FV recurrente. Aunque se puede conseguir la estabilización hemodinámica con dispositivos de asistencia ventricular, la probabilidad de recurrencia de la TV o la FV es alta y el tratamiento intervencionista resulta difícil ${ }^{254}$.

\subsubsection{Bradicardia y bloqueo del corazón}

Puede producirse bradicardia y bloqueo del corazón, que se asocia con mayor mortalidad hospitalaria. El BAV se debe más frecuentemente a oclusión proximal de la arteria coronaria derecha o una arteria circunfleja dominante. La pronta revascularización coronaria resuelve muy frecuentemente la conducción ${ }^{253}$. Cuando la bradicardia da lugar a un deterioro hemodinámico grave (normalmente con bloqueo avanzado o completo del corazón en ausencia de ritmo de escape de la unión estable) o cuando persiste a pesar de revascularización coronaria, puede ser necesario el control transitorio del ritmo ventricular con un cable de marcapasos colocado percutáneamente en el ventrículo derecho ${ }^{271}$. Para la bradicardia o el bloqueo cardiaco persistente, puede ser necesaria la estimulación cardiaca permanente, que se debe realizar según las guías actuales sobre estimulación cardiaca ${ }^{10}$.

\subsubsection{Valor pronóstico de la fibrilación ventricular precoz}

La FV precoz (es decir, que se produce en las primeras $48 \mathrm{~h}$ ) durante el SCA se asocia con un aumento de la mortalidad hospitalaria de hasta 5 veces ${ }^{277}$ y probablemente identifica un riesgo de mortalidad a más largo plazo. No todas las muertes que se producen posteriormente son súbitas, y la decisión de implantar un DAI debe basarse en la presencia de otros factores de riesgo además de FV o TV en el marco del SCA 278,279 .

\subsection{Periodo precoz tras un infarto de miocardio}

\subsubsection{Estratificación de riesgos de muerte súbita cardiaca}

Estratificación de riesgos de muerte súbita cardiaca precoz (primeros 10 días) tras un infarto de miocardio

\begin{tabular}{lcccc}
\hline Recomendaciones & Clase $^{\mathrm{a}}$ & Nivel $^{\mathrm{b}}$ & Ref $^{\mathrm{c}}$ \\
\hline $\begin{array}{l}\text { Se puede considerar la EVP precoz tras un infarto } \\
\text { de miocardio para pacientes con FEVI reducida } \\
\begin{array}{l}(\leq 40 \%) \text { para determinar el riesgo de muerte súbita } \\
\text { No se recomiendan pruebas no invasivas }\end{array}\end{array}$ & B & 280-282 \\
\hline $\begin{array}{l}\text { (p. ej., microalternancia de la onda T, pruebas } \\
\text { para disfunción autonómica o ECG-SP) para la } \\
\text { estratificación de riesgo en la fase precoz tras un } \\
\text { infarto de miocardio }\end{array}$ & & B & 283,284 \\
\hline
\end{tabular}

ECG-SP: electrocardiograma de señal promediada; EVP: estimulación ventricular programada; FEVI: fracción de eyección del ventrículo izquierdo.

aClase de recomendación.

bNivel de evidencia.

'Referencias que respaldan las recomendaciones.

La MSC es una importante causa de muerte tras un infarto de miocardio y con frecuencia se debe a infarto recurrente. No obstante, el implante precoz de un desfibrilador tras un infarto no mejora el pronóstico, probablemente debido a causas de muerte competitivas ${ }^{274,275}$. Se recomienda revascularización y tratamiento médico óptimo (incluidos bloqueadores beta, terapia doble antiplaquetaria y estatinas) y prevención y tratamiento de la IC, que son los pilares de la prevención de la muerte súbita en este grupo de pacientes. Aunque se han estudiado y abandonado varios marcadores no invasivos de riesgo de muerte súbita en esta cohorte, algunos datos respaldan el uso de la estimulación ventricular programada precoz en supervi- vientes a infarto de miocardio con FEVI reducida, ya que los que no sufren TV monomórfica inducible tienen bajo riesgo de posterior muerte súbita ${ }^{285}$. Son necesarios estudios aleatorizados para definir de manera concluyente el papel de la estimulación ventricular programada para la estratificación de riesgos en el periodo precoz tras un infarto de miocardio.

\subsubsection{Momento para colocar el desfibrilador automático implantable después de un infarto de miocardio: valoración de la disfunción del ventrículo izquierdo antes y después del alta}

Momento de colocación del desfibrilador automático implantable después de un infarto de miocardio. Determinación de la fracción de eyección del ventrículo izquierdo

\begin{tabular}{lccc}
\hline Recomendaciones & Clase $^{\mathrm{a}}$ & Nivel $^{\mathrm{b}}$ & Ref $^{\mathrm{c}}$ \\
\hline $\begin{array}{l}\text { Se recomienda la determinación precoz (antes del } \\
\text { alta) de la FEVI de todo paciente con infarto } \\
\text { de miocardio }\end{array}$ & I & C & 286-288 \\
\hline $\begin{array}{l}\text { Se recomienda volver a determinar la FEVI } \\
\text { 6-12 semanas después del infarto de miocardio } \\
\text { para valorar la posible necesidad de implantar } \\
\text { un DAI para prevención primaria }\end{array}$ & & & \\
\hline
\end{tabular}

DAI: desfibrilador automático implantable; FEVI: fracción de eyección del ventrículo izquierdo.

aClase de recomendación.

bNivel de evidencia.

'Referencias que respaldan las recomendaciones.

Se puede considerar el implante precoz (antes de 40 días) de un DAI o el uso temporal ( $<40$ días) de un chaleco desfibrilador en presencia de condiciones específicas como alteración preexistente de la FEVI, revascularización incompleta y aparición de arritmia más de 48 h después de establecerse un SCA. Se debe valorar el tipo de arritmia ventricular (TV o FV monomórfica, polimórfica, pleomórfica), así como la longitud de ciclo de la TV (rachas cortas no sostenidas o rachas largas no sostenidas). Si se llevó a cabo una estimulación programada, se debería valorar la inducibilidad y el tipo de arritmia inducida (TV monomórfica, TV polimórfica, FV) $274,275$.

Se debería valorar la FEVI 6-12 semanas después del infarto de miocardio en pacientes estables y en los que están con medicación optimizada para la IC con objeto de determinar una indicación potencial para implante de desfibrilador en prevención primaria. Esta evaluación debería estar estructurada y ofrecerse a todos los pacientes ${ }^{271,286-288}$

\subsection{Cardiopatía isquémica estable después de un infarto de miocardio con fracción de eyección conservada}

La terapia moderna de revascularización y prevención secundaria facilita la conservación de la FEVI en la mayoría de los pacientes que se presentan precozmente con un infarto de miocardio. Aunque el riesgo de MSC de estos pacientes es sustancialmente inferior que el de los pacientes con FEVI muy reducida, el número absoluto de víctimas de MSC con FEVI conservada es alto. Se necesitan estrategias mejoradas de detección del riesgo de MSC en la población de riesgo intermedio.

\subsubsection{Estratificación de riesgo}

La mayoría de los estudios que han evaluado la utilidad de la estratificación de riesgo no invasiva se han realizado en pacientes con FEVI muy alterada $(<40 \%)$ o poblaciones mixtas. En estos estudios no se ha descrito el resultado del subgrupo de pacientes con FEVI $>40 \%$ o los subgrupos eran demasiado pequeños para hacer posible el análisis y 
Estratificación de riesgo de pacientes con cardiopatía isquémica estable después de un infarto de miocardio con fracción de eyección conservada

\begin{tabular}{lcccc}
\hline Recomendaciones & Clase $^{\mathrm{a}}$ & Nivel $^{\mathrm{b}}$ & Ref $^{\mathrm{c}}$ \\
\hline $\begin{array}{l}\text { Se debe considerar la EVP para supervivientes a un } \\
\text { infarto de miocardio con función del VI conservada } \\
\text { y síncope por lo demás inexplicable }\end{array}$ & Ila & C & $280-282$ \\
\hline
\end{tabular}

EVP: estimulación ventricular programada; VI: ventrículo izquierdo.

aClase de recomendación.

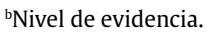

'Referencias que respaldan las recomendaciones.

la interpretación de los datos. Hasta la fecha, en pacientes con infarto de miocardio antiguo y FEVI conservada, no se ha demostrado suficiente especificidad y sensibilidad de ninguna técnica de estratificación de riesgo no invasiva.

Hay alguna evidencia, a partir de subgrupos de estudios a gran escala, de que la estimulación ventricular programada (EVP) es útil para la estratificación de riesgo en pacientes posinfartados con valores de FEVI intermedios o $>40 \%^{280-282}$. El ensayo PRESERVE-EF (NCT02124018), en curso, aborda precisamente esta cuestión.

\subsubsection{Recomendaciones para una estrategia óptima}

Revascularización de pacientes con cardiopatía isquémica estable después de un infarto de miocardio con fracción de eyección conservada

\begin{tabular}{lccc}
\hline Recomendaciones & Clase $^{\mathrm{a}}$ & Nivel $^{\mathrm{b}}$ & Ref $^{\mathrm{c}}$ \\
\hline $\begin{array}{l}\text { Se recomienda revascularización coronaria para } \\
\text { reducir el riesgo de MSC de los pacientes con FV } \\
\text { cuando la aparición de esa se precede de isquemia } \\
\text { miocárdica aguda }\end{array}$ & I & B & 289,290 \\
\hline
\end{tabular}

FV: fibrilación ventricular; MSC: muerte súbita cardiaca.

aClase de recomendación.

bNivel de evidencia.

cReferencias que respaldan las recomendaciones.

Recientemente se ha publicado una guía para la revascularización coronaria $^{13}$. Proporciona clara información de manejo y se remite al lector a los documentos fuente para la obtención de detalles.

En pacientes con $\mathrm{Cl}$ y arritmias ventriculares, es esencial la valoración de la enfermedad coronaria obstructiva y la isquemia. La revascularización quirúrgica puede aumentar la supervivencia y prevenir la MSC. El implante de un electrodo epicárdico de DAI en el momento de la revascularización aortocoronaria no se asocia a beneficio en mortalidad general. La intervención coronaria percutánea también se asocia a una marcada disminución en la mortalidad cardiaca por producirse menos muertes por infarto de miocardio o muerte súbita.

La revascularización puede ir asociada a un aumento de la FEVI $\geq 5-6 \%$ en un $15-65 \%$ de los pacientes estables. Esto es particularmente cierto para aquellos con evidencia de miocardio isquémico o hibernante en estudios de imagen preoperatorios ${ }^{291,292}$. La mayoría de los pacientes con FEVI muy deprimida inmediatamente después de un IMCEST muestran una función sistólica significativamente mejorada después de 3 meses $^{286}$. Se debería revaluar la FEVI 6-12 semanas después de la revascularización coronaria para determinar las indicaciones potenciales de implante de DAI para prevención primaria.

En pacientes que sobreviven a MSC, la revascularización puede reducir la recurrencia de arritmias potencialmente mortales y MSC y también mejorar los resultados de los pacientes, en particular si hay evidencia de isquemia que precede a la MSC. Es menos probable que la TV monomórfica sostenida en pacientes con infarto de miocardio previo resulte afectada por la revascularización. No es probable que la revascularización miocárdica prevenga la MSC recurrente en pacientes con cicatrización miocárdica extensa y FEVI marcadamente reducida.

\subsubsection{Uso de fármacos antiarrítmicos}

Uso de fármacos antiarrítmicos

\begin{tabular}{lccc}
\hline Recomendaciones & Clase $^{\mathrm{a}}$ & Nivel $^{\mathrm{b}}$ & Ref $^{\mathrm{c}}$ \\
\hline $\begin{array}{l}\text { Se puede considerar la amiodarona para el alivio } \\
\text { de los síntomas de arritmias ventriculares de } \\
\text { supervivientes a un infarto de miocardio, pero no } \\
\text { tiene efecto en la mortalidad }\end{array}$ & Ilb & B & 293,294 \\
\hline $\begin{array}{l}\text { No se recomienda la terapia con bloqueadores } \\
\text { de los canales de sodio (clase IC) para prevenir la } \\
\text { muerte súbita de pacientes con CI o supervivientes } \\
\text { a un infarto de miocardio }\end{array}$ & III & B & \multirow{2}{*}{131} \\
\hline
\end{tabular}

CI: cardiopatía isquémica.

aClase de recomendación.

bNivel de evidencia.

'Referencias que respaldan las recomendaciones.

El papel de los fármacos antiarrítmicos en la prevención de la MSC para pacientes posinfartados con FEVI conservada es pequeño. La mayoría de los datos proceden del estudio CAST ${ }^{129}$, que mostró que los bloqueadores de los canales de sodio (agentes de clase IA e IC) aumentan la mortalidad tras un infarto de miocardio. Los fármacos de clase II (bloqueadores beta) tienen un papel establecido en la reducción de la mortalidad de los pacientes posinfartados con FEVI reducida, y este papel protector puede persistir también en pacientes con FEVI conservada, pero no se ha probado su efecto en la MSC. Finalmente, el agente de clase III amiodarona no parece que reduzca la MSC en pacientes posinfartados con FEVI conservada. Sin embargo,

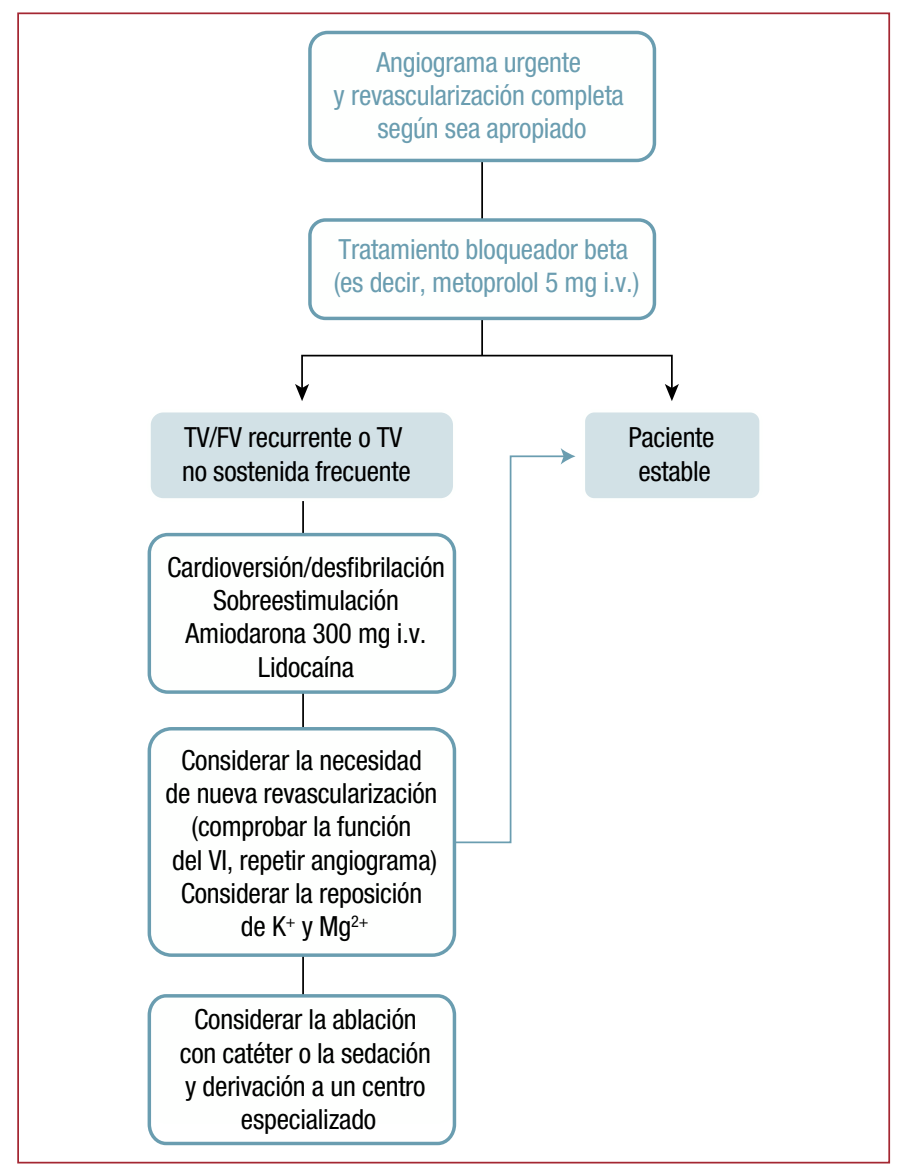

Figura 3. Proceso diagnóstico para pacientes con arritmias ventriculares sostenidas y SCA. FV: fibrilación ventricular; i.v.: intravenoso; SCA: síndrome coronario agudo; TV: taquicardia ventricular; VI: ventrículo izquierdo. 
puede tener un papel en el alivio de los síntomas y la reducción de los episodios arrítmicos en este grupo de pacientes.

Para arritmias sintomáticas pero no potencialmente mortales (EV o TVNS corta y lenta), la amiodarona es el fármaco de elección, ya que suprime las arritmias sin empeorar el pronóstico ${ }^{293,294}$.

\subsubsection{Ablación con catéter}

En un 1-2\% de los pacientes se produce TV tardíamente después de un infarto de miocardio, a menudo tras un intervalo de años. La TV recurrente se puede tratar eficazmente mediante ablación con catéter, que redujo drásticamente la recurrencia de TV en pequeñas series de pacientes tratados en centros especializados. Merece más estudio saber si es beneficiosa la ablación primaria de la TV monomórfica sostenida bien tolerada para los pacientes con FEVI > 40\% sin DAI. Hasta entonces, habría que considerar el implante de DAI para los supervivientes a un infarto de miocardio que padecen TV sostenida o FV en ausencia de isquemia aguda, incluso tras una ablación eficaz con catéter $^{261-265}$.

\section{TERAPIAS PARA PACIENTES CON DISFUNCIÓN DEL VENTRÍCULO IZQUIERDO CON O SIN INSUFICIENCIA CARDIACA}

Se producen arritmias ventriculares en la mayoría de los pacientes con IC, y la muerte súbita es común en esta población ${ }^{1,8,295,296}$. La presencia y la gravedad de las arritmias ventriculares aumentan junto con la gravedad de la IC, pero su valor para predecir la muerte súbita no está claro ${ }^{297-300}$. Ciertamente, la identificación de un mayor riesgo de muerte súbita en pacientes con IC ha resultado notablemente difícil, y la única asociación constante (e independiente) que se ha comunicado es con el grado de disfunción del VI o la FEVI.

\subsection{Prevención primaria de la muerte súbita cardiaca}

\subsubsection{Fármacos}

Uso de fármacos para pacientes con disfunción del ventrículo izquierdo

\begin{tabular}{lcccc}
\hline Recomendaciones & Clase $^{\mathrm{a}}$ & Nivel $^{\mathrm{b}}$ & Ref $^{\mathrm{c}}$ \\
\hline $\begin{array}{l}\text { Se recomienda una terapia farmacológica óptima } \\
\text { con IECA (o ARA-II cuando el paciente no los tolere), }\end{array}$ & I & A & 301-304 \\
$\begin{array}{l}\text { bloqueadores beta y ARM para pacientes con IC y } \\
\text { disfunción sistólica (FEVI } \leq 35-40 \% \text { ) para reducir la } \\
\text { mortalidad total y la MSC }\end{array}$ & & \\
\hline
\end{tabular}

ARA-II: antagonistas del receptor de la angiotensina II; ARM: antagonistas de los receptores de mineralocorticoides; FEVI: fracción de eyección del ventrículo izquierdo; IC: insuficiencia cardiaca; IECA: inhibidores de la enzima de conversión de la angiotensina; MSC: muerte súbita cardiaca.

${ }^{a}$ Clase de recomendación.

bNivel de evidencia.

Referencias que respaldan las recomendaciones.

Los IECA, los bloqueadores beta y los ARM están recomendados para pacientes con IC y disfunción sistólica (FEVI $\leq 35-40 \%$ ), ya que reducen la mortalidad por cualquier causa y la muerte súbita ${ }^{8}$ (véase la sección 5 ).

Los IECA reducen la mortalidad por cualquier causa en un $15-25 \%$ y están recomendados para todos los pacientes con FEVI reducida ${ }^{8,305}$. Los bloqueadores beta reducen la mortalidad un 35\% y tienen propiedades antiisquémicas que dan lugar a efectos antiarrítmicos específicos, y estos agentes reducen específicamente la incidencia de muerte súbita ${ }^{8}$. Datos recientes del Beta-Blockers in Heart Failure Collaborative Group han cuestionado la presunción clínica de que los bloqueadores beta mejoran el pronóstico de los pacientes con IC y FA y defienden que los clínicos elijan una terapia acorde para este subgrupo de pacientes con IC ${ }^{306}$. Para explorar aún más esta observación provocadora, los autores afirman que "se necesitan urgentemente y se esperan con interés datos de estudios específicamente de pacientes con IC y FA» ${ }^{307}$.

Los ARM reducen la mortalidad y las tasas de muerte súbita de pacientes con IC que ya reciben IECA y bloqueadores beta ${ }^{13,308,309}$. En el ensayo más reciente, que incluyó eplerenona, un 20\% de los pacientes también tenían un dispositivo implantado (DAI o TRC), pero el fármaco fue igualmente efectivo en pacientes con y sin terapias del dispositivo ${ }^{309}$. Este efecto beneficioso de los ARM en la incidencia de MSC en pacientes con disfunción sistólica del VI quedó confirmado por un metanálisis de 6 estudios que mostraban que los pacientes tratados con ARM tenían un $23 \%$ menos de probabilidades de sufrir MSC que los controles ( $O R=0,77 ;$ IC95\%, 0,66-0,89; $p=0,001)^{310}$. Muchos pacientes con IC aún utilizan diuréticos y digoxina, pero estos no reducen las tasas de mortalidad por cualquier causa o de muerte súbita. Los ARA-II y la ivabradina solo están recomendados para subgrupos de pacientes con $\mathrm{IC}^{8}$. La amiodarona no afecta al resultado en pacientes con $\mathrm{IC}^{132} \mathrm{y}$, dada su elevada incidencia de toxicidad farmacológica ${ }^{8}$, no se recomienda el uso generalizado para estos pacientes. Sin embargo, en casos de (taqui)arritmias ventriculares sintomáticas en pacientes con IC (como los que sufren choques del desfibrilador o arritmias ventriculares no sostenidas sintomáticas), la amiodarona es el agente antiarrítmico de elección, ya que no empeora los resultados ${ }^{132}$. Otros fármacos antiarrítmicos no están recomendados para pacientes con IC por cuestiones de seguridad ${ }^{8}$.

En los últimos 10 años, ha habido más conciencia de que muchos pacientes con signos y síntomas de IC tienen una FE normal o conservada (ICFEc) ${ }^{8,311}$. Muchas de las terapias que mejoran la supervivencia en la IC con FE reducida (ICFEr) son menos eficaces en la ICFEc. Una proporción relativamente grande de estos pacientes tienen comorbilidades no cardiovasculares y, aunque es común la muerte súbita ${ }^{312}$, no ha habido estudios sobre DAI o TRC con potencia suficiente. La mayoría de los ensayos con fármacos a gran escala en la IC se realizaron antes de disponer de los resultados positivos de ensayos de referencia con $\mathrm{DAI}^{63,64}$ y TRC $^{313,314}$ (en 2005); la evidencia obtenida de estos ensayos condujo a una firme recomendación en las guías sobre IC y un enorme aumento en su uso ${ }^{7,315}$.

\subsubsection{Desfibriladores automáticos implantables}

\begin{tabular}{|c|c|c|c|}
\hline Recomendaciones & Clase $^{\mathrm{a}}$ & Nivel $^{\mathrm{b}}$ & $\operatorname{Ref}^{c}$ \\
\hline \multicolumn{4}{|c|}{$\begin{array}{l}\text { Se recomienda terapia con DAI para reducir la MSC } \\
\text { de pacientes con IC sintomática (NYHA II-III), FEVI } \\
\leq 35 \% \text { después de al menos } 3 \text { meses de terapia } \\
\text { médica óptima y esperanza de vida con buen estado } \\
\text { funcional } \geq 1 \text { año: }\end{array}$} \\
\hline $\begin{array}{l}\text { - Etiología isquémica (al menos } 6 \text { semanas } \\
\text { después del infarto de miocardio) }\end{array}$ & I & A & 63,64 \\
\hline - Etiología no isquémica & I & B & $\begin{array}{l}64,316 \\
317\end{array}$ \\
\hline
\end{tabular}

DAI: desfibrilador automático implantable; FEVI: fracción de eyección del ventrículo izquierdo; IC: insuficiencia cardiaca; MSC: muerte súbita cardíaca; NYHA: clase funcional de la New York Heart Association.

aClase de recomendación.

bNivel de evidencia.

'Referencias que respaldan las recomendaciones.

Se han realizado estudios en pacientes con una parada cardiaca previa (es decir, en prevención secundaria) o que requerían criterios electrofisiológicos adicionales, sobre el valor del DAI en pacientes con disfunción del VI. Dos grandes ensayos han aportado datos sobre la prevención primaria de la MSC mediante DAI en pacientes con ICFEr: 
el SCD-HeFT ${ }^{64}$ y el MADIT-II ${ }^{63,318}$. En el SCD-HeFT, el uso de DAI se asoció con una reducción del riesgo de muerte del 23\% (HR = 0,77; IC95\%, $0,62-0,96 ; \mathrm{p}=0,007)$ y una reducción absoluta de la mortalidad a 5 años del 7\% (del 29 al 22\%). Hubo una reducción del 60\% en la muerte súbita del grupo de DAI ${ }^{319}$. El efecto en la mortalidad por cualquier causa no varió según las causas de la IC fueran isquémicas o no isquémicas, pero hubo diferencia según la clase funcional: los DAI fueron muy eficaces en los pacientes en NYHA II, pero no tuvieron efecto aparente en la mortalidad de los pacientes en NYHA III. En el ensayo MADIT-II, los pacientes del grupo de DAI tuvieron una disminución del $31 \%$ en la mortalidad por cualquier causa $(H R=0,69$; IC95\%, 0,51-0,93; p = 0,016), y un análisis posterior a partir de este estudio mostró que el beneficio de los DAI en esta población era dependiente del tiempo ${ }^{318}$, con mayor beneficio para los pacientes cuyo infarto de miocardio índice distaba más de la aleatorización.

Aunque hay más datos que respaldan el uso de DAI en supervivientes a un infarto de miocardio (es decir, etiología isquémica), en pacientes con ICFEr con etiologías no isquémicas también está respaldada una reducción en la mortalidad por cualquier causa y la mortalidad arrítmica. En el ensayo DEFINITE ${ }^{316}$ se observó una tendencia a la reducción de la mortalidad en el grupo de DAI ( HR = 0,65; IC95\%, 0,401,$06 ; \mathrm{p}=0,08$ ), mientras que la muerte súbita cardiaca se redujo significativamente (HR =0,20; IC95\%, 0,06-0,71; $\mathrm{p}=0,006$ ). En el ensayo SCD-HeFT ${ }^{63}$, se observó una reducción de la mortalidad por cualquier causa ( $\mathrm{HR}=0,73$; IC95\%, 0,50-1,07; $\mathrm{p}=0,06$ ) entre los pacientes sin infarto previo (e IC no isquémica). En el mismo ensayo, y también para pacientes con etiología isquémica, solo hubo una tendencia a la reducción de la mortalidad por cualquier causa $(H R=0,79$; IC95\%, $0,60-1,04 ; p=0,05$ ), lo que parece indicar que los 2 subgrupos probablemente eran demasiado pequeños para alcanzar significación estadística ${ }^{63}$. Por consiguiente, en un metanálisis de Desai et al $^{317}$ de 5 ensayos en prevención primaria que incluyeron a 1.854 pacientes con IC no isquémica, el uso de DAI se asoció a una significativa reducción del $31 \%$ en la mortalidad total ( $\mathrm{HR}=0,69$; IC95\%, 0,55-0,87; $\mathrm{p}=0,002)$. La terapia con DAI no está recomendada para pacientes con IC en fase final (NYHA IV) o que tengan una esperanza de vida estimada $<1$ año.

Actualmente no hay ensayos clínicos aleatorizados que demuestren el valor del DAI para los pacientes asintomáticos (NYHA I) con disfunción sistólica (FEVI $\leq 35-40 \%$ ) o con ICFEc $>40-45 \%$, por lo que los DAI no están recomendados para la prevención primaria en estos pacientes.

\subsubsection{Desfibriladores automáticos implantables en pacientes en clase funcional IV de la New York Heart Association en lista de espera para trasplante cardiaco}

Desfibriladores automáticos implantables para pacientes en New York Heart Association IV en lista de espera para trasplante cardiaco

\begin{tabular}{lcccc}
\hline Recomendaciones & Clase $^{\mathrm{a}}$ & Nivel $^{\mathrm{b}}$ & Ref $^{\mathrm{c}}$ \\
\hline $\begin{array}{l}\text { Se debe considerar implante de DAI para la } \\
\text { prevención primaria y secundaria de la MSC } \\
\text { de pacientes que están en lista de espera } \\
\text { para trasplante cardiaco }\end{array}$ & Ila & C & 320,321 \\
\hline
\end{tabular}

DAI: desfibrilador automático implantable; MSC: muerte súbita cardiaca; NYHA: clase funcional de la New York Heart Association.

aClase de recomendación.

bNivel de evidencia.

'Referencias que respaldan las recomendaciones.

No existen datos de ensayos aleatorizados en cuanto al valor de los DAI para pacientes en NYHA IV. En general se acepta que la terapia con DAI no está recomendada para pacientes con síntomas graves refractarios a fármacos que no son candidatos a TRC, dispositivo de asistencia ventricular o trasplante cardiaco ${ }^{8,11}$. Sin embargo, puede ser distinta la situación para pacientes ambulatorios en NYHA IV que están en lista de espera para trasplante cardiaco. Estos pacientes con frecuencia tienen que esperar al menos 1 año y su riesgo de muerte súbita es elevado. Los datos de 2 estudios observacionales que en conjunto examinaron a casi 2.000 pacientes, uno de ellos reciente ${ }^{320} \mathrm{y}$ el otro más antiguo (en el que el uso de bloqueadores beta era bajo) ${ }^{321}$, indican un beneficio en supervivencia para los pacientes con DAI.

\subsubsection{Terapia de resincronización cardiaca}

6.1.4.1. Insuficiencia cardiaca con fracción de eyección del ventrículo izquierdo reducida en clase III de la New York Heart Association/ clase IV ambulatoria

Tabla A

Terapia de resincronización cardiaca en prevención primaria de muerte súbita para pacientes en ritmo sinusal y New York Heart Association III/clase ambulatoria IV

\begin{tabular}{|c|c|c|c|}
\hline Recomendaciones & Clase $^{\mathrm{a}}$ & Nivel $^{\mathrm{b}}$ & $\operatorname{Ref}^{c}$ \\
\hline $\begin{array}{l}\text { Para pacientes con } \mathrm{FEVI} \leq 35 \% \text {, BRIH a pesar de al } \\
\text { menos } 3 \text { meses de terapia farmacológica óptima } \\
\text { y esperanza de vida con buen estado funcional } \\
\geq 1 \text { año, se recomienda TRC para reducir } \\
\text { la mortalidad por cualquier causa: }\end{array}$ & & & $322-326$ \\
\hline - Con duración del QRS > 150 ms & I & A & $\begin{array}{l}313,314 \\
327-329\end{array}$ \\
\hline - Con duración del QRS de 120-150 ms & I & B & 313,314 \\
\hline $\begin{array}{l}\text { Para pacientes con FEVI } \leq 35 \% \text {, sin BRIH a pesar de } \\
\text { al menos } 3 \text { meses de terapia farmacológica óptima } \\
\text { y esperanza de vida con buen estado funcional } \\
\geq 1 \text { año, se debe o se puede considerar la TRC } \\
\text { para reducir la mortalidad por cualquier causa: }\end{array}$ & & & $\begin{array}{c}326, \\
323-325\end{array}$ \\
\hline - Con duración del QRS > 150 ms & IIa & B & 313,314 \\
\hline - Con duración del QRS de $120-150$ ms & IIb & B & 313,314 \\
\hline
\end{tabular}

BRIH: bloqueo de la rama izquierda del haz de His; FEVI: fracción de eyección de ventrículo izquierdo; NYHA: clase funcional de la New York Heart Association; TRC: terapia de resincronización cardiaca.

${ }^{\mathrm{a}}$ Clase de recomendación.

bNivel de evidencia.

'Referencias que respaldan las recomendaciones.

Tabla B

Terapia de resincronización cardiaca en la prevención primaria de la muerte súbita para pacientes con fibrilación auricular permanente en New York Heart Association III/clase ambulatoria IV

\begin{tabular}{|c|c|c|c|}
\hline Recomendaciones & Clase $^{\mathrm{a}}$ & Nivel $^{\mathrm{b}}$ & $\operatorname{Ref}^{c}$ \\
\hline $\begin{array}{l}\text { Se debe considerar la TRC para reducir la } \\
\text { mortalidad por cualquier causa de pacientes con } \\
\text { IC crónica, QRS } \geq 120 \text { ms y FEVI } \leq 35 \% \text { que siguen } \\
\text { estando en NYHA III/clase ambulatoria IV a pesar } \\
\text { de al menos } 3 \text { meses de terapia farmacológica } \\
\text { óptima y tienen esperanza de vida con buen estado } \\
\text { funcional } \geq 1 \text { año, siempre que se pueda conseguir } \\
\text { una estimulación biventricular lo más próxima } \\
\text { posible al } 100 \%\end{array}$ & IIa & B & 330,331 \\
\hline $\begin{array}{l}\text { Se debe considerar la ablación del NAV en caso } \\
\text { de estimulación biventricular incompleta }\end{array}$ & IIa & B & 332,333 \\
\hline
\end{tabular}

FEVI: fracción de eyección del ventrículo izquierdo; IC: insuficiencia cardiaca; NAV: nódulo auriculoventricular; NYHA: clase funcional de la New York Heart Association; TRC: terapia de resincronización cardiaca.

${ }^{a}$ Clase de recomendación.

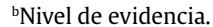

'Referencias que respaldan las recomendaciones. 
Para pacientes en ritmo sinusal, se dan recomendaciones sobre la morfología del BRIH frente a la ausencia de BRIH y también en cuanto a la duración del QRS (120-150 frente a > $150 \mathrm{~ms})^{10}$ (tabla A en esta sección). Para pacientes con FA, se dan recomendaciones en la tabla B en esta sección.

Dos grandes ensayos clínicos aleatorizados, COMPANION ${ }^{313}$ y CARE-HF ${ }^{314}$, en pacientes con IC de moderada a grave (clase III-IV) y en ritmo sinusal han mostrado que la TRC reduce la morbilidad y la mortalidad en esta población.

El estudio COMPANION incluyó a pacientes con ICFEr y QRS $\geq 120 \mathrm{~ms}$. Al compararlos con pacientes que ya seguían una terapia médica óptima sola, se observó una reducción en la mortalidad por cualquier causa con marcapasos de TRC (TRC-M) (HR = 0,76; IC95\%, $0,58-1,01 ; \mathrm{p}=0,059)$ y una reducción del $36 \%$ con TRC-D (HR = 0,64; IC95\%, 0,48-0,86; $\mathrm{p}=0,003)$. En este estudio, la TRC-D, pero no la TRC-M, redujo la tasa de MSC.

Aunque el criterio para la duración del QRS era también $\geq 120 \mathrm{~ms}$ en el ensayo CARE-HF, debieron cumplir más criterios de disincronía los pacientes con un intervalo QRS de 120-149 ms. La TRC-M redujo la mortalidad por cualquier causa un $36 \%$ ( $\mathrm{HR}=0,64$; IC95\%, 0,48-0,85; $\mathrm{p}<0,002)^{64}$. En un informe a largo plazo procedente del ensayo CARE-HF (seguimiento medio, 37 meses), la TRC-M también redujo la muerte súbita un $46 \%$ (HR = 0,54; IC95\%, 0,35-0,84; $\mathrm{p}=0,005)$, con una reducción de la mortalidad total en ese momento del $40 \%$ $(\mathrm{HR}=0,60 ; \text { IC95\%, 0,47-0,77; } \mathrm{p}<0,001)^{335}$.

Los ensayos COMPANION y CARE-HF proporcionan conjuntamente evidencia firme en favor del uso de TRC (TRC-M o TRC-D) en pacientes con ICFEr, con síntomas de moderados a graves, con QRS ancho, especialmente los que tienen morfología de BRIH. Otros diversos estudios, registros y un metanálisis han abordado la cuestión de la respuesta a la TRC según la morfología del QRS, y la mayoría apoyaba el punto de vista de que la morfología del QRS con BRIH identifica a un subgrupo de pacientes con mayor beneficio; se da aquí una breve descripción de estudios, registros y metanálisis clave.

Los datos del registro de DAI de Medicare ${ }^{326}$, que incluyó a 14.946 pacientes, mostró que la TRC-D no es efectiva en pacientes con BRDH, como indica la mayor mortalidad a 3 años del BRDH en comparación con el BRIH (HR = 1,37; IC95\%, 1,26-1,49; p < 0,001). El estudio REVERSE $^{336}$ confirmó la reducción en el criterio de valoración clínico compuesto solo en pacientes con BRIH ( OR $=0,53$; $p<0,0032$ ) y mostró que no había ningún beneficio en pacientes $\sin \mathrm{BRIH}(\mathrm{OR}=0,74$; $\mathrm{p}=0,21$ ). De modo similar, el análisis de la morfología del QRS en el estudio MADIT-CRT ${ }^{322}$ mostró una reducción en el criterio de valoración primario en pacientes con morfología de BRIH en el QRS (HR = 0,$47 ; p<0,001$ ), pero no en pacientes con morfología diferente de $\mathrm{BRIH}(\mathrm{HR}=1,24 ; \mathrm{p}=0,257)$. También es interesante que los riesgos de TV, FV y muerte estuvieran significativamente reducidos solo en pacientes con BRIH. Se ha publicado recientemente un análisis a largo plazo que incluyó a pacientes del estudio MADIT-CRT ${ }^{148}$ y confirmó que, tras 7 años de seguimiento, se observa beneficio en supervivencia con la TRC-D en pacientes con morfología de BRIH en el QRS (HR = 0,59; IC95\%, 0,43-0,80; $\mathrm{p}<0,001$ ), mientras que los pacientes con morfología distinta de BRIH no mostraban efecto y posiblemente sí efectos deletéreos relacionados con la TRC-D (HR = 1,57; IC95\%, 1,03-2,39; $\mathrm{p}=0,04)$. Cuando se analizaron los datos del ensayo RAFT, según los datos de morfología del QRS, la TRC mostró mayor beneficio en pacientes con morfología de BRIH frente a la distinta de BRIH ${ }^{323}$. Es interesante que para los pacientes con morfología distinta de BRIH en QRS > 160 ms hubiera una reducción moderada en el resultado primario ( $\mathrm{HR}=0,52 ; \mathrm{IC} 95 \%, 0,29-0,96 ; \mathrm{p}=0,033)$. A pesar de que solo había 53 pacientes en este grupo, merece la pena explorar el beneficio potencial de la TRC en la morfología de QRS distinta del BRIH en presencia de una marcada anchura del QRS (QRS $\geq 160 \mathrm{~ms}$ ). Esta observación está respaldada por los resultados del metanálisis de Cleland et $\mathrm{al}^{334}$, que incluyó datos de los estudios CARE-HF, MIRACLE, REVERSE, MIRACLE ICD y RAFT. A pesar de un aparente beneficio de la TRC en pacientes con BRIH en el análisis univariable, los resultados del modelo multivariable indicaban que solo la duración del QRS predecía la magnitud del efecto de la TRC en los resultados. En un metanálisis de ensayos clínicos de TRC dirigidos a 485 pacientes con morfología de BRDH en el QRS, Nery et a ${ }^{324}$ mostraron que no hay beneficio con la TRC (HR = 2,04; IC95\%, 1,32-3,15; p = 0,001); desafortunadamente, no se aportaron datos sobre la duración del QRS.

Sipahi et $\mathrm{al}^{325}$ realizaron un metanálisis en el que examinaron 33 ensayos clínicos que investigaban el efecto de la morfología del QRS en la TRC, pero solo 4 (COMPANION, CARE-HF, MADIT-CRT y RAFT) incluían resultados según la morfología del QRS. Cuando evaluaron el efecto de la TRC en un compuesto de eventos clínicos adversos en 3.349 pacientes con BRIH basal, observaron una reducción del riesgo del 36\% con el uso de TRC ( $R R=0,64$; IC95\%, 0,52-0,77; $p<0,00001$ ). Sin embargo, no se observó dicho beneficio en pacientes con anomalías de la conducción distintas del BRIH (RR $=0,97 ;$ IC95\%, 0,82-1,15; $\mathrm{p}=0,75)^{325}$. Es interesante que, cuando el análisis se limitó a ensayos sin DAI (CARE-HF y COMPANION), aún se observaba beneficio de la TRC solo en pacientes con BRIH $(\mathrm{p}<0,000001)$.

En un reciente gran metanálisis de 6 ensayos clínicos aleatorizados (COMPANION, CARE-HF, MADIT-CRT, MIRACLE, RAFT y REVERSE) ${ }^{337}$ que incluyeron a 6.914 participantes ( 1.683 con morfología de QRS distinta del BRIH), la TRC no se asoció a reducción de muertes u hospitalizaciones por IC de pacientes con morfología de QRS distinta del BRIH (HR = 1,09; IC95\%, 0,85-1,39) ${ }^{337}$.

Por lo tanto, el QRS ancho con morfología distinta del BRIH sigue siendo un área de incertidumbre para la TRC. Con base en estos datos, pese a que la mayoría de los pacientes en Europa reciben TRC-D ${ }^{314}$, las recomendaciones se expresan en general para la TRC.

Existen discrepancias en los documentos previos (guías de la American College of Cardiology Foundation/AHA y el documento de consenso sobre estimulación cardiaca de la European Heart Rhythm Association/ESC) acerca de la clase de recomendación de TRC para pacientes con QRS de 120-150 ms. Según un metanálisis de Sipahi et $\mathrm{a}^{328}$, la TRC redujo significativamente la mortalidad por cualquier causa o las hospitalizaciones de los pacientes con $\mathrm{QRS} \geq 150 \mathrm{~ms}(\mathrm{RR}=$ 0,60; IC95\%, 0,53-0,67; $<<0,001)$, pero no en pacientes con QRS de $120-150 \mathrm{~ms}$ ( $R R=0,95$; IC95\%, 0,82-1,10; $\mathrm{p}=0,49$ ). Sin embargo, se han señalado inconvenientes metodológicos debidos a la multiplicidad de análisis en el estudio de Sipahi et $\mathbf{a l}^{338}$, de modo que de momento habría que considerar solamente exploratoria la conclusión de que la TRC es efectiva solo para pacientes con $\mathrm{QRS} \geq 150 \mathrm{~ms}^{338}$. No se recomienda la TRC para pacientes con IC y QRS $<120 \mathrm{~ms}^{339}$.

Para pacientes con FA, habría que considerar la TRC para los que tienen una FEVI marcadamente reducida, pero no se ha visto que reduzca la mortalidad o la muerte súbita en ellos ${ }^{8,340}$. En el ensayo RAFT, 229 pacientes (el 13\% de la población total de 1.798) tenían FA o flutter auricular basal ${ }^{327}$. Aunque formalmente no hubo una interacción significativa entre el ritmo basal y el efecto del tratamiento (DAI frente a TRC-D, $p=0,14$ ), el número de pacientes en este estudio era pequeño y el efecto en pacientes con FA o flutter auricular parecía ser menor que en los que estaban en ritmo sinusal. El éxito de la TRC en pacientes con FA, en su mayor parte, está determinado por el grado de estimulación biventricular, y esto solo se puede conseguir por medio de ablación del NAV en muchos pacientes ${ }^{10}$.

Aunque la decisión de realizar una ablación del NAV en estos pacientes aún está en debate, datos recientes apuntan a que la supervivencia a largo plazo tras la TRC de los pacientes con FA sometidos a ablación del NAV es similar a la observada en pacientes en ritmo sinusal ${ }^{333}$. Resumiendo, se puede considerar la TRC para pacientes con IC, $\mathrm{FA}$ permanente y $\mathrm{FEVI} \leq 35 \%$ si: $a$ ) se requiere estimulación ventricular o el paciente por lo demás cumple con los criterios para la TRC, y $b$ ) se consigue casi un $100 \%$ de estimulación ventricular con TRC y ablación del NAV o control de la frecuencia farmacológica (nivel de recomendación de clase 2A B). 
6.1.4.2. Insuficiencia cardiaca con fracción de eyección ventricular izquierda reducida pero con síntomas leves (clase II de la New York Heart Association)

Tabla C

Terapia de resincronización cardiaca con desfibrilador ${ }^{\mathrm{a}}$ en la prevención primaria de la muerte súbita para pacientes en ritmo sinusal con insuficiencia cardiaca leve (NYHA II)

\begin{tabular}{|c|c|c|c|}
\hline Recomendaciones & Clase $^{b}$ & Nivel $^{c}$ & $\operatorname{Ref}^{\mathrm{d}}$ \\
\hline $\begin{array}{l}\text { Se recomienda TRC-D para reducir la mortalidad } \\
\text { por cualquier causa para pacientes con QRS } \\
\geq 130 \mathrm{~ms} \text {, FEVI } \leq 30 \% \text {, BRIH a pesar de al menos } \\
3 \text { meses de terapia farmacológica óptima y esperanza } \\
\text { de vida con buen estado funcional } \geq 1 \text { año }\end{array}$ & I & $\mathrm{A}$ & $\begin{array}{c}148,322, \\
323,325, \\
327,329\end{array}$ \\
\hline $\begin{array}{l}\text { Se puede considerar la TRC-D para prevenir la } \\
\text { hospitalización por IC de pacientes con QRS } \\
\geq 150 \mathrm{~ms} \text {, independientemente de su morfología, } \\
\text { FEVI } \leq 35 \% \text { a pesar de al menos } 3 \text { meses de terapia } \\
\text { farmacológica óptima y esperanza de vida con buen } \\
\text { estado funcional } \geq 1 \text { año }\end{array}$ & IIb & A & $\begin{array}{c}148, \\
327-329, \\
334\end{array}$ \\
\hline
\end{tabular}

BRIH: bloqueo de la rama izquierda del haz de His; FEVI: fracción de eyección del ventrículo izquierdo; IC: insuficiencia cardiaca; NYHA: clase funcional de la New York Heart Association; TRC-D: terapia de resincronización cardiaca con desfibrilador.

aEstas recomendaciones se refieren específicamente a la TRC-D, ya que los estudios sobre el efecto de la resincronización en pacientes en NYHA II usaron solo TRC-D.

'Clase de recomendación.

cNivel de evidencia.

${ }^{\mathrm{d}}$ Referencias que respaldan las recomendaciones.

Dos ensayos controlados aleatorizaron a 3.618 pacientes con IC leve a terapia farmacológica óptima más DAI o tratamiento farmacológico óptimo más TRC-D ${ }^{327,329}$.

El estudio MADIT-CRT ${ }^{329}$ incluyó a 1.820 pacientes levemente sintomáticos (NYHA I-II) con FEVI $\leq 30 \%$ y QRS $\geq 130 \mathrm{~ms}$. El informe inicial mostró una reducción del $34 \%$ en el criterio de valoración primario de muerte por cualquier causa o eventos de IC (DAI frente a TRC-D, el 25,3 frente al 17,2\%; HR = 0,66; IC95\%, 0,52-0,84; p = 0,001). En un informe de seguimiento a largo plazo del MADIT-CRT (seguimiento medio, 7 años) ${ }^{148}$, la TRC-D redujo significativamente la mortalidad (HR = 0,59; IC95\%, 0,43-0,80; $\mathrm{p}<0,001$ ) en comparación con el DAI únicamente, el cual, sin embargo, quedaba confinado a pacientes con BRIH basal, mientras que no se observó ningún efecto beneficioso en los que no tenían BRIH ( $\mathrm{p}<0,001$ para la interacción) (tabla C en esta sección).

El ensayo RAFT ${ }^{327}$ incluyó a 1.798 pacientes con IC de leve a moderada (NYHA II-III), FEVI $\leq 30 \%$ y QRS $\geq 120 \mathrm{~ms}$ (o QRS de ritmo controlado $\geq 200 \mathrm{~ms}$ ). En comparación con los pacientes solo con DAI, el grupo de TRC-D mostró una reducción del RR de mortalidad por cualquier causa del 25\% ( $\mathrm{HR}=0,75$; IC95\%, 0,62-0,91; $\mathrm{p}=0,003)$, lo que sustancia el uso sistemático de la TRC para pacientes con ICFEr y síntomas leves.

\subsection{Extrasístoles ventriculares en pacientes con enfermedad cardiaca estructural/disfunción del ventrículo izquierdo}

Las EV y los episodios de TVNS son comunes en pacientes con disfunción del VI y pueden ser la consecuencia o la causa de disfunción del VI. Las EV y los episodios de TVNS en sujetos con cardiopatía estructural contribuyen a un mayor riesgo de mortalidad, y más de $10 \mathrm{EV}$ por hora o episodios de TVNS son un marcador aceptable de mayor riesgo ${ }^{344}$. Si los pacientes están sintomáticos debido a EV o TVNS o si las EV o las TVNS contribuyen a una FEVI reducida ("miocardiopatía inducida por taquicardia o taquimiocardiopatía»), habría que considerar la amiodarona o la ablación con catéter.
Tratamiento de pacientes con disfunción del ventrículo izquierdo y extrasístoles ventriculares

\begin{tabular}{llcc}
\hline Recomendaciones & Clase $^{\mathrm{a}}$ & Nivel $^{\mathrm{b}}$ & Ref $^{\mathrm{c}}$ \\
\hline $\begin{array}{l}\text { Para pacientes con frecuentes EV o TVNS } \\
\text { sintomáticas: }\end{array}$ & & & \\
\hline Se debe considerar la amiodarona & Ila & B & 64 \\
\hline Se debe considerar la ablación con catéter & Ila & B & $341-343$ \\
\hline $\begin{array}{l}\text { Se debe considerar la ablación con catéter para } \\
\text { pacientes con disfunción del VI asociada a EV }\end{array}$ & Ila & B & $341-343$ \\
\hline
\end{tabular}

EV: extrasístole ventricular; TVNS: taquicardia ventricular no sostenida; VI: ventrículo izquierdo.

aClase de recomendación.

bNivel de evidencia.

cReferencias que respaldan las recomendaciones.

Una elevada carga de EV (> 24\%) en pacientes con disfunción del VI y un intervalo de acoplamiento de las EV bastante corto $(<300 \mathrm{~ms})$ apuntan a miocardiopatía inducida por $\mathrm{EV}^{342}$. En tales pacientes, la ablación con catéter puede suprimir las EV y restaurar la función del VI ${ }^{341}$.

\subsection{Taquicardia ventricular sostenida}

\subsubsection{Terapia con fármacos}

Tratamiento de pacientes con disfunción del ventrículo izquierdo y taquicardia ventricular monomórfica sostenida recurrente

\begin{tabular}{lccc}
\hline Recomendaciones & Clase $^{\mathrm{a}}$ & Nivel $^{\mathrm{b}}$ & Ref $^{\mathrm{c}}$ \\
\hline $\begin{array}{l}\text { Para los pacientes con disfunción del VI y TV } \\
\text { sostenida, se recomienda optimizar la medicación } \\
\text { para la IC según la actual guía sobre IC }\end{array}$ & I & $\mathrm{C}$ & 8 \\
\hline $\begin{array}{l}\text { Se debe considerar el tratamiento con amiodarona } \\
\text { para prevenir la TV en pacientes con o sin DAI }\end{array}$ & Ila & C & 64 \\
\hline
\end{tabular}

DAI: desfibrilador automático implantable; IC: insuficiencia cardiaca; TV: taquicardia ventricular; VI: ventrículo izquierdo.

aClase de recomendación.

bNivel de evidencia.

'Referencias que respaldan las recomendaciones.

A los pacientes con disfunción del VI con o sin IC que presentan TV sostenida se los debe tratar según la guía de IC recientemente publicada, de modo similar que a los pacientes con disfunción del VI sin $\mathrm{TV}^{8}$. Además, la terapia médica con fármacos para la TV sostenida debe abordar el máximo bloqueo simpático. En el estudio MADIT-II, los pacientes con DAI tratados con las dosis más altas de bloqueadores beta obtuvieron una significativa reducción en los episodios de TV o FV recurrentes que requieren intervención del DAI, en comparación con los pacientes que no tomaban bloqueadores beta $(\mathrm{HR}=0,48$; IC95\%, 0,26-0,89; $\mathrm{p}=0,02)^{8}$. El estudio Optimal Pharmacological Therapy in Cardioverter Defibrillator Patients (OPTIC) comparó el uso de bloqueadores beta, sotalol y bloqueadores beta más amiodarona para evitar choques del DAI ${ }^{156}$. La terapia con amiodarona más bloqueadores beta redujo significativamente el riesgo de choques en comparación con el tratamiento únicamente con bloqueadores beta $(\mathrm{HR}=$ 0,27; IC95\%, 0,14-0,52; p < 0,001) y sotalol (HR = 0,43; IC95\%, 0,22$0,85 ; \mathrm{p}=0,02)$. Sin embargo, la interrupción del fármaco fue más frecuente entre los pacientes que tomaban sotalol o una combinación de amiodarona y un bloqueador beta. Las tasas de interrupción del fármaco a 1 año en este estudio fueron del 18,2\% con amiodarona, el $23,5 \%$ con sotalol y el 5,3\% con el bloqueador beta solo.

En el ensayo SCD-HeFT, los pacientes con disfunción del VI e IC en NYHA II-III recibieron terapia convencional para la IC, terapia conven- 
cional más amiodarona o terapia convencional y un DAI monocame$\mathrm{ral}^{64}$. En comparación con la terapia convencional para la IC, la adición de amiodarona no aumentó la mortalidad.

\subsubsection{Ablación con catéter}

Prevención de las recurrencias de taquicardia ventricular para pacientes con disfunción del ventrículo izquierdo y taquicardia ventricular sostenida

\begin{tabular}{|c|c|c|c|}
\hline Recomendaciones & Clase $^{a}$ & Nivel $^{\mathrm{b}}$ & $\operatorname{Ref}^{c}$ \\
\hline $\begin{array}{l}\text { Para pacientes que presentan TV o tormenta } \\
\text { eléctrica incesante que da lugar a descargas del DAI, } \\
\text { se recomienda la ablación con catéter urgente } \\
\text { en centros especializados o experimentados }\end{array}$ & I & B & 183 \\
\hline $\begin{array}{l}\text { Para pacientes con descargas del DAI recurrentes } \\
\text { debido a TV sostenida, se recomienda la } \\
\text { amiodarona o la ablación con catéter }\end{array}$ & I & B & $\begin{array}{c}64,156 \\
184-186\end{array}$ \\
\hline $\begin{array}{l}\text { Se recomienda implantar un DAI a pacientes } \\
\text { sometidos a ablación con catéter siempre que } \\
\text { cumplan los criterios de elegibilidad para DAI }\end{array}$ & I & C & $\begin{array}{c}\text { Este } \\
\text { panel de } \\
\text { expertos }\end{array}$ \\
\hline $\begin{array}{l}\text { Para pacientes con DAI, se debe considerar la } \\
\text { amiodarona o la ablación con catéter después de un } \\
\text { primer episodio de TV sostenida }\end{array}$ & IIa & B & $\begin{array}{c}64,184- \\
186\end{array}$ \\
\hline
\end{tabular}

DAI: desfibrilador automático implantable; TV: taquicardia ventricular

aClase de recomendación.

bNivel de evidencia.

cReferencias que respaldan las recomendaciones.

Según el sustrato, la ablación con catéter para la TV sostenida puede dar lugar a una interrupción aguda y reducción de las recurrencias de TV en pacientes con cardiopatía estructural.

\subsubsection{Pacientes con disfunción del ventrículo izquierdo}

En pacientes con disfunción del VI y TV sostenida, la reentrada sobre las cicatrices es el mecanismo fisiopatológico común, y la ablación se dirige al istmo crítico en el circuito de reentrada. La TV es mayormente monomórfica. Si no se dispone de un ECG de 12 derivaciones de la TV clínica de pacientes con DAI, la longitud de ciclo de los electrogramas de DAI almacenados durante la TV puede facilitar la identificación de la TV clínica durante el EEF. Comúnmente se utilizan catéteres de ablación irrigados, que facilitan la formación de una lesión más profunda y reducen el riesgo de carbonizaciones durante la aplicación de energía.

Actualmente no se conoce la mejor estrategia de ablación. Se carece de ensayos clínicos aleatorizados que comparen la ablación con catéter durante la TV con un enfoque basado en el sustrato. Además, no hay consenso sobre el objetivo ideal del procedimiento. Aunque se debería intentar la eliminación de todas las TV clínicas, que no quede ninguna TV inducible, clínica o no clínica tras la ablación puede ser el criterio preferido.

Los pacientes pueden presentarse con tormentas eléctricas. La ablación con catéter puede finalizar de manera aguda este evento potencialmente mortal, y se ha demostrado que disminuye la tasa de recurrencias de tormenta eléctrica respecto al tratamiento médico aislado $^{183}$. Los pacientes con TV relacionada con una cicatriz posmiocárdica tienden a tener mejor resultado tras la ablación con catéter que los pacientes con TV debida a miocardiopatía no isquémica. Cinco estudios prospectivos han evaluado el papel de la ablación con catéter en el tratamiento de la TV sostenida ${ }^{184-188}$. El estudio Multicenter Thermocool notificó una tasa de eficacia aguda, definida como abolición de todas las TV inducibles, del $49 \%$ y quedaron libres de TV a medio plazo el $53 \%$ de los pacientes tras 6 meses de seguimiento ${ }^{185}$. En el estudio del Cooled RF Multicenter Investigators Group, se consiguió una eficacia aguda definida como eliminación de todas las TV inducibles en un $41 \%$ de los pacientes ${ }^{184}$. El $46 \%$ de los pacientes estaban libres de arritmias ventriculares recurrentes a los $8 \pm 5$ meses de seguimiento. En el estudio prospectivo Euro-VT, la ablación fue efectiva de manera aguda en un $81 \%$ de los pacientes y el $51 \%$ quedaron libres de TV recurrente $^{186}$. El ensayo SMASH-VT evaluó el papel de la ablación con catéter en pacientes con infarto de miocardio previo y FEVI reducida ${ }^{187}$. Se sometió a los pacientes a implante de DAI por haber presentado FV, TV hemodinámicamente inestable o síncope con TV inducible durante un estudio electrofisiológico invasivo. El grupo control se sometió a implante de DAI únicamente. Ningún paciente recibió fármacos antiarrítmicos. Se realizó ablación con catéter mediante técnica de ablación de sustrato dirigida a eliminar potenciales ventriculares anormales en ritmo sinusal sin necesidad de inducción de TV. Durante un seguimiento medio de $23 \pm 6$ meses, se produjo una reducción significativa en la incidencia de episodios de TV, del $33 \%$ del grupo control al $12 \%$ del grupo de ablación. Además, la tasa de choques de DAI apropiados disminuyó del 31 al 9\% tras la ablación con catéter.

El estudio VTACH aleatorizó prospectivamente a pacientes con infarto de miocardio previo, FE reducida $(\leq 50 \%)$ y TV hemodinámicamente estable a ablación con catéter o ninguna otra terapia aparte del implante posterior de un DAI ${ }^{188}$. El criterio de valoración primario fue el tiempo transcurrido hasta la primera recurrencia de TV o FV. La tasa de supervivencia libre de TV recurrente a los 24 meses era mayor en el grupo de ablación que en el grupo control (el 47 frente al 29\%; $\mathrm{HR}=0,61 ; \mathrm{IC95 \% ,0,37-0,99;} \mathrm{p}=0,045)$. El número medio de choques del DAI apropiados por paciente y año disminuyó de 3,4 $\pm 9,2$ a 0,6 \pm 2,1 entre los pacientes sometidos a ablación con catéter $(p=0,018)$. La ablación con catéter no afectó a la mortalidad.

En general, la tasa de eficacia de la ablación con catéter para la TV está determinada por la extensión de las cicatrices relacionadas con el infarto, representada como áreas de bajo voltaje en sistemas de mapeo electroanatómicos ${ }^{209}$, aunque las unidades dedicadas al tratamiento de pacientes mediante ablación con catéter de la TV pueden tener un impacto positivo en el resultado ${ }^{210}$.

\subsubsection{Taquicardia por reentrada rama-rama}

Prevención de las recurrencias de taquicardia ventricular en pacientes con taquicardia por reentrada rama-rama

\begin{tabular}{lcccc}
\hline Recomendaciones & Clase $^{\mathrm{a}}$ & Nivel $^{\mathrm{b}}$ & Ref $^{\mathrm{c}}$ \\
\hline $\begin{array}{l}\text { Se recomienda la ablación con catéter como terapia } \\
\text { de primera línea para pacientes que presentan } \\
\text { taquicardia por reentrada rama-rama }\end{array}$ & I & C & 345,346 \\
\hline
\end{tabular}

aClase de recomendación.

bivel de evidencia.

'Referencias que respaldan las recomendaciones.

La taquicardia rama-rama es una rara taquicardia por mecanismo de macrorreentrada que típicamente afecta a la rama derecha del haz de His como brazo anterógrado y la rama izquierda del haz de His como brazo retrógrado. En el ECG de superficie de 12 derivaciones, se observa morfología de BRIH con desviación del eje a la izquierda. La reentrada rama-rama se asocia con frecuencia a miocardiopatía ${ }^{347}$. La ablación con catéter de una de las ramas del haz de His es curativa, aunque el objetivo preferido es la rama derecha, ya que es más fácilmente accesible para la ablación ${ }^{347}$. Como la alteración estructural subyacente permanece inalterada, habría que considerar seriamente la colocación concomitante de un $\mathrm{DAI}^{347}$.

\subsubsection{Desfibrilador automático implantable}

El implante de un DAI en pacientes con TV sostenida aumenta la supervivencia en comparación con la terapia con fármacos antiarrítmicos. Hasta la fecha, no se ha llevado a cabo ningún ensayo que com- 
pare la ablación con catéter para la TV sostenida sin implante de DAI y el implante de DAI únicamente. En vista de la escasez de datos y la tasa de recurrencias bastante alta tras la ablación con catéter de la TV sostenida, habría que considerar el implante de DAI para todos los pacientes con disfunción del VI (FEVI < 45\%) y TV sostenida.

\section{MIOCARDIOPATÍAS}

Las miocardiopatías son trastornos miocárdicos definidos por anomalías estructurales y funcionales del miocardio ventricular que no se explican únicamente por estenosis limitante de flujo de las arterias coronarias o condiciones anormales de carga circulatoria ${ }^{348}$. Se agrupan según las características morfológicas y funcionales y se subclasifican en formas familiares y no familiares. Casi todas las miocardiopatías pueden ir asociadas a arritmias ventriculares y mayor riesgo de MSC, que varía con la etiología y la gravedad de la enfermedad.

\subsection{Miocardiopatía dilatada}

\subsubsection{Definiciones, epidemiología y datos de supervivencia}

La MCD se define como dilatación y disfunción sistólica del VI en ausencia de condiciones anormales de carga o de $\mathrm{Cl}$ suficientes para causar una alteración sistólica global ${ }^{348}$. Algunos defectos genéticos que causan MCD también pueden causar disfunción sistólica sin dilatación del VI o dar lugar a cicatrización miocárdica solo detectable por RMC.

La MCD se produce en personas de todas las edades y etnias. En adultos, es más común en varones que en mujeres, con una prevalencia general de $1 / 2.500$ individuos y una incidencia anual estimada conservadoramente de $7 / 100.000^{349}$. En niños, la incidencia anual es de 0,57 casos $/ 100.000^{350}$.

Se encuentran mutaciones genéticas potencialmente patógenas en al menos un $20 \%$ de los adultos con MCD y un $10-20 \%$ de los familiares tienen evidencia de enfermedad en el cribado clínico ${ }^{351}$. Las mutaciones de los genes de las proteínas del sarcómero y desmosómicas son las más comunes, pero son frecuentes mutaciones en la (LMNA) y la desmina de pacientes con trastornos de la conducción cardiaca ${ }^{352,353}$. Un pequeño número de pacientes tienen una enfermedad ligada a $\mathrm{X}$ causada por mutaciones en el gen de la distrofina. Hay un amplio espectro de afecciones adquiridas que pueden causar MCD, como las enfermedades inflamatorias, infecciosas y sistémicas, así como diversos fármacos y toxinas. En algunos casos, los pacientes están genéticamente predispuestos a sufrir MCD tras exposición a desencadenantes exógenos como infección, fármacos citotóxicos, alcohol y gestación.

\subsubsection{Enfoque de la estratificación de riesgo y del tratamiento}

La mortalidad por cualquier causa de pacientes adultos con MCD no seleccionados ha disminuido sustancialmente con el uso de antagonistas neurohormonales y la terapia con dispositivos ${ }^{358}$. La mortalidad de los niños con MCD es relativamente alta el primer año de vida, pero a partir de entonces muchos niños recuperan la función o permanecen clínicamente estables ${ }^{359}$. Las principales causas de muerte cardiovascular en la MCD son IC progresiva y MSC secundaria a arritmias ventriculares o, menos frecuentemente, bradiarritmias. Se han propuesto muchas variables no invasivas como factores predictivos de muerte súbita, pero en un reciente metanálisis de 45 estudios que incluyeron a 6.088 pacientes, las variables funcionales y electrocardiográficas proporcionaron una discriminación entre pacientes de alto y bajo riesgo solo moderada. La mayor OR fue con QRS fragmentado y alternancia de la onda $\mathrm{T}$; ninguna de las pruebas autonómicas resultaron ser predictores significativos ${ }^{115}$. Se ha evaluado el papel de la imagen por RMC en un metanálisis de 9 estudios en pacientes con miocardiopatía no isquémica ${ }^{360}$, y se indica que el realce tardío del gadolinio en los pacientes se asocia a mayor riesgo de mortalidad por cualquier causa, hospitalización por IC y MSC. Se necesita determinar
Estratificación de riesgo y tratamiento para pacientes con miocardiopatía dilatada

\begin{tabular}{|c|c|c|c|}
\hline Recomendaciones & Clase $^{\mathrm{a}}$ & Nivel $^{\mathrm{b}}$ & $\operatorname{Ref}^{c}$ \\
\hline $\begin{array}{l}\text { Para pacientes con MCD, se recomienda terapia } \\
\text { médica óptima (IECA, bloqueadores beta y ARM) } \\
\text { para reducir el riesgo de muerte súbita e IC } \\
\text { progresiva }\end{array}$ & I & A & 8 \\
\hline $\begin{array}{l}\text { Se recomienda identificar y tratar inmediatamente } \\
\text { factores arritmogénicos (como fármacos } \\
\text { proarrítmicos o hipopotasemia) y comorbilidades } \\
\text { (como enfermedad del tiroides) de pacientes } \\
\text { con MCD y arritmias ventriculares }\end{array}$ & I & C & 8 \\
\hline $\begin{array}{l}\text { Se recomienda angiografía coronaria para pacientes } \\
\text { con } \mathrm{MCD} \text { estable y riesgo de } \mathrm{CI} \text { intermedio } \\
\text { y arritmias ventriculares de nueva aparición }\end{array}$ & I & B & 8 \\
\hline $\begin{array}{l}\text { Se recomienda el DAI para pacientes con MCD, TV/ } \\
\text { FV hemodinámicamente no tolerada y esperanza } \\
\text { de vida con buen estado funcional }>1 \text { año }\end{array}$ & I & A & $151-154$ \\
\hline $\begin{array}{l}\text { Se recomienda el DAI para pacientes con MCD, IC } \\
\text { sintomática (NYHA II-III), FEVI } \leq 35 \% \text { a pesar de } \\
\text { al menos } 3 \text { meses de tratamiento farmacológico } \\
\text { óptimo y esperanza de vida con buen estado } \\
\text { funcional > } 1 \text { año }\end{array}$ & I & B & $\begin{array}{c}64,313 \\
316,317 \\
354\end{array}$ \\
\hline $\begin{array}{l}\text { Se recomienda la ablación con catéter para } \\
\text { pacientes con MCD y TV por reentrada rama-rama } \\
\text { refractaria a la terapia médica }\end{array}$ & I & B & $\begin{array}{c}8,208 \\
345,346\end{array}$ \\
\hline $\begin{array}{l}\text { Se debe considerar el DAI para pacientes con MCD } \\
\text { y una mutación en } L M N A \text { causante de enfermedad } \\
\text { confirmada y factores de riesgo clínicos }{ }^{\mathrm{d}}\end{array}$ & IIa & B & 71 \\
\hline $\begin{array}{l}\text { Se debe considerar la amiodarona para pacientes } \\
\text { con DAI que sufren descargas apropiadas } \\
\text { recurrentes a pesar de una programación óptima } \\
\text { del dispositivo }\end{array}$ & IIa & C & 229 \\
\hline $\begin{array}{l}\text { Se puede considerar la ablación con catéter para } \\
\text { pacientes con MCD y arritmias ventriculares no } \\
\text { causadas por reentrada rama-rama refractaria a la } \\
\text { terapia médica }\end{array}$ & IIb & C & 355 \\
\hline $\begin{array}{l}\text { Se puede considerar el EEF invasivo con EVP para la } \\
\text { estratificación de riesgo de MSC }\end{array}$ & IIb & B & 115 \\
\hline $\begin{array}{l}\text { No se recomienda la amiodarona para el } \\
\text { tratamiento de la TVNS asintomática de pacientes } \\
\text { con MCD }\end{array}$ & III & A & 313,354 \\
\hline $\begin{array}{l}\text { No se recomienda el uso de bloqueadores de los } \\
\text { canales de sodio y dronedarona para tratar las } \\
\text { arritmias ventriculares de pacientes con MCD }\end{array}$ & III & A & $\begin{array}{l}129,356, \\
357\end{array}$ \\
\hline
\end{tabular}

ARM: antagonistas de los receptores de mineralocorticoides; CI: cardiopatía isquémica; DAI: desfibrilador automático implantable; EEF: estudio electrofisiológico; EVP: estimulación ventricular programada; FEVI: fracción de eyección del ventrículo izquierdo; IC: insuficiencia cardiaca; IECA: inhibidores de la enzima de conversión de la angiotensina; MCD: miocardiopatía dilatada; MSC: muerte súbita cardiaca; NYHA: clase funcional de la New York Heart Association; TV: taquicardia ventricular; TVNS: taquicardia ventricular no sostenida.

aClase de recomendación.

bNivel de evidencia.

cReferencias que respaldan las recomendaciones.

dFactores de riesgo de los pacientes con una mutación en LMNA confirmada: TVNS durante la monitorización con ECG ambulatoria, FEVI < $45 \%$ en la primera evaluación, sexo masculino y mutaciones sin cambio de sentido (inserción, deleción, truncamientos o mutaciones de empalme).

el valor incremental del realce tardío del gadolinio sobre otros marcadores pronósticos.

Un EEF invasivo con EVP podría tener un papel en pacientes con $\mathrm{MCD}^{115}$.

\subsubsection{Estudios con desfibrilador automático implantable en la miocardiopatía dilatada}

Una serie de estudios han comparado la terapia con DAI sola o en combinación con TRC frente a placebo o amiodarona en pacientes con 
MCD 64,151-154,313,316,317,354. La mayoría se realizaron en una época en la que la mejor terapia médica evolucionó para incluir IECA, bloqueadores beta y $\mathrm{ARM}^{358}$. Los primeros ensayos clínicos aleatorizados de terapia con DAI no tenían suficiente potencia para detectar diferencias clínicamente significativas en la supervivencia, y en algunos casos (p. ej., el DEFINITE) la tasa de mortalidad total resultó inferior a la prevista antes de la inclusión. El seguimiento era relativamente corto en algunos estudios, así que, como en otras situaciones, la relación entre descargas apropiadas y pronóstico es aún incierta. Ningún estudio ha investigado prospectivamente el beneficio de los DAI en subgrupos etiológicos de MCD específicos.

\subsubsection{Prevención primaria}

Cuatro estudios aleatorizados (CAT ${ }^{361}$, AMIOVIRT ${ }^{354}$, DEFINITE ${ }^{316} \mathrm{y}$ SCD-HeFT ${ }^{64}$ ) examinaron el efecto de la terapia con DAI para la prevención primaria de la MSC. Otro estudio, el COMPANION ${ }^{313}$, comparó la TRC-D, la TRC-P y la terapia con amiodarona en pacientes con IC avanzada (NYHA III-IV) y un intervalo QRS > $120 \mathrm{~ms}$. Los estudios difieren en cuanto a diseño: CAT, AMIOVIRT y DEFINITE incluyeron solo a pacientes con MCD no isquémica, mientras que SCD-HeFT y COMPANION incluyeron a pacientes con disfunción del VI isquémica y no isquémica. Solo el COMPANION demostró una reducción estadísticamente significativa en la muerte súbita con DAI en comparación con una terapia médica óptima. La mortalidad por cualquier causa fue menor en el grupo de TRC-D que en el de terapia farmacológica (HR = 0,50; IC95\%, 0,29-0,88; p = 0,015), pero se asoció a un riesgo significativamente mayor de eventos adversos moderados o graves por cualquier causa (el 69 frente al 61\% en la rama de terapia médica; $\mathrm{p}=$ $0,03)$. El análisis agrupado de los 5 estudios de prevención primaria (1.854 pacientes con MCD no isquémica) demostró una reducción estadísticamente significativa del $31 \%$ en la mortalidad por cualquier causa con DAI frente a terapia médica ( $R R=0,69$; IC95\%, 0,55-0,87; $\mathrm{p}=0,002)^{317}$. Este efecto persistió tras excluir el COMPANION $(\mathrm{RR}=0,74 ; \mathrm{IC95 \%}, 0,58-0,96 ; \mathrm{p}=0,02)^{317}$. Las recomendaciones para la terapia con DAI en esta guía se basan en estos análisis.

\subsubsection{Prevención secundaria}

Tres estudios (AVID ${ }^{153}, \mathrm{CASH}^{152}$ y $\mathrm{CIDS}^{151}$; véase la tabla 5 del anexo web) examinaron la terapia con DAI para la prevención secundaria en pacientes con antecedentes de parada cardiaca abortada o TV sintomática. En el estudio CASH, se aleatorizó inicialmente a los pacientes a recibir DAI o uno de 3 fármacos: amiodarona, metoprolol o propafenona, pero el grupo de propafenona finalizó pronto debido a un aumento en la mortalidad. El análisis final agrupó los datos de los grupos de amiodarona y metoprolol. Los 3 estudios incluyeron a un total de 1.963 pacientes, de los que solo 292 (14,8\%) tenían miocardiopatía no isquémica. Ni el estudio AVID ni el CIDS describieron una reducción significativa en la mortalidad por cualquier causa con la terapia con DAI en el subgrupo de pacientes con miocardiopatía no isquémica; no se comunicaron los resultados de este subgrupo en el estudio CASH, que también difería de los estudios AVID y CIDS en que la FEVI media era superior y más del $50 \%$ de los pacientes recibieron sistemas de DAI epicárdicos. En un metanálisis posterior que agrupó los datos de AVID y CIDS, hubo una reducción no significativa del 31\% en la mortalidad por cualquier causa respecto a la terapia médica ${ }^{154}$.

\subsubsection{Mortalidad por causas específicas}

Pocos estudios han examinado el pronóstico o el tratamiento en subtipos específicos de MCD. Los mejor caracterizados son ese aproximadamente $5-10 \%$ de pacientes que tienen enfermedad causada por mutaciones en el gen $L M N A^{71,352}$. La enfermedad cardiaca relacionada con LMNA muestra una penetrancia relacionada con la edad, con inicio de arritmias auriculares de aparición precoz seguidas del desarro- llo de una enfermedad del sistema de conducción y un alto riesgo de muerte súbita, frecuentemente con solo una leve dilatación y alteración sistólica del VI. En un registro multicéntrico de 269 portadores de mutación en $L M N A$, el análisis multivariable demostró que la TVNS durante la monitorización ambulatoria mediante ECG, una FEVI < 45\% en la primera evaluación, el sexo masculino y las mutaciones con sentido (inserción-deleción/truncación o mutaciones de empalme) eran factores independientes de riesgo de arritmias ventriculares malignas $^{71}$. Se produjeron arritmias ventriculares malignas solo en personas con al menos 2 de estos factores de riesgo y cada factor de riesgo adicional sumaba al riesgo acumulado.

\subsubsection{Tratamiento de las arritmias ventriculares en la miocardiopatía} dilatada

Los pacientes con MCD y arritmias ventriculares recurrentes deben recibir una terapia médica óptima con IECA, bloqueadores beta y ARM según la guía de la ESC sobre IC crónica ${ }^{8}$. Habría que buscar y tratar siempre que fuera posible factores precipitantes de arritmias ventriculares obvios (como fármacos proarrítmicos o hipopotasemia) o comorbilidades (como enfermedad del tiroides). En pacientes previamente estables con arritmias ventriculares de nueva aparición, habría que considerar la angiografía coronaria para aquellos con riesgo de $\mathrm{CI}$ intermedio-alto. Habría que considerar la amiodarona para pacientes con DAI que sufren choques apropiados recurrentes a pesar de una programación óptima del dispositivo ${ }^{229}$, pero no se debería utilizar para tratar episodios de TVNS asintomáticos. El uso de bloqueadores de los canales de sodio y dronedarona no está recomendado para pacientes con función del VI reducida debido a sus potenciales efectos proarrítmicos ${ }^{129,152,357,362,363}$.

\subsubsection{Ablación de la taquicardia ventricular}

El sustrato para la TV en la MCD es muy complejo y refleja las múltiples causas de la enfermedad. Estudios que evalúan diferentes estrategias de ablación en la MCD describen, a lo sumo, un éxito pequeño que no mejora cuando se realiza un mapeo epicárdico y endocárdico. En un registro reciente que comparó a 63 pacientes con miocardiopatía no isquémica y 164 con disfunción isquémica del $\mathrm{VI}^{208}$, solo se consiguió la ablación de la TV clínica en un 18,3\% del grupo con miocardiopatía no isquémica. Por lo tanto, se debería reservar la ablación con catéter de la TV en pacientes con MCD para quienes se presentan con un claro mecanismo de TV (p. ej., reentrada rama-rama) y realizarla en centros experimentados.

\subsection{Miocardiopatía hipertrófica}

\subsubsection{Definiciones, epidemiología y datos de supervivencia}

La MCH se caracteriza por un aumento en el grosor de la pared del VI que no solo se explica por condiciones de carga circulatoria del VI anormales ${ }^{116}$. Esta definición se aplica a niños y adultos y no hace suposiciones acerca de la etiología, pero, para los fines de esta guía, las recomendaciones sobre la prevención de la MSC se aplican a pacientes sin enfermedades metabólicas, infiltrativas o de otro tipo, que tienen historias naturales y tratamiento muy diferentes.

Estudios realizados en Norteamérica, Europa, Asia y África comunican una prevalencia de hipertrofia inexplicable del VI en una franja del 0,02-0,23\% de los adultos, con tasas muy inferiores entre los pacientes menores de 25 años $^{116}$. Aunque la $\mathrm{MCH}$ se transmite más frecuentemente como un rasgo genético autosómico dominante, la mayoría de los estudios indican una pequeña preponderancia masculina, y la frecuencia de $\mathrm{MCH}$ en diferentes grupos raciales es similar ${ }^{116}$.

La mortalidad cardiovascular anual total y la tasa de muertes o descargas apropiadas del DAI por TV/FV en adultos con MCH no seleccionados son del $1-2$ y el $0,81 \%$ respectivamente ${ }^{364,365}$. Otras causas 
importantes de muerte cardiovascular son IC, tromboembolia y BAV.

\subsubsection{Enfoque de la estratificación de riesgo y del tratamiento}

Prevención de la muerte súbita cardiaca de pacientes con miocardiopatía hipertrófica

\begin{tabular}{|c|c|c|c|}
\hline Recomendaciones & Clase $^{\mathrm{a}}$ & Nivel $^{\mathrm{b}}$ & $\operatorname{Ref}^{c}$ \\
\hline $\begin{array}{l}\text { Se recomienda a los pacientes con } \mathrm{MCH} \text { evitar los } \\
\text { deportes de competición }^{\mathrm{d}}\end{array}$ & I & C & 366 \\
\hline $\begin{array}{l}\text { Se recomienda implante de DAI para pacientes que } \\
\text { han sobrevivido a una parada cardiaca debida a TV } \\
\text { o FV o tienen TV sostenida espontánea que causa } \\
\text { síncope o deterioro hemodinámico y esperanza } \\
\text { de vida > } 1 \text { año }\end{array}$ & I & B & $\begin{array}{c}116 \\
367-372\end{array}$ \\
\hline $\begin{array}{l}\text { Se recomienda la estratificación de riesgos con la } \\
\text { calculadora HCM Risk-SCD para estimar el riesgo } \\
\text { de muerte súbita a } 5 \text { años de los pacientes de edad } \\
\geq 16 \text { años sin antecedentes de reanimación de TV o } \\
\text { FV o TV sostenida espontánea que cause síncope } \\
\text { o deterioro hemodinámico }\end{array}$ & I & B & 116,365 \\
\hline $\begin{array}{l}\text { Se recomienda valorar el riesgo de MSC a } 5 \text { años en } \\
\text { una primera evaluación y a intervalos de } 1-2 \text { años } \\
\text { o cuando haya un cambio en el estado clínico }\end{array}$ & I & B & 116,365 \\
\hline $\begin{array}{l}\text { Se debe considerar implante de DAI para pacientes } \\
\text { con un riesgo estimado de muerte súbita a } \\
5 \text { años } \geq 6 \% \text { y esperanza de vida }>1 \text { año tras una } \\
\text { valoración clínica detallada que tenga en cuenta el } \\
\text { riesgo de complicaciones durante toda la vida y el } \\
\text { impacto de un DAI en el estilo de vida, el estatus } \\
\text { socioeconómico y la salud psicológica }\end{array}$ & Ila & B & 116,368 \\
\hline $\begin{array}{l}\text { Se puede considerar implante de DAI para } \\
\text { pacientes individuales con un riesgo estimado de } \\
\text { MSC a } 5 \text { años } \geq 4-<6 \% \text { y esperanza de vida }>1 \text { año } \\
\text { tras una valoración clínica detallada que tenga en } \\
\text { cuenta el riesgo de complicaciones durante toda la } \\
\text { vida y el impacto de un DAI en el estilo de vida, el } \\
\text { estatus socioeconómico y la salud psicológica }\end{array}$ & IIb & B & $\begin{array}{c}116,365 \\
368\end{array}$ \\
\hline $\begin{array}{l}\text { Se puede considerar el implante de DAI para } \\
\text { pacientes individuales con un riesgo estimado de } \\
\text { MSC a } 5 \text { años < } 4 \% \text { si tienen características clínicas } \\
\text { de probada importancia pronóstica y la valoración } \\
\text { del riesgo de complicaciones durante toda la vida y } \\
\text { el impacto de un DAI en el estilo de vida, el estatus } \\
\text { socioeconómico y la salud psicológica indican un } \\
\text { beneficio neto de la terapia con DAI }\end{array}$ & IIb & B & $\begin{array}{c}116,365 \\
368\end{array}$ \\
\hline $\begin{array}{l}\text { No se recomienda el EEF invasivo con EVP para la } \\
\text { estratificación del riesgo de MSC }\end{array}$ & III & C & 116 \\
\hline
\end{tabular}

DAI: desfibrilador automático implantable; EEF: estudio electrofisiológico; ESC: Sociedad Europea de Cardiología; EVP: estimulación ventricular programada; FV: fibrilación ventricular; MCH: miocardiopatía hipertrófica; MSC: muerte súbita cardiaca; TV: taquicardia ventricular.

aClase de recomendación.

${ }^{\mathrm{b}}$ Nivel de evidencia.

'Referencias que respaldan las recomendaciones.

dLa guía de la ESC define deporte de competición como la dedicación amateur o profesional al entrenamiento de ejercicio de manera regular y la participación en competiciones oficiales (para más detalles, véase las pertinentes guías de la ESC).

\subsubsection{Arritmias ventriculares en la miocardiopatía hipertrófica}

Se produce TVNS durante la monitorización ambulatoria mediante ECG en un $\sim 25 \%$ de los pacientes ${ }^{373,374}$. Su prevalencia aumenta con la edad y guarda correlación con el grosor de la pared del VI y el realce tardío del gadolinio en la RMC ${ }^{375}$. La TVNS durante la monitorización ambulatoria se asocia a mayor riesgo de $\mathrm{MSC}^{373}$. La TVNS documentada durante o inmediatamente después del ejercicio es muy rara, pero puede conllevar mayor riesgo de $\mathrm{MSC}^{376}$.
La TV monomórfica sostenida documentada ( $\geq 30 \mathrm{~s}$ ) es poco común, pero puede ser más frecuente en pacientes con aneurismas apicales del VI. Se debe excluir CI en los pacientes con episodios prolongados o sintomáticos en presencia de factores de riesgo de aterosclerosis coronaria ${ }^{377}$. Para los pacientes con TV sostenida mal tolerada se debe considerar terapia con DAI y bloqueadores beta o amiodarona para suprimir nuevos episodios. En pacientes con evidencia de un origen focal de la TV, se puede considerar el EEF y la ablación.

\subsubsection{Enfoque de la estratificación de riesgos y del tratamiento de pacientes adultos}

Históricamente, el riesgo de MSC de los pacientes con $\mathrm{MCH}$ se ha estimado con una simple puntuación basada en cierto número de parámetros clínicos seleccionados ${ }^{367,378,379}$. Se han propuesto otras características clínicas, como la fibrosis miocárdica (determinada por RMC con contraste), aneurismas apicales del VI y múltiples mutaciones de los genes de las proteínas sarcoméricas, que se pueden usar para guiar la terapia con DAI para pacientes que están en situación de riesgo intermedio, con pocos datos de apoyo. La guía de la ESC sobre MCH recomienda el uso de una calculadora (HCM Risk-SCD) que estima el riesgo a 5 años ${ }^{116}$.

Las variables predictivas usadas en el modelo se asocian todas a mayor riesgo de MSC en al menos un análisis multivariable publicado (http://doc2do.com/hcm/webHCM.html). La calculadora está específicamente diseñada para su uso en pacientes de edad $\geq 16$ años y no está destinada al uso en atletas de élite o en individuos con enfermedades (p. ej., enfermedad de Anderson-Fabry) y síndromes (p. ej., síndrome de Noonan) metabólicos o infiltrativos. El modelo no emplea gradientes de TSVI inducidos por el ejercicio y no se ha validado antes y después de una miectomía o ablación del septo con alcohol.

El EEF invasivo con EVP no contribuye a la estratificación de riesgos de MSC en la MCH, y no se recomienda su uso sistemático en pacientes con síncope o síntomas que indiquen arritmia ${ }^{116}$.

Contrariamente a la guía de $\mathrm{MCH}$ recientemente publicada ${ }^{116}$, no se ha incorporado una recomendación de clase III para pacientes con un riesgo estimado $<4 \%$ a 5 años, debido al grado de incertidumbre en la estimación del riesgo, que requiere precaución cuando se excluye una categoría de pacientes para ser tratados con un DAI.

\subsubsection{Enfoque de la estratificación de riesgos y del tratamiento de pacientes pediátricos}

Para pacientes de edad < 16 años, se recomienda el implante de un DAI (epicárdico si es necesario) tras una arritmia ventricular potencialmente letal. Se dispone de pocos datos sobre el uso de marcadores de riesgo clínicos para guiar la prevención primaria, en particular en niños muy pequeños (edad $<8$ años). La guía de la ESC vigente recomienda considerar la hipertrofia grave del VI (definida como un grosor máximo de la pared del $\mathrm{VI} \geq 30 \mathrm{~mm}$ o una puntuación $\mathrm{Z} \geq 6$ ), el síncope inexplicable, la TVNS e historia familiar de muerte súbita como factores importantes de riesgo de MSC en niños ${ }^{116}$. Habría que considerar el implante de un DAI en niños que tienen 2 o más de estos importantes factores de riesgo. Para pacientes individuales con un solo factor de riesgo, se puede considerar el implante de un DAI tras una cuidadosa consideración de los riesgos y beneficios para el niño. Los desfibriladores monocamerales bastan en la mayoría de los casos y reducen la probabilidad de complicaciones ${ }^{116}$.

\subsubsection{Prevención de la muerte súbita cardiaca}

\subsubsection{Fármacos y consejos sobre el estilo de vida}

Se debe aconsejar a los pacientes con MCH que no participen en deportes de competición y desanimarles de realizar una actividad 
física intensa, especialmente cuando tengan factores de riesgo de MSC reconocidos o un gradiente en el TSVI. No hay ensayos clínicos aleatorizados de antiarrítmicos en MCH. La amiodarona posiblemente reduzca la incidencia de MSC en pacientes con TVNS durante la monitorización ambulatoria mediante ECG, pero frecuentemente no consigue prevenir la MSC en muchos estudios ${ }^{380,381}$. Se usa disopiramida y bloqueadores beta para tratar la obstrucción del TSVI, pero no hay evidencia de que reduzcan el riesgo de $\mathrm{MSC}^{116}$. De modo similar, la actual guía de la ESC sobre MCH no recomienda la miectomía quirúrgica o la ablación septal con alcohol para reducir el riesgo de MSC de pacientes con obstrucción del TSVI ${ }^{116}$.

\subsubsection{Desfibriladores automáticos implantables}

Prevención secundaria. Aunque no existen ensayos de DAI en la $\mathrm{MCH}$, estudios de cohortes observacionales y metanálisis muestran que la parada cardiaca abortada o la TV sostenida se asocian a alto riesgo de posteriores arritmias cardiacas mortales ${ }^{368}$. Por esta razón, los DAI están recomendados para este pequeño grupo de pacientes ${ }^{116}$.

Prevención primaria. Se recomienda someter a los pacientes con $\mathrm{MCH}$ a una evaluación clínica estandarizada en línea con la guía de la ESC sobre $\mathrm{MCH}^{116}$. Debe incluir historia clínica y familiar, un ECG ambulatorio de $48 \mathrm{~h}$, una ecocardiografía transtorácica (o RMC en caso de ventanas ecográficas inadecuadas) y una prueba de ejercicio limitada por los síntomas. Las recomendaciones para el implante de DAI se basan en el riesgo de MSC a 5 años calculado con el modelo HCM Risk-SCD y teniendo en cuenta la edad y la salud general del paciente.

\subsection{Miocardiopatía arritmogénica del ventrículo derecho}

\subsubsection{Definiciones, epidemiología y supervivencia}

La MAVD es un trastorno progresivo del músculo cardiaco caracterizado por arritmias ventriculares, IC y MSC ${ }^{382}$. La característica histológica de la enfermedad es la sustitución de los miocardiocitos por tejido adiposo y fibroso ${ }^{382,383}$. Clínicamente, la MAVD se define por anormalidades estructurales y funcionales del VD, pero se produce implicación del VI en más del 50\% de los pacientes $^{384}$. Los criterios actuales del grupo de trabajo utilizan parámetros histológicos, genéticos, electrocardiográficos y de imagen para clasificar a los pacientes en categorías diagnósticas definidas, limítrofes y posibles ${ }^{382}$.

En la mayoría de los casos, la MAVD se hereda como una característica genética autosómica dominante causada por mutaciones en genes que codifican las proteínas desmosómicas (plakoglobina), desmoplakina, plakofilina-2, desmogleína-2 y desmocolina-2. Una minoría de casos están causados por mutaciones en genes no desmosómicos y formas recesivas raras (p. ej., síndrome de Carvajal y enfermedad de Naxos) asociadas a un fenotipo cutáneo de hiperqueratosis palmar y plantar ${ }^{52}$.

La MAVD tiene una prevalencia estimada de $1 / 1.000$ a $1 / 5.000$ de la población general y es una causa importante de MSC de atletas y adultos jóvenes ${ }^{385,386}$. Las manifestaciones clínicas, palpitaciones, síncope, TV y MSC entre otras, aparecen normalmente entre la segunda y la cuarta década de vida. La progresión de la enfermedad puede dar lugar a IC derecha o biventricular. La tasa anual de mortalidad comunicada en diferentes estudios varía considerablemente, dependiendo de las características de las cohortes descritas. Los datos de un metanálisis comunicaron unas tasas anualizadas de mortalidad cardiaca, mortalidad no cardiaca y trasplantes de corazón del 0,9, el 0,8 y el $0,9 \%$ respectivamente ${ }^{387}$.

\subsubsection{Enfoque de la estratificación de riesgo y del tratamiento}

Estratificación de riesgo y tratamiento de pacientes con miocardiopatía arritmogénica del ventrículo derecho

\begin{tabular}{|c|c|c|c|}
\hline Recomendaciones & Clase $^{\mathrm{a}}$ & Nivel $^{\mathrm{b}}$ & $\operatorname{Ref}^{c}$ \\
\hline $\begin{array}{l}\text { Se recomienda evitar los deportes de competición } \\
\text { a los pacientes con MAVD }\end{array}$ & I & C & 388 \\
\hline $\begin{array}{l}\text { Para pacientes con EV y TVNS frecuentes, se } \\
\text { recomienda bloqueadores beta titulados a la dosis } \\
\text { máxima tolerada como terapia de primera línea } \\
\text { para mejorar los síntomas }\end{array}$ & I & C & $\begin{array}{c}\text { Este } \\
\text { panel de } \\
\text { expertos }\end{array}$ \\
\hline $\begin{array}{l}\text { Se recomienda implante de DAI para pacientes } \\
\text { con antecedentes de MSC abortada y TV } \\
\text { hemodinámicamente mal tolerada }\end{array}$ & I & C & 389 \\
\hline $\begin{array}{l}\text { Se debe considerar la amiodarona para mejorar los } \\
\text { síntomas de pacientes con EV o TVNS frecuente } \\
\text { que no toleran o tienen contraindicados los } \\
\text { bloqueadores beta }\end{array}$ & IIa & C & 390,391 \\
\hline $\begin{array}{l}\text { Para pacientes con EV o TV sintomáticas frecuentes } \\
\text { que no responden a la terapia médica, se debe } \\
\text { considerar la ablación con catéter, realizada en } \\
\text { centros experimentados, para mejorar los síntomas } \\
\text { y prevenir descargas del DAI respectivamente }\end{array}$ & IIa & B & $\begin{array}{l}183,202 \\
207,392 \\
393\end{array}$ \\
\hline $\begin{array}{l}\text { Se debe considerar implante de DAI para } \\
\text { pacientes con MAVD que tienen TV sostenida } \\
\text { hemodinámicamente bien tolerada, ponderando } \\
\text { el riesgo de la terapia con DAI tras incluir las } \\
\text { complicaciones a largo plazo y el beneficio para el } \\
\text { paciente }\end{array}$ & IIa & B & $\begin{array}{l}387,394, \\
395\end{array}$ \\
\hline $\begin{array}{l}\text { Se puede considerar implante de DAI para } \\
\text { pacientes adultos con uno o más factores de } \\
\text { riesgo de arritmias ventriculares identificados } \\
\text { y esperanza de vida > } 1 \text { año tras una valoración } \\
\text { clínica detallada que tenga en cuenta el riesgo } \\
\text { de complicaciones a lo largo de toda la vida y el } \\
\text { impacto de un DAI en el estilo de vida, el estatus } \\
\text { socioeconómico y la salud psicológica }\end{array}$ & IIb & C & $\begin{array}{c}\text { Este } \\
\text { panel de } \\
\text { expertos }\end{array}$ \\
\hline $\begin{array}{l}\text { Se puede considerar el EEF invasivo con EVP para la } \\
\text { estratificación del riesgo de MSC }\end{array}$ & IIb & C & 113,114 \\
\hline
\end{tabular}

DAI: desfibrilador automático implantable; EEF: estudio electrofisiológico; ESC: Sociedad Europea de Cardiología; EV: extrasístoles ventriculares; MAVD: miocardiopatía arritmogénica del ventrículo derecho; TV: taquicardia ventricular TVNS: taquicardia ventricular no sostenida.

aClase de recomendación.

bNivel de evidencia.

'Referencias que respaldan las recomendaciones.

'La guía de la ESC definen deporte de competición como la dedicación amateur o profesional al entrenamiento de ejercicio de manera regular y la participación en competiciones oficiales (para más detalles, véase las pertinentes guías de la ESC).

\subsubsection{Arritmias ventriculares en la miocardiopatía arritmogénica del ventrículo derecho}

Hasta dos tercios de los pacientes tienen arritmias ventriculares en la monitorización mediante ECG en reposo o ambulatoria y en las pruebas de ejercicio ${ }^{396-399}$. Estas arritmias ventriculares tienen normalmente origen en el VD (es decir, que muestran una morfología de $\mathrm{BRIH}$ ), pero el eje QRS durante la TV normalmente difiere del eje QRS en el TSVD ${ }^{400}$, y muchos pacientes tienen múltiples morfologías del QRS. En un reciente registro prospectivo de pacientes predominantemente tratados con un DAI, la mayoría de las terapias apropiadas eran para la TV monomórfica sostenida ${ }^{401}$. 


\subsubsection{Tratamiento de las arritmias ventriculares}

Se dispone de pocos datos sistemáticos sobre la eficacia de los fármacos antiarrítmicos en la MAVD y se desconoce el impacto de la terapia médica en la mortalidad. Con base en gran medida en estudios de EVP seriada, se recomiendan convencionalmente los bloqueadores beta (en particular sotalol) como primer enfoque para pacientes con frecuente ectopia ventricular o AVNS ${ }^{391}$. Sin embargo, en un registro observacional reciente, no pareció que los bloqueadores beta y el sotalol redujeran las arritmias ventriculares ${ }^{390}$; la amiodarona fue superior en la prevención de arritmias ventriculares en una pequeña cohorte de pacientes ${ }^{390}$.

Se puede usar EEF invasivos con mapeo de voltaje para identificar regiones de sustitución fibrograsa y guiar la ablación de la arritmia ventricular con catéter ${ }^{202,207,392,402}$. La supresión aguda de la TV es eficaz más a menudo en pacientes que se presentan con una sola o unas pocas morfologías dominantes de TV seleccionadas y la ablación epicárdica puede aumentar las tasas de eficacia. Ya que ni los fármacos antiarrítmicos ni la ablación con catéter proporcionan suficiente protección contra la MSC, se debería usar la ablación para reducir la frecuencia de episodios de arritmia más que para mejorar el pronóstico.

\subsubsection{Restricción del ejercicio}

El entrenamiento de resistencia a nivel de competición probablemente exacerba el fenotipo de MAVD ${ }^{81,403}$. Por lo tanto, aunque no hay ensayos controlados que demuestren un efecto beneficioso, se recomienda evitar el entrenamiento de resistencia de alto nivel.

\subsubsection{Desfibriladores automáticos implantables}

La mayoría de los estudios sobre la estratificación de riesgos y la terapia con DAI son retrospectivos y de cohortes de alto riesgo seleccionadas y relativamente pequeñas procedentes de un solo centro. Muchos también proporcionan poca información sobre la indicación de DAI. En una revisión sistemática (24 estudios) y un metanálisis (18 estudios) recientes de 610 pacientes a los que se dio seguimiento una media de 3,8 años ${ }^{387}$, la tasa anualizada de intervención apropiada con DAI fue del 9,5\%. Se describe una colocación de los electrodos del DAI dificultosa en el $18,4 \%$ de los casos y con mal funcionamiento de los electrodos, infección y desplazamiento en el 9,8 , el 1,4 y el 3,3\% de los casos respectivamente. La tasa anual de terapias inapropiadas del DAI fue del 3,7\%.

Los pacientes con antecedentes de MSC abortada, TV mal tolerada y síncope tienen el mayor riesgo de MSC (hasta un 10\% por año), y se recomienda el implante de DAI para este grupo ${ }^{387}$. Otros factores de riesgo de MSC o descargas apropiadas del DAI descritos en diferentes cohortes incluyen TV sostenida documentada, síncope inexplicable, TVNS frecuente, historia familiar de muerte súbita prematura, enfermedad extensa del VD, marcada prolongación del QRS, realce tardío de gadolinio en la RMC (incluida la que afecta el VI), disfunción del VI e inducción de TV durante el EEF113,114,387,389,395,404-406. Se produce heterocigosis compuesta o digénica en más del 10\% de los portadores de la mutación de los genes desmosómicos causante de MAVD y puede ser un factor de riesgo de eventos arrítmicos importantes y $\mathrm{MSC}^{407}$. Como los estudios que examinan los resultados en la MAVD son tan diversos, las recomendaciones sobre el implante de DAI en prevención primaria suponen un reto. Con base en los datos disponibles, el consenso es que habría que considerar a los pacientes con síncope inexplicable para un DAI. Para pacientes sin síncope, se puede considerar el DAI tras una valoración clínica detallada que tenga en cuenta la historia familiar, la gravedad de la función del VD y el VI, el riesgo de complicaciones a lo largo de toda la vida y el impacto de un DAI en el estilo de vida, el estatus socioeconómico y la salud psicológica.

\subsection{Miocardiopatías infiltrativas}

\subsubsection{Amiloidosis cardiaca}

\section{Amiloidosis cardiaca}

\begin{tabular}{lccc}
\hline Recomendaciones & Clase $^{\mathrm{a}}$ & Nivel $^{\mathrm{b}}$ & Ref $^{\mathrm{c}}$ \\
\hline $\begin{array}{l}\text { Se debe considerar el DAI para pacientes con } \\
\text { amiloidosis de cadenas ligeras o amiloidosis }\end{array}$ & Ila & C & $408-412$ \\
$\begin{array}{l}\text { cardiaca asociada a transtiretina hereditaria, } \\
\text { arritmias ventriculares causantes de inestabilidad } \\
\text { hemodinámica y esperanza de vida con buen estado }\end{array}$ & & & \\
funcional > 1 año & & & \\
\hline
\end{tabular}

DAI: desfibrilador automático implantable.

aClase de recomendación.

bNivel de evidencia.

'Referencias que respaldan las recomendaciones.

Los 2 tipos principales de amiloidosis cardiaca son la amiloidosis de cadenas ligeras, causada por el depósito de cadenas ligeras monoclonales, y la amiloidosis asociada a transtiretina hereditaria, en la que se deposita transtiretina normal (de tipo salvaje) o mutante en el miocardio ${ }^{413,414}$. Hasta hace bastante poco, la amiloidosis cardiaca se asociaba a un pronóstico muy pobre, con una supervivencia media < 1 año tras la aparición de los síntomas de IC, pero los avances en la terapia para la amiloidosis de cadenas ligeras han mejorado la supervivencia ${ }^{415}$.

Hasta la mitad de todos los pacientes con amiloidosis cardiaca mueren de manera súbita ${ }^{413,416}$. La muerte se atribuye a menudo a disociación electromecánica, pero informes de casos describen la supresión exitosa de la arritmia ventricular sostenida con $\mathrm{DAI}^{408}$. Se describen arritmias ventriculares durante la monitorización ambulatoria en más del $25 \%$ de los pacientes con amiloidosis cardiaca ${ }^{409-411}$, pero no parece que su presencia prediga MSC. Altas concentraciones de troponinas cardiacas y NT-proBNP son marcadores sensibles de implicación cardiaca y predicen el resultado adverso en pacientes con amiloidosis de cadenas ligeras, pero no existen datos que indiquen que se pueda usar estos biomarcadores para identificar a los pacientes que podrían beneficiarse de un DAI. Con base en esos pocos datos, habría que considerar los DAI para pacientes con amiloidosis de cadenas ligeras o amiloidosis asociada a transtiretina hereditaria que sufren arritmias ventriculares sostenidas y tienen una esperanza de vida $>1$ año. Los datos son insuficientes para hacer recomendaciones sobre prevención primaria.

\subsection{Miocardiopatía restrictiva}

\section{Miocardiopatía restrictiva}

\begin{tabular}{lccc}
\hline Recomendaciones & Clase $^{\mathrm{a}}$ & Nivel $^{\mathrm{b}}$ & Ref $^{\mathrm{c}}$ \\
\hline $\begin{array}{l}\text { Para reducir el riesgo de MSC, se recomienda el } \\
\text { DAI para pacientes con miocardiopatía restrictiva, } \\
\text { arritmia ventricular sostenida causante de }\end{array}$ & I & C & $\begin{array}{c}412, \\
\text { inestabilidad hemodinámica y esperanza de vida } \\
\text { con buen estado funcional }>1 \text { año }\end{array}$ \\
\end{tabular}

DAI: desfibrilador automático implantable; MSC: muerte súbita cardiaca.

${ }^{a}$ Clase de recomendación.

${ }^{\mathrm{b}}$ Nivel de evidencia.

cReferencias que respaldan las recomendaciones.

El término miocardiopatía restrictiva se refiere a corazones en los que hay una fisiología restrictiva, volúmenes diastólicos normales o reducidos de uno o ambos ventrículos, volúmenes sistólicos normales o reducidos y un grosor de la pared ventricular normal. La miocardio- 
patía restrictiva es la menos común de todas las miocardiopatías y la causa una serie de trastornos genéticos y adquiridos ${ }^{412}$. En las sociedades occidentales, la causa más común en adultos es la amiloidosis, seguida de las mutaciones en los genes de las proteínas sarcoméricas y de trastornos metabólicos ${ }^{421}$.

Los pacientes con miocardiopatía restrictiva se presentan típicamente con signos y síntomas de IC biventricular y se los diagnostica por rasgos característicos mediante imagen cardiaca no invasiva y cateterización cardiaca. La miocardiopatía restrictiva se asocia a mal pronóstico a largo plazo. En niños, la supervivencia a 1, 2 y 5 años fue del 82 , el 80 y el $68 \%$ respectivamente ${ }^{417-420}$; los valores correspondientes para la supervivencia sin trasplante fueron del 48 , el 34 y el $22 \%$. Hay menos datos de adultos, pero las tasas de supervivencia a 5 años son similares. Entre los factores de riesgo de muerte por cualquier causa se incluyen la clase funcional de la NYHA, el tamaño de la aurícula izquierda y el sexo masculino ${ }^{417-420}$. Para los niños el riesgo de muerte súbita puede ser mayor, en particular si hay evidencia por ECG de isquemia miocárdica.

El tratamiento de la miocardiopatía restrictiva es mayormente paliativo. Los síntomas de IC se tratan con diuréticos y control de la frecuencia cardiaca para optimizar el llenado del VI. Se debe usar anticoagulación en todos los pacientes con FA. No hay datos prospectivos sobre el implante profiláctico de DAI en la miocardiopatía restrictiva, por lo que, para pacientes con arritmias ventriculares sostenidas sintomáticas, las indicaciones del DAI deben ser similares a las de otras enfermedades del músculo cardiaco, teniendo en cuenta el pronóstico a corto plazo relacionado con la IC. La prevención primaria se debe determinar por la etiología subyacente y la presencia de factores de riesgo de MSC establecidos.

\subsection{Otras miocardiopatías}

\subsubsection{Ventrículo izquierdo no compactado}

No compactado se refiere a la presencia de trabeculaciones ventriculares prominentes y cavidades intertrabeculares profundas en el ventrículo izquierdo o derecho, que con frecuencia se asocian a una fina capa miocárdica epicárdica compactada ${ }^{422}$. En algunos pacientes, la ausencia de compactación se asocia a dilatación y disfunción sistólica ventriculares. El VI no compactado se produce en asociación con trastornos cardiacos congénitos y aisladamente. La enfermedad familiar se produce en un $18-50 \%$ de los adultos con VI no compactado aislado, en su mayor parte con un patrón de herencia autosómico dominante. Se describen numerosas mutaciones en los genes codificantes de las proteínas del sarcómero y manipuladoras del calcio y en otros genes relacionados con miocardiopatía como $L M N A, L D B 3$ y Taffazin ${ }^{423}$.

Muchos pacientes con VI no compactado son completamente asintomáticos, pero algunos se presentan con IC, tromboembolia, arritmias o MSC. La mayor edad, el diámetro telediastólico del VI en el momento de la presentación, la IC sintomática, la FA permanente o persistente, los bloqueos de rama y la enfermedad neuromuscular asociada son factores descritos como predictivos de aumento de la mortalidad, pero hay pocos datos que indiquen que el VI no compactado por sí solo sea una indicación de DAI ${ }^{422-425}$. La necesidad de DAI debe estar guiada por la gravedad de la disfunción sistólica del VI y la presencia de arritmias ventriculares sostenidas usando los mismos criterios que para la MCD (véase la sección 7.1).

\subsubsection{Miocardiopatía chagásica}

La enfermedad de Chagas es una enfermedad miocárdica causada por el parásito Trypanosoma cruzi. Se calcula que actualmente en todo el mundo 8-10 millones de personas están infectadas y que un 20-40\% desarrollará enfermedad miocárdica crónica, a veces muchas décadas después de la infección inicial. Anormalidades en el sistema de con-
Miocardiopatía chagásica

\begin{tabular}{lccc}
\hline Recomendaciones & Clase $^{\mathrm{a}}$ & Nivel $^{\mathrm{b}}$ & Ref $^{\mathrm{c}}$ \\
\hline $\begin{array}{l}\text { Se debe considerar el DAI para pacientes con } \\
\text { miocardiopatía chagásica, FEVI < 40\% y esperanza } \\
\text { de vida con buen estado funcional > } 1 \text { año }\end{array}$ & Ila & C & $426-430$ \\
\hline
\end{tabular}

DAI: desfibrilador automático implantable; FEVI: fracción de eyección del ventrículo izquierdo.

aClase de recomendación.

bNivel de evidencia.

'Referencias que respaldan las recomendaciones.

ducción, incluidos el BRDH y el bloqueo fascicular anterior izquierdo, con frecuencia son las primeras manifestaciones, seguidas de anormalidades en el movimiento segmentario de la pared del VI, arritmias ventriculares complejas, disfunción del nódulo sinusal y anormalidades de la conducción más avanzadas. En los estadios posteriores de la enfermedad, se producen dilatación y disfunción sistólica del VI progresivas ${ }^{426-430}$.

Las tasas registradas de mortalidad anual de pacientes con enfermedad de Chagas varían del 0,2 al 19,2\%, lo que refleja las características de las diferentes poblaciones de estudio. Los factores independientes de predicción de muerte más consistentes son la disfunción del VI, la clase funcional de la NYHA y la TVNS. El riesgo asociado a la combinación de TVNS y disfunción del VI puede ser hasta 15 veces mayor.

Principalmente gracias al estudio de Gali et al $^{430}$, que examinó el efecto del DAI en pacientes con enfermedad de Chagas, se ha obtenido evidencia de que el mayor beneficio se produce en pacientes con FEVI $<40 \%$, aunque la mayoría de los pacientes con DAI recibieron terapias apropiadas independientemente de su función sistólica del VI.

\section{SÍNDROMES ARRÍTMICOS HEREDITARIOS}

\subsection{Síndrome de QT largo}

\subsubsection{Definiciones y epidemiología}

Diagnóstico del síndrome del QT largo (en ausencia de causas secundarias de prolongación del QT)

\begin{tabular}{|c|c|c|c|}
\hline Recomendaciones & Clase $^{\mathrm{a}}$ & Nivel $^{\mathrm{b}}$ & $\operatorname{Ref}^{c}$ \\
\hline $\begin{array}{l}\text { Se diagnostica SQTL con } \\
\text { - QTc } \geq 480 \text { ms en ECG de } 12 \text { derivaciones } \\
\text { repetidos o } \\
\text { - Puntuación de riesgo de } \mathrm{SQTL}>3^{431}\end{array}$ & I & C & $\begin{array}{c}\text { Este } \\
\text { panel de } \\
\text { expertos }\end{array}$ \\
\hline $\begin{array}{l}\text { Se diagnostica SQTL en presencia de una } \\
\text { mutación en SQTL patogénica confirmada, } \\
\text { independientemente de la duración del QT }\end{array}$ & I & C & $\begin{array}{c}\text { Este } \\
\text { panel de } \\
\text { expertos }\end{array}$ \\
\hline $\begin{array}{l}\text { Se debe considerar el diagnóstico del SQTL por } \\
\text { ECG en presencia de un QTc } \geq 460 \text { ms en ECG de } \\
12 \text { derivaciones repetidos de pacientes con un } \\
\text { evento de síncope inexplicable en ausencia de } \\
\text { causas secundarias de prolongación del QT }\end{array}$ & Ila & C & $\begin{array}{c}\text { Este } \\
\text { panel de } \\
\text { expertos }\end{array}$ \\
\hline
\end{tabular}

ECG: electrocardiograma; OTc: OT corregido; SOTL: síndrome del OT largo.

aClase de recomendación.

bNivel de evidencia.

'Referencias que respaldan las recomendaciones.

Este panel ha modificado los criterios diagnósticos de SQTL propuestos en el documento de consenso de la EHRA/Heart Rhythm Society ${ }^{14}$. Concretamente, se pensó que un QTc > $500 \mathrm{~ms}$-umbral propuesto para el diagnóstico de SQTL en pacientes asintomáticos sin 
historia familiar de la enfermedad- es muy conservador e idéntico a la duración del QT asociada a alto riesgo de eventos arrítmicos en la MSC ${ }^{1,67}$. Por consiguiente, hemos utilizado un QT corregido (QTc) $\geq 480 \mathrm{~ms}$ o una puntuación $>3^{431}$ para el diagnóstico clínico. En presencia de síncope inexplicable, sin embargo, un QTc $\geq 460 \mathrm{~ms}$ es suficiente para hacer un diagnóstico.

El SQTL se caracteriza por un intervalo QT prolongado y arritmias ventriculares desencadenadas principalmente por activación adrenérgica. La media de edad a la presentación es 14 años. Se estima que la tasa anual de MSC de pacientes con SQTL no tratado es de entre el 0,3367 y el $0,9 \% 432$, mientras que para el síncope se estima en un $\sim 5 \%$.

Se han asociado al SQTL mutaciones en trece genes, la mayoría codificantes de subunidades de canales iónicos de potasio, sodio o calcio dependientes de voltaje. El cribado genético identifica una mutación causante de enfermedad en un 75\% de los casos de SQTL y 3 genes principales (KCNQ1, KCNH2 y SCN5A) dan cuenta del $90 \%$ de los casos con genotipo positivo ${ }^{52}$.

Se puede agrupar los subtipos de SQTL en las 3 categorías siguientes:

- SQTL autosómico dominante (síndrome de Romano-Ward; prevalencia, 1/2.500), que incluye LQT1-6 y LQT9-13 y se caracteriza por una prolongación aislada del intervalo QT.

- SQTL autosómico dominante con manifestación extracardiaca, que comprende:

- LQT7 (síndrome de Andersen-Tawil), que muestra un intervalo QT largo con onda U prominente, TV polimórfica o bidireccional, dismorfismos faciales y parálisis periódica hiperpotasémica/ hipopotasémica ${ }^{433}$.

- LQT8 (síndrome de Timothy), caracterizado por QT largo, sindactilia, malformaciones cardiacas, trastorno del espectro del autismo y dismorfismos.

- SQTL autosómico recesivo (síndrome de Jervell y Lange-Nielsen), que combina un intervalo QT extremadamente largo con sordera congénita.

\subsubsection{Enfoque de la estratificación de riesgos y del tratamiento}

Estratificación de riesgo y tratamiento en el síndrome del QT largo

\begin{tabular}{|c|c|c|c|}
\hline Recomendaciones & Clase $^{\mathrm{a}}$ & Nivel $^{\mathrm{b}}$ & $\operatorname{Ref}^{c}$ \\
\hline $\begin{array}{l}\text { Se recomiendan los siguientes cambios en el estilo } \\
\text { de vida para todo paciente con diagnóstico de SQTL: } \\
\text { - Evitar fármacos que prolongan el QT (http:// } \\
\text { www.crediblemeds.org) } \\
\text { - Corregir las alteraciones electrolíticas } \\
\text { (hipopotasemia, hipomagnesemia, hipocalcemia) } \\
\text { que pueden producirse por diarreas, vómitos } \\
\text { o afecciones metabólicas } \\
\text { - Evitar desencadenantes de arritmias específicos } \\
\text { en cuanto a genotipo (natación extenuante, } \\
\text { especialmente en el SQTL1, y a los pacientes } \\
\text { con SQTL2, la exposición a ruidos fuertes) }\end{array}$ & I & B & 434 \\
\hline $\begin{array}{l}\text { Se recomiendan los bloqueadores beta para } \\
\text { pacientes con diagnóstico clínico de SQTL }\end{array}$ & I & B & 435 \\
\hline $\begin{array}{l}\text { Se recomienda implante de DAI más bloqueadores } \\
\text { beta para pacientes con SQTL y parada cardiaca } \\
\text { previa }\end{array}$ & I & B & $436-438$ \\
\hline $\begin{array}{l}\text { Se debe considerar los bloqueadores beta para } \\
\text { portadores de una mutación en SQTL que cause el } \\
\text { síndrome e intervalo QT normal }\end{array}$ & IIa & B & 67 \\
\hline $\begin{array}{l}\text { Se debe considerar implante de DAI además de } \\
\text { bloqueadores beta para pacientes con SQTL que } \\
\text { hayan sufrido síncope y/o TV mientras recibían la } \\
\text { dosis de bloqueadores beta adecuada }\end{array}$ & IIa & B & 439 \\
\hline
\end{tabular}

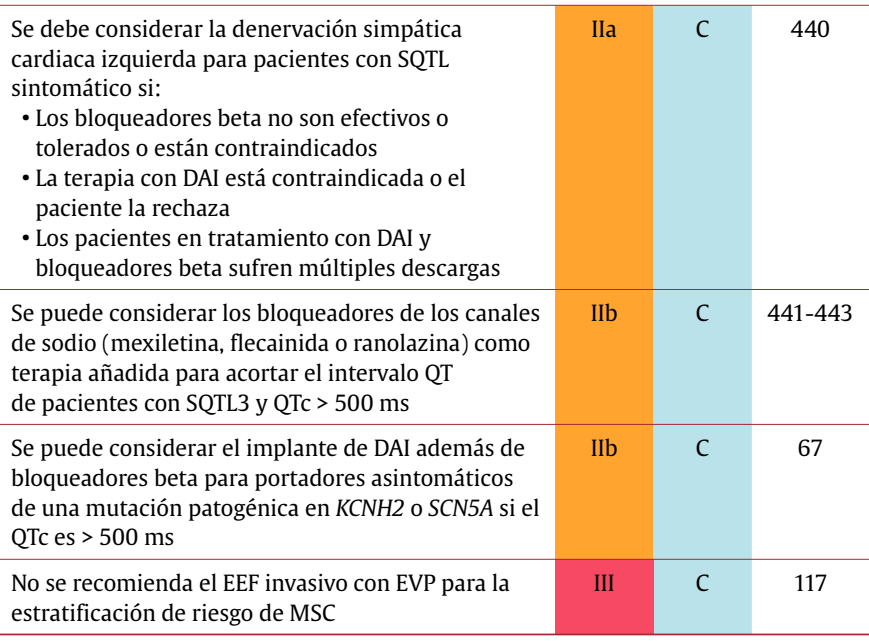

DAI: desfibrilador automático implantable; EEF: estudio electrofisiológico; EVP: estimulación ventricular programada; MSC: muerte súbita cardiaca; QTc: QT corregido; SQTL: síndrome del QT largo; SQTL1: SQTL tipo 1; SQTL2: SQTL tipo 2; SQTL3: SQTL tipo 3; TV: taquicardia ventricular.

${ }^{\mathrm{a} C l a s e}$ de recomendación.

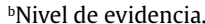

'Referencias que respaldan las recomendaciones.

Habría que considerar parámetros clínicos, electrocardiográficos y genéticos para la estratificación del riesgo individual ${ }^{67}$. Los supervivientes a una parada cardiaca tienen alto riesgo de recurrencia, incluso tomando bloqueadores beta (el 14\% en 5 años de terapia): esta evidencia respalda el uso de DAI en supervivientes a parada cardiaca ${ }^{436}$. La aparición de eventos sincopales se asocia a mayor riesgo de parada cardiaca ${ }^{439,444}$. Las mujeres con SQTL tienen mayor riesgo durante un periodo posparto de 9 meses (especialmente mujeres con el genotipo LQT2 $)^{445}$. En pacientes con LQT1 y LQT2, la localización y el tipo de mutación pueden ir asociados a diferentes riesgos de eventos cardiacos. Sin embargo, estos hallazgos requieren más estudio antes de aplicarlos a la práctica clínica ${ }^{14}$. Los portadores silentes de mutaciones patogénicas tienen un riesgo de eventos cardiacos moderado, que se estima en un $10 \%$ entre el nacimiento y los 40 años de edad; se debe considerar el uso de bloqueadores beta para este grupo de pacientes $^{446}$.

Se puede considerar individualizadamente terapia profiláctica con DAI para pacientes de alto riesgo, como mujeres con LQT2 y QTc $>500 \mathrm{~ms}$, pacientes con QTc $>500 \mathrm{~ms}$ y signos de inestabilidad eléctrica y pacientes con perfiles genéticos de alto riesgo (portadores de 2 mutaciones, incluido el síndrome de Jervell y Lange-Nielsen o el síndrome de Timothy).

No hay datos que respalden valor pronóstico alguno del EEF invasivo con EVP en pacientes con SQTL ${ }^{117}$.

\subsection{Síndrome de QT corto}

\subsubsection{Definiciones y epidemiología}

El SQTC se caracteriza por una duración reducida de la repolarización cardiaca, que constituye el sustrato para el desarrollo de arritmias potencialmente mortales. Cinco genes se han ligado al SQTC (KCNH2, KCNQ1, KCNJ2, CACNA1C y CACNB2b), pero el rendimiento del rastreo genético sigue siendo bajo (un $20 \%$ en total) ${ }^{119}$.

La enfermedad parece ser muy mortal en todos los grupos de edad, incluidos los niños en sus primeros meses de vida, y la probabilidad de una primera parada cardiaca hacia los 40 años es $>40 \% 119,447$. Dado el pequeño tamaño de las poblaciones estudiadas hasta ahora, la elevada mortalidad puede reflejar parcialmente un sesgo de la informa- 
Diagnóstico del síndrome del QT corto

\begin{tabular}{lcccc}
\hline Recomendaciones & Clase $^{\mathrm{a}}$ & Nivel $^{\mathrm{b}}$ & Ref $^{\mathrm{c}}$ \\
\hline Se diagnostica SQTC en presencia de QTc $\leq 340 \mathrm{~ms}$ & I & C & $\begin{array}{c}\text { Este } \\
\text { panel de } \\
\text { expertos }\end{array}$ \\
\hline $\begin{array}{l}\text { Se debe considerar SQTC en presencia de QTc } \\
\leq 360 \text { ms y uno o más de los siguientes: }\end{array}$ & Ila & C & $\begin{array}{c}\text { Este } \\
\text { panel de } \\
\text { expertos }\end{array}$ \\
- Una mutación patogénica confirmada & & & \\
- Historia familiar de SQTC & & & \\
- Historia familiar de muerte súbita a edad \\
$\quad$ < 40 años \\
- Supervivencia a un episodio de TV/FV \\
en ausencia de enfermedad cardiaca
\end{tabular}

FV: fibrilación ventricular; QTc: QT corregido; SQTC: síndrome del QT corto; TV: taquicardia ventricular.

aClase de recomendación.

Nivel de evidencia.

'Referencias que respaldan las recomendaciones.

ción relacionado con la infradetección de SQTC en pacientes asintomáticos.

\subsubsection{Enfoque de la estratificación de riesgo y del tratamiento}

Estratificación de riesgos y tratamiento en el síndrome del QT corto

\begin{tabular}{lccc}
\hline Recomendaciones & Clase $^{\mathrm{a}}$ & Nivel $^{\mathrm{b}}$ & Ref $^{\mathrm{c}}$ \\
\hline $\begin{array}{l}\text { Se recomienda implante de DAI para pacientes } \\
\text { con diagnóstico de SQTC: } \\
\text { - Supervivientes a una parada cardiaca abortada } \\
\text { - Con TV sostenida espontánea documentada }\end{array}$ & I & C & 119,447 \\
\hline $\begin{array}{l}\text { Se puede considerar quinidina o sotalol para } \\
\text { pacientes con diagnóstico de SQTC cualificados para } \\
\text { DAI pero que lo tienen contraindicado o lo rechazan }\end{array}$ & IIb & C & 118,448 \\
\hline $\begin{array}{l}\text { Se puede considerar quinidina o sotalol para } \\
\text { pacientes asintomáticos con diagnóstico de SQTC } \\
\text { e historia familiar de MSC }\end{array}$ & IIb & C & \multirow{2}{*}{118,448} \\
\hline $\begin{array}{l}\text { No se recomienda el EEF invasivo con EVP para la } \\
\text { estratificación de riesgo de MSC }\end{array}$ & III & C & \multirow{2}{*}{118,119} \\
\hline
\end{tabular}

DAI: desfibrilador automático implantable; EEF: estudio electrofisiológico; EVP: estimulación ventricular programada; MSC: muerte súbita cardiaca; SQTC: síndrome del QT corto.

${ }^{a}$ Clase de recomendación.

${ }^{b}$ Nivel de evidencia.

'Referencias que respaldan las recomendaciones.

Los pacientes con SQTC que sobreviven a una parada cardiaca previa deberían recibir un DAI para prevención secundaria, ya que la tasa de recurrencias de parada cardiaca se ha estimado en un $10 \%$ al año ${ }^{119}$.

La estrategia óptima para la prevención primaria de la parada cardiaca en el SQTC no está clara, dada la falta de factores independientes de riesgo de parada cardiaca, como el síncope ${ }^{119}$. No se dispone de datos para cuantificar el riesgo de episodios arrítmicos durante la actividad física de competición en pacientes con SQTC.

Se podría considerar individualizadamente el DAI para pacientes con SQTC y firme historia familiar de MSC y algunos otros con evidencia de QTc acortado, pero no hay datos suficientes para hacer recomendaciones generalizadas ${ }^{14}$

Los informes sobre pequeñas cohortes de pacientes parecen indicar que la terapia con quinidina puede prolongar el intervalo QTc y posiblemente reducir los episodios arrítmicos. Los pacientes en tratamiento con quinidina deben ser cuidadosamente monitorizados en cuanto a prolongación del QT y posibles episodios proarrítmicos ${ }^{118,448}$.
Se puede considerar el uso de quinidina para supervivientes a parada cardiaca que estén en condiciones para recibir un DAI pero tengan una contraindicación a este o lo rechacen ${ }^{118,448}$.

Hasta ahora, no hay datos que respalden el papel de la EVP para predecir episodios arrítmicos.

\subsection{Síndrome de Brugada}

\subsubsection{Definiciones y epidemiología}

Diagnóstico del síndrome de Brugada
\begin{tabular}{llccc}
\hline Recomendaciones & Clase $^{\mathrm{a}}$ & Nivel $^{\mathrm{b}}$ & Ref $^{\mathrm{c}}$ \\
\hline $\begin{array}{l}\text { Se diagnostica síndrome de Brugada a pacientes } \\
\text { con elevación del segmento ST con morfología de } \\
\text { tipo } 1 \geq 2 \text { mm en una o más derivaciones entre las } \\
\text { precordiales derechas V1 y V2, posicionadas en el } \\
\text { segundo, el tercer o el cuarto espacio intercostal, } \\
\text { que se produce espontáneamente o después de } \\
\text { una prueba de provocación con fármacos con } \\
\text { administración intravenosa de bloqueadores de } \\
\text { los canales de sodio (como ajmalina, flecainida, } \\
\text { procainamida o pilsicainida) }\end{array}$ & & & & \\
\end{tabular}

Clase de recomendación

bNivel de evidencia.

'Referencias que respaldan las recomendaciones.

La prevalencia del síndrome de Brugada parece ser mayor en el sudeste asiático que en los países occidentales; la prevalencia varía de $1 / 1.000$ a $1 / 10.000^{449}$.

El síndrome de Brugada se hereda como un rasgo dominante y muestra una penetrancia relacionada con la edad y el sexo: las manifestaciones clínicas de la enfermedad son más frecuentes en adultos y son 8 veces más frecuentes en varones que en mujeres ${ }^{450}$. Se produce FV a una media de edad de $41 \pm 15$ años, pero puede manifestarse a cualquier edad, normalmente durante el reposo o el sueño ${ }^{451}$. La fiebre, el consumo excesivo de alcohol y las comidas copiosas son desencadenantes que desenmascaran un patrón de ECG de tipo I y predisponen a la FV.

En un reciente metanálisis, la incidencia anual de episodios arrítmicos (TV sostenida o FV o terapia apropiada del DAI o muerte súbita) en pacientes con síndrome de Brugada era del 13,5\% de los sujetos con antecedente de parada cardiaca súbita, el 3,2\% de los pacientes con síncope y el $1 \%$ de los asintomáticos ${ }^{452}$.

Al menos 12 genes se han asociado al síndrome de Brugada, pero solo 2 (SCN5A y CACN1AC) dan cuenta individualmente de más del $5 \%$ de los pacientes con genotipo positivo ${ }^{52}$. Los resultados del rastreo genético no influyen actualmente en el pronóstico o el tratamiento.

\subsubsection{Enfoque de la estratificación de riesgo y del tratamiento}

El único tratamiento capaz de reducir el riesgo de MSC en el síndrome de Brugada es el DAI, por lo que se recomienda para pacientes con TV o FV documentada o que se presenten con un ECG espontáneo de tipo 1 y antecedente de síncope ${ }^{14,451}$. Se ha debatido el valor pronóstico de la EVP y la mayoría de los estudios clínicos no han confirmado su valor predictivo, ya sea positivo o negativo, de eventos cardiacos en el seguimiento ${ }^{14,456}$. Se ha propuesto la quinidina como terapia preventiva para pacientes con síndrome de Brugada, con base en datos que muestran que reduce la inducibilidad de FV durante la EVP; sin embargo, no hay datos que confirmen su capacidad para reducir el riesgo de MSC. Recientemente, se ha señalado que la ablación con catéter epicárdica sobre el TSVD anterior puede prevenir las tormentas eléctricas en pacientes con episodios recurrentes, pero los 
Estratificación de riesgo y tratamiento en el síndrome de Brugada

\begin{tabular}{|c|c|c|c|}
\hline Recomendaciones & Clase $^{\mathrm{a}}$ & Nivel $^{\mathrm{b}}$ & $\operatorname{Ref}^{c}$ \\
\hline $\begin{array}{l}\text { Se recomiendan los siguientes cambios en el estilo } \\
\text { de vida a todos los pacientes con diagnóstico } \\
\text { de síndrome de Brugada: } \\
\text { - Evitar fármacos que puedan inducir elevación } \\
\text { del segmento ST en las derivaciones precordiales } \\
\text { derechas (http://www.brugadadrugs.org) } \\
\text { - Evitar el consumo excesivo de alcohol y las } \\
\text { comidas copiosas } \\
\text { - Tratamiento inmediato de cualquier fiebre } \\
\text { con fármacos antipiréticos }\end{array}$ & I & C & $\begin{array}{l}\text { Este } \\
\text { panel de } \\
\text { expertos }\end{array}$ \\
\hline $\begin{array}{l}\text { Se recomienda implante de DAI para pacientes } \\
\text { con diagnóstico de síndrome de Brugada: } \\
\text { - Supervivientes a una parada cardiaca abortada } \\
\text { y/o } \\
\text { - Con TV sostenida espontánea documentada }\end{array}$ & I & C & 451 \\
\hline $\begin{array}{l}\text { Se debe considerar el implante de DAI para } \\
\text { pacientes con un patrón de ECG de tipo I } \\
\text { espontáneo diagnóstico y antecedente de síncope }\end{array}$ & IIa & C & 451 \\
\hline $\begin{array}{l}\text { Se debe considerar quinidina o isoproterenol en } \\
\text { pacientes con síndrome de Brugada para tratar las } \\
\text { tormentas eléctricas }\end{array}$ & Ila & C & 453 \\
\hline $\begin{array}{l}\text { Se debe considerar la quinidina para pacientes } \\
\text { cualificados para un DAI pero que lo tienen } \\
\text { contraindicado, lo rechazan o requieren } \\
\text { tratamiento para arritmias supraventriculares }\end{array}$ & Ila & C & 454 \\
\hline $\begin{array}{l}\text { Se puede considerar implante de DAI para } \\
\text { pacientes con diagnóstico de síndrome de } \\
\text { Brugada que sufran FV durante la EVP con } 2 \text { o } 3 \\
\text { extraestímulos en } 2 \text { sitios }\end{array}$ & IIb & C & 120 \\
\hline $\begin{array}{l}\text { Se puede considerar la ablación con catéter para } \\
\text { pacientes con antecedente de tormentas eléctricas } \\
\text { o descargas repetidas del DAI }\end{array}$ & IIb & $\mathrm{C}$ & 201,455 \\
\hline
\end{tabular}

DAI: desfibrilador automático implantable; ECG: electrocardiograma; EVP: estimulación ventricular programada; FV: fibrilación ventricular; TV: taquicardia ventricular.

aClase de recomendación.

bNivel de evidencia.

'Referencias que respaldan las recomendaciones.

datos requieren confirmación antes de su introducción en la práctica clínica general ${ }^{455}$.

\subsection{Taquicardia ventricular polimórfica catecolaminérgica}

\subsubsection{Definiciones y epidemiología}

Diagnóstico de taquicardia ventricular polimórfica catecolaminérgica

\begin{tabular}{lccc}
\hline Recomendaciones & Clase $^{\mathrm{a}}$ & Nivel $^{\mathrm{b}}$ & Ref $^{\mathrm{c}}$ \\
\hline $\begin{array}{l}\text { Se diagnostica TVPC en presencia de un corazón } \\
\text { estructuralmente normal, ECG normal y TV } \\
\text { bidireccional o polimórfica inducida por ejercicio } \\
\text { o emociones }\end{array}$ & I & C & $\begin{array}{c}14,52, \\
457\end{array}$ \\
\hline $\begin{array}{l}\text { Se diagnostica TVPC a pacientes portadores de } \\
\text { mutación(es) patogénica(s) en los genes RyR2 } \\
\text { o CASQ2 }\end{array}$ & & & \\
\hline
\end{tabular}

ECG: electrocardiograma; TV: taquicardia ventricular; TVPC: TV polimórfica catecolaminérgica.

${ }^{a}$ Clase de recomendación.

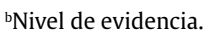

cReferencias que respaldan las recomendaciones.

La TVPC es un trastorno arritmogénico hereditario raro caracterizado por TV bidireccional y polimórfica de inducción adrenérgica. La enfermedad tiene una prevalencia estimada de $1 / 10.000^{14}$.
Se han identificado 2 tipos genéticos de TVPC: una variante dominante debida a mutaciones en el gen codificante del receptor de rianodina cardiaco (RyR2) y una variante recesiva rara causada por mutación en el gen de calsecuestrina cardiaca (CASQ2)52. Se han identificado mutaciones en otros genes, como KCNJ2, Ank2, TRDN y CALM1, en pacientes con características clínicas similares a la TVPC. Sin embargo, actualmente no está claro si son fenocopias de TVPC ${ }^{14}$.

Las manifestaciones clínicas de la TVPC aparecen normalmente en la primera década de la vida y se originan por la actividad física o el estrés emocional ${ }^{458}$. El diagnóstico supone un reto, ya que los pacientes con TVPC tienen ECG y ecocardiograma normales, por lo que se recomienda una prueba de estrés por ejercicio que provoque arritmias auriculares y ventriculares (TV bidireccional o polimórfica) para establecer el diagnóstico ${ }^{14}$. También se ha propuesto el uso de infusión de catecolaminas, pero su sensibilidad no está claramente definida ${ }^{14,459}$, por lo que no se ha establecido una recomendación sobre esta cuestión específica.

\subsubsection{Enfoque de la estratificación de riesgo y del tratamiento}

Estratificación de riesgo y tratamiento en la taquicardia ventricular polimórfica catecolaminérgica

\begin{tabular}{|c|c|c|c|}
\hline Recomendaciones & Clase $^{\mathrm{a}}$ & Nivel $^{\mathrm{b}}$ & $\operatorname{Ref}^{c}$ \\
\hline $\begin{array}{l}\text { Se recomiendan los siguientes cambios en el estilo } \\
\text { de vida a todos los pacientes con diagnóstico de } \\
\text { TVPC: evitar deportes de competición, ejercicio } \\
\text { extenuante y ambientes estresantes }\end{array}$ & I & C & $\begin{array}{c}\text { Este } \\
\text { panel de } \\
\text { expertos }\end{array}$ \\
\hline $\begin{array}{l}\text { Se recomiendan los bloqueadores beta para todo } \\
\text { paciente con diagnóstico clínico de TVPC por la } \\
\text { presencia de arritmias ventriculares espontáneas } \\
\text { o inducidas por estrés documentadas }\end{array}$ & I & C & 458,460 \\
\hline $\begin{array}{l}\text { Se recomienda implante de DAI además de } \\
\text { bloqueadores beta con o sin flecainida para } \\
\text { pacientes con diagnóstico de TVPC que sufren } \\
\text { parada cardiaca, síncope recurrente o TV } \\
\text { polimórfica/bidireccional a pesar de la terapia } \\
\text { óptima }\end{array}$ & I & C & 458,461 \\
\hline $\begin{array}{l}\text { Se debe considerar la terapia con bloqueadores } \\
\text { beta para familiares genéticamente positivos, } \\
\text { incluso tras una prueba de ejercicio negativa }\end{array}$ & IIa & C & 461,462 \\
\hline $\begin{array}{l}\text { Se debe considerar la flecainida además de } \\
\text { bloqueadores beta para pacientes con diagnóstico } \\
\text { de TVPC que sufren síncope recurrente o TV } \\
\text { polimórfica/bidireccional mientras están en } \\
\text { tratamiento con bloqueadores beta cuando el } \\
\text { DAI conlleve riesgos, esté contraindicado, no esté } \\
\text { disponible o el paciente lo rechace }\end{array}$ & IIa & C & 463 \\
\hline $\begin{array}{l}\text { Se debe considerar la flecainida además de } \\
\text { bloqueadores beta para pacientes con diagnóstico } \\
\text { de TVPC portadores de DAI para reducir las } \\
\text { descargas apropiadas }\end{array}$ & IIa & C & 463 \\
\hline $\begin{array}{l}\text { Se puede considerar la denervación simpática } \\
\text { cardiaca izquierda para pacientes con diagnóstico } \\
\text { de TVPC que sufran síncope recurrente o TV } \\
\text { polimórfica/bidireccional/varias descargas del } \\
\text { DAI apropiadas mientras están en tratamiento } \\
\text { con bloqueadores beta o bloqueadores beta más } \\
\text { flecainida y pacientes que no los toleran o los } \\
\text { tienen contraindicados }\end{array}$ & IIb & C & 464,465 \\
\hline $\begin{array}{l}\text { No se recomienda el EEF invasivo con EVP para la } \\
\text { estratificación del riesgo de MSC }\end{array}$ & III & C & 14 \\
\hline
\end{tabular}

DAI: desfibrilador automático implantable; EEF: estudio electrofisiológico; EVP: estimulación ventricular programada; MSC: muerte súbita cardiaca; TV: taquicardia ventricular; TVPC: taquicardia ventricular polimórfica catecolaminérgica.

${ }^{a}$ Clase de recomendación.

bNivel de evidencia.

'Referencias que respaldan las recomendaciones. 
El diagnóstico en la infancia, la falta de terapia con bloqueadores beta y la persistencia de arritmias complejas durante la prueba de estrés con ejercicio a la dosis total de bloqueadores beta son factores independientes predictivos de eventos arrítmicos ${ }^{461}$.

La mayoría de los centros de referencia tratan a los pacientes con nadolol pese a no disponerse de datos comparativos sobre diferentes tipos de bloqueadores beta.

La restricción del ejercicio y los bloqueadores beta sin actividad simpaticomimética intrínseca son la terapia de primera línea para pacientes con TVPC ${ }^{14}$.

Los datos preliminares dan a entender que la flecainida reduce significativamente la carga de arritmias ventriculares en un pequeño número de pacientes con TVPC, y se debería considerar como la primera adición a los bloqueadores beta cuando el control de las arritmias sea incompleto ${ }^{462,463}$. Parece que la denervación simpática cardiaca izquierda tiene algún grado de eficacia en el tratamiento de pacientes con TVPC que no toleran los bloqueadores beta, pero se necesitan más datos y un seguimiento más largo para cuantificar su eficacia ${ }^{464,465}$. Los supervivientes a una parada cardiaca deberían recibir bloqueadores beta y un DAI; también habría que considerar la flecainida si el control arrítmico en la prueba de estrés por ejercicio es incompleto ${ }^{14}$. También habría que considerar un DAI para pacientes con TVPC que no responden a los bloqueadores beta y a la flecainida ${ }^{14}$. Se debe programar el DAI con largos tiempos de detección antes de las descargas, ya que los choques dolorosos pueden aumentar el tono simpático y desencadenar más arritmias, que darían lugar a un ciclo maligno de choques del DAI e incluso la muerte ${ }^{466}$.

La EVP no tiene valor diagnóstico o pronóstico en la TVPC, ya que no se puede inducir TV bidireccional ni polimórfica ${ }^{14}$.

\subsection{Síndrome de repolarización precoz}

\subsubsection{Definiciones y epidemiología}

La presencia de un patrón de repolarización precoz en las derivaciones inferior o lateral se ha asociado a FV idiopática en estudios de casos y controles ${ }^{467,468}$. Debido a la gran incidencia del patrón de repolarización precoz en la población general, parece razonable diagnosticar "síndrome de repolarización precoz" solo a pacientes con un patrón y reanimados de un evento de FV idiopática o TV polimórfica documentado.

La genética de la repolarización precoz probablemente sea poligénica en muchos casos. No hay una evidencia clara de transmisión familiar del síndrome de repolarización precoz.

Dadas las incertidumbres en la interpretación del patrón de repolarización precoz como factor predictivo de MSC, este panel de expertos ha decidido que en este momento no hay suficiente evidencia para hacer recomendaciones sobre el tratamiento de esta afección.

\section{ARRITMIAS PEDIÁTRICAS Y ENFERMEDAD CARDIACA CONGÉNITA}

\subsection{Tratamiento de las arritmias ventriculares en niños con corazón estructuralmente normal}

En niños, pueden aparecer arritmias ventriculares en enfermedades cardiacas congénitas (ECC), canalopatías o miocardiopatías hereditarias, miocarditis y tumores cardiacos (rabdomiomas neonatales), así como en corazones estructuralmente normales. En niños por lo demás sanos, las EV monomórficas aisladas son muy comunes, particularmente en niños pequeños (20\%) y adolescentes (20-35\%), principalmente con origen en el TSVD. Cuando las EV se producen frecuentemente (un 5-10\% de todos los latidos) o son más complejas, se recomienda una evaluación cardiaca que incluya RMC y recogida de la historia familiar para excluir canalopatías o miocardiopatías hereditarias. Se recomienda hacer un seguimiento para identificar el
Tratamiento de las arritmias ventriculares en niños con corazón estructuralmente normal

\begin{tabular}{|c|c|c|c|}
\hline Recomendaciones & Clase $^{a}$ & Nivel $^{\mathrm{b}}$ & $\operatorname{Ref}^{c}$ \\
\hline $\begin{array}{l}\text { Se recomienda hacer un seguimiento de los niños } \\
\text { asintomáticos con EV aisladas frecuentes o un ritmo } \\
\text { ventricular acelerado y función ventricular normal } \\
\text { sin tratamiento }\end{array}$ & I & B & 469,470 \\
\hline $\begin{array}{l}\text { Se recomienda terapia médica o ablación con } \\
\text { catéter para niños con EV o TV frecuentes que se } \\
\text { considera causantes de disfunción ventricular }\end{array}$ & I & C & $\begin{array}{l}\text { Este } \\
\text { panel de } \\
\text { expertos }\end{array}$ \\
\hline $\begin{array}{l}\text { Se debe considerar la ablación con catéter cuando la } \\
\text { terapia médica no sea eficaz o deseable para niños } \\
\text { sintomáticos con TV del TSVD/EV idiopáticas o TV } \\
\text { fascicular izquierda sensible a verapamilo }\end{array}$ & IIa & B & $471-474$ \\
\hline $\begin{array}{l}\text { Para niños sintomáticos con extrasístoles } \\
\text { ventriculares o TV con origen en TSVI idiopático, } \\
\text { cúspides aórticas o en epicardio, se debe considerar } \\
\text { la ablación con catéter por personal experimentado } \\
\text { tras fracaso de la terapia médica } \\
\text { o como alternativa a la terapia médica crónica }\end{array}$ & IIa & B & 473,474 \\
\hline $\begin{array}{l}\text { Se debe considerar los bloqueadores de los canales } \\
\text { de sodio (agentes de clase IC) como alternativa a los } \\
\text { bloqueadores beta o el verapamilo para niños } \\
\text { con TV del tracto de salida }\end{array}$ & IIa & C & 471 \\
\hline $\begin{array}{l}\text { No se recomienda la ablación con catéter para niños } \\
\text { menores de } 5 \text { años excepto cuando haya fallado la } \\
\text { terapia médica previa o hemodinámicamente no se } \\
\text { tolere la TV }\end{array}$ & III & B & 475 \\
\hline $\begin{array}{l}\text { No se recomienda el uso de verapamilo para niños } \\
\text { menores de } 1 \text { año }\end{array}$ & III & C & 476 \\
\hline
\end{tabular}

EV: extrasístole ventricular; TSVD: tracto de salida del ventrículo derecho; TSVI: tracto de salida del ventrículo izquierdo; TV: taquicardia ventricular.

${ }^{a}$ Clase de recomendación.

bNivel de evidencia.

cReferencias que respaldan las recomendaciones.

desarrollo de disfunción del VI, TV (no) sostenida o miocardiopatías, que apenas se producen. El tratamiento médico o la ablación con catéter raramente están indicados, ya que la mayoría de los niños permanecen asintomáticos y las EV a menudo se resuelven con el tiempo ${ }^{469,470,477-480}$. Se puede encontrar ritmo idioventricular acelerado en recién nacidos y niños pequeños por lo demás sanos, normalmente como hallazgo casual. Se trata de una arritmia benigna y, de modo similar a las EV en niños, generalmente desaparece sin tratamiento en el primer año de vida ${ }^{481}$. La incidencia de TV sostenida descrita en la población pediátrica general es de 1/100.000 niños en 10 años. La prevalencia de TVNS y sostenida también es baja, de 2-8/100.000 niños en edad escolar ${ }^{482,483}$.

La mayoría de las TV idiopáticas se presentan primeramente en niños de más edad y adolescentes, con origen en sitios similares a los de los adultos (TSVD, TSVI o cúspides aórticas). La TV fascicular izquierda sensible al verapamilo es menos común ${ }^{471-474}$. La TV incesante, que se origina comúnmente en el VI, se asocia a hamartomas intracardiacos en la infancia. Estas taquicardias con frecuencia dan lugar a IC y tienen una mortalidad significativa a pesar de una terapia agresiva con fármacos, ablación con catéter e incluso tratamiento quirúrgico ${ }^{484}$. La TV polimórfica o la EV multiforme se producen poco frecuentemente en niños con corazones normales y normalmente se asocian a canalopatías o miocardiopatías hereditarias, enfermedad cardiaca estructural o inflamatoria o anormalidades metabólicas o toxicológicas.

En niños mayores, las recomendaciones relativas al tratamiento de las TV idiopáticas son similares a las de los adultos. En niños pequeños, los estudios sobre la eficacia y la seguridad del tratamiento con fármacos de las TV idiopáticas se limitan principalmente a bloqueadores beta y verapamilo, y se dispone de menos datos sobre bloqueadores de los canales de sodio (clase IC) y fármacos de clase III ${ }^{471,472}$. En 
niños menores de 1 año, se debe evitar el verapamilo (i.v.), ya que puede dar lugar a deterioro hemodinámico agudo ${ }^{476}$.

En niños pequeños, las tasas de complicaciones de la ablación con catéter parecen ser superiores y preocupa el aumento de lesiones por radiofrecuencia y crioenergía en el miocardio ventricular ${ }^{475,485-487}$. Las TV idiopáticas y la EV compleja en niños tienden a resolverse espontáneamente en un periodo de meses a años ${ }^{471}$. Por lo tanto, en este grupo de edad, la ablación con catéter, incluida la ablación de TV en TSVD, solo está indicada como terapia de segunda línea y se debe realizar en centros experimentados.

\subsection{Muerte súbita cardiaca y arritmias ventriculares en pacientes con enfermedad cardiaca congénita}

La ECC es el defecto más común al nacimiento, con una incidencia de 700-800/100.000 nacidos vivos ${ }^{499}$. Los pacientes con ECC representan un grupo heterogéneo cuya esperanza de vida ha mejorado espectacularmente tras los avances conseguidos en las técnicas de diagnóstico y quirúrgicas. La mayoría de los pacientes con ECC vivirán hasta la edad adulta ${ }^{500}$. A pesar de estos logros, la reparación de la ECC en la infancia frecuentemente se sigue de IC y arritmias que pueden causar muerte cardiaca tardía al adulto joven.

La incidencia de MSC en la población total con ECC es baja (el 0,09\% al año), pero es mayor que en controles de edad equiparable ${ }^{501}$. El riesgo de MSC es dependiente del tiempo y aumenta progresivamente tras la segunda década de vida. Hasta ahora, no se han realizado ensayos clínicos aleatorizados para delinear los factores de riesgo de MSC o el beneficio de las terapias de prevención primaria. Estudios retrospectivos han demostrado que la MSC representa un 14-26\% de todas las muertes tras la reparación inicial ${ }^{497,501-503}$. En un amplio estudio de adultos con una gama de ECC, se produjo un $14 \%$ de MSC relacionadas con arritmias. La MSC se producía mayoritariamente en reposo y no se limitó a pacientes con defectos graves. En este estudio, los factores de riesgo de MSC eran similares a los de la miocardiopatía isquémica, incluidas taquicardia supraventricular, disfunción ventricular sistémica o pulmonar y duración prolongada del $\mathrm{QRS}^{497}$.

Los defectos cardiacos congénitos con mayor riesgo de MSC son la tetralogía de Fallot, la transposición (congénitamente corregida) de las grandes arterias, las lesiones por obstrucción del corazón izquierdo y los corazones univentriculares ${ }^{497,501-503}$. La mayoría de los estudios sobre valoración de riesgos se han realizado en pacientes con tetralogía de Fallot, que muestran un riesgo de MSC del 2-3\% por década, que aumenta tardíamente tras corrección quirúrgica ${ }^{495,501,504}$. Aunque se han identificado muchos, los más potentes factores de riesgo de MSC son una duración del QRS > $180 \mathrm{~ms}$, la sobrecarga de volumen del VD, la disfunción del VI o la TV sostenida clínica o inducible ${ }^{494-496}$. Se ha indicado que la EVP es útil para la estratificación de riesgo ${ }^{496}$. Estudios retrospectivos sobre la terapia con DAI en la tetralogía de Fallot han señalado altas tasas de descargas apropiadas, de un 8-10\% al año en prevención primaria y secundaria ${ }^{488}$.

Para los pacientes con transposición de las grandes arterias tras la operación de desviación auricular (Mustard o Senning), el riesgo de MSC es de un $\sim 5 \%$ por década ${ }^{501,505}$. La presencia de taquiarritmia auricular e insuficiencia sistémica del VD es un factor de riesgo de MSC importante ${ }^{498}$. Son mecanismos subyacentes a la MSC la taquiarritmia auricular con conducción AV 1:1 rápida con deterioro a FV, así como las arritmias ventriculares primarias. Actualmente, la ablación con catéter de la taquicardia auricular es una terapia efectiva y relevante para reducir el riesgo de MSC en este grupo de pacientes. La EVP no parece útil para la estratificación de riesgo general. El DAI para la prevención secundaria parece ser efectivo, mientras que el DAI en prevención primaria para pacientes con disfunción ventricular parece ser menos útil, con una tasa de choques del $0,5 \%$ al año ${ }^{489}$. Actualmente no se usa la desviación auricular; por consiguiente, esta población de pacientes está decreciendo gradualmente.
Prevención de la muerte súbita cardiaca y tratamiento de las arritmias ventriculares de pacientes con enfermedad cardiaca congénita

\begin{tabular}{|c|c|c|c|}
\hline Recomendaciones & Clase $^{\mathrm{a}}$ & Nivel $^{\mathrm{b}}$ & $\operatorname{Ref}^{c}$ \\
\hline $\begin{array}{l}\text { Tras evaluación para definir la causa del suceso y } \\
\text { excluir cualquier causa reversible, se recomienda } \\
\text { implante de DAI para pacientes con ECC } \\
\text { supervivientes a una parada cardiaca abortada }\end{array}$ & I & B & $488-491$ \\
\hline $\begin{array}{l}\text { Se recomienda implante de DAI para pacientes con } \\
\text { ECC y TV sostenida sintomática ya sometidos a } \\
\text { evaluación hemodinámica y electrofisiológica }\end{array}$ & I & B & $488-492$ \\
\hline $\begin{array}{l}\text { Se recomienda la ablación con catéter como terapia } \\
\text { adicional o alternativa al DAI para pacientes } \\
\text { con ECC que tienen TV monomórfica recurrente } \\
\text { o terapias del DAI apropiadas no manejables } \\
\text { por reprogramación del dispositivo o terapia } \\
\text { con fármacos }\end{array}$ & I & C & 492 \\
\hline $\begin{array}{l}\text { Se recomienda terapia con DAI para adultos con } \\
\text { ECC y FEVI sistémica }<35 \% \text {, fisiología biventricular, } \\
\text { IC sintomática a pesar de un tratamiento médico } \\
\text { óptimo y NYHA II-III }\end{array}$ & I & C & 493,494 \\
\hline $\begin{array}{l}\text { Se debe considerar el implante de DAI para } \\
\text { pacientes con ECC y síncope de origen desconocido } \\
\text { en presencia de disfunción ventricular avanzada, } \\
\text { TV sostenida o FV inducible en la EVP }\end{array}$ & IIa & B & $\begin{array}{c}488,490 \\
491\end{array}$ \\
\hline $\begin{array}{l}\text { Se debe considerar el implante de DAI para } \\
\text { pacientes seleccionados con tetralogía de Fallot } \\
\text { y múltiples factores de riesgo de MSC, entre ellos } \\
\text { disfunción del VI, TV no sostenida, QRS > } 180 \mathrm{~ms} \\
\text { o TV sostenida inducible en la EVP }\end{array}$ & IIa & B & $\begin{array}{c}488 \\
494-496\end{array}$ \\
\hline $\begin{array}{l}\text { Se debe considerar la ablación con catéter como } \\
\text { alternativa a la terapia con fármacos para la TV } \\
\text { monomórfica sostenida sintomática de pacientes } \\
\text { con ECC y DAI }\end{array}$ & IIa & B & 492 \\
\hline $\begin{array}{l}\text { Se puede considerar la terapia con DAI para } \\
\text { pacientes con disfunción simple o sistémica del VD } \\
\text { avanzada en presencia de otros factores de riesgo, } \\
\text { como TV no sostenida, NYHA II-III o regurgitación } \\
\text { de válvulas auriculoventriculares sistémica grave }\end{array}$ & IIb & B & $\begin{array}{c}489,497 \\
498\end{array}$ \\
\hline $\begin{array}{l}\text { Se puede considerar la EVP para la estratificación } \\
\text { de los riesgos de MSC para pacientes con tetralogía } \\
\text { de Fallot y uno o más factores de riesgo, entre ellos } \\
\text { disfunción del VI, TV no sostenida y QRS > } 180 \mathrm{~ms}\end{array}$ & IIb & B & 496 \\
\hline $\begin{array}{l}\text { Se puede considerar la EVP para pacientes con ECC } \\
\text { y TV no sostenida para determinar el riesgo de TV } \\
\text { sostenida }\end{array}$ & IIb & C & $\begin{array}{c}\text { Este } \\
\text { panel de } \\
\text { expertos }\end{array}$ \\
\hline $\begin{array}{l}\text { Se puede considerar la ablación quirúrgica guiada } \\
\text { por mapeo electrofisiológico para pacientes con } \\
\text { ECC sometidos a cirugía cardiaca, con TV sostenida } \\
\text { clínica y con TV monomórfica sostenida inducible } \\
\text { con istmo crítico identificado }\end{array}$ & IIb & C & $\begin{array}{c}\text { Este } \\
\text { panel de } \\
\text { expertos }\end{array}$ \\
\hline $\begin{array}{l}\text { No se recomienda la ablación con catéter o la } \\
\text { terapia antiarrítmica profiláctica para la EV } \\
\text { infrecuente asintomática de pacientes con ECC } \\
\text { y función ventricular estable }\end{array}$ & III & C & $\begin{array}{c}\text { Este } \\
\text { panel de } \\
\text { expertos }\end{array}$ \\
\hline $\begin{array}{l}\text { No se recomienda la EVP para estratificar el riesgo } \\
\text { de pacientes con ECC en ausencia de otros factores } \\
\text { de riesgo o síntomas }\end{array}$ & III & B & 496 \\
\hline
\end{tabular}

DAI: desfibrilador automático implantable; ECC: enfermedad cardiaca congénita; EV: extrasístole ventricular; EVP: estimulación ventricular programada; FEVI: fracción de eyección del ventrículo izquierdo; FV: fibrilación ventricular; IC: insuficiencia cardiaca; MSC: muerte súbita cardiaca; NYHA: clase funcional de la New York Heart Association; TV: taquicardia ventricular; VD: ventrículo derecho; VI: ventrículo izquierdo.

aClase de recomendación.

${ }^{b}$ Nivel de evidencia.

'Referencias que respaldan las recomendaciones.

La adecuada reparación de la estenosis aórtica congénita (incluidas las válvulas bicúspides) reduce sustancialmente el riesgo natal de MSC, lo cual frecuentemente obvia la necesidad de terapia antiarrítmica específica ${ }^{501,506}$. 
En pacientes con corazones univentriculares tras la operación de Fontan, la morbilidad a largo plazo se caracteriza por taquicardia auricular compleja y aparición de IC, que aumenta progresivamente con la edad. La MSC relacionada con la arritmia no es rara en pacientes de Fontan, con una incidencia del $9 \%$ en un seguimiento medio de 12 años, pero aún no se han identificado factores de riesgo ${ }^{507}$. Los datos sobre la eficacia del DAI en pacientes de Fontan siguen siendo escasos.

En general, el DAI para pacientes con ECC ha cambiado de prevención secundaria a primaria en las últimas dos décadas ${ }^{490,491}$. Estudios de cohortes retrospectivos han mostrado que, además de arritmias ventriculares, la función ventricular alterada, ya sea izquierda o derecha, se ha convertido en firme factor de riesgo de MSC de pacientes con diferentes tipos de ECC ${ }^{493-495,497,498}$. Esto subraya la importancia de tratar eficazmente la disfunción ventricular mediante intervenciones quirúrgicas de defectos residuales, optimizar la medicación y, si es aplicable, TRC. En general, los pacientes con ECC y síncope o TV no sostenida deben pasar por evaluación hemodinámica y electrofisiológica. La EVP puede ser útil para identificar a pacientes en riesgo de MSC. Se debería considerar como alternativa, o además del DAI, la ablación con catéter y tratamiento quirúrgico para pacientes con TV sostenida recurrente tras reparación quirúrgica de la ECC ${ }^{492}$.

\subsection{Terapia con desfibrilador automático implantable en pacientes pediátricos}

Desfibrilador automático implantable en pacientes pediátricos

\begin{tabular}{lccc}
\hline Recomendaciones & Clase $^{\mathrm{a}}$ & Nivel $^{\mathrm{b}}$ & Ref $^{\mathrm{c}}$ \\
\hline $\begin{array}{l}\text { Se recomienda implante de DAI para pacientes } \\
\text { pediátricos supervivientes a parada cardiaca } \\
\text { en ausencia de causas reversibles }\end{array}$ & I & B & $\begin{array}{c}490,508, \\
509\end{array}$ \\
\hline $\begin{array}{l}\text { Se recomienda implante de DAI en combinación } \\
\text { con terapia médica para pacientes pediátricos de } \\
\text { alto riesgo con canalopatías, miocardiopatías o ECC } \\
\text { hereditarias }\end{array}$ & & & \\
\hline $\begin{array}{l}\text { Se debe considerar el estudio periódico del } \\
\text { umbral de desfibrilación de los sistemas de DAI } \\
\text { no transvenosos de niños pequeños durante el } \\
\text { crecimiento }\end{array}$ & Ila & C & 512 \\
\hline
\end{tabular}

DAI: desfibrilador automático implantable; ECC: enfermedad cardiaca congénita.

aClase de recomendación.

Nivel de evidencia.

Referencias que respaldan las recomendaciones.

La MSC es un fenómeno raro en pacientes pediátricos y el uso de DAI es, por lo tanto, poco común, con una tasa anual de implantes $<1$ / millón $^{508,513}$ en prevención primaria o secundaria ${ }^{490,509}$. Los pacientes pediátricos con riesgo de MSC forman un grupo heterogéneo con una amplia variedad de enfermedades cardiacas subyacentes, incluidas canalopatías o miocardiopatías hereditarias, y el amplio espectro de las ECC ${ }^{490,509}$. Las indicaciones actuales para el implante de DAI en adultos se aplican a pacientes pediátricos. La mayoría de las recomendaciones para enfermedades cardiacas relevantes para la población pediátrica tienen un nivel de evidencia $\mathrm{B}$ o $\mathrm{C}$.

En contraste con la guía para adultos, los DAI no se usan sistemáticamente en pacientes pediátricos con MCD y disfunción del VI avanzada debido a la baja incidencia de MSC en este grupo de edad ${ }^{514,515}$. La interpretación y la comparación de resultados de series de DAI pediátricas siguen siendo difíciles debido a que a menudo se ha evaluado la terapia con DAI para una variedad de afecciones y es frecuente la inclusión de adultos con ECC. Varias series de DAI pediátricas han comunicado choques apropiados en prevención secundaria en un 40-67\% de los pacientes. Cuando se utiliza el DAI en prevención pri- maria, las tasas de descargas apropiadas varían del 10 al 26\% en un seguimiento medio de 2-4 años ${ }^{490,508,510,511,516-519}$.

Fracturas de los electrodos y roturas de aislantes, problemas vasculares, infecciones y aumentos tardíos en el umbral de desfibrilación son más comunes en la población pediátrica que en adultos, probablemente debido a sus mayores niveles de actividad, su menor tamaño corporal y el crecimiento ${ }^{520}$. Estudios de gran tamaño indican tasas anuales de fracturas de electrodos del 5,3 y el 6,5\%, con la edad $<8$ años y el electrodo Fidelis ${ }^{\circledR}$ como factores de riesgo independientes ${ }^{521,522}$. En la mayoría de las series pediátricas, la incidencia de descargas inapropiadas es notablemente alta, del 17 al 30\%490,508,511,516-519. Los choques inapropiados debidos a taquicardia sinusal, arritmias supraventriculares y sobredetección de ondas T son comunes y se pueden reducir por programación individual, en particular usando frecuencias de detección más elevadas. Para pacientes pediátricos de más edad, como en adultos, se usan mayoritariamente sistemas de DAI bicamerales transvenosos. En pacientes más jóvenes, se usan habitualmente sistemas monocamerales para evitar obstrucción venosa, dejando un asa del electrodo del DAI en la aurícula derecha para permitir el crecimiento. En infantes y niños pequeños, los sistemas de DAI no transvenosos alternativos parecen seguros y eficaces ${ }^{512}$. Estos sistemas se construyen insertando el generador en el abdomen, un electrodo subcutáneo en el tórax izquierdo y el electrodo ventricular en el epicardio ${ }^{508,512}$. También se han descrito otras variantes ${ }^{508}$. Usando estos sistemas alternativos, se producen aumentos tardíos del umbral de desfibrilación más frecuentemente, y habría que considerar el estudio periódico del umbral de desfibrilación ${ }^{512}$.

La TRC se ha convertido en un complemento importante del tratamiento de la IC de pacientes pediátricos, más habitualmente cuando hay indicación de estimulación antibradicardia ${ }^{523,524}$. La TRC-D puede ser beneficiosa para pacientes seleccionados, en particular población con ECC posoperada, pero los datos que respaldan su uso son escasos.

\section{TAQUICARDIAS VENTRICULARES Y FIBRILACIÓN VENTRICULAR EN CORAZONES ESTRUCTURALMENTE NORMALES}

\subsection{Taquicardia ventricular del tracto de salida}

\section{Tratamiento de la taquicardia ventricular del tracto de salida}

\begin{tabular}{|c|c|c|c|}
\hline Recomendaciones & Clase $^{\mathrm{a}}$ & Nivel $^{\mathrm{b}}$ & $\operatorname{Ref}^{c}$ \\
\hline $\begin{array}{l}\text { Se recomienda la ablación con catéter de la TV/ } \\
\text { EV del TSVD de pacientes sintomáticos y/o con } \\
\text { terapia fallida con fármacos antiarrítmicos } \\
\text { (p. ej., bloqueadores beta) o con función del VI } \\
\text { disminuida debido a elevada densidad de EV del } \\
\text { TSVD }\end{array}$ & I & B & $525-528$ \\
\hline $\begin{array}{l}\text { Se recomienda el tratamiento con bloqueadores } \\
\text { de los canales de sodio (agentes de clase IC) } \\
\text { para pacientes sintomáticos con TV/EV del TSVI/ } \\
\text { cúspides aórticas/epicárdica }\end{array}$ & I & C & $529-531$ \\
\hline $\begin{array}{l}\text { Para pacientes sintomáticos, se debe considerar la } \\
\text { ablación con catéter de la TV/EV del TSVI/cúspides } \\
\text { aórticas/epicárdica por personal experimentado } \\
\text { después de que hayan fallado uno o más } \\
\text { bloqueadores de los canales de sodio (agentes } \\
\text { de clase IC) o el paciente no desee someterse } \\
\text { a tratamiento a largo plazo con fármacos } \\
\text { antiarrítmicos }\end{array}$ & IIa & B & $\begin{array}{c}195,531- \\
533\end{array}$ \\
\hline
\end{tabular}

EV: extrasístole ventricular; TSVD: tracto de salida del ventrículo derecho; TSVI: tracto de salida del ventrículo izquierdo; TV: taquicardia ventricular; VI: ventrículo izquierdo.

${ }^{a}$ Clase de recomendación.

bNivel de evidencia.

'Referencias que respaldan las recomendaciones. 
Los tractos de salida ventriculares son los orígenes más comunes de TV/EV idiopática ${ }^{525,534-536}$. Aproximadamente un $70 \%$ se origina en el TSVD $^{536}$. Otros orígenes incluyen los senos aórticos de Valsalva ${ }^{537-540}$, el TSVI ${ }^{539-541}$, las grandes venas cardiacas ${ }^{195,539,541}$, el miocardio epicárdico $^{195,539,541,542}$, la continuidad mitroaórtica ${ }^{529,543}$ y raramente la arteria pulmonar ${ }^{544-546}$. La TV del tracto de salida focal idiopática se produce normalmente en pacientes sin enfermedad cardiaca estructural; sin embargo, en algunos pacientes se han demostrado por RMC sutiles anormalidades de la pared ${ }^{547,548}$. Tienen un mecanismo focal secundario a automatismo aumentado, microrreentrada o actividad desencadenada $^{549-552}$. La TV del TSVD idiopática se presenta típicamente entre los 20 y los 50 años y más frecuentemente en mujeres ${ }^{553}$. Existen 2 formas típicas: TV inducida por ejercicio/estrés y TV monomórfica repetitiva que aparece en reposo. La TVNS repetitiva aparece en un 60-92\% de los casos, mientras que la TV incesante aparece solo ocasionalmente ${ }^{549-552}$.

La TV sostenida paroxística separada por largos periodos de EV infrecuentes es menos común. Los episodios aumentan en frecuencia y duración durante el ejercicio o el estrés emocional; las pruebas de ejercicio pueden provocar TV de los tractos de salida focales durante el ejercicio o las fases de recuperación. La morfología típica del QRS es un eje inferior con morfología dominante de BRIH ${ }^{525,534-541}$. Las EV o el primer latido de la TV generalmente tienen intervalos de acoplamiento con el complejo QRS precedente relativamente largos ${ }^{553}$. La TV es monomórfica; sin embargo, la morfología del QRS puede variar ligeramente. Múltiples morfologías distintas de la TV son muy raras y levantan sospechas de TV relacionada con cicatrices, como en la MAVD $^{535}$. Aunque la TV de los tractos de salida idiopática sigue un curso benigno, ocasionalmente puede aparecer TV maligna ${ }^{551,553}$. El ECG en ritmo sinusal habitualmente es normal; sin embargo, un $~ 10 \%$ tienen BRDH completo o incompleto ${ }^{554}$. Se debe realizar pruebas de ejercicio e imagen cardiaca para excluir enfermedad cardiaca estructural subyacente, y el cateterismo cardiaco puede estar justificado en algunos casos.

El tratamiento se justifica solo si los pacientes están sintomáticos. Merece la pena señalar que los síntomas pueden estar relacionados con disfunción del VI, considerando que la TV idiopática puede ser una causa de miocardiopatía inducida por taquicardia o taquimiocardiopatía ${ }^{555}$. En tales pacientes, habría que considerar el tratamiento con bloqueadores de los canales de sodio (agentes de clase IC) o la ablación con catéter. Para los pacientes con TV del TSVD/EV, se debería recomendar la ablación con catéter primaria, mientras que para los pacientes con TV del TSVI/EV, solo se debería considerar la ablación con catéter tras el fracaso del tratamiento antiarrítmico.

La estrecha proximidad anatómica del TSVD, el TSVI y las grandes venas cardiacas limita la localización precisa del origen de la TV según la morfología del QRS, excepto para la taquicardia clásica del TSVD. La localización precisa se debe guiar por mapeo de activación o mapeo de estimulación en el EEF ${ }^{332,537-540}$ y debe comenzar en el TSVD (incluido el seno arterial pulmonar), seguido de las grandes venas cardiacas, las cúspides aórticas y el TSVI endocárdico. Cuando la ablación en un sitio con activación ventricular precoz no elimina la arritmia clínica, se puede considerar el mapeo epicárdico.

\subsubsection{Taquicardias del tracto de salida del ventrículo derecho}

Clínicamente, las TV del TSVD tienen longitudes de ciclo más cortas y es más probable que se asocien a síncope en comparación con las arritmias del TSVI ${ }^{550-552}$. El ECG típico de TV del TSVD/EV tiene una transición R/S posterior en V4 en comparación con la TV del TSVI/EV. En informes publicados, las tasas de eficacia de la ablación con catéter aguda de la TV del TSVD/EV realizada por operadores experimentados son $>95 \%$ en pacientes sin enfermedad cardiaca estructural ${ }^{525,534-540}$; sin embargo, se dispone solo de pocos datos de seguimiento a largo plazo $^{527,528}$. Las tasas de complicaciones comunicadas son bajas, con solo casos muy raros de rotura del TSVD, particularmente en la pared libre $^{525}$. Por lo tanto, para los pacientes sintomáticos con ECG de superficie muy indicativo de taquiarritmia del TSVD, se recomienda un EEF, y se debería practicar ablación con catéter primaria cuando el mapeo haya confirmado un origen de la TV en el TSVD/EV.

\subsubsection{Taquicardias del tracto de salida del ventrículo izquierdo}

La ablación de la TV del TSVI/EV requiere un conocimiento profundo y un mapeo cuidadoso incluyendo el TSVI, las cúspides aórticas, la arteria pulmonar y el epicardio ${ }^{532,556}$. El TSVI septal, aunque es principalmente muscular, incluye el septo ventricular membranoso. El cuadrante posterior consiste en una extensa cortina fibrosa. Los TSVI lateral y anterior son estructuras musculares. Epicárdicamente, las arterias coronarias descendente anterior izquierda y circunfleja izquierda yacen en posición superior a la porción aórtica del TSVI y ocupan la porción más superior del VI, denominada cima del VI por McAlpine ${ }^{557}$. Esta es una fuente importante de TV/EV idiopática. Típicamente, las TV del TSVI/EV tienen un eje inferior con transición precoz en V1/V2 y BRIH o BRDH (el 70 y el 30\% respectivamente) ${ }^{195,529,530,532,533,537-543,558}$.

Las tasas de complicaciones de la ablación con catéter no son desdeñables e incluyen complicaciones importantes como rotura y taponamiento cardiaco, accidente cerebrovascular, daño valvular y daño en las arterias coronarias. Como puede ser necesario un abordaje combinado transeptal y retrógrado para el mapeo y la ablación completos debido a la complejidad anatómica, la ablación del TSVI se debe realizar solo en centros altamente experimentados tras el fracaso de al menos un bloqueador de los canales de sodio (agentes de clase IC) ${ }^{532}$.

\subsubsection{Taquicardias ventriculares de las cúspides aórticas}

La TV que se origina en los senos de Valsalva representa un 20\% de las TV de los tractos de salida idiopáticas, la mayoría de la cúspide coronaria izquierda, seguida de la cúspide coronaria derecha, la unión cúspide coronaria derecha-cúspide coronaria izquierda y raramente la cúspide no coronaria fibrosa ${ }^{195,529,537-543}$. Los ECG muestran típicamente un QRS amplio con transición precoz en V1-V2 ${ }^{537,538}$. La principal complicación de la ablación en las cúspides aórticas es la oclusión aguda del tronco coronario izquierdo. Por lo tanto, es importante identificar antes de la ablación el ostium coronario izquierdo o derecho por angiografía, ecocardiografía intracardiaca o TC. Se debe observar un margen $>6 \mathrm{~mm}$ desde el tronco coronario izquierdo, usando energía convencional con aumento gradual de la potencia empleada. Raramente se ha descrito lesión de la válvula aórtica ${ }^{559}$. Hasta ahora, las tasas de complicaciones son bajas y es probable que se hayan considerado a la baja, ya que estas arritmias generalmente se tratan en centros altamente experimentados. Por lo tanto, la ablación se debería realizar solo tras el fracaso de al menos un bloqueador de los canales de sodio (agentes de clase IC).

\subsubsection{Taquicardias ventriculares epicárdicas del tracto de salida}

Habría que considerar un abordaje epicárdico solo tras una ablación endocárdica ineficaz de la TV del tracto de salida/EV 195,530,539-541,558. La mayoría de las TV epicárdicas focales se originan en una posición adyacente a las grandes venas cardiacas o las arterias coronarias ${ }^{195,539-541}$, y la lesión de las arterias coronarias es un problema importante ${ }^{531,560-562}$. La orejuela auricular izquierda suprayacente y los cojinetes de grasa epicárdicos también pueden ser obstáculos anatómicos para la ablación.

\subsubsection{Otras (incluidas las arterias pulmonares)}

Solo en casos clínicos y series de casos se ha descrito la ablación eficaz de la TV originada en la arteria pulmonar ${ }^{544-546}$. Sin embargo, no existe miocardio en esta región, a excepción del de los senos pulmonares $^{556}$. Los registros de ECG muestran típicamente BRIH con ondas $\mathrm{R}$ altas en las derivaciones inferiores y transición en V4/V5 $5^{544-546}$. Las 
tasas de complicaciones de la ablación con catéter, generalmente realizada en centros altamente experimentados, son desconocidas debido al pequeño número de pacientes implicados.

\subsection{Taquicardias ventriculares de origen misceláneo}

Tratamiento para prevenir recurrencias de la taquicardia ventricular idiopática

\begin{tabular}{|c|c|c|c|}
\hline Recomendaciones & Clase $^{a}$ & Nivel $^{\mathrm{b}}$ & $\operatorname{Ref}^{c}$ \\
\hline $\begin{array}{l}\text { Se recomienda la ablación con catéter por } \\
\text { personal experimentado como tratamiento de } \\
\text { primera línea para pacientes sintomáticos con TV } \\
\text { izquierdas idiopáticas }\end{array}$ & I & B & $\begin{array}{l}346,347 \\
563-575\end{array}$ \\
\hline $\begin{array}{l}\text { Cuando no se disponga de ablación con catéter } \\
\text { o no se desea para pacientes sintomáticos } \\
\text { con TV izquierda idiopática, se recomienda el } \\
\text { tratamiento con bloqueadores beta, verapamilo } \\
\text { o bloqueadores de los canales de sodio (agentes } \\
\text { de clase IC) }\end{array}$ & I & C & $\begin{array}{c}\text { Este } \\
\text { panel de } \\
\text { expertos }\end{array}$ \\
\hline $\begin{array}{l}\text { Se recomienda el tratamiento con bloqueadores } \\
\text { beta, verapamilo o bloqueadores de los canales } \\
\text { de sodio (agentes de clase IC) para pacientes } \\
\text { sintomáticos con taquicardia de los músculos } \\
\text { papilares }\end{array}$ & I & C & $\begin{array}{c}\text { Este } \\
\text { panel de } \\
\text { expertos }\end{array}$ \\
\hline $\begin{array}{l}\text { Se recomienda el tratamiento con bloqueadores } \\
\text { beta, verapamilo o bloqueadores de los canales } \\
\text { de sodio (agentes de clase IC) para pacientes } \\
\text { sintomáticos con taquicardia de los anillos mitral } \\
\text { y tricúspide }\end{array}$ & I & C & $\begin{array}{c}\text { Este } \\
\text { panel de } \\
\text { expertos }\end{array}$ \\
\hline $\begin{array}{l}\text { Para pacientes sintomáticos con taquicardia de } \\
\text { los músculos papilares, se debe considerar la } \\
\text { ablación con catéter ecoguiada realizada por } \\
\text { personal experimentado si han fallado uno o más } \\
\text { bloqueadores de los canales de sodio (agentes de } \\
\text { clase IC) o el paciente rechaza la terapia a largo } \\
\text { plazo con fármacos antiarrítmicos }\end{array}$ & IIa & B & $576-578$ \\
\hline $\begin{array}{l}\text { Para pacientes sintomáticos con taquicardia de los } \\
\text { anillos mitral y tricúspide, se debe considerar la } \\
\text { ablación con catéter por personal experimentado } \\
\text { si han fallado uno o más bloqueadores de los } \\
\text { canales de sodio (agentes de clase IC) o el paciente } \\
\text { rechaza la terapia a largo plazo con fármacos } \\
\text { antiarrítmicos }\end{array}$ & IIa & B & $\begin{array}{c}534,579- \\
581\end{array}$ \\
\hline
\end{tabular}

TV: taquicardia ventricular.

${ }^{a}$ Clase de recomendación.

bNivel de evidencia.

'Referencias que respaldan las recomendaciones.

\subsubsection{Taquicardia ventricular izquierda idiopática}

Se puede producir TV izquierda idiopática monomórfica y polimórfica en pacientes con y sin enfermedad cardiaca estructural subyacente. Pueden dividirse en diferentes entidades: TV fascicular izquierda sensible a verapamilo, taquicardia por reentrada ramarama, TV interfascicular y TV de Purkinje focal ${ }^{582}$.

La forma más común es la TV fascicular posterior izquierda (>90\%), que se produce predominantemente en pacientes jóvenes sin enfermedad cardiaca estructural. En el ECG de superficie, la TV fascicular posterior izquierda aparece con morfología de BRDH, un eje superior y un complejo QRS relativamente estrecho. Se recomienda la ablación con catéter en centros experimentados como tratamiento de primera línea, ya que la TV fascicular posterior izquierda afecta mayormente a pacientes jóvenes y el tratamiento a largo plazo basado en fármacos con verapamilo es ineficaz ${ }^{563-567}$. Las tasas de recurrencias tras una ablación eficaz varían del 0 al 20\%564,568-570.

La TV fascicular anterior izquierda y la TV fascicular septal superior izquierda causan, respectivamente, menos del 10\% y menos del $1 \%$ de las TV fasciculares izquierdas. En el ECG de superficie, la TV fas- cicular anterior izquierda se caracteriza por morfología de BRDH y desviación del eje a la derecha, mientras que la TV fascicular septal superior izquierda muestra un complejo QRS estrecho y un eje normal o desviación del eje a la derecha. Para ambos tipos de TV, se recomienda la ablación con catéter como tratamiento de primera línea en centros de ablación experimentados ${ }^{571-573}$.

La taquicardia por reentrada rama-rama se produce habitualmente en pacientes con defectos de la conducción intraventricular preexistentes, como largos intervalos His-ventrículo o bloqueo de ramas $^{346,347,574}$. La taquicardia por reentrada rama-rama es susceptible de ablación con catéter ya sea en la rama izquierda o (más habitualmente) por ablación de la rama derecha, al menos en centros experimentados, y comúnmente da lugar a taquicardia no inducible y se puede considerar curativa ${ }^{346,347,575}$. El implante de DAI generalmente no está indicado para pacientes con corazones normales.

\subsubsection{Taquicardia ventricular de los músculos papilares}

Las TV o EV idiopáticas pueden surgir de los músculos papilares del VD o el VI en un pequeño número de pacientes ${ }^{576-578}$. Cuando se originan del músculo papilar posterior izquierdo, normalmente se presentan con morfología de BRDH y un eje QRS superior derecho o izquierdo y QRS $>150 \mathrm{~ms}^{576}$. En caso de falta de respuesta a los bloqueadores de los canales de sodio (agentes de clase IC) o los bloqueadores beta, la ablación con catéter de las EV o las TV que surgen de los músculos papilares es una opción de tratamiento efectiva ${ }^{578}$. Sin embargo, la estabilidad del catéter durante el mapeo y la ablación en la región de los músculos papilares supone un reto. Habría que considerar seriamente abordaje transeptal y guía mediante ecocardiografía intracardiaca. La insuficiencia mitral tras una ablación eficaz es una complicación posible pero rara.

\subsubsection{Taquicardia ventricular de los anillos (mitral y tricúspide)}

El anillo mitral es origen de un $~ 5 \%$ de todas las EV y TV idiopáticas $^{534,579-581}$. El complejo QRS se presenta normalmente con patrón de $\mathrm{BRDH}$, onda $\mathrm{S}$ persistente en la derivación $\mathrm{V} 6 \mathrm{y}$ transición de onda $\mathrm{R}$ precordial en la derivación $\mathrm{V} 1$ o, en algunos casos, entre las derivaciones V1 y V2. Se ha descrito una incidencia de origen en el anillo tricúspide de hasta un $8 \%$ de todas las TV y EV idiopáticas ${ }^{581}$. La taquicardia se presenta normalmente con morfología de BRIH y desviación del eje a la izquierda. En caso de respuesta insuficiente a los fármacos antiarrítmicos de clase IC o bloqueadores beta, la ablación con catéter (realizada en centros experimentados) en el sitio de activación ventricular más precoz o en un sitio con concordancia perfecta en el mapeo de estimulación es una opción de tratamiento eficaz para las taquicardias de los anillos tanto mitral como tricúspide ${ }^{581}$.

\subsection{Fibrilación ventricular idiopática}

\section{Tratamiento de la fibrilación ventricular idiopática}

\begin{tabular}{lccc}
\hline Recomendaciones & Clase $^{\mathrm{a}}$ & Nivel $^{\mathrm{b}}$ & Ref $^{\mathrm{c}}$ \\
\hline $\begin{array}{l}\text { Se recomienda implante de DAI para supervivientes } \\
\text { a FV idiopática }\end{array}$ & I & B & 154,583 \\
\hline $\begin{array}{l}\text { Se recomienda la ablación con catéter, realizada } \\
\text { por personal experimentado, de las EV que } \\
\text { desencadenan FV recurrente que da lugar } \\
\text { a terapias del DAI }\end{array}$ & I & B & \begin{tabular}{c}
467, \\
\hline $\begin{array}{l}\text { Se recomienda la ablación con catéter, realizada } \\
\text { por personal experimentado, de las EV que dan } \\
\text { lugar a tormenta eléctrica }\end{array}$
\end{tabular} \\
\hline
\end{tabular}

DAI: desfibrilador automático implantable; EV: extrasístole ventricular; FV: fibrilación ventricular: MSC: muerte súbita cardiaca.

aClase de recomendación.

bNivel de evidencia.

'Referencias que respaldan las recomendaciones. 
La FV idiopática es un diagnóstico por exclusión, pero puede cambiar en el futuro gracias a un mejor diagnóstico de la enfermedad cardiaca estructural subyacente o nueva evidencia de defectos en los canales iónicos. Se recomienda seriamente el implante de un DAI para la prevención secundaria.

La terapia antiarrítmica con bloqueadores beta o antiarrítmicos de clase III puede reducir, pero raramente prevenir, los episodios de FV recurrentes ${ }^{154}$. En pacientes con FV y enfermedad cardiaca estructural subyacente, así como en pacientes con FV idiopática, se puede identificar la EV que se origina en diversas localizaciones dentro del sistema de Purkinje o en el TSVD como desencadenantes y dianas potenciales para la ablación con catéter ${ }^{467,584-588}$. Se debe considerar la ablación con catéter de la FV recurrente desencadenante de EV para pacientes con frecuentes episodios de FV, pero se basa en la presencia de dichos latidos extrasistólicos durante el procedimiento, principalmente tras un episodio de FV o una tormenta de FV. Para pacientes sin EV espontáneas, se recomienda un ECG Holter de 12 derivaciones previo a la intervención para documentar la morfología de las extrasístoles y guiar la ablación.

Se ha comunicado una tasa de eficacia a largo plazo, definida como ausencia de FV, TV polimórfica o MSC tras un seguimiento $>5$ años, del $82 \% 586,588$. Independientemente de los resultados de la ablación con catéter, se debería implantar DAI a todos los pacientes con FV idiopática.

\subsection{Torsade de pointes con acoplamiento corto}

Tratamiento de la torsade de pointes con acoplamiento corto

\begin{tabular}{lccc}
\hline Recomendaciones & Clase $^{\mathrm{a}}$ & Nivel $^{\mathrm{b}}$ & Ref $^{\mathrm{c}}$ \\
\hline $\begin{array}{l}\text { Se recomienda DAI para pacientes con diagnóstico } \\
\text { concluyente de TdP con acoplamiento corto }\end{array}$ & I & B & 589 \\
\hline $\begin{array}{l}\text { Se debe considerar el verapamilo intravenoso para } \\
\text { suprimir de manera aguda/prevenir una tormenta } \\
\text { eléctrica o descargas del DAI recurrentes }\end{array}$ & Ila & B & 590,591 \\
\hline $\begin{array}{l}\text { Se debe considerar la ablación con catéter para } \\
\text { la supresión/prevención a largo plazo de una } \\
\text { tormenta eléctrica o descargas del DAI recurrentes }\end{array}$ & Ila & B & 586 \\
\hline
\end{tabular}

DAI: desfibrilador automático implantable; TdP: torsade de pointes.

${ }^{a}$ Clase de recomendación.

bNivel de evidencia.

'Referencias que respaldan las recomendaciones.

La TdP con acoplamiento corto es una variante rara de la TV polimórfica de etiología desconocida. La TdP se caracteriza por su patrón típico de ECG en forma de actividad eléctrica no uniforme pero organizada con cambios progresivos en morfología, amplitud y polaridad. La TdP con acoplamiento corto se caracteriza por un intervalo con acoplamiento extremadamente corto de la primera contracción ventricular prematura $(<300 \mathrm{~ms})$ que inicia la taquicardia. Esta afecta predominantemente a pacientes jóvenes que con frecuencia se presentan con síncope de etiología sin aclarar e historia familiar de MSC $^{589-591}$. En la mayoría de los casos, la TdP se desorganiza a FV. Aunque aún no se entiende bien los mecanismos, puede haber una conexión con un desequilibrio del sistema nervioso autónomo ${ }^{592}$. El verapamilo intravenoso parece ser el único fármaco que puede suprimir la arritmia, pero no reduce el riesgo de MSC ${ }^{590,591}$. Por consiguiente, se recomienda seriamente el implante de $\mathrm{DAI}^{589}$. En casos de recurrencia de arritmia ventricular desencadenada por extrasístoles ventriculares monomórficas a pesar de la terapia con fármacos, habría que considerar seriamente la ablación con catéter. El objetivo de la ablación es la EV que inicia la TdP.

\section{ENFERMEDADES CARDIACAS INFLAMATORIAS, REUMÁTICAS Y VALVULARES}

Tratamiento de las arritmias ventriculares en la enfermedad cardiaca inflamatoria

\begin{tabular}{|c|c|c|c|}
\hline Recomendaciones & Clase $^{\mathrm{a}}$ & Nivel $^{\mathrm{b}}$ & $\operatorname{Ref}^{c}$ \\
\hline $\begin{array}{l}\text { Para los pacientes con presentación de } \\
\text { taquiarritmias ventriculares sostenidas } \\
\text { potencialmente mortales en el contexto de } \\
\text { sospecha clínica de miocarditis, se recomienda } \\
\text { derivarlos a centros especializados con capacidad } \\
\text { para monitorización hemodinámica, cateterismo } \\
\text { cardiaco y biopsia endomiocárdica y utilizar } \\
\text { dispositivos de asistencia ventricular izquierda y } \\
\text { terapias especializadas para las arritmias }\end{array}$ & I & C & 593-596 \\
\hline $\begin{array}{l}\text { Se recomienda el implante temporal de marcapasos } \\
\text { para pacientes con bradicardia o bloqueo cardiaco } \\
\text { que desencadenan arritmias ventriculares durante } \\
\text { la fase aguda de la miocarditis/pancarditis }\end{array}$ & I & C & 593,594 \\
\hline $\begin{array}{l}\text { Se debe considerar tratamiento antiarrítmico } \\
\text { para pacientes con TV no sostenida o sostenida } \\
\text { sintomática durante la fase aguda de la miocarditis }\end{array}$ & Ila & C & 594 \\
\hline $\begin{array}{l}\text { Se debe considerar implante de DAI o marcapasos } \\
\text { para pacientes con enfermedades cardiacas } \\
\text { inflamatorias tras la resolución del episodio agudo }\end{array}$ & IIa & C & 593,597 \\
\hline $\begin{array}{l}\text { Para pacientes con TV sostenida que produce } \\
\text { deterioro hemodinámico y aparece tras la } \\
\text { resolución de los episodios agudos, se debe } \\
\text { considerar el implante de DAI si se espera que el } \\
\text { paciente sobreviva más de } 1 \text { año con buen estado } \\
\text { funcional }\end{array}$ & Ila & C & 8 \\
\hline $\begin{array}{l}\text { Tras enfermedades cardiacas inflamatorias con } \\
\text { disfunción residual del VI grave y/o inestabilidad } \\
\text { eléctrica ventricular, se debe considerar el chaleco } \\
\text { desfibrilador hasta la total recuperación o el } \\
\text { implante de DAI }\end{array}$ & IIa & C & 598,599 \\
\hline $\begin{array}{l}\text { Si se espera una supervivencia > } 1 \text { año con buen } \\
\text { estado funcional, se puede considerar implantar el } \\
\text { DAI más precozmente en pacientes con miocarditis } \\
\text { de células gigantes o sarcoidosis que tenían arritmia } \\
\text { ventricular sostenida con deterioro hemodinámico } \\
\text { o parada cardiaca abortada, debido al pronóstico } \\
\text { adverso de estas afecciones }\end{array}$ & IIb & C & 600 \\
\hline $\begin{array}{l}\text { Se puede considerar la demostración } \\
\text { inmunohistológica de infiltrados inflamatorios } \\
\text { miocárdicos persistentes o la evidencia por RMC de } \\
\text { fibrosis localizada anormal tras miocarditis aguda } \\
\text { como indicadores adicionales de mayor riesgo } \\
\text { de MSC en la enfermedad cardiaca inflamatoria }\end{array}$ & IIb & C & 601 \\
\hline
\end{tabular}

DAI: desfibrilador automático implantable; MSC: muerte súbita cardiaca; RMC: resonancia magnética cardiaca; TV: taquicardia ventricular; VI: ventrículo izquierdo.

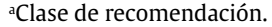

bNivel de evidencia.

'Referencias que respaldan las recomendaciones.

\subsection{Miocarditis}

La miocarditis es el resultado patológico de una infección miocárdica o autoinmune que causa destrucción inflamatoria activa de los miocitos. Etiológicamente, podría estar implicado un amplio espectro de agentes infecciosos, incluidos virus, bacterias, clamidias, rickettsias, hongos y protozoos, así como reacciones tóxicas y de hipersensibilidad $^{609}$. Los enterovirus (Coxsackie B), adenovirus, Parvovirus B19 y el virus del herpes humano tipo 6 están entre los agentes causales más comunes. También se puede producir miocarditis en pacientes con infecciones avanzadas por el virus de la inmunodeficiencia humana debido a cardiotoxicidad con apoptosis celular inducida por la glucoproteína 120 viral, infecciones oportunistas, respuesta autoin- 
munitaria, toxicidad cardiaca relacionada con fármacos y posiblemente deficiencias nutricionales ${ }^{609,610}$.

La imagen microscópica típica requerida para el diagnóstico de miocarditis consiste en la presencia de células inflamatorias junto con miocitos necróticos. Según el informe de la Organización Mundial de la Salud, la miocarditis se define como una enfermedad inflamatoria del miocardio diagnosticada por criterios histológicos, inmunológicos e inmunohistoquímicos establecidos ${ }^{611}$. En el mismo documento, se hace referencia a la miocarditis asociada a disfunción cardiaca como miocardiopatía inflamatoria, y entre las recomendaciones relevantes de la ESC se recomienda usar ambas definiciones ${ }^{593}$.

Por lo tanto, la biopsia endomiocárdica sigue siendo la referencia para el diagnóstico definitivo de miocarditis, y debería realizarse especialmente en pacientes cuya enfermedad curse con riesgo vital. La RMC se ha hecho habitual y es una prueba sensible y no invasiva para la confirmación de la miocarditis aguda incluso antes de la biopsia endomiocárdica. Como pruebas esenciales de primera línea para confirmar el diagnóstico en pacientes con una presentación clínica compatible con miocarditis, se debería incluir ECG de 12 derivaciones, ecocardiograma transtorácico y determinación de concentraciones de biomarcadores (incluidas las troponinas), velocidad de sedimentación eritrocitaria y proteína $\mathrm{C}$ reactiva. El diagnóstico de miocarditis debería basarse en los criterios resumidos por Caforio et $\mathrm{al}^{593}$.

En la fase aguda de la enfermedad, la miocarditis puede ser asintomática o presentarse con un curso inespecífico no reconocido. Considerando las arritmias malignas asociadas a la miocarditis, hay que distinguir 2 marcos clínicos distintos:

- Miocarditis fulminante aguda con taquiarritmias ventriculares malignas refractarias en el contexto de IC aguda grave, y pronóstico adverso a corto plazo con muerte prematura debida a fallo multiorgánico.

- Evolución a largo plazo hacia miocardiopatía inflamatoria con disfunción del VI y con resultado de alto riesgo de MSC, similar al de la MCD.

\subsubsection{Miocarditis aguda y fulminante}

El tratamiento de la IC y las arritmias potencialmente fatales es el reto clínico principal en la miocarditis aguda. Los pacientes con miocarditis fulminante tienen una elevada mortalidad aguda y un grave riesgo de taquiarritmias ventriculares refractarias potencialmente mortales. Para los pacientes que se presentan con un síndrome de IC que apunta a ser primera manifestación de MCD o con sospecha de miocarditis aguda posible o probable, se recomiendan medidas de soporte, evitar el ejercicio y usar IECA y bloqueadores beta para bloqueo neurohormonal. Anomalías progresivas en el movimiento de la pared con deterioro de la función del VI en la ecocardiografía, concentraciones persistentes o fluctuantes de troponinas cardiacas, ensanchamiento del complejo QRS y arritmias ventriculares no sostenidas frecuentes pueden preceder a una arritmia sostenida maligna en el marco de la miocarditis aguda ${ }^{594,612}$.

Los pacientes con arritmias ventriculares o bloqueo cardiaco en el marco de la miocarditis aguda necesitan larga monitorización electrocardiográfica y deben ser hospitalizados.

La enfermedad de Lyme y la miocarditis diftérica se asocian con frecuencia a diversos grados de bloqueo cardiaco, lo que también puede desencadenar taquiarritmias ventriculares. Por lo tanto, se recomienda el implante de un marcapasos transitorio en pacientes con miocarditis aguda que se presentan con bloqueo cardiaco sintomático (como con otras causas de bloqueo cardiaco sintomático agudo). Se recomienda la estimulación cardiaca para pacientes con disfunción del nódulo sinusal o BAV sintomáticos tras miocarditis (como con otras causas de disfunción del nódulo sinusal o el NAV). Las taquiarritmias ventriculares desencadenadas por BAV de alto grado requieren inserción temporal de marcapasos. Si se desarrollan BAV persistentes, se recomienda la estimulación permanente. Sin embargo, la selección del dispositivo debe reflejar la presencia, el alcance y el pronóstico (progresión o regresión) de la disfunción del VI con objeto de escoger apropiadamente el marcapasos o el DAI con o sin capacidad de resincronización cardiaca. Debido al pronóstico adverso para los pacientes con miocarditis de células gigantes o sarcoidosis, para estos pacientes se puede considerar el implante más precoz de un marcapasos ${ }^{596}$.

La miocarditis fulminante es una entidad clínica diferente, con un pronóstico adverso a corto plazo pero relativamente bueno a largo plazo. Las arritmias sostenidas refractarias son típicas de la forma fulminante de la miocarditis. Según un registro japonés, la tasa de supervivencia a corto plazo de los pacientes con miocarditis fulminante es solo del $58 \% 595,613$.

La taquicardia ventricular fue la arritmia sostenida más común en 2.148 niños con miocarditis aguda, un $76 \%$ de los 314 casos con arritmias en el curso de la enfermedad. Los pacientes con arritmias sostenidas tenían un riesgo de parada cardiaca, necesidad de asistencia circulatoria mecánica o muerte muy alto en comparación con los pacientes sin arritmias (OR = 5,4; IC95\%, 3,9-7,4; $\mathrm{p}<0,001)^{596}$.

La miocarditis de células gigantes es una forma grave de miocarditis con un curso clínico ominoso, que a menudo afecta a pacientes jóvenes. Se confirma el diagnóstico por biopsia endomiocárdica que muestre células gigantes multinucleadas típicas en lesiones inflamatorias. Los pacientes pueden sufrir bloqueo cardiaco que requiera marcapasos temporales o permanentes. Sin embargo, las tormentas eléctricas refractarias con TV o FV incesante tienen un pronóstico particularmente adverso pese a un tratamiento antiarrítmico agresivo.

Sorprendentemente, en un estudio retrospectivo entre pacientes adultos tras miocarditis aguda, los que presentaban la forma fulminante tenían mejor pronóstico a largo plazo que aquellos con miocarditis no fulminante. Después de 11 años, un 93\% de los pacientes con miocarditis fulminante estaban vivos sin trasplante cardiaco, en comparación con solo un $45 \%$ con la forma no fulminante ${ }^{614}$.

Se recomienda asistencia hemodinámica agresiva con asistencia cardiopulmonar percutánea o un balón de contrapulsación intraaórtico además de terapia con fármacos para pacientes con miocarditis aguda o fulminante para superar la ominosa, aunque con frecuencia curable, fase aguda de la enfermedad. Se debería iniciar la asistencia cardiopulmonar percutánea si la TV o la FV refractaria no responden a 3-5 intentos de desfibrilación ${ }^{594}$.

La importante asociación entre miocarditis no diagnosticada y MSC queda subrayada por los datos post mortem que implican miocarditis en la MSC de adultos jóvenes a tasas de un 8,6-44\%

Los datos sobre los agentes causales son escasos. Chlamydia myocarditis está implicada en la muerte súbita de 5 de 15 atletas suecos jóvenes de élite tras la identificación de ARN de clamidias en el corazón $^{619}$.

Durante la fase aguda de la miocarditis, se debe posponer el implante de DAI hasta la resolución del episodio agudo. Dado que la miocarditis puede curarse por completo, continúa la controversia en cuanto a la indicación de implante de DAI y la elección del momento adecuado para ello incluso más allá de la fase aguda. Para los pacientes con miocarditis y TV o FV, salvar el periodo crítico hasta la recuperación total mediante un chaleco desfibrilador parece ser una opción terapéutica prometedora ${ }^{598,599}$. La presencia de arritmia ventricular maligna 0 bloqueo cardiaco en la miocarditis de células gigantes o la sarcoidosis cardiaca podría justificar que se considere antes el DAI, debido al conocido alto riesgo de muerte arrítmica o necesidad de trasplante ${ }^{600}$.

\subsubsection{Miocarditis que da lugar a miocardiopatía inflamatoria}

Se ha identificado la miocarditis como causa de MCD en hasta un $10 \%$ de los casos de grandes series prospectivas. Es importante que la miocardiopatía inflamatoria está implicada en la patogenia de 
la MCD, con mal pronóstico. En estudios de seguimiento a largo plazo de pacientes que han sufrido miocarditis aguda, el $21 \%$ sufrió MCD ${ }^{620}$.

Por otra parte, se identificó un genoma viral en el miocardio de dos tercios de los pacientes con disfunción del VI «idiopática». Además, las infecciones cardiacas virales persistentes pueden ser una causa importante de disfunción progresiva del VI de pacientes con MCD y sospecha de miocarditis previa ${ }^{621}$. Sin embargo, Kindermann et a ${ }^{597}$ no confirmaron estas observaciones, pero identificaron evidencia inmunohistológica de infiltrados inflamatorios en el miocardio como factor primario asociado a un aumento $\geq 3$ veces del riesgo de muerte cardiaca o trasplante cardiaco. A los 5 años de seguimiento, un $61 \%$ de los pacientes en NYHA III-IV con inmunohistología positiva que no recibieron bloqueadores beta murieron o se sometieron a trasplante cardiaco ${ }^{597}$.

En pacientes con TV sostenida sintomática documentada pero de etiología poco clara, también habría que sospechar miocarditis, y una exploración por RMC puede revelar tejido miocárdico fibrótico anormal, frecuentemente localizado en regiones subepicárdicas e intramurales. En una cohorte de 405 pacientes con sospecha de miocarditis, todos los pacientes que murieron súbitamente o sufrieron MSC abortada o descarga de DAI tenían pruebas de RMC anormales ${ }^{601}$. Se ha descrito recientemente la ablación eficaz de focos arritmogénicos epicárdicos en la miocarditis mediante catéter de radiofrecuencia ${ }^{622}$.

El tratamiento farmacológico de las arritmias de pacientes con cardiopatía inflamatoria no difiere de los principios clínicos generalmente aceptados. El tratamiento de las arritmias fuera de la fase aguda debería estar en línea con la actual guía de la ESC sobre arritmias e implante de dispositivos en el tratamiento de la IC crónica ${ }^{8}$. En general, las indicaciones de DAI en la miocardiopatía inflamatoria son las mismas que para la MCD no isquémica. Para la prevención secundaria de la MSC, se recomienda el implante de un DAI en pacientes con miocarditis tras parada cardiaca debida a FV o tras TV sintomática. Se recomienda la TRC-D para la prevención primaria de pacientes con función del VI alterada (FEVI < 35\%) y BRIH en NYHA II-IV8. Como la función del VI puede mejorar con el tiempo en pacientes con miocardiopatía inflamatoria debido al curso natural de la enfermedad o el apropiado tratamiento para la IC, no se debe indicar prematuramente el implante de DAI/TRC-D.

\subsection{Endocarditis}

Las arritmias ventriculares en la endocarditis infecciosa son factores predictivos de muy mal pronóstico ${ }^{623}$. Sin embargo, no existen recomendaciones específicas para su tratamiento más allá de los principios generales. La formación de abscesos en el anillo valvular (más frecuentemente el aórtico que el mitral) puede dar lugar a bloqueo cardiaco de primer o segundo grado. El bloqueo cardiaco de nueva aparición en un paciente con endocarditis debe levantar sospechas clínicas de un absceso. El deterioro hemodinámico agudo relacionado con insuficiencia aórtica aguda secundaria a endocarditis puede dar lugar a TV sostenida y es una indicación de cirugía precoz ${ }^{605}$.

\subsection{Enfermedad cardiaca reumática}

La fiebre reumática aguda puede causar una pancarditis que afecte al pericardio, el miocardio y el endocardio. No hay datos específicos sobre arritmias ventriculares en la enfermedad cardiaca reumática y su tratamiento debe seguir los principios generales.

El BAV completo durante la fiebre reumática aguda es raro y normalmente transitorio. Habría que considerar la estimulación cardiaca temporal cuando es sintomática o cuando se desencadenan arritmias ventriculares graves.

\subsection{Pericarditis}

Puede producirse MSC en el curso de la enfermedad pericárdica como resultado de procesos patológicos diversos, entre ellos procesos tanto constrictivos como restrictivos resultantes de traumatismo, inflamación o etiologías neoplásicas e infecciosas. Sin embargo, no hay evidencia que asocie arritmias ventriculares específicas y enfermedad pericárdica. Además, la MSC de estos pacientes tiene principalmente una causa hemodinámica y no arrítmica.

\subsection{Sarcoidosis cardiaca}

La sarcoidosis cardiaca es una entidad clínica rara y difícil de diagnosticar, con un amplio espectro de manifestaciones que van desde alteraciones en el ECG asintomáticas y sutiles hasta IC y MSC. La sarcoidosis cardiaca es una causa rara de TV (el 5\% de todas las miocardiopatías no isquémicas a las que se hace referencia en la TV).

Estudios realizados por mapeo cardiaco de voltaje han demostrado cicatrización extendida y confluente del VD con localización epicárdica predominante. La cicatrización del VI era más irregular en el septo basal, la pared anterior y las regiones perivalvulares. Dicho sustrato es capaz de sostener gran número de circuitos reentrantes.

La ablación con catéter conjuntamente con fármacos antiarrítmicos es una terapia paliativa eficaz para finalizar la tormenta de TV y eliminar una o más TV inducibles en la mayoría de los pacientes, pero las recidivas son habituales y estos pacientes requieren el implante de un DAI ${ }^{624,625}$.

\subsection{Enfermedad cardiaca valvular}

Tratamiento de las arritmias ventriculares en la enfermedad cardiaca valvular

\begin{tabular}{lcccc}
\hline Recomendaciones & Clase $^{\mathrm{a}}$ & Nivel $^{\mathrm{b}}$ & Ref $^{\mathrm{c}}$ \\
\hline $\begin{array}{l}\text { Se recomienda implante de DAI para pacientes } \\
\text { con enfermedad cardiaca valvular que, tras } \\
\text { reparación quirúrgica, satisfacen los criterios para } \\
\text { la prevención primaria y secundaria de la MSC }\end{array}$ & I & C & $602-604$ \\
\hline $\begin{array}{l}\text { Se recomienda el tratamiento quirúrgico de la } \\
\text { insuficiencia aórtica aguda debida a endocarditis } \\
\text { asociada a TV sostenida, a menos que esté } \\
\text { contraindicado por alguna otra razón }\end{array}$ & I & C & 605,606 \\
\hline $\begin{array}{l}\text { Se debe considerar el EEF con posible ablación con } \\
\text { catéter para pacientes que sufren TV tras cirugía } \\
\text { valvular, con objeto de identificar y curar la TV } \\
\text { por reentrada rama-rama }\end{array}$ & Ila & C & 607,608 \\
\hline
\end{tabular}

DAI: desfibrilador automático implantable; EEF: estudio electrofisiológico; MSC: muerte súbita cardiaca; TV: taquicardia ventricular.

aClase de recomendación.

bNivel de evidencia.

'Referencias que respaldan las recomendaciones.

La enfermedad cardiaca valvular, tanto en el periodo preoperatorio como tras la cirugía valvular, predispone a los pacientes a arritmias ventriculares. Etiológicamente, la mayor masa miocárdica, la dilatación y el estrés de la pared de los ventrículos y la isquemia subendocárdica en ausencia de $\mathrm{CI}$, junto con daño miocárdico crónico y fibrosis posquirúrgica iatrogénica, pueden ser causa de una mayor incidencia de taquiarritmias ventriculares complejas que pueden ir asociadas a TV sostenida y MSC ${ }^{606}$. Después, el sustrato arritmogénico maligno puede incrementarse por las frecuentes enfermedades cardiacas estructurales concomitantes, principalmente CI e IC.

En el pasado, varios investigadores describieron una mayor incidencia de TVNS en pacientes con enfermedad cardiaca de las válvulas aórtica y mitral ${ }^{626,627}$. En estudios más antiguos sobre la historia natural de la enfermedad cardiaca valvular, se producía la muerte súbita de un $15-20 \%$ de los pacientes adultos con estenosis aórtica a una media de edad de 60 años. Entre los pacientes sintomáticos no operados, se produce muerte súbita con una prevalencia de hasta el $34 \% 628,629$. En un estudio, un $60 \%$ de todas las muertes cardiacas que se produjeron durante el seguimiento no quirúrgico de pacientes con insuficiencia mitral grave fueron súbitas ${ }^{630}$. 
Un estudio de 348 pacientes con insuficiencia mitral debido al fallo de una valva reveló que la muerte súbita no es rara entre los pacientes de más edad tratados de manera conservadora. Dado que la corrección de este tipo de insuficiencia mitral parece asociarse a baja incidencia de muerte súbita, se debería considerar la reparación antes, tras la obligada búsqueda cuidadosa de $\mathrm{CI}$ acompañante ${ }^{631}$. Tras la reparación de la insuficiencia mitral, más de 2 episodios de TVNS durante la monitorización ambulatoria eran predictivos de muerte súbita durante un seguimiento de 9 años ${ }^{632}$. Las tasas totales de MSC de pacientes con válvulas protésicas varían considerablemente, de un 15 a un $30 \%$, con un riesgo anual estimado del $0,2-0,9 \% 633$. En una gran serie de 1.533 pacientes sometidos a remplazo de válvula aórtica o mitral, las arritmias causaron un 6\% de las muertes ${ }^{634}$. En un estudio cooperativo estadounidense, la muerte súbita representó un $23 \%$ de las muertes por remplazo de la válvula mitral y un $16 \%$ por remplazo de la válvula aórtica ${ }^{635,636}$.

Martínez-Rubio et al ${ }^{607}$ demostraron que la inducibilidad de TV, junto con sobrecarga de volumen del VI, es predictiva de eventos arrítmicos malignos en pacientes que se presentan con TV, FV o síncope. Un EEF tiene una importancia clínica considerable para los pacientes que sufren TV tras la cirugía valvular. En hasta un 30\% de los pacientes, la TV (que se producía mayormente en el primer mes tras la cirugía) se debía a reentrada rama-rama, una arritmia potencialmente curable mediante ablación con catéter ${ }^{608}$.

Tenían enfermedad cardiaca valvular como etiología presumiblemente dominante un $7 \%$ de los pacientes derivados para implante de DAI para prevención secundaria ${ }^{602}$. Esta experiencia de un solo centro ha mostrado que 31 pacientes con enfermedad cardiaca valvular y taquiarritmias ventriculares malignas protegidos con DAI tuvieron un desenlace favorable. Su supervivencia no fue inferior que la de los pacientes con $\mathrm{CI}$ y era más favorable que la de los pacientes con $\mathrm{MCD}^{602}$. En la experiencia de Yang et al ${ }^{603}$, los pacientes con enfermedad cardiaca valvular y disfunción del VI residual tras cirugía valvular sometidos a un enfoque personalizado para el implante de DAI en prevención primaria tuvieron una supervivencia total y libre de arritmias similar que los pacientes con miocardiopatía isquémica.

Más recientemente, se ha demostrado que los pacientes con enfermedad cardiaca valvular sometidos a implante de DAI en prevención primaria o secundaria de la MSC tienen tasas de descargas del DAI apropiadas y mortalidad similares a las de quienes tienen $\mathrm{CI}$ o MCD ${ }^{604}$.

\section{RIESGO ARRÍTMICO EN POBLACIONES SELECCIONADAS}

\subsection{Pacientes psiquiátricos}

\section{Riesgo arrítmico en pacientes psiquiátricos}

\begin{tabular}{|c|c|c|c|}
\hline Recomendaciones & Clase $^{\mathrm{a}}$ & Nivel $^{\mathrm{b}}$ & $\operatorname{Ref}^{c}$ \\
\hline $\begin{array}{l}\text { Se recomienda ajustar la dosis o interrumpir } \\
\text { el agente perjudicial si, tras tratamiento con } \\
\text { fármacos antipsicóticos, el intervalo QTc alcanza } \\
\text { una duración > } 500 \mathrm{~ms} \text { o aumenta más de } 60 \mathrm{~ms} \\
\text { respecto al basal }\end{array}$ & I & C & 637 \\
\hline $\begin{array}{l}\text { Se recomienda determinar la concentración } \\
\text { plasmática de potasio para evitar la hipopotasemia } \\
\text { durante el tratamiento con fármacos antipsicóticos }\end{array}$ & I & C & 638 \\
\hline $\begin{array}{l}\text { Se recomienda evitar el tratamiento con más de un } \\
\text { fármaco prolongador del intervalo QT }\end{array}$ & I & C & 639,640 \\
\hline $\begin{array}{l}\text { Se debe considerar la evaluación del intervalo } \\
\text { QT antes de iniciar el tratamiento y durante la } \\
\text { titulación de la dosis con fármacos antipsicóticos }\end{array}$ & Ila & C & $\begin{array}{l}638,641, \\
642\end{array}$ \\
\hline
\end{tabular}

QTc: QT corregido.

aClase de recomendación.

bNivel de evidencia.

Referencias que respaldan las recomendaciones.

\subsubsection{Epidemiología}

Los pacientes con esquizofrenia, anorexia nerviosa y otros trastornos de la salud mental tienen una incidencia de muerte súbita mayor que la esperada ${ }^{643}$, que se cree relacionada tanto con estas enfermedades como con su tratamiento. Por ejemplo, los pacientes con esquizofrenia tienen un riesgo de MSC que es 3 veces el de la población general $^{644}$. Más aún, se sabe que una serie de fármacos antipsicóticos $\mathrm{y}$ antidepresivos aumentan el riesgo de arritmias ventriculares y $\mathrm{MSC}^{639}$ y se cree que el mecanismo principal son las $\operatorname{TdP}^{645}$.

Ray et al ${ }^{646}$ estudiaron la asociación entre el uso de fármacos antipsicóticos (principalmente antipsicóticos convencionales) y la muerte súbita en más de 480.000 pacientes, y hallaron evidencia de un efecto dependiente de la dosis, con mayor riesgo para los pacientes con enfermedad cardiovascular. En otro gran estudio reciente de Ray et $\mathrm{al}^{647}$, también se demostró la asociación entre muerte súbita y antipsicóticos atípicos, con un efecto dependiente de la dosis.

En un estudio reciente de $\mathrm{Wu}$ et $\mathrm{al}^{639}$, se incluyó a 17.718 pacientes con episodios de arritmias ventriculares o MSC para examinar los efectos de los fármacos antipsicóticos en el riesgo de arritmia ventricular/ MSC. Se asoció el uso de fármacos antipsicóticos a un aumento del riesgo de arritmias ventriculares o MSC de 1,53 veces (IC95\%, 1,38-1,70; $\mathrm{p}<0,005$ ), y los antipsicóticos con gran potencia de bloqueo de los canales de potasio del gen humano relacionado con ether-à-go-go tenían el mayor riesgo de arritmias ventriculares o MSC (tabla 6).

\subsubsection{Diagnóstico}

Fármacos tales como los antidepresivos tricíclicos se asocian a mayor aumento de QTc y TdP que los inhibidores selectivos de la recaptación de serotonina. A menudo se encuentran implicados un importante bloqueo de los canales de sodio y factores de riesgo basales, incluidas arritmias previas, función del VI alterada, terapia con digoxina en curso e hipopotasemia (diuréticos) ${ }^{638,642,648,649}$. La combinación de diferentes fármacos se debe monitorizar cuidadosamente aunque estos fármacos no sean conocidos por alargar el intervalo QT.

\subsubsection{Tratamiento}

Se recomienda determinar el perfil de riesgo cardiaco y, en caso de hallazgos positivos, evaluación por un cardiólogo. Tras iniciar el tratamiento con fármacos, se recomienda un chequeo cardiaco y, en caso de prolongación del QTc > 500 ms o nuevos síntomas cardiacos, revaluar el tratamiento ${ }^{641}$. Se debe evitar el uso concomitante de fármacos que interactúen con el metabolismo de un fármaco que alargue el QT. Es importante conocer todas las medicaciones concomitantes, incluso las compradas sin receta ${ }^{641}$.

\subsection{Pacientes neurológicos}

\subsubsection{Muerte súbita inexplicable en la epilepsia}

La muerte súbita inexplicable en la epilepsia se define como la muerte no accidental de una persona con epilepsia. La mayoría de los casos se producen por la noche o durante el sueño y no son presenciados $^{650}$. El principal factor de riesgo de muerte súbita inesperada en la epilepsia son las convulsiones frecuentes, especialmente las tonicoclónicas generalizadas ${ }^{651-660}$.

Se debería someter a cribado electrocardiográfico a los pacientes con epilepsia para descartar enfermedades que simulan una epilepsia. Además, la epilepsia también puede deberse a canalopatía neurológica, que puede producir interacciones entre anomalías de los canales iónicos del corazón y el cerebro ${ }^{658,661-664}$. La mejor manera de prevenir la muerte súbita inesperada en la epilepsia es maximizar el control de las convulsiones. 
Tabla 6

Riesgo de arritmia ventricular o muerte súbita cardiaca relacionado con el uso actual de antisicóticos entre 17.718 pacientes

\begin{tabular}{|c|c|c|c|c|}
\hline Clase y agente antipsicótico & Periodo de casos, $\mathrm{n}$ & Periodo de control, $\mathrm{n}$ & OR (IC95\%) & ORa (IC95\%) \\
\hline Uso de antipsicóticos & 5.625 & 5.117 & $1,84(1,67-2,03)$ & $1,53(1,38-1,70)$ \\
\hline Antipsicóticos de primera generación & 2.070 & 1.770 & $2,02(1,76-2,33)$ & $1,66(1,43-1,91)$ \\
\hline Clorpromazina & 248 & 218 & $1,98(1,28-3,05)$ & $1,45(0,93-2,27)$ \\
\hline Clopentixol & 30 & 25 & $2,66(0,71-10,04)$ & $2,4(0,46-12,48)$ \\
\hline Clotiapina & 135 & 117 & $2,68(1,33-5,39)$ & $2,16(1,03-4,53)$ \\
\hline Flupentixol & 400 & 382 & $1,28(0,92-1,78)$ & $1,07(0,77-1,51)$ \\
\hline Haloperidol & 833 & 730 & $1,83(1,47-2,27)$ & $1,46(1,17-1,83)$ \\
\hline Loxapina & 14 & 14 & $1(0,14-7,10)$ & $0,49(0,04-5,87)$ \\
\hline Proclorperazina & 272 & 172 & $2,04(1,60-2,61)$ & $1,69(1,32-2,17)$ \\
\hline Tioridazina & 194 & 173 & $2,17(1,24-3,79)$ & $1,78(1,01-3,15)$ \\
\hline Trifluoperazina & 87 & 73 & $1,88(1,02-3,44)$ & $1,37(0,73-2,57)$ \\
\hline Antipsicóticos de segunda generación & 4.017 & 3.736 & $1,63(1,45-1,84)$ & $1,36(1,20-1,54)$ \\
\hline Amisulprida & 90 & 88 & $1,14(0,56-2,34)$ & $0,94(0,45-1,96)$ \\
\hline Aripriprazol & 35 & 34 & $1,14(0,41-3,15)$ & $0,9(0,31-2,59)$ \\
\hline Clozapina & 141 & 130 & $2,64(1,09-6,38)$ & $2,03(0,83-4,94)$ \\
\hline Olanzapina & 245 & 221 & $2,01(1,23-3,29)$ & $1,64(0,98-2,72)$ \\
\hline Quetiapina & 1.421 & 1.326 & $1,51(1,26-1,82)$ & $1,29(1,07-1,56)$ \\
\hline Risperidona & 1.163 & 1.066 & $1,67(1,36-2,05)$ & $1,39(1,13-1,72)$ \\
\hline Sulpirida & 1.015 & 930 & $1,59(1,29-1,95)$ & $1,26(1,02-1,56)$ \\
\hline Ziprasidona & 27 & 26 & $1,2(0,37-3,93)$ & $0,8(0,24-2,67)$ \\
\hline Zotepina & 154 & 142 & $1,86(0,97-3,56)$ & $1,5(0,77-2,91)$ \\
\hline
\end{tabular}

IC95\%: intervalo de confianza del 95\%; OR: odds ratio; ORa: odds ratio ajustada.

Reproducido con permiso de Wu et al ${ }^{639}$.

\subsubsection{Trastornos neuromusculares}

Riesgo arrítmico en pacientes con trastornos neuromusculares

\begin{tabular}{|c|c|c|c|}
\hline Recomendaciones & Clase $^{\mathrm{a}}$ & Nivel $^{\mathrm{b}}$ & $\operatorname{Ref}^{c}$ \\
\hline $\begin{array}{l}\text { Se recomienda hacer un seguimiento anual de } \\
\text { los pacientes con distrofias musculares, incluso } \\
\text { en la fase oculta de la enfermedad, cuando están } \\
\text { asintomáticos y el ECG es normal }\end{array}$ & I & B & $665-668$ \\
\hline $\begin{array}{l}\text { Se recomienda tratar a los pacientes con } \\
\text { trastornos neuromusculares que tienen arritmias } \\
\text { ventriculares igual que a pacientes sin trastornos } \\
\text { neuromusculares }\end{array}$ & I & C & $\begin{array}{c}\text { Este } \\
\text { panel de } \\
\text { expertos }\end{array}$ \\
\hline $\begin{array}{l}\text { Se recomienda implante de marcapasos } \\
\text { permanente para pacientes con enfermedades } \\
\text { neuromusculares y BAV de tercer o segundo grado } \\
\text { avanzado a cualquier nivel anatómico }\end{array}$ & I & B & 669 \\
\hline $\begin{array}{l}\text { Se puede considerar el implante de marcapasos } \\
\text { permanente para pacientes con distrofia miotónica } \\
\text { de tipo } 1 \text { (enfermedad de Steinert), síndrome de } \\
\text { Kearns-Sayre o distrofia muscular de cinturas con } \\
\text { cualquier grado de BAV (incluso de primer grado) } \\
\text { considerando el riesgo de progresión rápida }\end{array}$ & IIb & B & $\begin{array}{c}666 \\
669-672\end{array}$ \\
\hline $\begin{array}{l}\text { Se puede considerar el uso de DAI en la distrofia } \\
\text { miotónica de tipo } 1 \text { (enfermedad de Steinert) y en } \\
\text { las distrofias musculares de Emery-Dreifuss y de } \\
\text { cinturas de tipo 1B cuando haya indicación para } \\
\text { estimulación cardiaca y evidencia de arritmias } \\
\text { ventriculares }\end{array}$ & IIb & B & $\begin{array}{c}71,669 \\
672-674\end{array}$ \\
\hline
\end{tabular}

BAV: bloqueo auriculoventricular; DAI: desfibrilador automático implantable; ECG: electrocardiograma.

aclase de recomendación.

bNivel de evidencia.

'Referencias que respaldan las recomendaciones.
Las distrofias musculares son un grupo de enfermedades hereditarias que afectan al músculo esquelético y cardiaco. La implicación cardiaca se produce como un proceso degenerativo con fibrosis y sustitución grasa del miocardio ${ }^{666}$ y las manifestaciones más frecuentes son MCD y trastornos de la conducción, los cuales pueden coexistir. En todas las distrofias musculares, la implicación de los músculos respiratorios puede tener impacto en la calidad y la cantidad de vida, y hay que tenerla en cuenta a la hora de considerar un dispositivo cardiaco profiláctico.

La implicación cardiaca es frecuente en la mayoría de los pacientes con distrofias de Duchenne y Becker, distrofia miotónica de tipo 1 (enfermedad de Steinert) y distrofias de Emery-Dreifuss y muscular de cinturas de tipo $1 \mathrm{~B}^{666}$ (tabla 7). El desarrollo de MCD es común en las distrofias musculares de Duchenne y Becker ${ }^{666}$. Se producen arritmias (latidos prematuros ventriculares y TVNS) y trastorno de la conducción tras el desarrollo de MCD, de modo que se debe alinear el tratamiento de la arritmia con las recomendaciones dadas para pacientes con MCD. En la distrofia muscular de Duchenne, se produce muerte súbita principalmente de los pacientes con insuficiencia tanto respiratoria como cardiaca. La proporción de muertes debidas a arritmias no está clara, pero se piensa que las arritmias ventriculares y la muerte súbita tienen en estos trastornos un papel similar que en otras MCD no isquémicas. El implante profiláctico de DAI debe seguir los mismos criterios que en las otras formas de MCD no isquémicas ${ }^{666}$.

La distrofia miotónica de tipo 1 (distrofia de Steinert) se presenta con trastornos de la conducción que con frecuencia requieren estimulación cardiaca con o sin MCD (tabla 7); hasta un tercio de las muertes de estos pacientes son súbitas e inesperadas ${ }^{666}$. En una revisión de 18 estudios (1.828 pacientes) de Petri et al ${ }^{667}$, se comunicó BAV de primer grado en casi un $30 \%$ de los pacientes, QRS $>120$ ms en un $20 \%$, EV frecuente en un 15\% y TVNS en un 4\%. Se describió disfunción sistólica del VI en un 7,2\% de los pacientes y FA o flutter auricular en un 
Tabla 7

Afección cardiaca en las distrofias musculares

\begin{tabular}{|c|c|c|c|c|c|c|}
\hline Miopatía & Gen & Afección cardiaca & $\begin{array}{l}\text { Frecuencia de } \\
\text { afección cardiaca }\end{array}$ & Arritmia ventricular & Arritmia auricular & $\begin{array}{l}\text { Muerte súbita } \\
\text { reportada }\end{array}$ \\
\hline Duchenne & Distrofina & MCD & $>90 \%$ & EV & Solo en fase tardía & Sí \\
\hline Becker & Distrofina & MCD & $60-75 \%$ & TV asociada a MCD & Asociada a MCD & Sí \\
\hline Miotónica tipo 1 & $\begin{array}{l}\text { Expansión de } \\
\text { repetición CGT }\end{array}$ & $\begin{array}{l}\text { Trastornos de } \\
\text { conducción y MCD }\end{array}$ & $60-80 \%$ & TV, DAI indicado & $\begin{array}{l}\text { Dependiente de la } \\
\text { edad }\end{array}$ & Sí, 30\% de muertes \\
\hline Miotónica tipo 2 & $\begin{array}{l}\text { Expansión de } \\
\text { repetición CGT }\end{array}$ & $\begin{array}{l}\text { Trastornos de } \\
\text { conducción }\end{array}$ & $10-25 \%$ & Poco común & Poco común & Sí \\
\hline Emery-Dreifuss & $\begin{array}{l}\text { Emerina, lamina } \\
\text { A y C }\end{array}$ & $\begin{array}{l}\text { Trastornos de } \\
\text { conducción y MCD }\end{array}$ & $>90 \%$ & TV, DAI indicado & $\begin{array}{l}\text { Común, parada } \\
\text { auricular }\end{array}$ & Sí, 30\% de muertes \\
\hline Muscular de cinturas tipo 1B & Lamina A y C & $\begin{array}{l}\text { Trastornos de } \\
\text { conducción y MCD }\end{array}$ & $>90 \%$ & TV, DAI indicado & Común & Sí, 30\% de muertes \\
\hline Muscular de cinturas tipo $2 \mathrm{C}-2 \mathrm{~F}$ & Sarcoglucanos & $\mathrm{MCD}$ & $<25 \%$ & Poco común & Pocos datos & Desconocido \\
\hline Muscular de cinturas tipo 2I & $\begin{array}{l}\text { Proteína } \\
\text { relacionada con } \\
\text { la fukutina }\end{array}$ & MCD & $20-80 \%$ & Poco común & No reportada & Desconocido \\
\hline Fascioescapulohumeral & $\begin{array}{l}\text { Contracción de } \\
\text { la repetición } \\
\text { D4Z4 }\end{array}$ & $\begin{array}{l}\text { Trastornos de } \\
\text { conducción }\end{array}$ & $5-15 \%$ & TV raras & Rara & No \\
\hline
\end{tabular}

DAI: desfibrilador automático implantable; EV: extrasístole ventricular; MCD: miocardiopatía dilatada; TV: taquicardia ventricular.

Adaptado con permiso de Groh et al ${ }^{666}$.

5\%. Con base en la elevada incidencia de trastornos de la conducción, se ha especulado que la MSC en la enfermedad de Steiner está causada principalmente por trastorno de la conducción progresivo; sin embargo, la evidencia de muerte súbita de pacientes con marcapa$\operatorname{sos}^{673}$ y TV espontáneas o inducibles parece indicar que las arritmias ventriculares son la causa de algunas de las muertes súbitas.

Lallemand et al ${ }^{668}$ estudiaron a pacientes con enfermedad de Steiner y realizaron mediciones invasivas seriadas de los intervalos Hisventrículo que mostraron que la aparición de nuevo trastorno de la conducción se sigue de alargamiento de la conducción infrahisiana a los 5 años. De modo similar, un estudio de Laurent et al ${ }^{673}$ señaló que una prolongación del intervalo His-ventrículo > $70 \mathrm{~ms}$ en un EEF invasivo es predictiva de BAV completo a los 6 años. Groh et al ${ }^{669}$ estudiaron a 406 pacientes adultos con distrofia miotónica de tipo 1 genéticamente confirmada, y mostraron que la gravedad del defecto de conducción auriculoventricular o intraventricular y la presencia de arritmias auriculares eran factores de riesgo de muerte súbita independientes. En un gran estudio observacional retrospectivo de Wahbi et al $^{672}$, el uso de EEF seguido de implante de marcapasos en pacientes con un intervalo His-ventrículo > 70 ms redujo la muerte súbita en comparación con pacientes en los que se siguió de valoración por ECG.

En los pacientes con distrofias musculares de Emery-Dreifuss y cinturas de tipo $1 \mathrm{~B}$ asociadas a mutaciones de la lamina $\mathrm{A}$ o $\mathrm{C}$, la muerte súbita causa un 30\% de todas las muertes ${ }^{71}$.

Algunas series de pacientes con las 2 distrofias de lamina A y C indicaron que la aparición de BAV se asocia a malos resultados y la estimulación cardiaca es insuficiente para prevenir la MSC, lo que respalda el uso de DAI profilácticos en lugar de marcapasos cuando haya implicación cardiaca ${ }^{674}$. Entre los factores de riesgo de muerte súbita y terapias apropiadas del DAI, se incluyen TVNS, FEVI $<45 \%$, sexo masculino y mutaciones sin cambio de sentido en $L M N A^{71}$. El tratamiento de la rara distrofia muscular de Emery-Dreifuss recesiva y ligada a $\mathrm{X}$ asociada a mutaciones en el gen de emerina es complicado por la falta de datos clínicos; en ausencia de información específica de genes, parece razonable adoptar la estrategia de tratamiento empleada en la forma dominante de Emery-Dreifuss ${ }^{666,671}$.

\subsection{Pacientes gestantes}

\subsubsection{Arritmias no relacionadas con miocardiopatía periparto}

\section{Tratamiento del riesgo arrítmico durante la gestación}

\begin{tabular}{|c|c|c|c|}
\hline Recomendaciones & Clase $^{\mathrm{a}}$ & Nivel $^{\mathrm{b}}$ & $\operatorname{Ref}^{c}$ \\
\hline $\begin{array}{l}\text { Se recomienda implante de DAI si surge una } \\
\text { indicación durante la gestación }\end{array}$ & I & C & 675 \\
\hline $\begin{array}{l}\text { Se recomiendan los bloqueadores beta durante } \\
\text { la gestación y también después del parto para } \\
\text { pacientes con SQTL o TVPC }\end{array}$ & I & C & 675,676 \\
\hline $\begin{array}{l}\text { Se recomienda metoprolol, propranolol o } \\
\text { verapamilo oral para el tratamiento a largo plazo } \\
\text { de la TV sostenida idiopática }\end{array}$ & I & C & 675,677 \\
\hline $\begin{array}{l}\text { Se recomienda la cardioversión eléctrica inmediata } \\
\text { para la TV sostenida, especialmente si es } \\
\text { hemodinámicamente inestable }\end{array}$ & I & $\mathrm{C}$ & 675,677 \\
\hline $\begin{array}{l}\text { Se debe considerar el sotalol o la procainamida } \\
\text { i.v. para la conversión aguda de la TV sostenida } \\
\text { monomórfica hemodinámicamente estable }\end{array}$ & IIa & C & 675 \\
\hline $\begin{array}{l}\text { Se debe considerar la amiodarona i.v. para la } \\
\text { conversión aguda de la TV monomórfica sostenida } \\
\text { si es hemodinámicamente inestable, refractaria } \\
\text { a la cardioversión eléctrica o no responde a otros } \\
\text { fármacos }\end{array}$ & IIa & C & $\begin{array}{l}675,677 \\
678\end{array}$ \\
\hline $\begin{array}{l}\text { Se puede considerar la ablación con catéter } \\
\text { para el tratamiento de las taquicardias refractarias } \\
\text { a fármacos mal tolerados }\end{array}$ & IIb & C & 675 \\
\hline
\end{tabular}

DAI: desfibrilador automático implantable; SQTL: síndrome del QT largo; TV: taquicardia ventricular; TVPC: taquicardia ventricular polimórfica catecolaminérgica.

aClase de recomendación.

bNivel de evidencia.

'Referencias que respaldan las recomendaciones. 


\subsubsection{Epidemiología}

La gestación añade un riesgo significativo a las mujeres con enfermedad cardiaca estructural ${ }^{675,679-681}$. Hay un aumento sustancial del riesgo de eventos cardiacos en mujeres con SQTL congénito en el periodo posparto (40 semanas después del parto), y se debería continuar el tratamiento con bloqueadores beta ${ }^{676,682}$ durante toda la gestación y después del parto. Las mujeres con síndrome de Brugada pueden tener gestación y periodo periparto seguros ${ }^{683,684}$.

\subsubsection{Diagnóstico}

Las palpitaciones pueden estar causadas por extrasístoles auriculares o ventriculares o incluso por taquicardia sinusal, y en su mayoría son benignas ${ }^{677,685-688}$. En muchas pacientes se produce una exacerbación sintomática de la taquicardia supraventricular paroxística durante la gestación. Durante la gestación puede presentarse TV de nueva aparición ${ }^{677,686-688}$ y puede estar relacionada con aumento de catecolaminas ${ }^{689}$. El riesgo de TV recurrente es mayor en pacientes con TV y enfermedad cardiaca estructural previas ${ }^{676,690,691}$.

\subsubsection{Tratamiento}

Cuando se encuentran arritmias benignas, las pacientes necesitan tranquilidad y deben evitar los estimulantes como la cafeína, el tabaco y el alcohol. La taquiarritmia sintomática se debe tratar mediante ablación con catéter antes de la gestación si esta es planeada. Si se recomienda la terapia con fármacos, se aconseja iniciarla lo más tarde posible en la gestación y emplear la menor dosis efectiva.

Las arritmias en ausencia de enfermedad cardiaca estructural durante la gestación normalmente son sensibles a la terapia con bloqueadores beta ${ }^{675,692,693}$. Se puede considerar el sotalol o los bloqueadores de los canales de sodio (agentes de clase IC) en ausencia de enfermedad cardiaca estructural si los bloqueadores beta son ineficaces.

Aunque el primer trimestre se asocia al mayor riesgo teratogénico, la exposición a fármacos más tarde en la gestación puede causar efectos adversos en el crecimiento y el desarrollo fetal, así como aumentar el riesgo de proarritmia. La Food and Drug Administration ha definido 5 categorías para el uso de fármacos antiarrítmicos durante la gestación $^{694}$ :

- A: los estudios controlados no muestran riesgo (sin fármaco antiarrítmico).

- B: la posibilidad de dañar al feto es remota (sotalol, lidocaína).

- C: los beneficios potenciales superan al riesgo (quinidina, adenosina, metoprolol, propranolol, verapamilo, diltiazem, digoxina, flecainida, propafenona).

- D: evidencia de riesgo positiva (fenitoína, amiodarona).

- X: contraindicado.

El tratamiento farmacológico de la TV del TSVD idiopática es verapamilo o bloqueadores beta (metoprolol o sotalol) como profilaxis si se asocian a síntomas graves o deterioro hemodinámico. La TV izquierda fascicular idiopática normalmente no responde a los bloqueadores beta y se puede tratar con verapamilo; el mecanismo de esta taquicardia depende de la entrada lenta de calcio en fibras de Purkinje parcialmente despolarizadas ${ }^{1}$. Puede ser necesaria la ablación con catéter en caso de taquicardias refractarias a fármacos y mal toleradas. Las pacientes con DAI pueden tener una gestación exitosa sin riesgo fetal ${ }^{695-697}$. Si surgen indicaciones de DAI durante la gestación, se puede considerar el uso de un DAI subcutáneo para evitar la fluoroscopia, pero se debe sopesar frente a la escasa experiencia disponible.

\subsubsection{Arritmias relacionadas con miocardiopatía periparto}

Tratamiento de arritmias relacionadas con miocardiopatía inducida por la gestación

\begin{tabular}{lccc}
\hline Recomendaciones & Clase $^{\mathrm{a}}$ & $\mathrm{Nivel}^{\mathrm{b}}$ & $\operatorname{Ref}^{\mathrm{c}}$ \\
\hline $\begin{array}{l}\text { Se recomienda cardioversión eléctrica o } \\
\text { desfibrilación para gestantes que sufran TV o FV } \\
\text { hemodinámicamente inestable }\end{array}$ & I & B & 698 \\
\hline $\begin{array}{l}\text { Se recomienda el tratamiento estándar de la IC } \\
\text { evitando fármacos contraindicados en la gestación } \\
\text { (IECA, ARA-II e inhibidores de la renina) }\end{array}$ & I & C & 698,699 \\
\hline
\end{tabular}

ARA-II: antagonistas del receptor de la angiotensina II; FV: fibrilación ventricular; IC: insuficiencia cardiaca; IECA: inhibidores de la enzima de conversión de la angiotensina; TV: taquicardia ventricular.

${ }^{a}$ Clase de recomendación.

bNivel de evidencia.

cReferencias que respaldan las recomendaciones.

La miocardiopatía periparto se define como IC causada por disfunción sistólica del VI que se presenta hacia el final de la gestación o en los meses siguientes al parto ${ }^{700}$. La causa de la miocardiopatía periparto es incierta, e infecciones, inflamación y procesos autoinmunes pueden participar en ella ${ }^{1,701}$. Se ha estimado la incidencia en 50/100.000 nacidos vivos $^{702}$. La tasa estimada de mortalidad relacionada con miocardiopatía periparto en Estados Unidos varía entre el 6 y el 10\% ${ }^{703}$. Estudios recientes indican que la miocardiopatía periparto puede ser una manifestación de MCD familiar asociada a mutaciones génicas ${ }^{704}$.

La miocardiopatía periparto se presenta habitualmente con IC secundaria a disfunción sistólica del VI hacia el final de la gestación o en los meses siguientes al parto. El VI puede no estar dilatado, pero la FE casi siempre está reducida $(<45 \%)^{698}$. Con esta reciente definición, la ventana temporal no está estrictamente definida ${ }^{705}$. Pueden producirse como resultado arritmias ventriculares complejas y parada cardiaca súbita. Habría que descartar la miocardiopatía posparto en mujeres que se presentan con TV de nueva aparición durante las últimas 6 semanas de gestación o al principio del posparto ${ }^{706}$.

Se debería aplicar la guía para el tratamiento de la IC aguda ${ }^{8}$. Durante la gestación, están contraindicados los IECA, los ARA-II y los inhibidores de la renina ${ }^{699,707}$. Se recomienda el tratamiento con bloqueadores beta para todas las pacientes con IC que lo toleren; se debe preferir los bloqueadores beta con propiedades preferentemente $\beta_{1}$-adrenérgicas (es decir, metoprolol). No se debe usar atenolol ${ }^{708}$. Se debe evitar los $\mathrm{ARM}^{709}$. Se debe interrumpir por cardioversión eléctrica las taquiarritmias ventriculares de potencial riesgo vital. El implante de un DAI en pacientes con arritmia ventricular o FE baja debe seguir las directrices estándar. Sin embargo, a la hora de tomar decisiones se debe considerar la relativamente alta (50\%) tasa de recuperación espontánea de la MCD tras el parto ${ }^{710}$.

\subsection{Apnea obstructiva del sueño}

\subsubsection{Bradiarritmias y taquiarritmias}

Tratamiento de arritmias ventriculares y bradiarritmias en la apnea del sueño

\begin{tabular}{|c|c|c|c|}
\hline Recomendaciones & Clase $^{\mathrm{a}}$ & Nivel $^{\mathrm{b}}$ & $\operatorname{Ref}^{\mathrm{c}}$ \\
\hline $\begin{array}{l}\text { Se debe considerar el síndrome de apneas del sueño } \\
\text { en el diagnóstico diferencial de las bradiarritmias }\end{array}$ & IIa & B & 711 \\
\hline $\begin{array}{l}\text { La presencia de apneas del sueño y saturación de } \\
\text { oxígeno reducida se puede considerar factor de } \\
\text { riesgo de MSC en sujetos con trastornos respiratorios } \\
\text { durante el sueño }\end{array}$ & IIb & C & 712 \\
\hline
\end{tabular}

MSC: muerte súbita cardiaca.

aClase de recomendación.

${ }^{\mathrm{b}}$ Nivel de evidencia.

'Referencias que respaldan las recomendaciones. 


\subsubsection{Epidemiología}

Los datos sobre prevalencia de la apnea obstructiva del sueño en la población general no son unívocos debido a la gran heterogeneidad de las poblaciones estudiadas; sin embargo, según un riguroso estudio poblacional que determinó las características epidemiológicas de la apnea obstructiva del sueño en 602 adultos de 30-60 años, la prevalencia de la enfermedad fue del $9 \%$ de las mujeres y el $24 \%$ de los varones $^{713}$. La prevalencia de las arritmias depende en gran medida de las comorbilidades presentes en las diferentes poblaciones. Los datos del Busselton Health Study ${ }^{714}$ y la Wisconsin Sleep Cohort ${ }^{715}$ apuntan a que la apnea obstructiva del sueño se asocia a mayor mortalidad. Se ha debatido la existencia de una conexión con la MSC.

Recientemente, Gami et al ${ }^{712}$ han demostrado que la apnea obstructiva del sueño asociada a una media de saturación de oxígeno nocturna reducida $<93 \%$ y una saturación de oxígeno nocturna mínima $<78 \%$ son factores de riesgo de MSC independientes $(\mathrm{p}<0,0001)$. Por lo tanto, se debe incluir la presencia de apnea obstructiva del sueño en baterías de pruebas para la estratificación del riesgo de MSC.

La frecuencia de arritmias cardiacas, principalmente nocturnas, aumenta con la gravedad del síndrome de apneas/hipopneas del sueño ${ }^{716-718}$

\subsubsection{Diagnóstico}

Las anormalidades del ritmo cardiaco más comunes en pacientes con síndrome de apneas/hipopneas del sueño son la bradicardia sinusal, la pausa sinusal, el BAV de primer y segundo grado Mobitz I y una mayor tasa de $\mathrm{EV}^{719-724}$. Se ha demostrado un patrón circadiano de

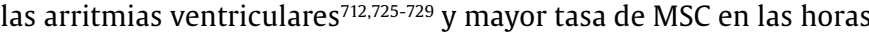
de sueño (entre las 0.00 y las 6.00).

\subsubsection{Tratamiento}

Actualmente, no hay evidencia que indique desviarse del tratamiento estándar de la arritmia ventricular de pacientes con síndrome de apneas/hipopneas del sueño; además, aún no se ha definido el valor de la presión aérea positiva continua para la prevención de arritmias ventriculares y MSC $\mathrm{C}^{711,730-733}$.

Se desconoce si el tratamiento apropiado de la apnea obstructiva del sueño podría modificar las manifestaciones clínicas y evitar la necesidad de terapia con marcapasos en los pacientes cuyas arritmias están relacionadas solo con eventos de obstrucción respiratoria ${ }^{733-739}$.

Están en estudio innovadoras terapias de estimulación más modernas para tratar el síndrome de apneas/hipopneas centrales del sueño con estimulación del nervio frénico y de las vías aéreas superiores para la forma obstructiva ${ }^{740}$.

\subsection{Proarritmia relacionada con fármacos}

Tratamiento de la proarritmia relacionada con fármacos

\begin{tabular}{lccc}
\hline Recomendaciones & Clase $^{\mathrm{a}}$ & Nivel $^{\mathrm{b}}$ & Ref $^{\mathrm{c}}$ \\
\hline $\begin{array}{l}\text { Se recomienda retirar los agentes perjudiciales } \\
\text { siempre que se sospechen arritmias inducidas } \\
\text { por fármacos y se hayan excluido otros sustratos } \\
\text { arritmogénicos }\end{array}$ & I & B & 362 \\
\hline $\begin{array}{l}\text { A pesar de una posible causa corregible de } \\
\text { la arritmia ventricular, se debe considerar la } \\
\text { necesidad de implante profiláctico de DAI basada } \\
\text { en una evaluación individualizada del futuro riesgo } \\
\text { de arritmias ventriculares de riesgo vital }\end{array}$ & Ila & C & 741,742 \\
\hline
\end{tabular}

DAI: desfibrilador automático implantable.

aClase de recomendación.

bivel de evidencia.

Referencias que respaldan las recomendaciones.

\subsubsection{Interacción fármaco-sustrato debida a sustrato de enfermedad subyacente}

Cuando se sospecha de arritmias inducidas por fármacos, se debe interrumpir cualquier fármaco perjudicial. Además, se debe realizar una valoración completa para excluir factores de riesgo cardiovascular que pudieran contribuir a un episodio arrítmico. Se debería sospechar arritmia inducida por fármacos si se ha excluido un sustrato arritmogénico hereditario o adquirido y el paciente está tratado con agentes conocidos por alterar las propiedades eléctricas del corazón (p. ej., induciendo prolongación del QT) o causar anormalidades electrolíticas.

En pacientes con hipertrofia del VI, el uso de sotalol se ha asociado a proarritmia ${ }^{743}$. De modo similar, hay cierta preocupación sobre el uso de flecainida y propafenona para estos pacientes, en particular cuando haya una hipertrofia significativa (grosor de la pared del VI $>1,4 \mathrm{~cm}$ ) o $\mathrm{CI}$ subyacente ${ }^{744}$.

No se debería usar fármacos bloqueadores de los canales de sodio en pacientes con antecedente de infarto de miocardio ${ }^{129}$ o TV sostenida debido a enfermedad cardiaca estructural. También habría que evitar en estas circunstancias otros fármacos con actividad bloqueadora de los canales de sodio como los antidepresivos tricíclicos. Si la función ventricular es anormal, la evaluación y el tratamiento deben ser similares que para pacientes que sufren arritmia ventricular en ausencia de fármacos antiarrítmicos.

\subsubsection{Interacción fármaco-fármaco debida a fármacos específicos y combinaciones}

Muchas medicaciones no cardiacas inhiben los canales de potasio (http://www.crediblemeds.org) y en pacientes susceptibles se asocian a riesgo de taquicardias en TdP. El tratamiento con varios antibióticos, como quinolonas o azitromicina, aumenta significativamente el riesgo de muerte y arritmia cardiaca ${ }^{125,745-747}$. Se ha visto que otros antibióticos macrólidos, incluidas la eritromicina y la claritromicina (también metabolizados por la enzima citocromo P450 3A4), aumentan el riesgo de TV polimórfica y muerte cardiaca, especialmente en mujeres ${ }^{748}$. La combinación de inhibidores del sistema renina-angiotensina y antibióticos tales como cotrimoxazol con hiperpotasemia no reconocida se ha asociado recientemente a un aumento del riesgo de muerte súbita ${ }^{749}$.

Los fármacos bloqueadores de los canales de sodio, tales como los antidepresivos tricíclicos, pueden producir prolongación del QRS y el ECG típico del síndrome de Brugada ${ }^{750}$. La cardiotoxicidad de la antraciclina es dependiente de la dosis, y las dosis acumuladas más altas aumentan el riesgo de miocardiopatía y arritmias mortales ${ }^{751,752}$. El 5-fluorouracilo puede causar FV por espasmo coronario ${ }^{753-755}$. El veneno de sapo puede producir toxicidad clínica parecida a la de la digoxina ${ }^{756}$; se ha descrito que productos como el té de dedalera producen efectos similares ${ }^{757,758}$. Otros muchos fármacos pueden producir espasmo coronario ${ }^{759-761}$.

Casi independientemente del fármaco específico que causó la TdP, el tratamiento debe dirigirse a evitar los medicamentos en los pacientes con alto riesgo de arritmia inducida por fármacos. El magnesio intravenoso puede suprimir los episodios de TdP sin acortar necesariamente el QT, incluso cuando la concentración de magnesio en suero sea normal ${ }^{762}$. La estimulación cardiaca temporal es altamente eficaz en el tratamiento de la TdP. También se puede usar isoproterenol. Se recomienda retirar cualquier fármaco perjudicial y corregir las anormalidades electrolíticas en estos pacientes.

\subsubsection{Riesgo proarrítmico de fármacos antiarrítmicos}

Los fármacos antiarrítmicos tienen efectos directos en los canales iónicos cardiacos. La flecainida, la propafenona y la quinidina tienen efectos bloqueadores de los canales de sodio ${ }^{763}$. En grandes estudios 
clínicos, como CAST y CASH, los fármacos bloqueadores de los canales de sodio aumentaban la mortalidad de los pacientes con infarto de miocardio previo ${ }^{129,764}$. Se observaron tendencias similares en los estudios previos de mexiletina ${ }^{363}$ y disopiramida ${ }^{362}$. En los pacientes en tratamiento de la TV sostenida, estos agentes pueden originar episodios de TV sostenida más frecuentes y a menudo de más difícil cardioversión ${ }^{765,766}$.

El d-sotalol, agente prolongador del QT (un antiarrítmico puro de clase III), aumentó ligeramente la mortalidad en un gran ensayo clínico aleatorizado en pacientes con infarto remoto ${ }^{137}$. En el estudio DIAMOND, un 3,3\% de los pacientes con IC grave tuvieron TdP las primeras 72 h de terapia con dofetilida ${ }^{767}$. La amiodarona puede causar TdP mucho menos habitualmente que otros antiarrítmicos prolongadores del QT ${ }^{768}$.

Las bradiarritmias son efectos farmacológicos comunes de digoxina, verapamilo, diltiazem y bloqueadores beta. Algunas arritmias son típicas de la toxicidad digitálica: automatismo auricular, nodular o ventricular aumentada, frecuentemente combinada con BAV.

En la mayoría de los casos, el tratamiento incluye interrupción del fármaco, monitorización del ritmo y mantenimiento de concentraciones séricas de potasio normales. El magnesio i.v. y la estimulación cardiaca temporal pueden ser de utilidad ${ }^{762}$. También se puede usar isoproterenol para aumentar el ritmo cardiaco y acortar la duración del potencial de acción ventricular para eliminar las despolarizaciones y la TdP762,769-771.

\subsubsection{Proarritmia debida a factores desencadenantes}

Varios factores desencadenantes, como hipopotasemia $(<3,5$ $\mathrm{mmol}$ ), un rápido aumento del potasio extracelular e hipomagnesemia, se asocian a arritmia ventricular y MSC ${ }^{772,773}$. La hipomagnesemia se asocia clásicamente a TV polimórfica o TdP, que pueden responder al magnesio i.v. ${ }^{774,775}$. La hipopotasemia con o sin hipomagnesemia puede ser causa de arritmia ventricular en sujetos con hipertensión e IC congestiva (precipitada por el uso de tiacidas y diuréticos de asa) ) $^{774}$. Múltiples factores, como bradicardia, isquemia, espasmo coronario, trombosis, inanición aguda ${ }^{776}$ y toxicidad/retirada aguda del alcohol ${ }^{777,778}$, pueden facilitar la aparición de arritmia ventricular y MSC. Los DAI también pueden causar la aparición de arritmia ventricular ${ }^{779-781 .}$.

Para estos pacientes se recomienda retirar cualquier fármaco perjudicial y corregir las anormalidades electrolíticas.

\subsection{Muerte súbita cardiaca después de un trasplante cardiaco}

Muchos estudios clínicos han demostrado que la muerte súbita es frecuente después de un trasplante cardiaco (más del 10\% de los receptores de trasplante cardiaco ${ }^{782}$. Algunos pacientes pueden sufrir muerte súbita tras una historia de varios episodios de rechazo grave.

En pacientes con rechazo agudo, se puede dañar el sistema de conducción, lo cual conduce a arritmias ventriculares y muerte súbita. Estos corazones pueden encontrarse en riesgo aumentado de arritmias durante el estrés hemodinámico de la hemodiálisis o la plasmaféresis $^{783}$. Se encuentra enfermedad coronaria en la mayoría de los pacientes de trasplante cardiaco con muerte súbita; puede deberse a hiperpotasemia, hemodiálisis o plasmaféresis como desencadenantes del evento, pero puede ser también una muerte arrítmica primaria.

El uso de DAI tras el trasplante cardiaco puede resultar apropiado para pacientes de alto riesgo seleccionados ${ }^{784}$.

\subsection{Muerte súbita cardiaca de atletas}

Los atletas se encuentran en un riesgo de MSC excesivo en comparación con los no atletas de edad similar ${ }^{26}$ : se estima que la incidencia
Prevención de la muerte súbita cardiaca de atletas

\begin{tabular}{|c|c|c|c|}
\hline Recomendaciones & Clase $^{a}$ & Nivel $^{\mathrm{b}}$ & $\operatorname{Ref}^{c}$ \\
\hline $\begin{array}{l}\text { Para los atletas, se recomienda una cuidadosa } \\
\text { recogida de la historia para descubrir enfermedad } \\
\text { cardiovascular subyacente, trastornos del ritmo, } \\
\text { episodios de síncope o historia familiar de MSC }\end{array}$ & I & C & $\begin{array}{l}\text { Este } \\
\text { panel de } \\
\text { expertos }\end{array}$ \\
\hline $\begin{array}{l}\text { Tras identificar anomalías del ECG que indiquen } \\
\text { cardiopatía estructural, se recomienda } \\
\text { ecocardiografía o RMC }\end{array}$ & I & C & $\begin{array}{l}\text { Este } \\
\text { panel de } \\
\text { expertos }\end{array}$ \\
\hline $\begin{array}{l}\text { Para los atletas más jóvenes, se debe considerar } \\
\text { examen físico y ECG de } 12 \text { derivaciones en reposo } \\
\text { para el cribado previo a la participación }\end{array}$ & IIa & C & $\begin{array}{l}\text { Este } \\
\text { panel de } \\
\text { expertos }\end{array}$ \\
\hline $\begin{array}{l}\text { Se debe cribar a los individuos de mediana edad } \\
\text { que realizan ejercicio de gran intensidad mediante } \\
\text { historia, examen físico, SCORE y ECG en reposo }\end{array}$ & IIa & C & 785 \\
\hline $\begin{array}{l}\text { El personal de las instalaciones deportivas debe } \\
\text { estar entrenado en reanimación cardiopulmonar } \\
\text { y el uso apropiado de desfibriladores automáticos } \\
\text { externos }\end{array}$ & IIa & C & 179,786 \\
\hline
\end{tabular}

ECG: electrocardiograma; MSC: muerte súbita cardiaca; RMC: resonancia magnética cardiaca; SCORE: evaluación sistemática de riesgos coronarios ${ }^{787}$.

aClase de recomendación.

bNivel de evidencia.

'Referencias que respaldan las recomendaciones.

anual de MSC en atletas jóvenes (< 35 años) oscila entre 0,7 y $3,0 / 100.000^{788}$. En atletas de más edad, la incidencia es mayor y se espera que aumente con la edad ${ }^{789}$. La intensidad de la actividad y la edad del atleta son factores de riesgo fundamentales.

Las causas más frecuentes de muerte súbita de los atletas más jóvenes son los trastornos arritmogénicos hereditarios (miocardiopatías y canalopatías) y la CI (tanto congénita como adquirida). En Estados Unidos, se estableció el National Registry of Sudden Death in Athletes en el Minneapolis Heart Institute en los años ochenta, que ha emitido informes sobre 1.866 muertes súbitas de individuos menores de 40 años durante un periodo observacional de 27 años. Sus datos muestran que un $36 \%$ de todas las muertes súbitas en este registro se atribuyen a causas cardiovasculares confirmadas, de las cuales las más frecuentes son la MCH (36\%), las anomalías congénitas de las arterias coronarias (17\%), la miocarditis (6\%), la MAVD (4\%) y las canalopatías $(3,6 \%)^{27}$. En Italia, investigadores de la región del Véneto realizaron un estudio de cohortes prospectivo que incluyó a sujetos mayores de 36 años implicados en deportes de competición entre 1979 y 1999. Se encontró MAVD como causa de MSC en un $24 \%$ de estos atletas, seguida de la CI aterosclerótica (20\%), el origen anómalo de las arterias coronarias (14\%) y el prolapso de la válvula mitral $(12 \%)^{26}$. En atletas de más edad (> 35-40 años), como en la población general, la enfermedad coronaria aterosclerótica representa más de la mitad de $\operatorname{casos}^{29}$.

El cribado previo a la participación parece eficaz ${ }^{790}$ en la prevención de la MSC, pero los programas de cribado varían mucho entre los países europeos y entre Europa y Estados Unidos ${ }^{791}$. El cribado cardiaco debe estar adaptado a la edad del atleta para que pueda dar cuenta de factores de riesgo específicos de la edad. En atletas jóvenes (35 o menos años), el cribado debe centrarse en miocardiopatías y canalopatías hereditarias (véanse las secciones 8 y 9). En atletas de más edad, la CI es la causa más común de MSC y el cribado también debe dirigirse a la detección de signos de isquemia ${ }^{792}$.

La European Association of Cardiovascular Prevention and Rehabilitation ha emitido recomendaciones para la evaluación cardiovascular de individuos activos de mediana edad/mayores involucrados en actividades deportivas en su tiempo libre ${ }^{792}$. El esquema de valoración de riesgos para individuos activos de mediana edad se resume en la figura 4.

Recientemente, Menafoglio et al $^{785}$ valoraron las implicaciones para el volumen de trabajo, el rendimiento y los costes económicos de 


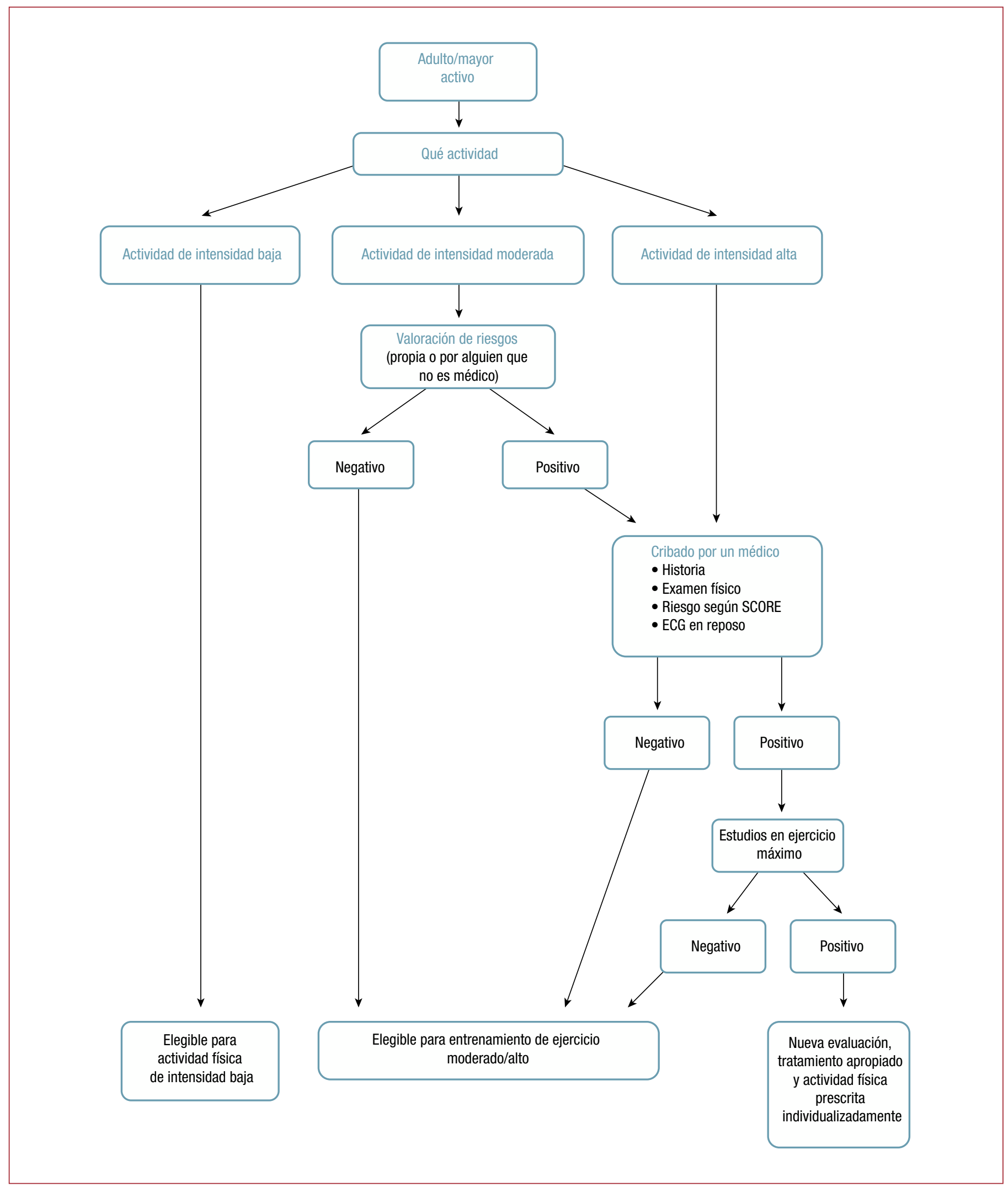

Figura 4. Protocolo de evaluación previa a la participación propuesto para individuos adultos o mayores activos y asintomáticos. ECG: electrocardiograma; SCORE: evaluación sistemática de riesgos coronarios. Adaptado de Borjesson et al ${ }^{792}$ con permiso. 
esta estrategia preventiva en 785 atletas de 35-56 años involucrados en deportes de gran intensidad. Se determinó un trastorno cardiovascular en el 2,8\% de los atletas y el coste supuso 199 dólares por atleta. Los autores concluyeron que la evaluación generalizada parece factible y a un coste razonable ${ }^{785}$.

Es importante que los entrenadores y el personal de las instalaciones deportivas estén adiestrados para enfrentarse a situaciones de emergencia, realizar reanimación cardiopulmonar y utilizar desfibriladores automáticos externos ${ }^{179,786}$.

\subsection{Síndrome de Wolff-Parkinson-White}

Tratamiento de pacientes con síndrome de Wolff-Parkinson-White

\begin{tabular}{lccc}
\hline Recomendaciones & Clase $^{\mathrm{a}}$ & Nivel $^{\mathrm{b}}$ & Ref $^{\mathrm{c}}$ \\
\hline $\begin{array}{l}\text { Se recomienda la ablación para pacientes con } \\
\text { síndrome de WPW reanimados de parada cardiaca } \\
\text { súbita debida a FA y conducción rápida por la vía } \\
\text { accesoria causante de FV }\end{array}$ & I & B & 793 \\
\hline $\begin{array}{l}\text { Se debe considerar la ablación para pacientes con } \\
\text { síndrome de WPW sintomáticos o que tengan vías } \\
\text { accesorias con periodos refractarios } \leq 240 \mathrm{~ms}\end{array}$ & Ila & B & 793 \\
\hline
\end{tabular}

FA: fibrilación auricular; FV: fibrilación ventricular; WPW: Wolff-Parkinson-White.

${ }^{a}$ Clase de recomendación.

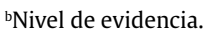

'Referencias que respaldan las recomendaciones.

El síndrome de Wolff-Parkinson-White (WPW) es una causa bastante infrecuente de MSC, con una incidencia anual estimada de un $0,05-0,2 \% 794$. Se puede producir MSC por aparición de FA con rápida respuesta ventricular que degenera en $\mathrm{FV}^{795}$. El principal factor de riesgo de MSC es la presencia de una vía accesoria con refractariedad anterógrada corta. En un reciente registro prospectivo de 8 años sobre 2.169 pacientes con síndrome de WPW, sufrieron MSC principalmente los pacientes con periodos refractarios anterógrados de la vía $\leq 240 \mathrm{~ms}$ y taquicardia por reentrada auriculoventricular iniciadora de $\mathrm{FA}^{793}$.

Se recomienda un EEF con ablación en pacientes con síndrome de WPW reanimados de una parada cardiaca abortada debida a FA y conducción rápida por la vía accesoria que causa $\mathrm{FV}^{796}$. Se debería considerar EEF y ablación si el paciente está sintomático (p. ej., con síncope o palpitaciones) o el periodo refractario de la vía accesoria es $\leq 240 \mathrm{~ms}^{793}$. El EEF debe incluir la medición del intervalo RR preexcitado más corto durante la FA inducida (o del intervalo RR preexcitado más corto durante la estimulación auricular rápida), la determinación del número y la localización de las vías accesorias, las propiedades anterógradas y retrógradas de las vías accesorias y el NAV y el periodo refractario eficaz de las vías accesorias y el ventrículo a múltiples longitudes de ciclo.

Se debe evitar el tratamiento con antagonistas del calcio (verapamilo) o digoxina para los pacientes con WPW, ya que estas medicaciones pueden aumentar la conducción anterógrada a través de la vía accesoria por aumento del periodo refractario en el NAV.

\subsection{Prevención de la muerte súbita cardiaca de ancianos}

El uso de fármacos antiarrítmicos en pacientes ancianos se debe ajustar para adaptarse a una disminución del aclaramiento renal y hepático, cambios en la composición corporal y las comorbilidades. También hay que considerar el riesgo de interacciones entre los fármacos y puede ser necesario un ajuste de la dosis. En ausencia de contraindicaciones específicas, habría que considerar los bloqueadores beta para pacientes ancianos que han sufrido infarto de miocardio, ya que se ha visto que previenen la MSC de los mayores de 65 años ${ }^{797}$.
Los DAI se usan ampliamente en los ancianos: análisis de subgrupos de los estudios AVID y MADIT-II demostraron beneficios equivalentes del DAI en pacientes ancianos y más jóvenes ${ }^{63,153}$. Un metanálisis que combinó datos de estudios sobre la prevención primaria de la MSC (MUSTT, MADIT-II, DEFINITE y SCD-HeFT) encontró que la terapia con DAI reduce la mortalidad por cualquier causa de los pacientes de edad $\geq 75$ años en ausencia de complicaciones relacionadas con el DAI (HR = 0,73; IC95\%, 0,51-0,974; $\mathrm{p}=0,03)^{798}$. Es interesante, sin embargo, que un metanálisis diferente apuntara a que la terapia con DAI podría ser menos beneficiosa para los pacientes ancianos con disfunción grave del VI (HR = 0,75; IC95\%, 0,61-0,91 $)^{799}$. Los datos agrupados de estudios de prevención secundaria (AVID, CASH y CIDS) revelaron que la terapia con DAI reduce significativamente la muerte por cualquier causa y la arrítmica en pacientes de edad $\leq 75$ años, pero no en los mayores de 75 (muerte por cualquier causa, $H R=1,06$; IC95\%, 0,69-1,64; p = 0,79; muerte arrítmica, HR = 0,90; IC95\%, 0,42$1,95 ; \mathrm{p}=0,79)^{800}$. Estudios observacionales y datos de registros de la práctica clínica diaria en prevención primaria demuestran que la edad por sí sola no debe excluir el implante de un dispositivo ${ }^{801,802}$.

La decisión de implantar un DAI debería considerar las consecuencias del dispositivo en la calidad de vida: en un subestudio del MADIT-II, no se estableció ninguna disminución significativa de los años de vida ajustados por calidad para los pacientes de 65 o más $a_{n}{ }^{803}$. En general, la edad no se encuentra entre los criterios considerados para el uso apropiado del DAI, ya que los octogenarios que mueren súbitamente pueden estar altamente funcionales incluso en el mes previo a su muerte ${ }^{804}$. El juicio clínico, junto con los deseos del paciente y la familia, puede contribuir a la decisión de desviarse de las recomendaciones estándar para el uso del DAI.

\subsection{Aspectos de la etapa final de la vida}

\section{Manejo de problemas en la etapa terminal}

\begin{tabular}{lcccc}
\hline Recomendaciones & Clase $^{\mathrm{a}}$ & Nivel $^{\mathrm{b}}$ & Ref $^{\mathrm{c}}$ \\
\hline $\begin{array}{l}\text { Se debe tomar en consideración comentar con los } \\
\text { pacientes cualificados para implante de DAI los } \\
\text { problemas de la etapa terminal antes del implante } \\
\text { y en momentos significativos en el curso de la } \\
\text { enfermedad }\end{array}$ & Ila & C & 805,806 \\
\hline $\begin{array}{l}\text { Se debe considerar la desactivación del DAI cuando } \\
\text { las condiciones clínicas se deterioren }\end{array}$ & Ila & C & 805,806 \\
\hline
\end{tabular}

DAI: desfibrilador automático implantable.

aClase de recomendación.

bNivel de evidencia.

'Referencias que respaldan las recomendaciones.

Los pacientes con enfermedad terminal frecuentemente contraen afecciones que predisponen a arritmias (hipoxia, dolor y alteraciones electrolíticas) y hasta un 20\% de los portadores de DAI reciben descargas en las últimas semanas de vida ${ }^{805,807,808}$.

Discutir la desactivación del DAI con el paciente y la familia para evitar sufrimientos y dolores innecesarios a una persona que se está muriendo es una necesidad importante, aunque con frecuencia se ignora. Habría que prestar una consideración individualizada a los deseos del paciente, respetando tanto el consentimiento informado como el rechazo informado. Cuando los pacientes no son capaces de tomar esta decisión por sí mismos, habría que oír a un miembro de la familia o a alguien que tome las decisiones por ellos o se debería cumplir el testamento vital del paciente, si lo hay ${ }^{805,808,809}$.

Debido a la complejidad de la cuestión, se puede encontrar información exhaustiva sobre cómo implementar las recomendaciones en 2 documentos de consenso de la EHRA ${ }^{805}$ y la Heart Rhythm Society ${ }^{809}$. Además, hay que tener en cuenta las normas y la legislación locales. 
La desactivación puede realizarse por programación del dispositivo o, si esto no es factible, por aplicación de un imán directamente contra el dispositivo. Puede ser preferible suspender solo las terapias antitaquicárdicas y mantener la estimulación antibradicardia con objeto de evitar el deterioro sintomático.

\section{LAGUNAS EN LA EVIDENCIA}

- La primera manifestación clínica de muerte súbita con frecuencia es mortal. Por lo tanto, la identificación de pacientes en riesgo de muerte súbita es la piedra angular en la prevención de la muerte súbita. La estratificación de riesgo para prevención primaria de la MSC con técnicas invasivas y no invasivas aún es insatisfactoria. Se necesita valorar nuevos enfoques, como la elaboración del perfil genético, el cribado electrocardiográfico y las técnicas de imagen. Se necesita urgentemente estudios sobre los mejores métodos para detectar a las poblaciones asintomáticas en riesgo de muerte súbita. Se necesitan métodos simples y baratos apropiados para el cribado masivo.

- Asegurar una cadena de cuidado eficaz y rápida es de máxima importancia para mejorar la supervivencia de las víctimas de muerte súbita. Se necesita más investigación para evaluar el diseño óptimo de dichas cadenas de supervivencia, incluidos el cuidado prehospitalario y los protocolos hospitalarios.

- Los éxitos en la prevención de la CI y la IC debidas a infartos de miocardio han reducido sustancialmente las tasas de muerte súbita. Se necesitan más estudios sobre las otras causas de muerte súbita para reducir aún más su incidencia.

- Más de la mitad de las víctimas de muerte súbita tienen función del VI conservada. Se necesitan con urgencia programas de investigación específicos para comprender los mecanismos que causan muerte súbita a pacientes con función del VI conservada, que probablemente requieran abordaje interdisciplinario con cardiólogos, genetistas, epidemiólogos y científicos básicos y traslacionales. Dicha investigación debería abarcar una mejor detección de pacientes con miocardiopatías hereditarias y trastornos arritmogénicos hereditarios, estratificación de riesgo de muerte súbita de los pacientes con ICFEc y valoración del riesgo de muerte súbita de los pacientes con FA.

- Los chalecos desfibriladores pueden ser una opción terapéutica interesante para pacientes seleccionados, pero requieren estudios aleatorizados de mayor tamaño antes de que se pueda definir totalmente indicaciones claras.

- Están justificados ensayos aleatorizados sobre la viabilidad de la estratificación de riesgo con EEF invasivo precozmente tras el infarto de miocardio.

- Ha transcurrido más de una década desde la publicación de los ensayos clínicos aleatorizados de referencia sobre prevención primaria de la MSC, que hasta ahora han servido como base para el uso de DAI en pacientes con disfunción sistólica del VI e IC. Los perfiles de los pacientes y los tratamientos médicos han cambiado significativamente desde entonces: los pacientes de hoy son de más edad y tienen más comorbilidades, tales como FA, enfermedad renal crónica y otras. Por lo tanto, se necesitan nuevos estudios clínicos para valorar el beneficio potencial de la prevención primaria de la MSC con DAI para la población actual de pacientes. Dado que no hay en curso ningún nuevo ensayo clínico aleatorizado relevante, los datos de registros prospectivos podrían arrojar más luz sobre este aspecto, muy importante desde el punto de vista clínico.

- Se necesita investigar más para establecer intervenciones basadas en la evidencia con objeto de reducir el impacto psicosocial y optimizar el cuidado y la asistencia para pacientes y familias con riesgo de MSC.

- Muchos pacientes con FE reducida mejorarán su FEVI con el tiempo. Algunos de estos pacientes recibirán un desfibrilador sin una necesidad clara, mientras que otros pueden permanecer en riesgo de muerte súbita pese a recuperar la función del VI. Se necesita investigar más sobre la mejor valoración de estos pacientes que facilite un tratamiento de la muerte súbita mejor y personalizado.

- El uso de TRC-D en pacientes con FA y el lugar de la ablación del NAV no se han definido claramente fuera de conjuntos de datos observacionales. Hay clara necesidad de estudios aleatorizados y de potencia adecuada sobre este común grupo de pacientes.

- El campo de las arritmias y miocardiopatías hereditarias ha experimentado importantes avances en los últimos 20 años, principalmente debido a la amplia disponibilidad del diagnóstico genético y la disponibilidad de datos clínicos de grandes registros. Sin embargo, aún existen deficiencias clave en la evidencia. Un gran número de pacientes con arritmias y miocardiopatías hereditarias primarias aún mueren antes de llegar al diagnóstico, lo que parece indicar la necesidad de mejores enfoques diagnósticos. También existen lagunas de conocimiento en los esquemas de estratificación de riesgos para enfermedades tales como el síndrome de Brugada, el SQTC, la MAVD y la mayoría de las miocardiopatías dilatadas no isquémicas.

- Las TV empeoran el pronóstico de pacientes con una variedad de enfermedades cardiacas estructurales. Se necesita con urgencia una nueva terapia antiarrítmica u otra terapia médica para que una población más amplia pueda quedar protegida de arritmias ventriculares malignas de primera aparición o recurrentes. Queda por estudiar si un tratamiento antiarrítmico específico puede mejorar ese pronóstico. Aunque se ha visto que la ablación con catéter de la TV recurrente en pacientes con cardiopatía estructural reduce significativamente el número de recurrencias de TV, el impacto de la ablación con catéter de la TV en la mortalidad no está claro y merece estudio. 


\section{MENSAJES SOBRE LO QUE SE DEBE Y LO QUE NO SE DEBE HACER}

Población general

Ante toda víctima de muerte súbita inexplicable, se recomienda el análisis de sangre y otros fluidos corporales adecuadamente recogidos para toxicología y patología molecular

Se recomienda establecer el acceso público a la desfibrilación en lugares donde la parada cardiaca sea relativamente común y se disponga de almacenamiento adecuado (p. ej., escuelas, estadios deportivos, grandes estaciones, casinos, etc.) o no se disponga de ningún otro acceso a la desfibrilación (como trenes, cruceros, aviones, etc.)

Pacientes con indicación de DAI

Se recomienda comentar con todos los pacientes los inconvenientes en la calidad de vida antes de implantar el DAI y en el curso de la enfermedad Cardiopatía isquémica

Se recomienda revaluar la FEVI 6-12 semanas después de un infarto de miocardio para valorar la necesidad potencial de implante de DAI para prevención primaria

Pacientes con insuficiencia cardiaca

Se recomienda la terapia con DAI para reducir la MSC de pacientes con IC sintomática (NYHA II-III), FEVI $\leq 35 \%$ después de al menos 3 meses de terapia médica óptima y esperanza de vida con buen estado funcional $\geq 1$ año:

- Etiología isquémica y al menos 6 semanas tras un infarto de miocardio

- Etiología no isquémica

Para reducir la mortalidad por cualquier causa, se recomienda TRC-D para pacientes con QRS $\geq 130 \mathrm{~ms}$, FEVI $\leq 30 \%$, BRIH a pesar de al menos 3 meses de terapia farmacológica óptima y esperanza de vida con buen estado funcional $\geq 1$ año

Para reducir la mortalidad por cualquier causa, se recomienda TRC para pacientes con FEVI $\leq 35 \%$, BRIH a pesar de al menos 3 meses de terapia farmacológica óptima y esperanza de vida con buen estado funcional $\geq 1$ año:

\begin{tabular}{|c|c|c|}
\hline • Con $\mathrm{QRS}>150 \mathrm{~ms}$ & I & A \\
\hline - Con QRS de $120-150 \mathrm{~ms}$ & I & B \\
\hline \multicolumn{3}{|l|}{ Enfermedades arritmogénicas hereditarias } \\
\hline Se recomienda a los pacientes con MAVD evitar los deportes de competición & I & C \\
\hline \multicolumn{3}{|l|}{ Recomendaciones emergentes } \\
\hline $\begin{array}{l}\text { Si hay riesgos/contraindicaciones para el DAI, este no está disponible o el paciente lo rechaza, se debe considerar la flecainida además de bloqueadores } \\
\text { beta para pacientes con diagnóstico de TVPC que sufren síncopes recurrentes o TV polimórfica/bidireccional mientras están en tratamiento } \\
\text { con bloqueadores beta }\end{array}$ & IIa & $\mathrm{C}$ \\
\hline Se debe considerar el DAI para pacientes con MCD, una mutación en LMNA causante de enfermedad confirmada y factores de riesgo clínico & IIa & B \\
\hline
\end{tabular}

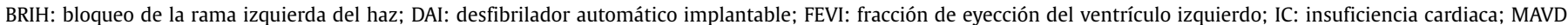

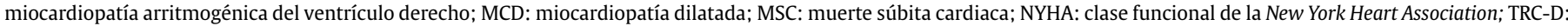
terapia de resincronización cardiaca con desfibrilador; TV: taquicardia ventricular; TVPC: taquicardia ventricular polimórfica catecolaminérgica.

aClase de recomendación.

${ }^{\mathrm{b}}$ Nivel de evidencia.

\section{ANEXO WEB}

Tabla web 1

Guías publicadas desde 2006 sobre la prevención de la MSC en la población general, excluidas las que tratan sobre enfermedades específicas

\begin{tabular}{|c|c|c|}
\hline Guía & Año & Ref \\
\hline Guía de la ESC/EHRA para el control del ritmo cardiaco y la TRC & 2007 & 4 \\
\hline Guía del ACC/AHA/HRS/AATS/STS para la terapia basada en dispositivos de anormalidades del ritmo cardiaco & 2008 & 5 \\
\hline Declaración científica de la AHA/ACCF/HRS sobre técnicas no invasivas de estratificación de riesgos para identificar a pacientes en riesgo de MSC & 2008 & 6 \\
\hline $\begin{array}{l}\text { Actualización enfocada de la ESC/HFA/EHRA de la guía de la ESC sobre la terapia con dispositivos en la insuficiencia cardiaca: una actualización de la guía } \\
\text { de la ESC de } 2008 \text { para el diagnóstico y el tratamiento de la IC aguda y crónica y la guía de la ESC de } 2007 \text { para la terapia cardiaca y de resincronización }\end{array}$ & 2010 & 7 \\
\hline Guía de la ESC/HFA para el diagnóstico y el tratamiento de la IC aguda y crónica & 2012 & 8 \\
\hline Guía de la ACCF/AHA para el tratamiento de la IC & 2013 & 9 \\
\hline Guía de la ESC/EHRA sobre el control del ritmo cardiaco y la TRC & 2013 & 10 \\
\hline $\begin{array}{l}\text { Actualización enfocada de la ACCF/AHA/HRS incorporada en la guía de la ACCF/AHA/HRS de } 2008 \text { para la terapia basada en dispositivos de anormalidades } \\
\text { del ritmo cardiaco }\end{array}$ & 2013 & 11 \\
\hline $\begin{array}{l}\text { Declaración de consenso de expertos de la HRS/ACC/AHA sobre el uso de la terapia con desfibrilador automático implantable en pacientes no incluidos } \\
\text { o no bien representados en ensayos clínicos }\end{array}$ & 2014 & 12 \\
\hline $\begin{array}{l}\text { Guía de la ESC/EACTS de } 2014 \text { sobre revascularización miocárdica: Grupo de Trabajo sobre Revascularización Miocárdica de la ESC y la European Association } \\
\text { for Cardio-Thoracic Surgery (EACTS) }\end{array}$ & 2014 & 13 \\
\hline Consenso de expertos de la EHRA/HRS/APHRS sobre arritmias ventriculares & 2014 & 3 \\
\hline
\end{tabular}

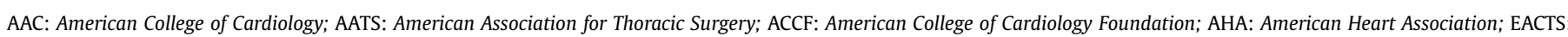

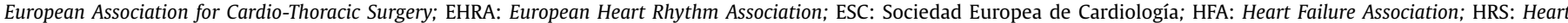
Rhythm Society; IC: insuficiencia cardiaca; MSC: muerte súbita cardiaca; STS: Society of Thoracic Surgeons; TRC: terapia de resincronización cardiaca. 
Tabla web 2

Prevalencia en series de autopsias de miocardiopatías hereditarias subyacentes o síndrome de muerte súbita arrítmica en individuos jóvenes (< 40 años), dividida entre atletas y población general

\begin{tabular}{|c|c|c|c|c|c|c|c|c|c|}
\hline Referencia (año) & País & Periodo & Franja de edad (años) & MSC, $\mathrm{n}$ & $\mathrm{MCH}, \%$ & $\mathrm{MCD}, \%$ & MAVD, \% & MC total, \% & SMSA, \% \\
\hline \multicolumn{10}{|l|}{ Población de atletas } \\
\hline Van Camp $(1995)^{25}$ & Estados Unidos & 1983-1993 & $13-24$ & 105 & 45 & 5 & 1 & 51 & 7 \\
\hline Corrado $(2003)^{26}$ & Italia & 1979-1999 & $12-35$ & 52 & 2 & 2 & 23 & 27 & 2 \\
\hline Maron $(2009)^{27}$ & Estados Unidos & 1980-2006 & $8-39$ & 690 & 36,3 & 2 & 4,3 & 42,6 & - \\
\hline Choi $(2013)^{28}$ & Estados Unidos & 2007-2008 & $11-30$ & 54 & 30 & 4 & - & 34 & 7 \\
\hline Suárez-Mier (2013) ${ }^{29}$ & España & $1995-2010$ & $9-35$ & 81 & 9,8 & - & 14,8 & 24,6 & 23,4 \\
\hline Maron $(2014)^{30}$ & Estados Unidos & 2002-2011 & $18-22$ & 64 & 33 & 3 & 4,6 & 40,6 & - \\
\hline \multicolumn{10}{|l|}{ Población general } \\
\hline Topaz $(1985)^{31}$ & Estados Unidos & $1960-1983$ & $7-35$ & 50 & 12 & - & - & 12 & 14 \\
\hline Drory $(1991)^{32}$ & Israel & 1976-1985 & $9-39$ & 137 & 11 & 3 & - & 14 & 14 \\
\hline Wisten $(2002)^{33}$ & Suecia & 1992-1999 & $15-35$ & 181 & 10,5 & 12,2 & 6,6 & 29,3 & 21 \\
\hline Corrado $(2003)^{26}$ & Italia & 1979-1999 & $12-35$ & 277 & 8,5 & 4 & 13,5 & 26 & 7 \\
\hline Eckart $(2004)^{34}$ & Estados Unidos & $1977-2001$ & $18-35$ & 108 & 7 & 1 & 1 & 9 & 40 \\
\hline Puranik (2005) $)^{35}$ & Australia & $1995-2004$ & $5-35$ & 241 & 5,8 & 5,4 & 1,6 & 12,8 & 26,5 \\
\hline Di Gioia $(2006)^{36}$ & Italia & 2001-2005 & $2-40$ & 100 & 4 & 4 & 12 & 20 & 19 \\
\hline Papadakis (2009) ${ }^{37}$ & Reino Unido & $2002-2005$ & $1-34$ & 1.677 & 5 & 12 & - & 17 & 14 \\
\hline Morris $(2009)^{38}$ & Irlanda & 2005 & $0-35$ & 69 & 14,5 & 1,5 & 1,5 & 17,5 & 40,6 \\
\hline $\operatorname{Lim}(2010)^{39}$ & Canadá & $2005-2007$ & $0-35$ & 100 & 8 & 1 & 4 & 13 & 35 \\
\hline Winkel $(2011)^{40}$ & Dinamarca & $2000-2006$ & $1-35$ & 314 & 0,6 & 1,3 & 5 & 7 & 43 \\
\hline Eckart $(2011)^{21}$ & Estados Unidos & 1998-2008 & $18-35$ & 298 & 12,8 & 4,7 & 1,3 & 18,8 & 41 \\
\hline Margey $(2011)^{41}$ & Irlanda & $2005-2007$ & $15-35$ & 116 & 14,7 & 2,6 & 1,7 & 19 & 27 \\
\hline Pilmer $(2013)^{42}$ & Canadá & 2008 & $2-40$ & 174 & 7 & 14 & 1,7 & 22,7 & 28 \\
\hline De Noronha (2014) ${ }^{43}$ & Reino Unido & 2007-2009 & $1-35$ & 422 & 5 & 2 & 3 & 10 & 54 \\
\hline Risgaard (2014) $)^{44}$ & Dinamarca & 2007-2009 & $1-35$ & 117 & 4,3 & - & 7,7 & 12 & 47,9 \\
\hline Winkel $(2014)^{45}$ & Dinamarca & $2000-2006$ & $1-18$ & 62 & 1,6 & 1,6 & 6,5 & 9,7 & 40,3 \\
\hline Pilmer $(2014)^{46}$ & Canadá & $2005-2009$ & $1-19$ & 116 & 7 & 2 & 8 & 17 & 52 \\
\hline Vassalini $(2015)^{47}$ & Italia & 1993-2012 & $1-40$ & 54 & 9,2 & - & 11,1 & 20,3 & 22,2 \\
\hline
\end{tabular}

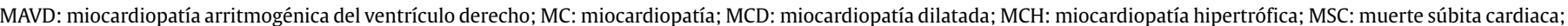
SMSA: síndrome de muerte súbita arrítmica (es decir, corazón normal).

Adaptado de Mazzanti et $\mathrm{al}^{48}$.

Tabla web 3

Definiciones comunes utilizadas al describir las arritmias ventriculares ${ }^{122}$

\begin{tabular}{|c|c|}
\hline Terminología: tipo de arritmia ventricular & Definición: clasificación electrocardiográfica \\
\hline TV bidireccional & TV con un cambio latido a latido en el eje QRS \\
\hline Taquicardia por reentrada rama-rama & $\begin{array}{l}\text { TV debida a reentrada en la que está implicado el sistema His-Purkinje, normalmente con morfología de BRIH, más común en } \\
\text { MCD con intervalo HV prolongado }\end{array}$ \\
\hline Ritmo idioventricular & Arritmia de 3 o más complejos consecutivos que se originan en los ventrículos a un ritmo $<100 \mathrm{lpm}$ \\
\hline TV monomórfica & Morfología de QRS único estable durante la TV \\
\hline TV no sostenida & Tres o más complejos ventriculares consecutivos en duración, que finalizan espontáneamente en menos de $30 \mathrm{~s}$ \\
\hline TV pleomórfica & Más de una morfología de QRS estable durante un episodio de TV \\
\hline TV polimórfica & Una morfología de QRS cambiante o multiforme a una duración de ciclo de entre 100 y 300 lpm durante la TV \\
\hline Extrasístoles ventriculares & $\begin{array}{l}\text { Una despolarización ventricular que se produce más precozmente de lo esperado y aparece en el ECG como un complejo QRS } \\
\text { ancho precoz sin una onda P relacionada precedente }\end{array}$ \\
\hline TV sostenida & TV de duración $\geq 30$ s o que requiere finalización antes de 30 s debido a deterioro hemodinámico \\
\hline Torsade de pointes & $\begin{array}{l}\text { TV caracterizada por retorcimiento de los complejos QRS alrededor de la línea isoeléctrica del ECG durante la arritmia, que } \\
\text { puede asociarse a un síndrome de QT largo }\end{array}$ \\
\hline Flutter ventricular & $\begin{array}{l}\text { Una TV regular (variaciones de la duración del ciclo } \leq 30 \mathrm{~ms} \text { ) de aproximadamente } 300 \mathrm{lpm} \text { con un aspecto monomórfico; } \\
\text { sin intervalo isoeléctrico entre complejos QRS sucesivos }\end{array}$ \\
\hline Fibrilación ventricular & $\begin{array}{l}\text { Ritmo ventricular rápido, normalmente }>300 \mathrm{lpm} \text { (duración del ciclo } \leq 200 \mathrm{~ms} \text { ), muy irregular, con marcada variabilidad en la } \\
\text { duración, la morfología y la amplitud del ciclo QRS }\end{array}$ \\
\hline Taquicardia ventricular & Arritmia de 3 o más complejos consecutivos en duración que se originan en los ventrículos a un ritmo $\geq 100$ lpm \\
\hline
\end{tabular}

BRIH: bloqueo de la rama izquierda del haz; ECG: electrocardiograma; MCD: miocardiopatía dilatada; TV: taquicardia ventricular. 
Tabla web 4

Exploraciones que pueden desvelar hallazgos específicos de la enfermedad

\begin{tabular}{|c|c|c|c|c|c|c|}
\hline $\begin{array}{l}\text { Estados de enfermedad e } \\
\text { investigaciones que desvelarían } \\
\text { hallazgos específicos de la } \\
\text { enfermedad }\end{array}$ & $\begin{array}{l}\text { Historia clínica, } \\
\text { agrupación familiar } \\
\text { de MSC }\end{array}$ & ECG & $\begin{array}{l}\text { Holter, registrador de } \\
\text { sucesos, registrador } \\
\text { de asa implantable }\end{array}$ & $\begin{array}{l}\text { Prueba de } \\
\text { ejercicio }\end{array}$ & ECG-SP & Imagen \\
\hline $\begin{array}{l}\text { Síndrome del QT largo, } \\
\text { síndrome del QT corto }\end{array}$ & $\begin{array}{l}\text { Eventos en situaciones } \\
\text { de provocación, } \\
\text { familiar }\end{array}$ & QTc largo, QTc corto & $\begin{array}{l}\text { QT largo, TdP, QT } \\
\text { corto, TdP, FA }\end{array}$ & - & - & - \\
\hline Síndrome de Brugada & $\begin{array}{l}\text { TV inducida por } \\
\text { fiebre, familiar }\end{array}$ & $\begin{array}{l}\text { Elevación del } \mathrm{ST} \geq 2 \mathrm{~mm} \\
\text { con aspecto curvado en } \\
\text { V1 o V2 situadas en el } \\
\text { segundo, el tercer o el } \\
\text { cuarto espacio intercostal }\end{array}$ & - & - & - & - \\
\hline $\begin{array}{l}\text { Taquicardia ventricular } \\
\text { polimórfica catecolaminérgica }\end{array}$ & $\begin{array}{l}\text { Síncope inducido por } \\
\text { el ejercicio, familiar }\end{array}$ & - & TV al realizar ejercicio & $\begin{array}{l}\text { TV al realizar } \\
\text { ejercicio }\end{array}$ & - & - \\
\hline $\begin{array}{l}\text { Miocardiopatía arritmogénica } \\
\text { del ventrículo derecho }\end{array}$ & Familiar & $\begin{array}{l}\text { Ondas T negativas en } \\
\text { V1-V3 }\end{array}$ & - & - & $\begin{array}{l}\text { Potenciales } \\
\text { tardíos }\end{array}$ & $\begin{array}{l}\text { Cambios } \\
\text { morfológicos, tamaño } \\
\text { del VD aumentado }\end{array}$ \\
\hline Miocardiopatía hipertrófica & Familiar & Hipertrofia del VI & - & - & - & $\begin{array}{l}\text { Hipertrofia del VI, } \\
\text { cicatrización }\end{array}$ \\
\hline Cardiopatía isquémica & Dolor torácico & $\begin{array}{l}\text { Ondas Q, cambios en el } \\
\text { ST, BRIH }\end{array}$ & - & $\begin{array}{l}\text { Cambios en el ST } \\
\text { inducidos por el } \\
\text { ejercicio }\end{array}$ & - & Discinesia tras IM \\
\hline Miocardiopatía dilatada & Disnea & - & - & - & - & $\begin{array}{l}\text { Disfunción sistólica- } \\
\text { FEVI reducida }\end{array}$ \\
\hline
\end{tabular}

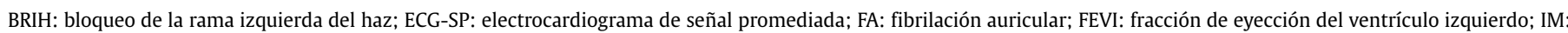
infarto de miocardio; TdP: torsade de pointes; TVNS: taquicardia ventricular no sostenida; VD: ventrículo derecho; VI: ventrículo izquierdo.

Tabla web 5

Metanálisis de estudios de prevención secundaria con DAI

\begin{tabular}{|c|c|c|c|c|c|}
\hline \multirow[t]{2}{*}{ Ensayo } & \multirow[t]{2}{*}{$\mathrm{N}$} & \multicolumn{2}{|c|}{ Mortalidad total } & \multicolumn{2}{|c|}{ Mortalidad arrítmica } \\
\hline & & Eventos & HR (IC95\%) & Eventos & HR (IC95\%) \\
\hline AVID $^{153}$ & 1.016 & 80 & $0,62(0,47-0,81)$ & 24 & $0,43(0,27-0,66)$ \\
\hline CIDS $^{151}$ & 659 & 83 & $0,82(0,61-1,10)$ & 30 & $0,68(0,43-1,08)$ \\
\hline $\mathrm{CASH}^{152}$ & 191 & 37 & $0,83(0,52-1,33)$ & 7 & $0,32(0,15-0,69)$ \\
\hline Acumulado & 1.866 & 200 & $0,72(0,60-0,87)$ & 61 & $0,50(0,37-0,67)$ \\
\hline
\end{tabular}

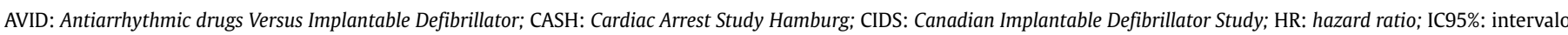
de confianza del 95\%. Modificado de Connolly et al ${ }^{154}$.

Para heterogeneidad, $\mathrm{p}=0,306$.

Tabla web 6

Ensayos con desfibrilador automático implantable subcutáneo

\begin{tabular}{|c|c|c|c|c|c|c|}
\hline Autor principal (año) & Pacientes, $\mathrm{n}$ & $\begin{array}{l}\text { Seguimiento } \\
\text { medio (meses) }\end{array}$ & $\begin{array}{l}\text { Detección } \\
\text { apropiada, \% }\end{array}$ & $\begin{array}{c}\text { Conversión eficaz } \\
\text { con UDF, \% }\end{array}$ & $\begin{array}{l}\text { Descargas inapropiadas } \\
\text { en el seguimiento, \% }\end{array}$ & $\begin{array}{l}\text { Complicaciones que } \\
\text { requieren reintervención, \% }\end{array}$ \\
\hline Bardy $(2010)^{159}$ & 55 & 10 & 100 & 98 & 9 & 11 \\
\hline Dabiri Abkenari (2011) $)^{161}$ & 31 & 9 & 100 & 100 & 16 & 10 \\
\hline Olde Nordkamp (2012) ${ }^{162}$ & 118 & 18 & NR & 100 & 13 & 14 \\
\hline Aydin $(2012)^{163}$ & 40 & 8 & NR & 97,5 & 5 & 13 \\
\hline Jarman $(2012)^{160}$ & 16 & 9 & 100 & 100 & 25 & 19 \\
\hline Jarman (2013) ${ }^{164}$ & 111 & 12 & 100 & 100 & 15 & 16 \\
\hline Köbe (2013) & 69 & 7 & NR & 95,5 & 4 & 4 \\
\hline Weiss $(2013)^{157}$ & 314 & 11 & 99,8 & 100 & 14 & 1,3 \\
\hline Lambiase $(2014)^{158}$ & 472 & 18,5 & NR & 99,7 & 7 & NR \\
\hline
\end{tabular}

NR: no registrado; UDF: umbral de desfibrilación. 


\section{APÉNDICE}

\section{Comité de Guías de Práctica Clínica de la ESC}

José Luis Zamorano (Presidente) (España), Victor Aboyans (Francia), Stephan Achenbach (Alemania), Stefan Agewall (Noruega), Lina Badimon (España), Gonzalo Barón-Esquivias (España), Helmut Baumgartner (Alemania), Jeroen J. Bax (Países Bajos), Héctor Bueno (España), Scipione Carerj (Italia), Veronica Dean (Francia), Çetin Erol (Turquía), Donna Fitzsimons (Reino Unido), Oliver Gaemperli (Suiza), Paulus Kirchhof (Reino Unido/Alemania), Philippe Kolh (Bélgica), Patrizio Lancellotti (Bélgica), Gregory Y.H. Lip (Reino Unido), Petros Nihoyannopoulos (Reino Unido), Massimo F. Piepoli (Italia), Piotr Ponikowski (Polonia), Marco Roffi (Suiza), Adam Torbicki (Polonia), Antonio Vaz Carneiro (Portugal), Stephan Windecker (Suiza).

Sociedades Cardiacas Nacionales de la ESC activamente implicadas en el proceso de revisión de las Guías de la ESC de 2015 para el tratamiento de pacientes con arritmias ventriculares y la prevención de la muerte súbita cardiaca

Armenia: Armenian Cardiologists Association, Armen Piruzyan; Austria: Austrian Society of Cardiology, Franz Xaver Roithinger; Bélgica: Belgian Society of Cardiology, Georges H. Mairesse; Bosnia y Herzegovina: Association of Cardiologists of Bosnia \& Herzegovina, Boris Goronja; Bulgaria: Bulgarian Society of Cardiology, Tchavdar Shalganov; Croacia: Croatian Cardiac Society, Davor Puljević; Chipre: Cyprus Society of Cardiology, Loizos Antoniades; República Checa: Czech Society of Cardiology, Josef Kautzner; Dinamarca: Danish Society of Cardiology, Jacob Moesgaard Larsen; Egipto: Egyptian Society of Cardiology, Mervat Aboulmaaty; Estonia: Estonian Society of Cardiology, Priit Kampus; Finlandia: Finnish Cardiac Society, Antti Hedman; Antigua República Yugoslava de Macedonia: Macedonian FYR Society of Cardiology, Lidija Kamcevska-Dobrkovic; Francia:
French Society of Cardiology, Olivier Piot; Georgia: Georgian Society of Cardiology, Kakhaber Etsadashvili; Alemania: German Cardiac Society, Lars Eckardt; Grecia: Hellenic Cardiological Society, Spyridon Deftereos; Hungría: Hungarian Society of Cardiology, László Gellér; Islandia: Icelandic Society of Cardiology, Sigfús Gizurarson; Irlanda: Irish Cardiac Society, David Keane; Israel: Israel Heart Society, Moti Haim; Italia: Italian Federation of Cardiology, Paolo Della Bella; Kazajistán: Association of Cardiologists of Kazakhstan, Ayan Abdrakhmanov; Kirguistán: Kyrgyz Society of Cardiology, Aibek Mirrakhimov; Letonia: Latvian Society of Cardiology, Oskars Kalejs; Libia: Libyan Cardiac Society, Hisham Ben Lamin; Lituania: Lithuanian Society of Cardiology, Germanas Marinskis; Luxemburgo: Luxembourg Society of Cardiology, Laurent Groben; Malta: Maltese Cardiac Society, Mark Sammut; Moldavia: Moldavian Society of Cardiology, Aurica Raducan; Marruecos: Moroccan Society of Cardiology, Ali Chaib; Noruega: Norwegian Society of Cardiology, Pål Morten Tande; Polonia: Polish Cardiac Society, Radoslaw Lenarczyk; Portugal: Portuguese Society of Cardiology, Francisco Bello Morgado; Rumanía: Romanian Society of Cardiology, Radu Vatasescu; Rusia: Russian Society of Cardiology, Evgeny N. Mikhaylov; Eslovaquia: Slovak Society of Cardiology, Peter Hlivak; España: Sociedad Española de Cardiología, Ángel Arenal; Suecia: Swedish Society of Cardiology, Mats Jensen-Urstad; Suiza: Swiss Society of Cardiology, Christian Sticherling; Países Bajos: Netherlands Society of Cardiology, Katja Zeppenfeld; Túnez: Tunisian Society of Cardiology and CardioVascular Surgery, Rafik Chettaoui; Turquía: Turkish Society of Cardiology, Mesut Demir; Reino Unido: British Cardiovascular Society, Edward Duncan; Ucrania: Ukrainian Association of Cardiology, Alexander Parkhomenko.

Filiación: Andrea Mazzanti, Coordinador: Cardiologia Molecolare, Fondazione Salvatore Maugeri, Via S. Maugeri 10/10 A, 27100 Pavia, Italia. Tel: +39 0382592051. Correo electrónico: andrea.mazzanti@fsm.it

El texto de CME «Guía de la ESC 2015 para el tratamiento de pacientes con arritmias ventriculares y la prevención de la muerte súbita cardiaca» está autorizado por el European Board for Accreditation in Cardiology (EBAC). El EBAC trabaja según las normas de calidad del European Accreditation Council for Continuing Medical Education (EACCME), que es una institución de la European Union of Medical Specialists (UEMS). En conformidad con las guías de EBAC/EACCME, todos los autores que han participado en este programa han revelado cualesquiera conflictos de intereses potenciales que pudieran causar un sesgo en el artículo. El Comité Organizador es responsable de asegurarse de que todos los conflictos de intereses potenciales relevantes para el programa sean declarados a los participantes con anterioridad a las actividades CME.

Las cuestiones de CME para este artículo están disponibles en: European Heart Journal (http://www.oxforde-learning.com/eurheartj) y Sociedad Europea de Cardiología (http://www.escardio.org/guidelines).

\section{BIBLIOGRAFÍA}

1. Zipes DP, Camm AJ, Borggrefe M, Buxton AE, Chaitman B, Fromer M, Gregoratos G, Klein G, Moss AJ, Myerburg RJ, Priori SG, Quinones MA, Roden DM, Silka MJ Tracy C, Blanc JJ, Budaj A, Dean V, Deckers JW, Despres C, Dickstein K, Lekakis J McGregor K, Metra M, Morais J, Osterspey A, Tamargo JL, Zamorano JL, Smith SC Jr, Jacobs AK, Adams CD, Antman EM, Anderson JL, Hunt SA, Halperin JL Nishimura R, Ornato JP, Page RL, Riegel B. ACC/AHA/ESC 2006 guidelines for management of patients with ventricular arrhythmias and the prevention of sudden cardiac death - executive summary: a report of the American College of Cardiology/American Heart Association Task Force and the European Society of Cardiology Committee for Practice Guidelines (Writing Committee to Develop Guidelines for Management of Patients with Ventricular Arrhythmias and the Prevention of Sudden Cardiac Death) Developed in collaboration with the European Heart Rhythm Association and the Heart Rhythm Society. Eur Heart J. 2006;27:2099-140.

2. Aliot EM, Stevenson WG, Almendral-Garrote JM, Bogun F, Calkins $\mathrm{CH}$, Delacretaz E, Bella PD, Hindricks G, Jais P, Josephson ME, Kautzner J, Kay GN, Kuck $\mathrm{KH}$ Lerman BB, Marchlinski F, Reddy V, Schalij MJ, Schilling R, Soejima K, Wilber D, European Heart Rhythm Association, European Society of Cardiology, Heart Rhythm Society. EHRA/HRS Expert Consensus on Catheter Ablation of Ventricular Arrhythmias: developed in a partnership with the European Heart Rhythm Association (EHRA), a Registered Branch of the European Society of Cardiology (ESC), and the Heart Rhythm Society (HRS); in collaboration with the American College of Cardiology (ACC) and the American Heart Association (AHA). Europace. 2009;11:771-817.
3. Pedersen CT, Kay GN, Kalman J, Borggrefe M, Della-Bella P, Dickfeld T, Dorian P, Huikuri H, Kim YH, Knight B, Marchlinski F, Ross D, Sacher F, Sapp J, Shivkumar K, Soejima K, Tada H, Alexander ME, Triedman JK, Yamada T, Kirchhof P, Document R, Lip GY, Kuck KH, Mont L, Haines D, Indik J, Dimarco J, Exner D, Iesaka Y, Savelieva I. EHRA/HRS/APHRS expert consensus on ventricular rrhythmias. Europace. 2014;16:1257-83.

4. Vardas PE, Auricchio A, Blanc JJ, Daubert JC, Drexler H, Ector H, Gasparini M, Linde C, Morgado FB, Oto A, Sutton R, Trusz-Gluza M, European Society of Cardiology, European Heart Rhythm Association. Guidelines for cardiac pacing and cardiac resynchronization therapy. The Task Force for Cardiac Pacing and Cardiac Resynchronization Therapy of the European Society of Cardiology. Developed in collaboration with the European Heart Rhythm Association. Europace. 2007;9:959-98.

5. Epstein AE, DiMarco JP, Ellenbogen KA, Estes NA 3rd, Freedman RA, Gettes LS, Gillinov AM, Gregoratos G, Hammill SC, Hayes DL, Hlatky MA, Newby LK, Page RL, Schoenfeld MH, Silka MJ, Stevenson LW, Sweeney MO, Smith SC Jr, Jacobs AK, Adams CD, Anderson JL, Buller CE, Creager MA, Ettinger SM, Faxon DP, Halperin JL, Hiratzka LF, Hunt SA, Krumholz HM, Kushner FG, Lytle BW, Nishimura RA, Ornato JP, Page RL, Riegel B, Tarkington LG, Yancy CW. ACC/AHA/HRS 2008 Guidelines for Device-Based Therapy of Cardiac Rhythm Abnormalities: a report of the American College of Cardiology/ American Heart Association Task Force on Practice Guidelines (Writing Committee to Revise the ACC/AHA/NASPE 2002 Guideline Update for Implantation of Cardiac Pacemakers and Antiarrhythmia Devices) developed in collaboration with the American Association for Thoracic Surgery and Society of Thoracic Surgeons. J Am Coll Cardiol. 2008;51:e1-62.

6. Goldberger JJ, Cain ME, Hohnloser SH, Kadish AH, Knight BP, Lauer MS, Maron BJ, Page RL, Passman RS, Siscovick D, Stevenson WG, Zipes DP. American Heart 
Association/American College of Cardiology Foundation/Heart Rhythm Society scientific statement on noninvasive risk stratification techniques for identifying patients at risk for sudden cardiac death: a scientific statement from the American Heart Association Council on Clinical Cardiology Committee on Electrocardiography and Arrhythmias and Council on Epidemiology and Prevention. Circulation. 2008;118:1497-518.

7. Dickstein K, Vardas PE, Auricchio A, Daubert JC, Linde C, McMurray J, Ponikowski P, Priori SG, Sutton R, van Veldhuisen DJ. 2010 focused update of ESC Guidelines on device therapy in heart failure: an update of the 2008 ESC Guidelines for the diagnosis and treatment of acute and chronic heart failure and the 2007 ESC Guidelines for cardiac and resynchronization therapy. Developed with the special contribution of the Heart Failure Association and the European Heart Rhythm Association. Eur J Heart Fail. 2010;12:1143-53.

8. McMurray JJ, Adamopoulos S, Anker SD, Auricchio A, Bohm M, Dickstein K, Falk V, Filippatos G, Fonseca C, Gomez-Sanchez MA, Jaarsma T, Kober L, Lip GY, Maggioni AP, Parkhomenko A, Pieske BM, Popescu BA, Ronnevik PK, Rutten FH, Schwitter J, Seferovic P, Stepinska J, Trindade PT, Voors AA, Zannad F, Zeiher A. ESC Guidelines for the diagnosis and treatment of acute and chronic heart failure 2012: The Task Force for the Diagnosis and Treatment of Acute and Chronic Heart Failure 2012 of the European Society of Cardiology. Developed in collaboration with the Heart Failure Association (HFA) of the ESC. Eur Heart J. 2012;33:1787847.

9. YancyCW, Jessup M, Bozkurt B, Butler J, Casey DE Jr, Drazner MH, Fonarow GC, Geraci SA, Horwich T, Januzzi JL, Johnson MR, Kasper EK, Levy WC, Masoudi FA, McBride PE, McMurray JJ, Mitchell JE, Peterson PN, Riegel B, Sam F, Stevenson LW, Tang WH, Tsai EJ, Wilkoff BL. 2013 ACCF/AHA guideline for the management of heart failure: executive summary: a report of the American College of Cardiology Foundation/American Heart Association Task Force on practice guidelines. Circulation. 2013;128:1810-52.

10. Brignole M, Auricchio A, Baron-Esquivias G, Bordachar P, Boriani G, Breithardt OA, Cleland J, Deharo JC, Delgado V, Elliott PM, Gorenek B, Israel CW, Leclercq C, Linde C, Mont L, Padeletti L, Sutton R, Vardas PE, Zamorano JL, Achenbach S, Baumgartner H, Bax JJ, Bueno H, Dean V, Deaton C, Erol C, Fagard R, Ferrari R, Hasdai D, Hoes AW, Kirchhof $P$, Knuuti J, Kolh P, Lancellotti P, Linhart A, Nihoyannopoulos P, Piepoli MF, Ponikowski P, Sirnes PA, Tamargo JL, Tendera M, Torbicki A, Wijns W, Windecker S, Document R, Kirchhof P, Blomstrom-Lundqvist C, Badano LP, Aliyev F, Bansch D, Baumgartner H, Bsata W, Buser P, Charron P, Daubert JC, Dobreanu D, Faerestrand S, Hasdai D, Hoes AW, Le Heuzey JY, Mavrakis H, McDonagh T, Merino JL, Nawar MM, Nielsen JC, Pieske B, Poposka L, Ruschitzka F, Tendera M, Van Gelder IC, Wilson CM. 2013 ESC Guidelines on cardiac pacing and cardiac resynchronization therapy: the Task Force on cardiac pacing and resynchronization therapy of the European Society of Cardiology (ESC). Developed in collaboration with the European Heart Rhythm Association (EHRA). Eur Heart J. 2013;34:2281-329.

11. Epstein AE, DiMarco JP, Ellenbogen KA, Estes NA 3rd, Freedman RA, Gettes LS, Gillinov AM, Gregoratos G, Hammill SC, Hayes DL, Hlatky MA, Newby LK, Page RL, Schoenfeld MH, Silka MJ, Stevenson LW, Sweeney MO, American College of Cardiology Foundation, American Heart Association Task Force on Practice Guidelines, Heart Rhythm Society. 2012 ACCF/AHA/HRS focused update incorporated into the ACCF/AHA/HRS 2008 guidelines for device-based therapy of cardiac rhythm abnormalities: a report of the American College of Cardiology Foundation/American Heart Association Task Force on Practice Guidelines and the Heart Rhythm Society. Circulation. 2013;127:e283-352.

12. Kusumoto FM, Calkins H, Boehmer J, Buxton AE, Chung MK, Gold MR, Hohnloser SH, Indik J, Lee R, Mehra MR, Menon V, Page RL, Shen WK, Slotwiner DJ, Stevenson LW, Varosy PD,Welikovitch L. HRS/ACC/AHA expert consensus statement on the use of implantable cardioverter-defibrillator therapy in patients who are not included or not well represented in clinical trials. J Am Coll Cardiol. 2014;64: 1143-77.

13. Windecker S, Kolh P, Alfonso F, Collet JP, Cremer J, Falk V, Filippatos G, Hamm C, Head SJ, Juni P, Kappetein AP, Kastrati A, Knuuti J, Landmesser U, Laufer G, Neumann FJ, Richter DJ, Schauerte P, Sousa Uva M, Stefanini GG, Taggart DP, Torracca L, Valgimigli M, Wijns W, Witkowski A. 2014 ESC/EACTS Guidelines on myocardial revascularization: the Task Force on Myocardial Revascularization of the European Society of Cardiology (ESC) and the European Association for Cardio-Thoracic Surgery (EACTS) developed with the special contribution of the European Association of Percutaneous Cardiovascular Interventions (EAPCI). Eur Heart J. 2014;35:2541-619.

14. Priori SG, Wilde AA, Horie M, Cho Y, Behr ER, Berul C, Blom N, Brugada J, Chiang CE, Huikuri H, Kannankeril P, Krahn A, Leenhardt A, Moss A, Schwartz PJ, Shimizu W, Tomaselli G, Tracy C. Executive summary: HRS/ EHRA/APHRS expert consensus statement on the diagnosis and management of patients with inherited primary arrhythmia syndromes. Europace. 2013;15:1389-406.

15. Fishman GI, Chugh SS, Dimarco JP, Albert CM, Anderson ME, Bonow RO, Buxton AE, Chen PS, Estes M, Jouven X, Kwong R, Lathrop DA, Mascette AM, Nerbonne JM, O'Rourke B, Page RL, Roden DM, Rosenbaum DS, Sotoodehnia N, Trayanova NA, Zheng ZJ. Sudden cardiac death prediction and prevention: report from a National Heart, Lung, and Blood Institute and Heart Rhythm Society Workshop. Circulation. 2010;122:2335-48.

16. Byard RW, Ranson D, Krous HF, Workshop P. National Australian workshop consensus on the definition of SIDS and initiation of a uniform autopsy approach to unexpected infant and early childhood death. Forensic Sci Med Pathol. 2005;1:289-92.

17. Basso C, Burke M, Fornes P, Gallagher PJ, de Gouveia RH, Sheppard M, Thiene G, van der Wal A, Association for European Cardiovascular P. Guidelines for autopsy investigation of sudden cardiac death. Virchows Arch. 2008;452:11-8.
18. Priori S, Schwartz P, Bardy G, Bigger IJ, Borggrefe M, Camm A, Cobb L, Ewy G, Hauer R, Kuck K, Lane R, Lazzara R, Marcus F, Muller J, Myerburg R, Touboul P, Verrier R, Wellens H, Zipes D. Survivors of out-of-hospital cardiac arrest with apparently normal heart. Need for definition and standardized clinical evaluation. Consensus Statement of the Joint Steering Committees of the Unexplained Cardiac Arrest Registry of Europe and of the Idiopathic Ventricular Fibrillation Registry of the United States. Circulation. 1997;95:265-72.

19. Niemeijer MN, van den Berg ME, Leening MJ, Hofman A, Franco OH, Deckers JW Heeringa J, Rijnbeek PR, Stricker BH, Eijgelsheim M. Declining incidence of sudden cardiac death from 1990-2010 in a general middle-aged and elderly population: the Rotterdam Study. Heart Rhythm. 2015;12:123-9.

20. Mendis SPP, Norrving B. Global Atlas on Cardiovascular Disease Prevention and Control. Geneva: World Health Organization, 2011.

21. Eckart RE, Shry EA, Burke AP, McNear JA, Appel DA, Castillo-Rojas LM, Avedissian L, Pearse LA, Potter RN, Tremaine L, Gentlesk PJ. Huffer L, Reich SS, Stevenson WG, Department of Defense Cardiovascular Death Registry G. Sudden death in young adults: an autopsy-based series of a population undergoing active surveillance. J Am Coll Cardiol. 2011;58:1254-61.

22. Maron BJ, Gohman TE, Aeppli D. Prevalence of sudden cardiac death during competitive sports activities in Minnesota high school athletes. J Am Coll Cardiol. 1998;32:1881-4.

23. van der Werf C, Hendrix A, Birnie E, Bots ML, Vink A, Bardai A, Blom MT, Bosch J, Bruins W, Das CK, Koster RW, Naujocks T, Schaap B, Tan HL, de Vos R, de Vries P, Woonink F, Doevendans PA, van Weert HC, Wilde AA, Mosterd A, van Langen IM. Improving usual care after sudden death in the young with focus on inherited cardiac diseases (the CAREFUL study): a community-based intervention study. Europace 2015 Apr 1. pii: euv059 [Epub ahead of print].

24. United Nations Economic Commission for Europe. UNECE statistical database. Available at http://w3.unece.org/pxweb.

25. Van Camp SP, Bloor CM, Mueller FO, Cantu RC, Olson HG. Nontraumatic sports death in high school and college athletes. Med Sci Sports Exerc. 1995;27:641-7.

26. Corrado D, Basso C, Rizzoli G, Schiavon M, Thiene G. Does sports activity enhance the risk of sudden death in adolescents and young adults? J Am Coll Cardiol. 2003;42:1959-63.

27. Maron BJ, Doerer JJ, Haas TS, Tierney DM, Mueller FO. Sudden deaths in young competitive athletes: analysis of 1866 deaths in the United States, 1980-2006. Circulation. 2009;119:1085-92.

28. Choi K, Pan YP, Pock M, Chang RK. Active surveillance of sudden cardiac death in young athletes by periodic Internet searches. Pediatr Cardiol. 2013;34:1816-22.

29. Suarez-Mier MP, Aguilera B, Mosquera RM, Sanchez-de-Leon MS. Pathology of sudden death during recreational sports in Spain. Forensic Sci Int. 2013;226:18896.

30. Maron BJ, Haas TS, Murphy CJ, Ahluwalia A, Rutten-Ramos S. Incidence and causes of sudden death in U.S. college athletes. J Am Coll Cardiol. 2014;63:163643.

31. Topaz O, Edwards JE. Pathologic features of sudden death in children, adolescents, and young adults. Chest. 1985;87:476-82

32. Drory Y, Turetz Y, Hiss Y, Lev B, Fisman EZ, Pines A, Kramer MR. Sudden unexpected death in persons less than 40 years of age. Am J Cardiol. 1991;68:1388-92.

33. Wisten A, Forsberg H, Krantz P, Messner T. Sudden cardiac death in 15-35-year olds in Sweden during 1992-99. J Intern Med. 2002;252:529-36.

34. Eckart RE, Scoville SL, Campbell CL, Shry EA, Stajduhar KC, Potter RN, Pearse LA, Virmani R. Sudden death in young adults: a 25-year review of autopsies in military recruits. Ann Intern Med. 2004;141:829-34.

35. Puranik R, Chow CK, Duflou JA, Kilborn MJ, McGuire MA. Sudden death in the young. Heart Rhythm. 2005;2:1277-82.

36. di Gioia CR, Autore C, Romeo DM, Ciallella C, Aromatario MR, Lopez A, Pagannone E, Giordano C, Gallo P, d'Amati G. Sudden cardiac death in younger adults: autopsy diagnosis as a tool for preventive medicine. Hum Pathol. 2006;37:794801.

37. Papadakis M, Sharma S, Cox S, Sheppard MN, Panoulas VF, Behr ER. The magnitude of sudden cardiac death in the young: a death certificate-based review in England and Wales. Europace. 2009;11:1353-8.

38. Morris VB, Keelan T, Leen E, Keating J, Magee H, O'Neill JO, Galvin J. Sudden cardiac death in the young: a 1-year post-mortem analysis in the Republic of Ireland. Ir J Med Sci. 2009;178:257-61.

39. Lim Z, Gibbs K, Potts JE, Sanatani S. A review of sudden unexpected death in the young in British Columbia. Can J Cardiol. 2010;26:22-6.

40. Winkel BG, Holst AG, Theilade J, Kristensen IB, Thomsen JL, Ottesen GL, Bundgaard $\mathrm{H}$, Svendsen JH, Haunso S, Tfelt-Hansen J. Nationwide study of sudden cardiac death in persons aged 1-35 years. Eur Heart J. 2011;32:983-90.

41. Margey R, Roy A, Tobin S, O'Keane CJ, McGorrian C, Morris V, Jennings S, Galvin J. Sudden cardiac death in 14- to 35-year olds in Ireland from 2005 to 2007: a retrospective registry. Europace. 2011;13:1411-8.

42. Pilmer CM, Porter B, Kirsh JA, Hicks AL, Gledhill N, Jamnik V, Faught BE, Hildebrandt D, McCartney N, Gow RM, Goodman J, Krahn AD. Scope and nature of sudden cardiac death before age 40 in Ontario: a report from the cardiac death advisory committee of the office of the chief coroner. Heart Rhythm. 2013;10:51723.

43. de Noronha SV, Behr ER, Papadakis M, Ohta-Ogo K, Banya W, Wells J, Cox S, Cox A, Sharma S, Sheppard MN. The importance of specialist cardiac histopathological examination in the investigation of young sudden cardiac deaths. Europace. 2014:16:899-907.

44. Risgaard B, Winkel BG, Jabbari R, Behr ER, Ingemann-Hansen O, Thomsen JL, Ottesen GL, Gislason GH, Bundgaard H, Haunso S, Holst AG, Tfelt-Hansen J. 
Burden of sudden cardiac death in persons aged 1 to 49 years: nationwide study in Denmark. Circ Arrhythm Electrophysiol. 2014;7:205-11.

45. Winkel BG, Risgaard B, Sadjadieh G, Bundgaard H, Haunso S, Tfelt-Hansen J. Sudden cardiac death in children (1-18 years): symptoms and causes of death in a nationwide setting. Eur Heart J. 2014;35:868-75.

46. Pilmer CM, Kirsh JA, Hildebrandt D, Krahn AD, Gow RM. Sudden cardiac death in children and adolescents between 1 and 19 years of age. Heart Rhythm. 2014;11:239-45.

47. Vassalini M, Verzeletti A, Restori M, De Ferrari F. An autopsy study of sudden cardiac death in persons aged 1-40 years in Brescia (Italy). J Cardiovasc Med. 2015;16:[Epub ahead of print].

48. Mazzanti A, O’Rourke S, Ng K, Miceli C, Borio G, Curcio A, Esposito F, Napolitano C, Priori SG. The usual suspects in sudden cardiac death of the young: a focus on inherited arrhythmogenic diseases. Expert Rev Cardiovasc Ther. 2014;12: 499-519.

49. Maron BJ. Sudden death in young athletes. N Engl J Med. 2003;349:1064-75.

50. Basso C, Carturan E, Pilichou K, Rizzo S, Corrado D, Thiene G. Sudden cardiac death with normal heart: molecular autopsy. Cardiovasc Pathol. 2010;19:321-5.

51. Tester DJ, Medeiros-Domingo A, Will ML, Haglund CM, Ackerman MJ. Cardiac channel molecular autopsy: insights from 173 consecutive cases of autopsynegative sudden unexplained death referred for postmortem genetic testing. Mayo Clin Proc. 2012;87:524-39.

52. Ackerman MJ, Priori SG, Willems S, Berul C, Brugada R, Calkins H, Camm AJ, Ellinor PT, Gollob M, Hamilton R, Hershberger RE, Judge DP, Le Marec H, McKenna WJ, Schulze-Bahr E, Semsarian C, Towbin JA, Watkins H, Wilde A, Wolpert C, Zipes DP. HRS/EHRA expert consensus statement on the state of genetic testing for the channelopathies and cardiomyopathies. Europace. 2011;13:1077-109.

53. Wellens HJ, Schwartz PJ, Lindemans FW, Buxton AE, Goldberger JJ, Hohnloser SH, Huikuri HV, Kaab S, La Rovere MT, Malik M, Myerburg RJ, Simoons ML, Swedberg K, Tijssen J, Voors AA, Wilde AA. Risk stratification for sudden cardiac death: current status and challenges for the future. Eur Heart J. 2014;35:1642-51.

54. Myerburg RJ, Kessler KM, Castellanos A. Sudden cardiac death. Structure, function, and time-dependence of risk. Circulation. 1992;85:I2-10.

55. Lloyd-Jones DM, Wilson PW, Larson MG, Beiser A, Leip EP, D’Agostino RB, Levy D. Framingham risk score and prediction of lifetime risk for coronary heart disease. Am J Cardiol. 2004;94:20-4.

56. Perk J, De Backer G, Gohlke H, Graham I, Reiner Z, Verschuren M, Albus C, Benlian P, Boysen G, Cifkova R, Deaton C, Ebrahim S, Fisher M, Germano G, Hobbs R, Hoes A, Karadeniz S, Mezzani A, Prescott E, Ryden L, Scherer M, Syvanne M, Scholte op Reimer WJ, Vrints C, Wood D, Zamorano JL, Zannad F. European Guidelines on cardiovascular disease prevention in clinical practice (version 2012). The Fifth Joint Task Force of the European Society of Cardiology and Other Societies on Cardiovascular Disease Prevention in Clinical Practice (constituted by representatives of nine societies and by invited experts). Eur Heart J. 2012;33:1635-701.

57. Jouven X, Desnos M, Guerot C, Ducimetiere P. Predicting sudden death in the population: the Paris Prospective Study I. Circulation. 1999;99:1978-83.

58. Friedlander Y, Siscovick DS, Weinmann S, Austin MA, Psaty BM, Lemaitre RN, Arbogast P, Raghunathan TE, Cobb LA. Family history as a risk factor for primary cardiac arrest. Circulation. 1998;97:155-60.

59. Dekker LR, Bezzina CR, Henriques JP, Tanck MW, Koch KT, Alings MW, Arnold AE, de Boer MJ, Gorgels AP, Michels HR, Verkerk A, Verheugt FW, Zijlstra F, Wilde AA Familial sudden death is an important risk factor for primary ventricula fibrillation: a case-control study in acute myocardial infarction patients. Circulation. 2006;114:1140-5.

60. Kaikkonen KS, Kortelainen ML, Linna E, Huikuri HV. Family history and the risk of sudden cardiac death as a manifestation of an acute coronary event. Circulation. 2006;114:1462-7.

61. Bezzina CR, Pazoki R, Bardai A, Marsman RF, de Jong JS, Blom MT, Scicluna BP, Jukema JW, Bindraban NR, Lichtner P, Pfeufer A, Bishopric NH, Roden DM, Meitinger T, Chugh SS, Myerburg RJ, Jouven X, Kaab S, Dekker LR, Tan HL, Tanck MW, Wilde AA. Genome-wide association study identifies a susceptibility locus at 21q21 for ventricular fibrillation in acute myocardial infarction. Nat enet 2010;42:688-91.

62. Arking DE, Junttila MJ, Goyette P, Huertas-Vazquez A, Eijgelsheim M, Blom MT Newton-Cheh C, Reinier K, Teodorescu C, Uy-Evanado A, Carter-Monroe N, Kaikkonen KS, Kortelainen ML, Boucher G, Lagace C, Moes A, Zhao X, Kolodgie F, Rivadeneira F, Hofman A, Witteman JC, Uitterlinden AG, Marsman RF, Pazoki R, Bardai A, Koster RW, Dehghan A, Hwang SJ, Bhatnagar P, Post W, Hilton G, Prineas RJ, Li M, Kottgen A, Ehret G, Boerwinkle E, Coresh J, Kao WH, Psaty BM, Tomaselli GF, Sotoodehnia N, Siscovick DS, Burke GL, Marban E, Spooner PM, Cupples LA, Jui J, Gunson K, Kesaniemi YA, Wilde AA, Tardif JC, O’Donnell CJ, Bezzina CR, Virmani R, Stricker BH, Tan HL, Albert CM, Chakravarti A, Rioux JD, Huikuri HV, Chugh SS Identification of a sudden cardiac death susceptibility locus at 2q24.2 through genome-wide association in European ancestry individuals. PLoS Genet 2011;7:e1002158.

63. Moss AJ, Zareba W, Hall WJ, Klein H, Wilber DJ, Cannom DS, Daubert JP, Higgins SL, Brown MW, Andrews ML. Prophylactic implantation of a defibrillator in patients with myocardial infarction and reduced ejection fraction. $\mathrm{N}$ Engl J Med. 2002;346:877-83.

64. Bardy GH, Lee KL, Mark DB, Poole JE, Packer DL, Boineau R, Domanski M, Troutman C, Anderson J, Johnson G, McNulty SE, Clapp-Channing N, DavidsonRay LD, Fraulo ES, Fishbein DP, Luceri RM, Ip JH, Sudden Cardiac Death in Heart Failure Trial (SCD-HeFT) Investigators. Amiodarone or an implantable cardioverter-defibrillator for congestive heart failure. $N$ Engl J Med. 2005;352:225-37.
65. Scott PA, Barry J, Roberts PR, Morgan JM. Brain natriuretic peptide for the prediction of sudden cardiac death and ventricular arrhythmias: a meta-analysis. Eur J Heart Fail. 2009;11:958-66.

66. Levine YC, Rosenberg MA, Mittleman M, Samuel M, Methachittiphan N, Link M, Josephson ME, Buxton AE. B-type natriuretic peptide is a major predictor of ventricular tachyarrhythmias. Heart Rhythm. 2014;11:1109-16.

67. Priori SG, Schwartz PJ, Napolitano C, Bloise R, Ronchetti E, Grillo M, Vicentini A, Spazzolini C, Nastoli J, Bottelli G, Folli R, Cappelletti D. Risk stratification in the long-QT syndrome. N Engl J Med. 2003;348:1866-74.

68. Spirito P, Bellone P, Harris KM, Bernabo P, Bruzzi P, Maron BJ. Magnitude of left ventricular hypertrophy and risk of sudden death in hypertrophic cardiomyopathy. N Engl J Med. 2000;342:1778-85.

69. Barsheshet A, Goldenberg I, O-Uchi J, Moss AJ, Jons C, Shimizu W, Wilde AA, McNitt S, Peterson DR, Zareba W, Robinson JL, Ackerman MJ, Cypress M, Gray DA, Hofman N, Kanters JK, Kaufman ES, Platonov PG, Qi M, Towbin JA, Vincent GM, Lopes CM. Mutations in cytoplasmic loops of the KCNQ1 channel and the risk of life-threatening events: implications for mutation-specific response to betablocker therapy in type 1 long-OT syndrome. Circulation. 2012;125:1988-96.

70. Moss AJ, ZarebaW, Kaufman ES, Gartman E, Peterson DR, Benhorin J, Towbin JA, Keating MT, Priori SG, Schwartz PJ, Vincent GM, Robinson JL, Andrews ML, Feng C, Hall WJ, Medina A, Zhang L,Wang Z. Increased risk of arrhythmic events in long-QT syndrome with mutations in the pore region of the human ether-a-gogo-related gene potassium channel. Circulation. 2002;105:794-9.

71. van Rijsingen IA, Arbustini E, Elliott PM, Mogensen J, Hermans-van Ast JF, van der Kooi AJ, van Tintelen JP, van den Berg MP, Pilotto A, Pasotti M, Jenkins S, Rowland C, Aslam U, Wilde AA, Perrot A, Pankuweit S, Zwinderman AH, Charron P, Pinto YM. Risk factors for malignant ventricular arrhythmias in lamin a/c mutation carriers a European cohort study. J Am Coll Cardiol. 2012;59:493-500.

72. Yoshinaga $M$, Ushinohama $H$, Sato $S$, Tauchi $N$, Horigome $H$, Takahashi $H$, Sumitomo N, Kucho Y, Shiraishi H, Nomura Y, ShimizuW, Nagashima M. Electrocardiographic screening of 1-month-old infants for identifying prolonged QT intervals. Circ Arrhythm Electrophysiol. 2013;6:932-8.

73. Yoshinaga M, Kucho Y, Sarantuya J, Ninomiya Y, Horigome H, Ushinohama H, Shimizu W, Horie M. Genetic characteristics of children and adolescents with long-QT syndrome diagnosed by school-based electrocardiographic screening programs. Circ Arrhythm Electrophysiol. 2014;7:107-12.

74. Schwartz PJ, Stramba-Badiale M, Crotti L, Pedrazzini M, Besana A, Bosi G, Gabbarini F, Goulene K, Insolia R, Mannarino S, Mosca F, Nespoli L, Rimini A, Rosati E, Salice P, Spazzolini C. Prevalence of the congenital long-QT syndrome. Circulation. 2009;120:1761-7.

75. Corrado D, Pelliccia A, Bjornstad HH, Vanhees L, Biffi A, Borjesson M, PanhuyzenGoedkoop N, Deligiannis A, Solberg E, Dugmore D, Mellwig KP, Assanelli D, Delise P, van-Buuren F, Anastasakis A, Heidbuchel H, Hoffmann E, Fagard R, Priori SG, Basso C, Arbustini E, Blomstrom-Lundqvist C, McKenna WJ, Thiene G. Cardiovascular pre-participation screening of young competitive athletes for prevention of sudden death: proposal for a common European protocol. Consensus Statement of the Study Group of Sport Cardiology of the Working Group of Cardiac Rehabilitation and Exercise Physiology and the Working Group of Myocardial and Pericardial Diseases of the European Society of Cardiology. Eur Heart J. 2005;26:516-24.

76. Maron BJ, Thompson PD, Ackerman MJ, Balady G, Berger S, Cohen D, Dimeff R, Douglas PS, Glover DW, Hutter AM Jr, Krauss MD, Maron MS, Mitten MJ, Roberts WO, Puffer JC. Recommendations and considerations related to preparticipation screening for cardiovascular abnormalities in competitive athletes: 2007 update: a scientific statement from the American Heart Association Council on Nutrition, Physical Activity, and Metabolism: endorsed by the American College of Cardiology Foundation. Circulation. 2007;115:1643-1455.

77. Ljungqvist A, Jenoure P, Engebretsen L, Alonso JM, Bahr R, Clough A, De Bondt G, Dvorak J, Maloley R, Matheson G, Meeuwisse W, Meijboom E, Mountjoy M, Pelliccia A, Schwellnus M, Sprumont D, Schamasch P, Gauthier JB, Dubi C, Stupp $\mathrm{H}$, Thill $\mathrm{C}$. The International Olympic Committee (IOC) consensus statement on periodic health evaluation of elite athletes, March 2009. Br J Sports Med. 2009;43:631-43.

78. Steinvil A, Chundadze T, Zeltser D, Rogowski O, Halkin A, Galily Y, Perluk H, Viskin $S$. Mandatory electrocardiographic screening of athletes to reduce their risk for sudden death proven fact or wishful thinking? J Am Coll Cardiol. 2011;57:1291-6.

79. Narain R, Dhutia H, Merghani A, Myers J, Malhotra A, Millar L, Sheikh N, Sharma $\mathrm{S}$, Papadakis M. Preventing sudden cardiac death in the young: results from a population-based screening program in the UK. European Journal of Preventive Cardiology. 2014;21 suppl: S1-S6.

80. Kaltman JR, Thompson PD, Lantos J, Berul CI, Botkin J, Cohen JT, Cook NR, Corrado D, Drezner J, Frick KD, Goldman S, Hlatky M, Kannankeril PJ, Leslie L, Priori S, Saul JP, Shapiro-Mendoza CK, Siscovick D, Vetter VL, Boineau R, Burns KM, Friedman RA. Screening for sudden cardiac death in the young: report from a national heart, lung, and blood institute working group. Circulation. 2011;123:1911-8.

81. James CA, Bhonsale A, Tichnell C, Murray B, Russell SD, Tandri H, Tedford RJ, Judge DP, Calkins $\mathrm{H}$. Exercise increases age-related penetrance and arrhythmic risk in arrhythmogenic right ventricular dysplasia/cardiomyopathy-associated desmosomal mutation carriers. J Am Coll Cardiol. 2013;62:1290-97.

82. Sawant AC, Bhonsale A, te Riele ASJM, Tichnell C, Murray B, Russell SD, Tandri H, Tedford RJ, Judge DP, Calkins H, James CA. Exercise has a disproportionate role in the pathogenesis of arrhythmogenic right ventricular dysplasia/cardiomyopathy in patients without desmosomal mutations. J Am Heart Assoc. 2014;3:e001471.

83. Behr ER, Dalageorgou C, Christiansen M, Syrris P, Hughes S, Tome Esteban MT, Rowland E, Jeffery S, McKenna WJ. Sudden arrhythmic death syndrome: familial evaluation identifies inheritable heart disease in the majority of families. Eur Heart J. 2008;29:1670-80. 
84. Charron P, Arad M, Arbustini E, Basso C, Bilinska Z, Elliott P, Helio T, Keren A McKenna WJ, Monserrat L, Pankuweit S, Perrot A, Rapezzi C, Ristic A, Seggewiss $\mathrm{H}$, van Langen I, Tavazzi L, European Society of Cardiology Working Group on Myocardial and Pericardial Diseases. Genetic counselling and testing in cardiomyopathies: a position statement of the European Society of Cardiology Working Group on Myocardial and Pericardial Diseases. Eur Heart J. 2010;31:2715-26

85. Christiaans I, Birnie E, Bonsel GJ, Wilde AA, van Langen IM. Uptake of genetic counselling and predictive DNA testing in hypertrophic cardiomyopathy. Eur J Hum Genet. 2008;16:1201-7.

86. Ormondroyd E, Oates S, Parker M, Blair E, Watkins H. Pre-symptomatic genetic testing for inherited cardiac conditions: a qualitative exploration of psychosocial and ethical implications. Eur J Hum Genet. 2014;22:88-93.

87. Ingles J, Yeates L, Hunt L, McGaughran J, Scuffham PA, Atherton J, Semsarian C. Health status of cardiac genetic disease patients and their at-risk relatives. Int J Cardiol. 2013;165:448-53.

88. Battista RN, Blancquaert I, Laberge AM, van Schendel N, Leduc N. Genetics in health care: an overview of current and emerging models. Public Health Genomics. 2012;15:34-45.

89. Ingles J, Lind JM, Phongsavan P, Semsarian C. Psychosocial impact of specialized cardiac genetic clinics for hypertrophic cardiomyopathy. Genet Med. 2008; $10: 117-20$

90. Christiaans I, van Langen IM, Birnie E, Bonsel GJ, Wilde AA, Smets EM. Quality of life and psychological distress in hypertrophic cardiomyopathy mutation carriers: a cross-sectional cohort study. Am J Med Genet A. 2009;149A:602-12.

91. McGorrian C, Constant O, Harper N, O'Donnell C, Codd M, Keelan E, Green A, O’Neill J, Galvin J, Mahon NG. Family-based cardiac screening in relatives of victims of sudden arrhythmic death syndrome. Europace. 2013:15:1050-8.

92. Moya A, Sutton R, Ammirati F, Blanc JJ, Brignole M, Dahm JB, Deharo JC, Gajek J, Gjesdal K, Krahn A, Massin M, Pepi M, Pezawas T, Ruiz Granell R, Sarasin F, Ungar A, van Dijk JG, Walma EP, Wieling W. Guidelines for the diagnosis and management of syncope. Eur Heart J. 2009;30:2631-71.

93. George S, Rodriguez I, Ipe D, Sager PT, Gussak I, Vajdic B. Computerized extraction of electrocardiograms from continuous 12-lead Holter recordings reduces measurement variability in a thorough QT study. J Clin Pharmacol. 2012;52:1891-900.

94. de Asmundis C, Conte G, Sieira J, Chierchia GB, Rodriguez-Manero M, Di Giovanni G, Ciconte G, Levinstein M, Baltogiannis G, Saitoh Y, Casado-Arroyo R, Brugada P. Comparison of the patient-activated event recording system vs. traditional $24 \mathrm{~h}$ Holter electrocardiography in individuals with paroxysmal palpitations or dizziness. Europace. 2014;16:1231-5.

95. Volosin K, Stadler RW, Wyszynski R, Kirchhof P. Tachycardia detection performance of implantable loop recorders: results from a large 'real-life' patient cohort and patients with induced ventricular arrhythmias. Europace. 2013;15:1215-22.

96. Kamath GS, Zareba W, Delaney J, Koneru JN, McKenna W, Gear K, Polonsky S, Sherrill D, Bluemke D, Marcus F, Steinberg JS. Value of the signal-averaged electrocardiogram in arrhythmogenic right ventricular cardiomyopathy/ dysplasia. Heart Rhythm. 2011;8:256-62.

97. Nava A, Folino AF, Bauce B, Turrini P, Buja GF, Daliento L, Thiene G. Signalaveraged electrocardiogram in patients with arrhythmogenic right ventricular cardiomyopathy and ventricular arrhythmias. Eur Heart J. 2000;21:58-65.

98. Gibbons RJ, Balady GJ, Bricker JT, Chaitman BR, Fletcher GF, Froelicher VF, Mark DB, McCallister BD, Mooss AN, O'Reilly MG, Winters WL, Gibbons RJ, Antman EM, Alpert JS, Faxon DP, Fuster V, Gregoratos G, Hiratzka LF, Jacobs AK, Russell RO, Smith SC. ACC/AHA 2002 guideline update for exercise testing: summary article. A report of the American College of Cardiology/American Heart Association Task Force on Practice Guidelines (Committee to Update the 1997 Exercise Testing Guidelines). J Am Coll Cardiol. 2002;40:1531-40.

99. Podrid PJ, Graboys TB. Exercise stress testing in the management of cardiac rhythm disorders. Med Clin North Am. 1984;68:1139-52.

100. Prastaro M, D'Amore C, Paolillo S, Losi M, Marciano C, Perrino C, Ruggiero D, Gargiulo P, Savarese G, Trimarco B, Perrone Filardi P. Prognostic role of transthoracic echocardiography in patients affected by heart failure and reduced ejection fraction. Heart Fail Rev. 2015;20:305-16.

101. Chiu DT, Shapiro NI, Sun BC, Mottley JL, Grossman SA. Are echocardiography, telemetry, ambulatory electrocardiography monitoring, and cardiac enzymes in emergency department patients presenting with syncope useful tests? A preliminary investigation. J Emerg Med. 2014;47:113-8.

102. Zellweger MJ, Hachamovitch R, Kang X, Hayes SW, Friedman JD, Germano G, Berman DS. Threshold, incidence, and predictors of prognostically high-risk silent ischemia in asymptomatic patients without prior diagnosis of coronary artery disease. J Nucl Cardiol. 2009;16:193-200.

103. Kang X, Berman DS, Lewin H, Miranda R, Erel J, Friedman JD, Amanullah AM. Comparative ability of myocardial perfusion single-photon emission computed tomography to detect coronary artery disease in patients with and without diabetes mellitus. Am Heart J. 1999;137:949-57.

104. Zelias A, Stepinska J, Andres J, Trabka-Zawicki A, Sadowski J, Zmudka K. Ten-year experience of an invasive cardiology centre with out-of-hospital cardiac arrest patients admitted for urgent coronary angiography. Kardiol Pol. 2014;72:687-99.

105. Zaman S, Narayan A, Thiagalingam A, Sivagangabalan G, Thomas S, Ross DL, Kovoor P. Significance of repeat programmed ventricular stimulation at electrophysiology study for arrhythmia prediction after acute myocardial infarction. Pacing Clin Electrophysiol. 2014;37:795-802.

106. Brembilla-Perrot B, Suty-Selton C, Houriez P, Claudon O, Beurrier D, de la Chaise AT. Value of non-invasive and invasive studies in patients with bundle branch block, syncope and history of myocardial infarction. Europace. 2001;3:187-94.
107. Dechering DG, Kochhauser S,Wasmer K, Zellerhoff S, Pott C, Kobe J, Spieker T, Piers SR, Bittner A, Monnig G, Breithardt G, Wichter T, Zeppenfeld K, Eckardt L. Electrophysiological characteristics of ventricular tachyarrhythmias in cardiac sarcoidosis versus arrhythmogenic right ventricular cardiomyopathy. Heart Rhythm. 2013;10:158-64.

108. Marine JE, Shetty V, Chow GV, Wright JG, Gerstenblith G, Najjar SS, Lakatta EG, Fleg JL. Prevalence and prognostic significance of exercise-induced nonsustained ventricular tachycardia in asymptomatic volunteers: BLSA (Baltimore Longitudinal Study of Aging). J Am Coll Cardiol. 2013;62:595-600.

109. Cheitlin MD, Armstrong WF, Aurigemma GP, Beller GA, Bierman FZ, Davis JL Douglas PS, Faxon DP, Gillam LD, Kimball TR, Kussmaul WG, Pearlman AS, Philbrick JT, Rakowski H, Thys DM. ACC/AHA/ASE 2003 guideline update for the clinical application of echocardiography-summary article: a report of the American College of Cardiology/American Heart Association Task Force on Practice Guidelines (ACC/AHA/ASE Committee to Update the 1997 Guidelines for the Clinical Application of Echocardiography). J Am Coll Cardiol. 2003;42:954-70.

110. Summitt J, Rosenheck S, Kou WH, Schmaltz S, Kadish AH, Morady F. Effect of basic drive cycle length on the yield of ventricular tachycardia during programmed ventricular stimulation. Am J Cardiol. 1990;65:49-52.

111. Denes P, Uretz E, Ezri MD, Borbola J. Clinical predictors of electrophysiologic findings in patients with syncope of unknown origin. Arch Intern Med. 1988; 148:1922-8.

112. Brignole M, Menozzi C, Moya A, Garcia-Civera R, Mont L, Alvarez M, Errazquin F, Beiras J, Bottoni N, Donateo P, International Study on Syncope of Uncertain Etiology (ISSUE) Investigators. Mechanism of syncope in patients with bundle branch block and negative electrophysiological test. Circulation. 2001;104:204550.

113. Roguin A, Bomma CS, Nasir K, Tandri H, Tichnell C, James C, Rutberg J, Crosson J, Spevak PJ, Berger RD, Halperin HR, Calkins H. Implantable cardioverterdefibrillators in patients with arrhythmogenic right ventricular dysplasia/cardiomyopathy. J Am Coll Cardiol. 2004;43:1843-52.

114. Bhonsale A, James CA, Tichnell C, Murray B, Gagarin D, Philips B, Dalal D, Tedford R, Russell SD, Abraham T, Tandri H, Judge DP, Calkins H. Incidence and predictors of implantable cardioverter-defibrillator therapy in patients with arrhythmogenic right ventricular dysplasia/cardiomyopathy undergoing implantable cardioverterdefibrillator implantation for primary prevention. J Am Coll Cardiol. 2011;58:1485-96.

115. Goldberger JJ, Subacius H, Patel T, Cunnane R, Kadish AH. Sudden cardiac death risk stratification in patients with nonischemic dilated cardiomyopathy. J Am Coll Cardiol. 2014;63:1879-89.

116. Elliott PM, Anastasakis A, Borger MA, Borggrefe M, Cecchi F, Charron P, Hagege AA, Lafont A, Limongelli G, Mahrholdt $H$, McKenna WJ, Mogensen J Nihoyannopoulos P, Nistri S, Pieper PG, Pieske B, Rapezzi C, Rutten FH, Tillmanns C, Watkins H. 2014 ESC Guidelines on diagnosis and management of hypertrophic cardiomyopathy: The Task Force for the Diagnosis and Management of Hypertrophic Cardiomyopathy of the European Society of Cardiology (ESC). Eur Heart J. 2014;35:2733-79.

117. Bhandari AK, ShapiroWA, Morady F, Shen EN, Mason J, Scheinman MM. Electrophysiologic testing in patients with the long QT syndrome. Circulation. 1985;71:63-71.

118. Giustetto C, Schimpf R, Mazzanti A, Scrocco C, Maury P, Anttonen O, Probst V, Blanc JJ, Sbragia P, Dalmasso P, Borggrefe M, Gaita F. Long-term follow-up of patients with short QT syndrome. J Am Coll Cardiol. 2011;58:587-95.

119. Mazzanti A, Kanthan A, Monteforte N, Memmi M, Bloise R, Novelli V, Miceli C, O’Rourke S, Borio G, Zienciuk-Krajka A, Curcio A, Surducan AE, Colombo M, Napolitano C, Priori SG. Novel insight into the natural history of short QT syndrome. J Am Coll Cardiol. 2014;63:1300-8.

120. Brugada J, Brugada R, Brugada P. Determinants of sudden cardiac death in individuals with the electrocardiographic pattern of Brugada syndrome and no previous cardiac arrest. Circulation. 2003;108:3092-6.

121. Middlekauff HR, Stevenson WG, Stevenson LW, Saxon LA. Syncope in advanced heart failure: high risk of sudden death regardless of origin of syncope. J Am Coll Cardiol. 1993;21:110-6.

122. Surawicz B, Knilas T. Chou's Electrocardiography in Clinical Practice. Philadelphia PA: Saunders Elsevier, 2008.

123. Amiodarone Trials Meta Analysis Investigators. Effect of prophylactic amiodarone on mortality after acute myocardial infarction and in congestive heart failure: meta-analysis of individual data from 6500 patients in randomised trials. Lancet. 1997;350:1417-24

124. Boutitie F, Boissel JP, Connolly SJ, Camm AJ, Cairns JA, Julian DG, Gent M, Janse MJ, Dorian P, Frangin G. Amiodarone interaction with beta-blockers: analysis of the merged EMIAT (European Myocardial Infarct Amiodarone Trial) and CAMIAT (Canadian Amiodarone Myocardial Infarction Trial) databases. The EMIAT and CAMIAT Investigators. Circulation. 1999;99:2268-75.

125. Ray WA, Murray KT, Meredith S, Narasimhulu SS, Hall K, Stein CM. Oral erythromycin and the risk of sudden death from cardiac causes. N Engl J Med. 2004;351:1089-96.

126. Mosholder AD, Mathew J, Alexander JJ, Smith H, Nambiar S. Cardiovascular risks with azithromycin and other antibacterial drugs. N Engl J Med. 2013;368:1665-8.

127. Belardinelli L, Giles WR, Rajamani S, Karagueuzian HS, Shryock JC. Cardiac late $\mathrm{Na}(+)$ current: proarrhythmic effects, roles in long QT syndromes, and pathological relationship to CaMKII and oxidative stress. Heart Rhythm. 2015;12:440-8.

128. Sarganas G, Garbe E, Klimpel A, Hering RC, Bronder E, HaverkampW. Epidemiology of symptomatic drug-induced long QT syndrome and torsade de pointes in Germany. Europace. 2014;16:101-8. 
129. Cardiac Arrhythmia Suppression Trial (CAST) Investigators. Preliminary report: effect of encainide and flecainide on mortality in a randomized trial of arrhythmia suppression after myocardial infarction. N Engl J Med. 1989;321:406-12.

130. Kontos MC, Diercks DB, Ho PM, Wang TY, Chen AY, Roe MT. Treatment and outcomes in patients with myocardial infarction treated with acute beta-blocke therapy: results from the American College of Cardiology's NCDRw. Am Heart J 2011;161:864-70.

131. Echt DS, Liebson PR, Mitchell LB, Peters RW, Obias-Manno D, Barker AH, Arensberg D, Baker A, Friedman L, Greene HL, Huther ML, Richardson DW, CAST Investigators. Mortality and morbidity in patients receiving encainide, flecainide, or placebo. The Cardiac Arrhythmia Suppression Trial. N Engl J Med. 1991;324:781-8.

132. Singh SN, Fletcher RD, Fisher SG, Singh BN, Lewis HD, Deedwania PC, Massie BM Colling C, Lazzeri D. Amiodarone in patients with congestive heart failure and asymptomatic ventricular arrhythmia. Survival Trial of Antiarrhythmic Therapy in Congestive Heart Failure. N Engl J Med. 1995;333:77-82.

133. Piccini JP, Berger JS, O'Connor CM. Amiodarone for the prevention of sudden cardiac death: a meta-analysis of randomized controlled trials. Eur Heart 2009;30:1245-53.

134. Singh BN, Singh SN, Reda DJ, Tang XC, Lopez B, Harris CL, Fletcher RD, Sharma SC, Atwood JE, Jacobson AK, Lewis HD Jr, Raisch DW, Ezekowitz MD, Sotalo Amiodarone Atrial Fibrillation Efficacy Trial (SAFE-T) Investigators. Amiodarone versus sotalol for atrial fibrillation. N Engl J Med. 2005;352:1861-72.

135. Lafuente-Lafuente C, Longas-Tejero MA, Bergmann JF, Belmin J. Antiarrhythmics for maintaining sinus rhythm after cardioversion of atrial fibrillation. Cochrane Database Syst Rev. 2012;5:CD005049.

136. Kuhlkamp V, Mewis C, Mermi J, Bosch RF, Seipel L. Suppression of sustained ventricular tachyarrhythmias: a comparison of d,l-sotalol with no antiarrhythmic drug treatment. J Am Coll Cardiol. 1999;33:46-52.

137. Waldo AL, Camm AJ, deRuyter H, Friedman PL, MacNeil DJ, Pauls JF, Pitt B, Pratt CM, Schwartz PJ, Veltri EP. Effect of d-sotalol on mortality in patients with left ventricular dysfunction after recent and remote myocardial infarction. The SWORD Investigators. Survival With Oral d-Sotalol. Lancet. 1996;348:7-12.

138. Hohnloser SH, Dorian P, Roberts R, Gent M, Israel CW, Fain E, Champagne J, Connolly SJ. Effect of amiodarone and sotalol on ventricular defibrillation threshold: the optimal pharmacological therapy in cardioverter defibrillator patients (OPTIC) trial. Circulation. 2006;114:104-9.

139. Bunch TJ, Mahapatra S, Murdock D, Molden J, Weiss JP, May HT, Bair TL, Made KM, Crandall BG, Day JD, Osborn JS, Muhlestein JB, Lappe DL, Anderson JL. Ranolazine reduces ventricular tachycardia burden and ICD shocks in patients with drug-refractory ICD shocks. Pacing Clin Electrophysiol. 2011;34:1600-6.

140. Pacifico A, Hohnloser SH, Williams JH, Tao B, Saksena S, Henry PD, Prystowsky EN. Prevention of implantable-defibrillator shocks by treatment with sotalol. N Engl J Med. 1999;340:1855-62.

141. Goyal A, Spertus JA, Gosch K, Venkitachalam L, Jones PG, Van den Berghe G Kosiborod M. Serum potassium levels and mortality in acute myocardial infarction. JAMA. 2012;307:157-64.

142. Alberte C, Zipes DP. Use of nonantiarrhythmic drugs for prevention of sudden cardiac death. J Cardiovasc Electrophysiol. 2003;14:S87-S95.

143. Pitt B, RemmeW, Zannad F, Neaton J, Martinez F, Roniker B, Bittman R, Hurley S Kleiman J, Gatlin M, Eplerenone Post-Acute Myocardial Infarction Heart Failure Efficacy and Survival Study Investigators. Eplerenone, a selective aldosterone blocker, in patients with left ventricular dysfunction after myocardial infarction. N Engl J Med. 2003;348:1309-21.

144. Dries DL, Domanski MJ, Waclawiw MA, Gersh BJ. Effect of antithrombotic therapy on risk of sudden coronary death in patients with congestive heart failure. Am Cardiol. 1997;79:909-13.

145. Mitchell LB, Powell JL, Gillis AM, Kehl V, Hallstrom AP. Are lipid-lowering drugs also antiarrhythmic drugs? An analysis of the Antiarrhythmics versus Implantable Defibrillators (AVID) trial. J Am Coll Cardiol. 2003;42:81-7.

146. Smith T, Jordaens L, Theuns DA, van Dessel PF, Wilde AA, Hunink MG. The costeffectiveness of primary prophylactic implantable defibrillator therapy in patients with ischaemic or non-ischaemic heart disease: a European analysis. Eur Heart J. 2013;34:211-9.

147. Goldenberg I, Gillespie J, Moss AJ, Hall WJ, Klein H, McNitt S, Brown MW, Cygankiewicz I, Zareba W, Executive Committee of the Multicenter Automatic Defibrillator Implantation Trial II. Long-term benefit of primary prevention with an implantable cardioverter-defibrillator: an extended 8-year follow-up study of the Multicenter Automatic Defibrillator Implantation Trial II. Circulation. 2010;122:1265-71.

148. Goldenberg I, Kutyifa V, Klein HU, Cannom DS, Brown MW, Dan A, Daubert JP Estes NA 3rd, Foster E, Greenberg H, Kautzner J, Klempfner R, Kuniss M, Merkely B, Pfeffer MA, Quesada A, Viskin S, McNitt S, Polonsky B, Ghanem A, Solomon SD, Wilber D, Zareba W, Moss AJ. Survival with cardiac-resynchronization therapy in mild heart failure. N Engl J Med. 2014;370:1694-701.

149. Garnreiter JM, Pilcher TA, Etheridge SP, Saarel EV. Inappropriate ICD shocks in pediatrics and congenital heart disease patients: Risk factors and programming strategies. Heart Rhythm. 2015;12:937-42.

150. van der Heijden AC, Borleffs CJ, Buiten MS, Thijssen J, van Rees JB, Cannegieter SC Schalij MJ, van Erven L. The clinical course of patients with implantable defibrillators: Extended experience on clinical outcome, device replacements, and device-related complications. Heart Rhythm. 2015;12:1169-76.

151. Connolly SJ, Gent M, Roberts RS, Dorian P, Roy D, Sheldon RS, Mitchell LB, Green MS, Klein GJ, O'Brien B. Canadian implantable defibrillator study (CIDS) a randomized trial of the implantable cardioverter defibrillator against amiodarone. Circulation. 2000;101:1297-302.
152. Kuck KH, Cappato R, Siebels J, Ruppel R. Randomized comparison of antiarrhythmic drug therapy with implantable defibrillators in patients resuscitated from cardiac arrest: the Cardiac Arrest Study Hamburg (CASH). Circulation. 2000;102:748-54.

153. The Antiarrhythmics versus Implantable Defibrillators (AVID) Investigators. A comparison of antiarrhythmic-drug therapy with implantable defibrillators in patients resuscitated from near-fatal ventricular arrhythmias. N Engl J Med. 1997;337:1576-83.

154. Connolly SJ, Hallstrom AP, Cappato R, Schron EB, Kuck KH, Zipes DP, Greene HL, Boczor S, Domanski M, Follmann D, Gent M, Roberts RS. Meta-analysis of the implantable cardioverter defibrillator secondary prevention trials. AVID, CASH and CIDS studies. Antiarrhythmics vs Implantable Defibrillator study. Cardiac Arrest Study Hamburg. Canadian Implantable Defibrillator Study. Eur Heart J. 2000;21:2071-8.

155. CASCADE Investigators. Randomized antiarrhythmic drug therapy in survivors of cardiac arrest (the CASCADE Study). Am J Cardiol. 1993;72:280-7.

156. Connolly SJ, Dorian P, Roberts RS, Gent M, Bailin S, Fain ES, Thorpe K, Champagne J, Talajic M, Coutu B, Gronefeld GC, Hohnloser SH, Optimal Pharmacological Therapy in Cardioverter Defibrillator Patients (OPTIC) Investigators. Comparison of beta-blockers, amiodarone plus beta-blockers, or sotalol for prevention of shocks from implantable cardioverter defibrillators: the OPTIC Study: a randomized trial. JAMA. 2006;295:165-71.

157. Weiss R, Knight BP, Gold MR, Leon AR, Herre JM, Hood M, Rashtian M, Kremers M, Crozier I, Lee KL, SmithW, Burke MC. Safety and efficacy of a totally subcutaneous implantable-cardioverter defibrillator. Circulation. 2013;128: 944-53.

158. Lambiase PD, Barr C, Theuns DA, Knops R, Neuzil P, Johansen JB, Hood M, Pedersen S, Kaab S, Murgatroyd F, Reeve HL, Carter N, Boersma L. Worldwide experience with a totally subcutaneous implantable defibrillator: early results from the EFFORTLESS S-ICD Registry. Eur Heart J. 2014;35:1657-65.

159. Bardy GH, Smith WM, Hood MA, Crozier IG, Melton IC, Jordaens L, Theuns D, Park RE, Wright DJ, Connelly DT, Fynn SP, Murgatroyd FD, Sperzel J, Neuzner J, Spitzer SG, Ardashev AV, Oduro A, Boersma L, Maass AH, Van Gelder IC, Wilde AA, van Dessel PF, Knops RE, Barr CS, Lupo P, Cappato R, Grace AA. An entirely subcutaneous implantable cardioverter-defibrillator. N Engl J Med. 2010;363: 36-44.

160. Jarman JW, Lascelles K, Wong T, Markides V, Clague JR, Till J. Clinical experience of entirely subcutaneous implantable cardioverter-defibrillators in children and adults: cause for caution. Eur Heart J. 2012:33:1351-9.

161. Dabiri Abkenari L, Theuns DA, Valk SD, Van Belle Y, de Groot NM, Haitsma D, Muskens-Heemskerk A, Szili-Torok T, Jordaens L. Clinical experience with a novel subcutaneous implantable defibrillator system in a single center. Clin Res Cardiol. 2011;100:737-44

162. Olde Nordkamp LR, Dabiri Abkenari L, Boersma LV, Maass AH, de Groot JR, van Oostrom AJ, Theuns DA, Jordaens LJ, Wilde AA, Knops RE. The entirely subcutaneous implantable cardioverter-defibrillator: initial clinical experience in a large Dutch cohort. J Am Coll Cardiol. 2012;60:1933-9.

163. Aydin A, Hartel F, Schluter M, Butter C, Kobe J, Seifert M, Gosau N, Hoffmann B, Hoffmann M, Vettorazzi E, Wilke I,Wegscheider K, Reichenspurner H, Eckardt L, Steven D, Willems S. Shock efficacy of subcutaneous implantable cardioverterdefibrillator for prevention of sudden cardiac death: initial multicenter experience. Circ Arrhythm Electrophysiol. 2012;5:913-9.

164. Jarman JW, Todd DM. United Kingdom national experience of entirely subcutaneous implantable cardioverter-defibrillator technology: important lessons to learn. Europace. 2013;15:1158-65.

165. Kobe J, Reinke F, Meyer C, Shin DI, Martens E, Kaab S, Loher A, Amler S, Lichtenberg A, Winter J, Eckardt L. Implantation and follow-up of totally subcutaneous versus conventional implantable cardioverter-defibrillators: a multicenter case-control study. Heart Rhythm. 2013;10:29-36.

166. Burke MC, Gold MR, Knight BP, Barr CS, Theuns DA, Boersma LV, Knops RE, Weiss R, Leon AR, Herre JM, Husby M, Stein KM, Lambiase PD. Safety and efficacy of the totally subcutaneous implantable defibrillator: 2-year results from a pooled analysis of the IDE Study and EFFORTLESS Registry. J Am Coll Cardiol. 2015;65:1605-15

167. Adler A, Halkin A, Viskin S.Wearable cardioverter-defibrillators. Circulation. 2013;127:854-60.

168. Auricchio A, Klein H, Geller CJ, Reek S, Heilman MS, Szymkiewicz SJ. Clinical efficacy of the wearable cardioverter-defibrillator in acutely terminating episodes of ventricular fibrillation. Am J Cardiol. 1998;81:1253-6.

169. Chung MK, Szymkiewicz SJ, Shao M, Zishiri E, Niebauer MJ, Lindsay BD, Tchou PJ. Aggregate national experience with the wearable cardioverter-defibrillator: event rates, compliance, and survival. J Am Coll Cardiol. 2010;56:194-203.

170. Epstein AE, Abraham WT, Bianco NR, Kern KB, Mirro M, Rao SV, Rhee EK, Solomon SD, Szymkiewicz SJ.Wearable cardioverter-defibrillator use in patients perceived to be at high risk early post-myocardial infarction. J Am Coll Cardiol. 2013;62:2000-7.

171. Klein HU, Goldenberg I, Moss AJ. Risk stratification for implantable cardioverter defibrillator therapy: the role of the wearable cardioverter-defibrillator. Eur Heart J. 2013;34:2230-42.

172. Kao AC, Krause SW, Handa R, Karia D, Reyes G, Bianco NR, Szymkiewicz SJ, Wearable defibrillator use In heart Failure (WIF) Investigators.Wearable defibrillator use in heart failure (WIF): results of a prospective registry. BMC Cardiovasc Disord. 2012;12:123.

173. Hallstrom AP, Ornato JP, Weisfeldt M, Travers A, Christenson J, McBurnie MA, Zalenski R, Becker LB, Schron EB, Proschan M. Public-access defibrillation and survival after out-of-hospital cardiac arrest. N Engl J Med. 2004;351:637-46. 
174. Capucci A, Aschieri D, Piepoli MF, Bardy GH, Iconomu E, Arvedi M. Tripling survival from sudden cardiac arrest via early defibrillation without traditional education in cardiopulmonary resuscitation. Circulation. 2002;106:1065-70.

175. de Vreede-Swagemakers JJ, Gorgels AP, Dubois-Arbouw WI, van Ree JW, Daemen MJ, Houben LG, Wellens HJ. Out-of-hospital cardiac arrest in the 1990's: a population-based study in the Maastricht area on incidence, characteristics and survival. J Am Coll Cardiol. 1997;30:1500-5.

176. Moriwaki Y, Tahara Y, Iwashita M, Kosuge T, Suzuki N. Risky locations for out-ofhospital cardiopulmonary arrest in a typical urban city. J Emerg Trauma Shock. 2014;7:285-94.

177. Bardy GH, Lee KL, Mark DB, Poole JE, Toff WD, Tonkin AM, SmithW, Dorian P, Yallop JJ, Packer DL, White RD, LongstrethW, Anderson J, Johnson G, Bischoff E, Munkers CD, Brown A, McNulty S, Ray LD, Clapp-Channing NE, Rosenberg Y, Salive M, Schron EB. Rationale and design of the Home Automatic External Defibrillator Trial (HAT). Am Heart J. 2008;155:445-54.

178. Weisfeldt ML, Sitlani CM, Ornato JP, Rea T, Aufderheide TP, Davis D, Dreyer J, Hess EP, Jui J, Maloney J, Sopko G, Powell J, Nichol G, Morrison LJ. Survival after application of automatic external defibrillators before arrival of the emergency medical system: evaluation in the resuscitation outcomes consortium population of 21 million. J Am Coll Cardiol. 2010;55:1713-20.

179. Nolan JP, Soar J, Zideman DA, Biarent D, Bossaert LL, Deakin C, Koster RW, Wyllie J, Bottiger B, Group ERCGW. European Resuscitation Council Guidelines for Resuscitation 2010 Section 1. Executive summary. Resuscitation. 2010;81:1219-76.

180. Zafari AM, Zarter SK, Heggen V, Wilson P, Taylor RA, Reddy K, Backscheider AG, Dudley SC Jr. A program encouraging early defibrillation results in improved inhospital resuscitation efficacy. J Am Coll Cardiol. 2004;44:846-52.

181. Nolan JP, Hazinski MF, Billi JE, Boettiger BW, Bossaert L, de Caen AR, Deakin CD, Drajer S, Eigel B, Hickey RW, Jacobs I, Kleinman ME, Kloeck W, Koster RW, Lim SH, Mancini ME, Montgomery WH, Morley PT, Morrison LJ, Nadkarni VM, O'Connor RE, Okada K, Perlman JM, Sayre MR, Shuster M, Soar J, Sunde K, Travers AH, Wyllie J, Zideman D. Part 1: Executive summary: 2010 International Consensus on Cardiopulmonary Resuscitation and Emergency Cardiovascular Care Science With Treatment Recommendations. Resuscitation. 2010;81(Suppl 1):e1-25.

182. Griffith MJ, Garratt CJ, Rowland E,Ward DE, Camm AJ. Effects of intravenous adenosine on verapamil-sensitive "idiopathic" ventricular tachycardia. Am J Cardiol. 1994;73:759-64.

183. Carbucicchio C, Santamaria M, Trevisi N, Maccabelli G, Giraldi F, Fassini G, Riva S, Moltrasio M, Cireddu M, Veglia F, Della Bella P. Catheter ablation for the treatment of electrical storm in patients with implantable cardioverter-defibrillators: short- and long-term outcomes in a prospective single-center study. Circulation. 2008; 117:462-9.

184. Calkins H, Epstein A, Packer D, Arria AM, Hummel J, Gilligan DM, Trusso J, Carlson M, Luceri R, Kopelman H, Wilber D, Wharton JM, Stevenson W. Catheter ablation of ventricular tachycardia in patients with structural heart disease using cooled radiofrequency energy: results of a prospective multicenter study. Cooled RF Multi Center Investigators Group. J Am Coll Cardiol. 2000;35:1905-14.

185. Stevenson WG, Wilber DJ, Natale A, Jackman WM, Marchlinski FE, Talbert T, Gonzalez MD, Worley SJ, Daoud EG, Hwang C, Schuger C, Bump TE, Jazayeri M, Tomassoni GF, Kopelman HA, Soejima K, Nakagawa H. Irrigated radiofrequency catheter ablation guided by electroanatomic mapping for recurrent ventricular tachycardia after myocardial infarction: the multicenter thermocool ventricular tachycardia ablation trial. Circulation. 2008;118:2773-82.

186. Tanner H, Hindricks G, Volkmer M, Furniss S, Kuhlkamp V, Lacroix D, C DEC Almendral J, Caponi D, Kuck KH, Kottkamp H. Catheter ablation of recurrent scarrelated ventricular tachycardia using electroanatomical mapping and irrigated ablation technology: results of the prospective multicenter Euro-VT-study. J Cardiovasc Electrophysiol. 2010;21:47-53.

187. Reddy VY, Reynolds MR, Neuzil P, Richardson AW, Taborsky M, Jongnarangsin K, Kralovec S, Sediva L, Ruskin JN, Josephson ME. Prophylactic catheter ablation for the prevention of defibrillator therapy. N Engl J Med. 2007;357:2657-65.

188. Kuck KH, Schaumann A, Eckardt L, Willems S, Ventura R, Delacretaz E, Pitschner HF, Kautzner J, Schumacher B, Hansen PS. Catheter ablation of stable ventricular tachycardia before defibrillator implantation in patients with coronary heart disease (VTACH): a multicentre randomised controlled trial. Lancet. 2010;375: 31-40.

189. Poole JE, JohnsonGW, Hellkamp AS, Anderson J, Callans DJ, Raitt MH, Reddy RK, Marchlinski FE, Yee R, Guarnieri T, Talajic M, Wilber DJ, Fishbein DP, Packer DL, Mark DB, Lee KL, Bardy GH. Prognostic importance of defibrillator shocks in patients with heart failure. N Engl J Med. 2008;359:1009-17.

190. Kamphuis HC, de Leeuw JR, Derksen R, Hauer RN, Winnubst JA. Implantable cardioverter defibrillator recipients: quality of life in recipients with and without ICD shock delivery: a prospective study. Europace. 2003;5:381-9.

191. de Bakker JM, van Capelle FJ, Janse MJ, Tasseron S, Vermeulen JT, de Jonge N, Lahpor JR. Slow conduction in the infarcted human heart. 'Zigzag' course of activation. Circulation. 1993;88:915-26.

192. de Chillou C, Lacroix D, Klug D, Magnin-Poull I, Marquie C, Messier M, Andronache M, Kouakam C, Sadoul N, Chen J, Aliot E, Kacet S. Isthmus characteristics of reentrant ventricular tachycardia after myocardial infarction. Circulation. 2002; $105: 726-31$.

193. Littmann L, Svenson RH, Gallagher JJ, Selle JG, Zimmern SH, Fedor JM, Colavita PG. Functional role of the epicardium in postinfarction ventricular tachycardia. Observations derived from computerized epicardial activation mapping, entrainment, and epicardial laser photoablation. Circulation. 1991;83:1577-91.

194. Berruezo A, Mont L, Nava S, Chueca E, Bartholomay E, Brugada J. Electrocardiographic recognition of the epicardial origin of ventricular tachycardias. Circulation. 2004;109:1842-7.
195. Daniels DV, Lu YY, Morton JB, Santucci PA, Akar JG, Green A, Wilber DJ. Idiopathic epicardial left ventricular tachycardia originating remote from the sinus of Valsalva: electrophysiological characteristics, catheter ablation, and identification from the 12-lead electrocardiogram. Circulation. 2006;113:1659-66.

196. Bazan V, Gerstenfeld EP, Garcia FC, Bala R, Rivas N, Dixit S, Zado E, Callans DJ, Marchlinski FE. Site-specific twelve-lead ECG features to identify an epicardial origin for left ventricular tachycardia in the absence of myocardial infarction. Heart Rhythm. 2007;4:1403-10.

197. Valles E, Bazan V, Marchlinski FE. ECG criteria to identify epicardial ventricular tachycardia in nonischemic cardiomyopathy. Circ Arrhythm Electrophysiol. 2010;3:63-71.

198. Arenal A, Perez-David E, Avila P, Fernandez-Portales J, Crisostomo V, Baez C Jimenez-Candil J, Rubio-Guivernau JL, Ledesma-Carbayo MJ, Loughlin G, Bermejo J, Sanchez-Margallo FM, Fernandez-Aviles F. Noninvasive identification of epicardial ventricular tachycardia substrate by magnetic resonance-based signal intensity mapping. Heart Rhythm. 2014;11:1456-64.

199. Perez-David E, Arenal A, Rubio-Guivernau JL, del Castillo R, Atea L, Arbelo E, Caballero E, Celorrio V, Datino T, Gonzalez-Torrecilla E, Atienza F, LedesmaCarbayo MJ, Bermejo J, Medina A, Fernandez-Aviles F. Noninvasive identification of ventricular tachycardia-related conducting channels using contrast-enhanced magnetic resonance imaging in patients with chronic myocardial infarction: comparison of signal intensity scar mapping and endocardial voltage mapping. J Am Coll Cardiol. 2011;57:184-94.

200. Bansch D, Bocker D, Brunn J, Weber M, Breithardt G, Block M. Clusters of ventricular tachycardias signify impaired survival in patients with idiopathic dilated cardiomyopathy and implantable cardioverter defibrillators. J Am Coll Cardiol. 2000;36:566-73.

201. Haissaguerre M, Extramiana F, Hocini M, Cauchemez B, Jais P, Cabrera JA, Farre J, Leenhardt A, Sanders P, Scavee C, Hsu LF, Weerasooriya R, Shah DC, Frank R, Maury P, Delay M, Garrigue S, Clementy J. Mapping and ablation of ventricular fibrillation associated with long-QT and Brugada syndromes. Circulation. 2003;108:925-8.

202. Berruezo A, Fernandez-Armenta J, Mont L, Zeljko H, Andreu D, Herczku C, Boussy T, Tolosana JM, Arbelo E, Brugada J. Combined endocardial and epicardial catheter ablation in arrhythmogenic right ventricular dysplasia incorporating scar dechanneling technique. Circ Arrhythm Electrophysiol. 2012;5:111-21.

203. Marchlinski FE, Callans DJ, Gottlieb CD, Zado E. Linear ablation lesions for control of unmappable ventricular tachycardia in patients with ischemic and nonischemic cardiomyopathy. Circulation. 2000;101:1288-96.

204. Jais P, Maury P, Khairy P, Sacher F, Nault I, Komatsu Y, Hocini M, Forclaz A, Jadidi AS, Weerasooryia R, Shah A, Derval N, Cochet H, Knecht S, Miyazaki S, Linton N, Rivard L, Wright M, Wilton SB, Scherr D, Pascale P, Roten L, Pederson M, Bordachar P, Laurent F, Kim SJ, Ritter P, Clementy J, Haissaguerre M. Elimination of local abnormal ventricular activities: a new end point for substrate modification in patients with scar-related ventricular tachycardia. Circulation. 2012;125:2184-96.

205. Di Biase L, Santangeli P, Burkhardt DJ, Bai R, Mohanty P, Carbucicchio C, Dello Russo A, Casella M, Mohanty S, Pump A, Hongo R, Beheiry S, Pelargonio G, Santarelli P, Zucchetti M, Horton R, Sanchez JE, Elayi CS, Lakkireddy D, Tondo C, Natale A. Endo-epicardial homogenization of the scar versus limited substrate ablation for the treatment of electrical storms in patients with ischemic cardiomyopathy. J Am Coll Cardiol. 2012;60:132-41.

206. Cano O, Hutchinson M, Lin D, Garcia F, Zado E, Bala R, Riley M, Cooper J, Dixit S Gerstenfeld E, Callans D, Marchlinski FE. Electroanatomic substrate and ablation outcome for suspected epicardial ventricular tachycardia in left ventricular nonischemic cardiomyopathy. J Am Coll Cardiol. 2009;54:799-808.

207. Bai R, Di Biase L, Shivkumar K, Mohanty P, Tung R, Santangeli P, Saenz LC, Vacca M, Verma A, Khaykin Y, Mohanty S, Burkhardt JD, Hongo R, Beheiry S, Dello Russo A, Casella M, Pelargonio G, Santarelli P, Sanchez J, Tondo C, Natale A. Ablation of ventricular arrhythmias in arrhythmogenic right ventricular dysplasia/ cardiomyopathy: arrhythmia-free survival after endo-epicardial substrate based mapping and ablation. Circ Arrhythm Electrophysiol. 2011;4:478-85.

208. Dinov B, Fiedler L, Schonbauer R, Bollmann A, Rolf S, Piorkowski C, Hindricks G Arya A. Outcomes in catheter ablation of ventricular tachycardia in dilated nonischemic cardiomyopathy compared with ischemic cardiomyopathy: results from the Prospective Heart Centre of Leipzig VT (HELP-VT) Study. Circulation. 2014; 129:728-36.

209. Kojodjojo P, Tokuda M, Bohnen M, Michaud GF, Koplan BA, Epstein LM, Albert CM John RM, Stevenson WG, Tedrow UB. Electrocardiographic left ventricular scar burden predicts clinical outcomes following infarct-related ventricular tachycardia ablation. Heart Rhythm. 2013;10:1119-24.

210. Della Bella P, Baratto F, Tsiachris D, Trevisi N, Vergara P, Bisceglia C, Petracca F Carbucicchio C, Benussi S, Maisano F, Alfieri O, Pappalardo F, Zangrillo A, Maccabelli G. Management of ventricular tachycardia in the setting of a dedicated unit for the treatment of complex ventricular arrhythmias: long-term outcome after ablation. Circulation. 2013;127:1359-68.

211. Peichl P, Wichterle D, Pavlu L, Cihak R, Aldhoon B, Kautzner J. Complications of catheter ablation of ventricular tachycardia: a single-center experience. Circ Arrhythm Electrophysiol. 2014;7:684-90.

212. Mukaddirov M, Demaria RG, Perrault LP, Frapier JM, Albat B. Reconstructive surgery of postinfarction left ventricular aneurysms: techniques and unsolved problems. Eur J Cardiothorac Surg. 2008;34:256-61.

213. Sartipy U, Albage A, Insulander P, Lindblom D. Surgery for ventricular tachycardia in patients undergoing surgical ventricular restoration: the Karolinska approach. J Interv Card Electrophysiol. 2007;19:171-8.

214. Moran JM, Kehoe RF, Loeb JM, Lichtenthal PR, Sanders JH Jr, Michaelis LL. Extended endocardial resection for the treatment of ventricular tachycardia and ventricular fibrillation. Ann Thorac Surg. 1982;34:538-52. 
215. O'Neill JO, Starling RC, Khaykin Y, McCarthy PM, Young JB, Hail M, Albert NM Smedira N, Chung MK. Residual high incidence of ventricular arrhythmias after left ventricular reconstructive surgery. J Thorac Cardiovasc Surg. 2005;130:1250-6.

216. Rastegar H, Link MS, Foote CB,Wang PJ, Manolis AS, Estes NA 3rd. Perioperative and long-term results with mapping-guided subendocardial resection and left ventricular endoaneurysmorrhaphy. Circulation. 1996;94:1041-8.

217. Page PL, Cardinal R, Shenasa M, KaltenbrunnerW, Cossette R, Nadeau R. Surgical treatment of ventricular tachycardia. Regional cryoablation guided by computerized epicardial and endocardial mapping. Circulation. 1989;80: I124-34.

218. Josephson ME, Harken AH, Horowitz LN. Endocardial excision: a new surgical technique for the treatment of recurrent ventricular tachycardia. Circulation. 1979;60:1430-9.

219. Krishnan SC, Josephson ME. Surgery for postinfarction ventricular tachycardia: is it obsolete? Pacing Clin Electrophysiol. 2000;23:1295-301.

220. Iwa T, Misaki T, Kawasuji M, Matsunaga Y, Tsubota M, Matsumoto Y. Long-term results of surgery for non-ischemic ventricular tachycardia. Eur J Cardiothorac Surg. 1991;5:191-7.

221. Karamlou T, Silber I, Lao R, McCrindle BW, Harris L, Downar E, Webb GD, Colman JM, Van Arsdell GS, Williams WG. Outcomes after late reoperation in patients with repaired tetralogy of Fallot: the impact of arrhythmia and arrhythmia surgery. Ann Thorac Surg. 2006;81:1786-93.

222. Tilz RR, Makimoto H, Lin T, Rillig A, Deiss S, Wissner E, Mathew S, Metzner A Rausch P, Kuck KH, Ouyang F. Electrical isolation of a substrate after myocardial infarction: a novel ablation strategy for unmappable ventricular tachycardiasfeasibility and clinical outcome. Europace. 2014;16:1040-52.

223. Schron EB, Exner DV, Yao Q Jenkins LS, Steinberg JS, Cook JR, Kutalek SP, Friedman PL, Bubien RS, Page RL, Powell J. Quality of life in the antiarrhythmics versus implantable defibrillators trial: impact of therapy and influence of adverse symptoms and defibrillator shocks. Circulation. 2002;105:589-94.

224. Irvine J, Dorian P, Baker B, O’Brien BJ, Roberts R, Gent M, Newman D, Connolly SJ Quality of life in the Canadian Implantable Defibrillator Study (CIDS). Am Heart J. 2002;144:282-9

225. Koopman HM, Vrijmoet-Wiersma CM, Langius JN, van den Heuvel F, Clur SA, Blank CA, Blom NA, ten Harkel AD. Psychological functioning and disease-related quality of life in pediatric patients with an implantable cardioverter defibrillator. Pediatr Cardiol. 2012;33:569-75.

226. Berg SK, Higgins M, Reilly CM, Langberg JJ, Dunbar SB. Sleep quality and sleepiness in persons with implantable cardioverter defibrillators: outcome from a clinical randomized longitudinal trial. Pacing Clin Electrophysiol. 2012;35: 431-43.

227. Vazquez LD, Kuhl EA, Shea JB, Kirkness A, Lemon J, Whalley D, Conti JB, Sears SF. Age-specific differences in women with implantable cardioverter defibrillators: an international multi center study. Pacing Clin Electrophysiol. 2008;31: 1528-34.

228. Magyar-Russell G, Thombs BD, Cai JX, Baveja T, Kuhl EA, Singh PP, Montenegro Braga Barroso M, Arthurs E, Roseman M, Amin N, Marine JE, Ziegelstein RC. The prevalence of anxiety and depression in adults with implantable cardioverter defibrillators: a systematic review. J Psychosom Res. 2011;71:223-31.

229. Braunschweig F, Boriani G, Bauer A, Hatala R, Herrmann-Lingen C, Kautzner J, Pedersen SS, Pehrson S, Ricci R, Schalij MJ. Management of patients receiving implantable cardiac defibrillator shocks: recommendations for acute and longterm patient management. Europace. 2010;12:1673-90.

230. Hoogwegt MT, Kupper N, Theuns DA, Zijlstra WP, Jordaens L, Pedersen SS Undertreatment of anxiety and depression in patients with an implantable cardioverter-defibrillator: impact on health status. Health Psychol. 2012;31: 745-53.

231. Lang S, Becker R, Wilke S, Hartmann M, HerzogW, Lowe B. Anxiety disorders in patients with implantable cardioverter defibrillators: frequency, course, predictors, and patients' requests for treatment. Pacing Clin Electrophysiol. 2014;37:35-47.

232. Kapa S, Rotondi-Trevisan D, Mariano Z, Aves T, Irvine J, Dorian P, Hayes DL. Psychopathology in patients with ICDs over time: results of a prospective study. Pacing Clin Electrophysiol. 2010;33:198-208.

233. Morken IM, Bru E, Norekval TM, Larsen AI, Idsoe T, Karlsen B. Perceived support from healthcare professionals, shock anxiety and post-traumatic stress in implantable cardioverter defibrillator recipients. J Clin Nurs. 2014;23:450-60.

234. Versteeg H, Theuns DA, Erdman RA, Jordaens L, Pedersen SS. Posttraumatic stress in implantable cardioverter defibrillator patients: the role of preimplantation distress and shocks. Int J Cardiol. 2011:146:438-9.

235. Morken IM, Isaksen K, Karlsen B, Norekval TM, Bru E, Larsen AI. Shock anxiety among implantable cardioverter defibrillator recipients with recent tachyarrhythmia. Pacing Clin Electrophysiol. 2012;35:1369-76.

236. Pedersen SS, van den Broek KC, Erdman RA, Jordaens L, Theuns DA. Preimplantation implantable cardioverter defibrillator concerns and type D personality increase the risk of mortality in patients with an implantable cardioverter defibrillator. Europace. 2010;12:1446-52.

237. Mastenbroek MH, Versteeg H, Jordaens L, Theuns DA, Pedersen SS. Ventricular tachyarrhythmias and mortality in patients with an implantable cardioverte defibrillator: impact of depression in the MIDAS cohort. Psychosom Med. 2014;76:58-65.

238. Dunbar SB, Dougherty CM, Sears SF, Carroll DL, Goldstein NE, Mark DB, McDaniel G, Pressler SJ, Schron E, Wang P, Zeigler VL. Educational and psychological interventions to improve outcomes for recipients of implantable cardioverter defibrillators and their families: a scientific statement from the American Heart Association. Circulation. 2012;126:2146-72.
239. Vijgen J, Botto G, Camm J, Hoijer CJ, Jung W, Le Heuzey JY, Lubinski A, Norekval TM, Santomauro M, Schalij M, Schmid JP, Vardas P. Consensus statement of the European Heart Rhythm Association: updated recommendations for driving by patients with implantable cardioverter defibrillators. Europace. 2009;11: 1097-107.

240. Johansson I, Stromberg A. Experiences of driving and driving restrictions in recipients with an implantable cardioverter defibrillator-the patient perspective. J Cardiovasc Nurs. 2010;25:E1-E10.

241. Steinke EE, Gill-Hopple K, Valdez D,Wooster M. Sexual concerns and educational needs after an implantable cardioverter defibrillator. Heart Lung. 2005;34: 299-308.

242. Steinke EE, Jaarsma T, Barnason SA, Byrne M, Doherty S, Dougherty CM, Fridlund B, Kautz DD, Martensson J, Mosack V, Moser DK. Sexual counselling for individuals with cardiovascular disease and their partners: a consensus document from the American Heart Association and the ESC Council on Cardiovascular Nursing and Allied Professions (CCNAP). Eur Heart J. 2013;34:3217-35.

243. Zeigler VL, Nelms T. Almost normal: experiences of adolescents with implantable cardioverter defibrillators. J Spec Pediatr Nurs. 2009;14:142-51.

244. Steg PG, Cambou JP, Goldstein P, Durand E, Sauval P, Kadri Z, Blanchard D, Lablanche JM, Gueret P, Cottin Y, Juliard JM, Hanania G, Vaur L, Danchin N. Bypassing the emergency room reduces delays and mortality in ST elevation myocardial infarction: the USIC 2000 registry. Heart. 2006;92:1378-83.

245. Soholm H, Wachtell K, Nielsen SL, Bro-Jeppesen J, Pedersen F, Wanscher M, Boesgaard S, Moller JE, Hassager C, Kjaergaard J. Tertiary centres have improved survival compared to other hospitals in the Copenhagen area after out-ofhospital cardiac arrest. Resuscitation. 2013;84:162-7.

246. Xiao G, Guo Q, Shu M, Xie X, Deng J, Zhu Y,Wan C. Safety profile and outcome of mild therapeutic hypothermia in patients following cardiac arrest: systematic review and meta-analysis. Emerg Med J. 2013;30:91-100.

247. Boersma E, Maas AC, Deckers JW, Simoons ML. Early thrombolytic treatment in acute myocardial infarction: reappraisal of the golden hour. Lancet. 1996;348:771-5.

248. Boersma E, Primary Coronary Angioplasty vs. Thrombolysis Group. Does time matter? A pooled analysis of randomized clinical trials comparing primary percutaneous coronary intervention and in-hospital fibrinolysis in acute myocardial infarction patients. Eur Heart J. 2006;27:779-88.

249. Keeley EC, Boura JA, Grines CL. Comparison of primary and facilitated percutaneous coronary interventions for ST-elevation myocardial infarction: quantitative review of randomised trials. Lancet. 2006;367:579-88.

250. Roffi M, Patrono C, Collet JP, Mueller C, Valgimigli M, Andreotti F, Bax JJ, Borger MA, Brotons C, Chew DP, Gencer B, Hasenfuss G, Kjeldsen K, Lancellotti P, Landmesser U, Mehilli J, Mukherjee D, Storey RF, Windecker S. 2015 ESC Guidelines for the Management of Acute Coronary Syndromes in Patients Presenting Without Persistent ST-Segment Elevation. Eur Heart J. 2015. doi:10.1093/eurheartj/ehv320.

251. Spaulding CM, Joly LM, Rosenberg A, Monchi M,Weber SN, Dhainaut JF, Carli P. Immediate coronary angiography in survivors of out-of-hospital cardiac arrest. N Engl J Med. 1997;336:1629-33.

252. Dumas F, Cariou A, Manzo-Silberman S, Grimaldi D, Vivien B, Rosencher J, Empana JP, Carli P, Mira JP, Jouven X, Spaulding C. Immediate percutaneous coronary intervention is associated with better survival after out-of-hospital cardiac arrest: insights from the PROCAT (Parisian Region Out of hospital Cardiac ArresT) registry. Circ Cardiovasc Interv. 2010;3:200-7.

253. Bowers TR, O'Neill WW, Grines C, Pica MC, Safian RD, Goldstein JA. Effect of reperfusion on biventricular function and survival after right ventricular infarction. N Engl J Med. 1998;338:933-40.

254. Reddy YM, Chinitz L, Mansour M, Bunch TJ, Mahapatra S, Swarup V, Di Biase L, Bommana S, Atkins D, Tung R, Shivkumar K, Burkhardt JD, Ruskin J, Natale A, Lakkireddy D. Percutaneous left ventricular assist devices in ventricular tachycardia ablation: multicenter experience. Circ Arrhythm Electrophysiol. 2014;7:244-50

255. Lamhaut L, Jouffroy R, Soldan M, Phillipe P, Deluze T, Jaffry M, Dagron C, Vivien B, Spaulding C, An K, Carli P. Safety and feasibility of prehospital extra corporeal life support implementation by non-surgeons for out-of-hospital refractory cardiac arrest. Resuscitation. 2013;84:1525-9.

256. Wang CH, Chou NK, Becker LB, Lin JW, Yu HY, Chi NH, Hunag SC, Ko WJ, Wang SS, Tseng LJ, Lin MH, Wu IH, Ma MH, Chen YS. Improved outcome of extracorporeal cardiopulmonary resuscitation for out-of-hospital cardiac arrest-a comparison with that for extracorporeal rescue for in-hospital cardiac arrest. Resuscitation. 2014;85:1219-24.

257. Piccini JP, Hranitzky PM, Kilaru R, Rouleau JL, White HD, Aylward PE, Van de Werf F, Solomon SD, Califf RM, Velazquez EJ. Relation of mortality to failure to prescribe beta blockers acutely in patients with sustained ventricular tachycardia and ventricular fibrillation following acute myocardial infarction (from the VALsartan In Acute myocardial iNfarcTion trial [VALIANT] Registry). Am J Cardiol. 2008;102:1427-32.

258. Wolfe CL, Nibley C, Bhandari A, Chatterjee K, Scheinman M. Polymorphous ventricular tachycardia associated with acute myocardial infarction. Circulation. 1991;84:1543-51.

259. Chatterjee S, Chaudhuri D, Vedanthan R, Fuster V, Ibanez B, Bangalore $S$, Mukherjee D. Early intravenous beta-blockers in patients with acute coronary syndrome-a meta-analysis of randomized trials. Int J Cardiol. 2013;168:915-21.

260. Bangalore S, Makani H, Radford M, Thakur K, Toklu B, Katz SD, DiNicolantonio JJ, Devereaux PJ, Alexander KP, Wetterslev J, Messerli FH. Clinical outcomes with beta-blockers for myocardial infarction: a meta-analysis of randomized trials. Am J Med. 2014;127:939-53. 
261. Enjoji Y, Mizobuchi M, Muranishi H, Miyamoto C, Utsunomiya M, Funatsu A, Kobayashi T, Nakamura S. Catheter ablation of fatal ventricular tachyarrhythmias storm in acute coronary syndrome-role of Purkinje fiber network. J Interv Card Electrophysiol. 2009;26:207-15.

262. Frankel DS, Mountantonakis SE, Robinson MR, Zado ES, Callans DJ, Marchlinski FE. Ventricular tachycardia ablation remains treatment of last resort in structural heart disease: argument for earlier intervention. J Cardiovasc Electrophysiol. 2011;22:1123-8.

263. Peichl P, Cihak R, Kozeluhova M, Wichterle D, Vancura V, Kautzner J. Catheter ablation of arrhythmic storm triggered by monomorphic ectopic beats in patients with coronary artery disease. J Interv Card Electrophysiol. 2010;27:51-9.

264. Deneke T, Lemke B, Mugge A, Shin DI, Grewe PH, Horlitz M, Balta O, Bosche L, Lawo T. Catheter ablation of electrical storm. Expert Rev Cardiovasc Ther. 2011;9:1051-8.

265. Deneke T, Shin DI, Lawo T, Bosche L, Balta O, Anders H, Bunz K, Horlitz M, Grewe $\mathrm{PH}$, Lemke B, Mugge A. Catheter ablation of electrical storm in a collaborative hospital network. Am J Cardiol. 2011;108:233-9.

266. Gorenek B, Blomstrom Lundqvist C, Brugada Terradellas J, Camm AJ, Hindricks G Huber K, Kirchhof P, Kuck KH, Kudaiberdieva G, Lin T, Raviele A, Santini M, Tilz RR, Valgimigli M, Vos MA, Vrints C, Zeymer U, Lip GY, Potpara T, Fauchier L, Sticherling C, Roffi M, Widimsky P, Mehilli J, Lettino M, Schiele F, Sinnaeve P, Boriani G, Lane D, Savelieva I. Cardiac arrhythmias in acute coronary syndromes: position paper from the joint EHRA, ACCA, and EAPCI task force. Europace. 2014; $16: 1655-73$.

267. Shaw DJ, Davidson JE, Smilde RI, Sondoozi T, Agan D. Multidisciplinary team training to enhance family communication in the ICU. Crit Care Med. 2014;42:265-71.

268. Piccini JP, Schulte PJ, Pieper KS, Mehta RH, White HD, Van de Werf F, Ardissino D, Califf RM, Granger CB, Ohman EM, Alexander JH. Antiarrhythmic drug therapy for sustained ventricular arrhythmias complicating acute myocardial infarction. Crit Care Med. 2011;39:78-83.

269. Huikuri HV, Castellanos A, Myerburg RJ. Sudden death due to cardiac arrhythmias. N Engl J Med. 2001;345:1473-82.

270. Hine LK, Laird N, Hewitt P, Chalmers TC. Meta-analytic evidence against prophylactic use of lidocaine in acute myocardial infarction. Arch Intern Med. 1989;149:2694-8.

271. Steg PG, James SK, Atar D, Badano LP, Blomstrom-Lundqvist C, Borger MA, Di Mario C, Dickstein K, Ducrocq G, Fernandez-Aviles F, Gershlick AH, Giannuzzi P, Halvorsen S, Huber K, Juni P, Kastrati A, Knuuti J, Lenzen MJ, Mahaffey KW, Valgimigli M, van't Hof A, Widimsky P, Zahger D. ESC Guidelines for the management of acute myocardial infarction in patients presenting with STsegment elevation. Eur Heart J. 2012;33:2569-619.

272. Borne RT, Varosy PD, Masoudi FA. Implantable cardioverter-defibrillator shocks: epidemiology, outcomes, and therapeutic approaches. JAMA Intern Med 2013;173:859-65.

273. Liang JJ, Hodge DO, Mehta RA, Russo AM, Prasad A, Cha YM. Outcomes in patients with sustained ventricular tachyarrhythmias occurring within $48 \mathrm{~h}$ of acute myocardial infarction: when is ICD appropriate? Europace. 2014;16:1759-66.

274. Hohnloser SH, Kuck KH, Dorian P, Roberts RS, Hampton JR, Hatala R, Fain E, Gent $\mathrm{M}$, Connolly SJ, Investigators D. Prophylactic use of an implantable cardioverterdefibrillator after acute myocardial infarction. N Engl J Med. 2004;351:2481-8.

275. Steinbeck G, Andresen D, Seidl K, Brachmann J, Hoffmann E, Wojciechowski D, Kornacewicz-Jach Z, Sredniawa B, Lupkovics G, Hofgartner F, Lubinski A, Rosenqvist M, Habets A,Wegscheider K, Senges J, IRIS Investigators. Defibrillator implantation early after myocardial infarction. N Engl J Med. 2009;361:1427-36.

276. Noc M, Fajadet J, Lassen JF, Kala P, MacCarthy P, Olivecrona GK, Windecker S, Spaulding C. Invasive coronary treatment strategies for out-of-hospital cardiac arrest: a consensus statement from the European Association for Percutaneous Cardiovascular Interventions (EAPCI)/Stent for Life(SFL) groups. EuroIntervention. 2014;10:31-7.

277. Bougouin W, Marijon E, Puymirat E, Defaye P, Celermajer DS, Le Heuzey JY, Boveda S, Kacet S, Mabo P, Barnay C, Da Costa A, Deharo JC, Daubert JC, Ferrieres J, Simon T, Danchin N. Incidence of sudden cardiac death after ventricular fibrillation complicating acute myocardial infarction: a 5-year cause-of-death analysis of the FAST-MI 2005 registry. Eur Heart J. 2014;35:116-22.

278. Avezum A, Piegas LS, Goldberg RJ, Brieger D, Stiles MK, Paolini R, Huang W, Gore JM. Magnitude and prognosis associated with ventricular arrhythmias in patients hospitalized with acute coronary syndromes (from the GRACE Registry). Am J Cardiol. 2008;102:1577-82.

279. Piccini JP, White JA, Mehta RH, Lokhnygina Y, Al-Khatib SM, Tricoci P, Pollack CV Jr, Montalescot G, Van de Werf F, Gibson CM, Giugliano RP, Califf RM, Harrington RA, Newby LK. Sustained ventricular tachycardia and ventricular fibrillation complicating non-ST-segment-elevation acute coronary syndromes. Circulation. 2012;126:41-9.

280. Buxton AE, Lee KL, DiCarlo L, Gold MR, Greer GS, Prystowsky EN, O’Toole MF, Tang A, Fisher JD, Coromilas J, Talajic M, Hafley G. Electrophysiologic testing to identify patients with coronary artery disease who are at risk for sudden death Multicenter Unsustained Tachycardia Trial Investigators. N Engl J Med. 2000;342:1937-45.

281. Buxton AE, Lee KL, Hafley GE, Pires LA, Fisher JD, Gold MR, Josephson ME, Lehmann MH, Prystowsky EN. Limitations of ejection fraction for prediction of sudden death risk in patients with coronary artery disease: lessons from the MUSTT study. J Am Coll Cardiol. 2007;50:1150-7.

282. Gatzoulis KA, Tsiachris D, Arsenos P, Archontakis S, Dilaveris P, Vouliotis A, Sideris S, Skiadas I, Kallikazaros I, Stefanadis C. Prognostic value of programmed ventricular stimulation for sudden death in selected high risk patients with structural heart disease and preserved systolic function. Int J Cardiol. 2014; $176: 1449-51$

283. Exner DV, Kavanagh KM, Slawnych MP, Mitchell LB, Ramadan D, Aggarwal SG, Noullett C, Van Schaik A, Mitchell RT, Shibata MA, Gulamhussein S, McMeekin J, Tymchak W, Schnell G, Gillis AM, Sheldon RS, Fick GH, Duff HJ. Noninvasive risk assessment early after a myocardial infarction the REFINE study. J Am Coll Cardiol. 2007;50:2275-84.

284. Malik M, Camm AJ, Janse MJ, Julian DG, Frangin GA, Schwartz PJ. Depressed heart rate variability identifies postinfarction patients who might benefit from prophylactic treatment with amiodarone: a substudy of EMIAT (the European Myocardial Infarct Amiodarone Trial). J Am Coll Cardiol. 2000;35:1263-75.

285. Zaman S, Narayan A, Thiagalingam A, Sivagangabalan G, Thomas S, Ross DL, Kovoor P. Long-term arrhythmia-free survival in patients with severe left ventricular dysfunction and no inducible ventricular tachycardia after myocardial infarction. Circulation. 2014:129:848-54.

286. Soholm H, Lonborg J, Andersen MJ, Vejlstrup N, Engstrom T, Moller JE, Hassager C. Repeated echocardiography after first ever ST-segment elevation myocardial infarction treated with primary percutaneous coronary intervention-is it necessary? Eur Heart J Acute Cardiovasc Care. 2014 Oct 15. pii: 2048872614556000 [Epub ahead of print].

287. Allman KC, Shaw LJ, Hachamovitch R, Udelson JE. Myocardial viability testing and impact of revascularization on prognosis in patients with coronary artery disease and left ventricular dysfunction: a meta-analysis. J Am Coll Cardiol. 2002;39:1151-8.

288. St John Sutton M, Pfeffer MA, Plappert T, Rouleau JL, Moye LA, Dagenais GR Lamas GA, Klein M, Sussex B, Goldman S. Quantitative two-dimensiona echocardiographic measurements are major predictors of adverse cardiovascular events after acute myocardial infarction. The protective effects of captopril. Circulation. 1994:89:68-75

289. Kelly P, Ruskin JN, Vlahakes GJ, Buckley MJ Jr, Freeman CS, Garan H. Surgical coronary revascularization in survivors of prehospital cardiac arrest: its effect on inducible ventricular arrhythmias and long-term survival. J Am Coll Cardiol. 1990;15:267-73.

290. van der Burg AE, Bax JJ, Boersma E, Pauwels EK, van der Wall EE, Schalij MJ. Impact of viability, ischemia, scar tissue, and revascularization on outcome after aborted sudden death. Circulation. 2003;108:1954-9.

291. Bax JJ, Visser FC, Poldermans D, Elhendy A, Cornel JH, Boersma E, van Lingen A, Fioretti PM, Visser CA. Time course of functional recovery of stunned and hibernating segments after surgical revascularization. Circulation. 2001;104:I314-8.

292. Funaro S, La Torre G, Madonna M, Galiuto L, Scara A, Labbadia A, Canali E, Mattatelli A, Fedele F, Alessandrini F, Crea F, Agati L. Incidence, determinants, and prognostic value of reverse left ventricular remodelling after primary percutaneous coronary intervention: results of the Acute Myocardial Infarction Contrast Imaging (AMICI) multicenter study. Eur Heart J. 2009;30:566-75.

293. Cairns JA, Connolly SJ, Roberts R, Gent M. Randomised trial of outcome after myocardial infarction in patients with frequent or repetitive ventricular premature depolarisations: CAMIAT. Canadian Amiodarone Myocardial Infarction Arrhythmia Trial Investigators. Lancet. 1997;349:675-82.

294. Julian DG, Camm AJ, Frangin G, Janse MJ, Munoz A, Schwartz PJ, Simon P. Randomised trial of effect of amiodarone on mortality in patients with leftventricular dysfunction after recent myocardial infarction: EMIAT. European Myocardial Infarct Amiodarone Trial Investigators. Lancet. 1997;349:667-74.

295. Solomon SD, Wang D, Finn P, Skali H, Zornoff L, McMurray JJ, Swedberg K, Yusuf S, Granger CB, Michelson EL, Pocock S, Pfeffer MA. Effect of candesartan on causespecific mortality in heart failure patients: the Candesartan in Heart failure Assessment of Reduction in Mortality and morbidity (CHARM) program. Circulation. 2004;110:2180-3.

296. Cleland JG, Massie BM, Packer M. Sudden death in heart failure: vascular or electrical? Eur J Heart Fail. 1999;1:41-5.

297. Gradman A, Deedwania P, Cody R, Massie B, Packer M, Pitt B, Goldstein S. Predictors of total mortality and sudden death in mild to moderate heart failure. Captopril-Digoxin Study Group. J Am Coll Cardiol. 1989;14:564-70.

298. Szabo BM, van Veldhuisen DJ, Crijns HJ, Wiesfeld AC, Hillege HL, Lie KI. Value of ambulatory electrocardiographic monitoring to identify increased risk of sudden death in patients with left ventricular dysfunction and heart failure. Eur Heart J. 1994;15:928-33.

299. Doval HC, Nul DR, Grancelli HO, Varini SD, Soifer S, Corrado G, Dubner S, Scapin $\mathrm{O}$, Perrone SV. Nonsustained ventricular tachycardia in severe heart failure. Independent marker of increased mortality due to sudden death. GESICAGEMA Investigators. Circulation. 1996;94:3198-203.

300. Teerlink JR, Jalaluddin M, Anderson S, Kukin ML, Eichhorn EJ, Francis G, Packer M Massie BM. Ambulatory ventricular arrhythmias in patients with heart failure do not specifically predict an increased risk of sudden death. PROMISE (Prospective Randomized Milrinone Survival Evaluation) Investigators. Circulation. 2000;101:40-6.

301. AlJaroudiWA, Refaat MM, Habib RH, Al-Shaar L, Singh M, Gutmann R, Bloom HL Dudley SC, Ellinor PT, Saba SF, Shalaby AA, Weiss R, McNamara DM, Halder I, London B, Genetic Risk Assessment of Defibrillator Events Investigators. Effect of angiotensin-converting enzyme inhibitors and receptor blockers on appropriate implantable cardiac defibrillator shock in patients with severe systolic heart failure (from the GRADE Multicenter Study). Am J Cardiol. 2015;115:924-31.

302. Pitt B, White H, Nicolau J, Martinez F, Gheorghiade M, Aschermann M, van Veldhuisen DJ, Zannad F, Krum H, Mukherjee R, Vincent J, EPHESUS Investigators. Eplerenone reduces mortality 30 days after randomization following acute myocardial infarction in patients with left ventricular systolic dysfunction and heart failure. J Am Coll Cardiol. 2005;46:425-31. 
303. Peck KY, Lim YZ, Hopper I, Krum H. Medical therapy versus implantable cardioverter-defibrillator in preventing sudden cardiac death in patients with left ventricular systolic dysfunction and heart failure: a meta-analysis of $>35,000$ patients. Int J Cardiol. 2014;173:197-203.

304. Chatterjee S, Udell JA, Sardar P, Lichstein E, Ryan JJ. Comparable benefit of betablocker therapy in heart failure across regions of the world: meta-analysis of randomized clinical trials. Can J Cardiol. 2014;30:898-903.

305. Garg R, Yusuf S. Overview of randomized trials of angiotensin-converting enzyme inhibitors on mortality and morbidity in patients with heart failure. Collaborative Group on ACE Inhibitor Trials. JAMA. 1995;273:1450-6.

306. Kotecha D, Holmes J, Krum H, Altman DG, Manzano L, Cleland JG, Lip GY, Coats AJ, Andersson B, Kirchhof P, von Lueder TG, Wedel H, Rosano G, Shibata MC, Rigby A Flather MD, Beta-Blockers in Heart Failure Collaborative Group. Efficacy of beta blockers in patients with heart failure plus atrial fibrillation: an individualpatient data meta-analysis. Lancet. 2014;384:2235-43.

307. Kotecha D, Altman DG, Manzano L, Flather MD, Beta-Blockers in Heart Failure Collaborative Group. beta blockers in patients with heart failure and atrial fibrillation-authors' reply. Lancet. 2015;385:1618-9.

308. Pitt B, Zannad F, Remme WJ, Cody R, Castaigne A, Perez A, Palensky J, Wittes J. The effect of spironolactone on morbidity and mortality in patients with severe heart failure. Randomized Aldactone Evaluation Study Investigators. N Engl J Med. 1999;341:709-17.

309. Zannad F, McMurray JJ, Krum H, van Veldhuisen DJ, Swedberg K, Shi H, Vincent J, Pocock SJ, Pitt B. Eplerenone in patients with systolic heart failure and mild symptoms. N Engl J Med. 2011;364:11-21.

310. Bapoje SR, Bahia A, Hokanson JE, Peterson PN, Heidenreich PA, Lindenfeld J, Allen LA, Masoudi FA. Effects of mineralocorticoid receptor antagonists on the risk of sudden cardiac death in patients with left ventricular systolic dysfunction: a meta-analysis of randomized controlled trials. Circ Heart Fail. 2013;6:166-73.

311. Borlaug BA, Paulus WJ. Heart failure with preserved ejection fraction: pathophysiology, diagnosis, and treatment. Eur Heart J. 2011;32:670-9.

312. Chan MM, Lam CS. How do patients with heart failure with preserved ejection fraction die? Eur J Heart Fail. 2013;15:604-13.

313. Bristow MR, Saxon LA, Boehmer J, Krueger S, Kass DA, De Marco T, Carson P, DiCarlo L, DeMets D, White BG, DeVries DW, Feldman AM, Comparison of Medical Therapy, Pacing, and Defibrillation in Heart Failure (COMPANION) Investigators. Cardiac-resynchronization therapy with or without an implantable defibrillator in advanced chronic heart failure. N Engl J Med. 2004;350:2140-50.

314. Cleland JG, Daubert JC, Erdmann E, Freemantle N, Gras D, Kappenberger L, Tavazzi L. The effect of cardiac resynchronization on morbidity and mortality in heart failure. N Engl J Med. 2005;352:1539-49.

315. van Veldhuisen DJ, Maass AH, Priori SG, Stolt P, van Gelder IC, Dickstein K, Swedberg K. Implementation of device therapy (cardiac resynchronization therapy and implantable cardioverter defibrillator) for patients with heart failure in Europe: changes from 2004 to 2008. Eur J Heart Fail. 2009;11:1143-51.

316. Kadish A, Dyer A, Daubert JP, Quigg R, Estes NA, Anderson KP, Calkins H, Hoch D, Goldberger J, Shalaby A, Sanders WE, Schaechter A, Levine JH, Defibrillators in Non-Ischemic Cardiomyopathy Treatment Evaluation Investigators. Prophylactic defibrillator implantation in patients with nonischemic dilated cardiomyopathy. N Engl J Med. 2004;350:2151-8.

317. Desai AS, Fang JC, Maisel WH, Baughman KL. Implantable defibrillators for the prevention of mortality in patients with nonischemic cardiomyopathy: a metaanalysis of randomized controlled trials. JAMA. 2004;292:2874-9.

318. Goldenberg I, Moss AJ, McNitt S, Zareba W, Hall WJ, Andrews ML, Wilber DJ, Klein HU. Time dependence of defibrillator benefit after coronary revascularization in the Multicenter Automatic Defibrillator Implantation Trial (MADIT)-II. J Am Coll Cardiol. 2006;47:1811-7.

319. Packer DL, Prutkin JM, Hellkamp AS, Mitchell LB, Bernstein RC, Wood F, Boehmer JP, Carlson MD, Frantz RP, McNulty SE, Rogers JG, Anderson J, JohnsonGW,Walsh MN, Poole JE, Mark DB, Lee KL, Bardy GH. Impact of implantable cardioverterdefibrillator, amiodarone, and placebo on the mode of death in stable patients with heart failure: analysis from the sudden cardiac death in heart failure trial. Circulation. 2009;120:2170-6.

320. Frohlich GM, Holzmeister J, Hubler M, Hubler S,Wolfrum M, Enseleit F, Seifert B Hurlimann D, Lehmkuhl HB, Noll G, Steffel J, Falk V, Luscher TF, Hetzer R, Ruschitzka F. Prophylactic implantable cardioverter defibrillator treatment in patients with end-stage heart failure awaiting heart transplantation. Heart. 2013;99:1158-65.

321. Sandner SE, Wieselthaler G, Zuckermann A, Taghavi S, Schmidinger H, Pacher R, Ploner M, Laufer G, Wolner E, Grimm M. Survival benefit of the implantable cardioverter-defibrillator in patients on the waiting list for cardiac transplantation. Circulation. 2001;104:I171-6.

322. Zareba W, Klein H, Cygankiewicz I, Hall WJ, McNitt S, Brown M, Cannom D, Daubert JP, Eldar M, Gold MR, Goldberger JJ, Goldenberg I, Lichstein E, Pitschner $\mathrm{H}$, Rashtian $\mathrm{M}$, Solomon S, Viskin S, Wang $\mathrm{P}$, Moss AJ, Investigators $\mathrm{M}-\mathrm{C}$. Effectiveness of Cardiac Resynchronization Therapy by QRS Morphology in the Multicenter Automatic Defibrillator Implantation Trial-Cardiac Resynchronization Therapy (MADIT-CRT). Circulation. 2011;123:1061-72.

323. Birnie DH, Ha A, Higginson L, Sidhu K, Green M, Philippon F, Thibault B,Wells G, Tang A. Impact of QRS morphology and duration on outcomes after cardiac resynchronization therapy: results from the Resynchronization-Defibrillation for Ambulatory Heart Failure Trial (RAFT). Circ Heart Fail. 2013;6:1190-8.

324. Nery PB, Ha AC, Keren A, Birnie DH. Cardiac resynchronization therapy in patients with left ventricular systolic dysfunction and right bundle branch block: a systematic review. Heart Rhythm. 2011;8:1083-7.
325. Sipahi I, Chou JC, Hyden M, Rowland DY, Simon DI, Fang JC. Effect of QRS morphology on clinical event reduction with cardiac resynchronization therapy: meta-analysis of randomized controlled trials. Am Heart J. 2012;163:260-7.

326. Bilchick KC, Kamath S, DiMarco JP, Stukenborg GJ. Bundle-branch block morphology and other predictors of outcome after cardiac resynchronization therapy in Medicare patients. Circulation. 2010;122:2022-30.

327. Tang AS,Wells GA, Talajic M, Arnold MO, Sheldon R, Connolly S, Hohnloser SH, Nichol G, Birnie DH, Sapp JL, Yee R, Healey JS, Rouleau JL, ResynchronizationDefibrillation for Ambulatory Heart Failure Trial (RAFT) Investigators. Cardiacresynchronization therapy for mild-to-moderate heart failure. $\mathrm{N}$ Engl J Med. 2010;363:2385-95.

328. Sipahi I, Carrigan TP, Rowland DY, Stambler BS, Fang JC. Impact of QRS duration on clinical event reduction with cardiac resynchronization therapy: metaanalysis of randomized controlled trials. Arch Intern Med. 2011;171:1454-62.

329. Moss AJ, Hall WJ, Cannom DS, Klein H, Brown MW, Daubert JP, Estes NA 3rd, Foster E, Greenberg H, Higgins SL, Pfeffer MA, Solomon SD, Wilber D, ZarebaW, MADIT-CRT Trial Investigators. Cardiac-resynchronization therapy for the prevention of heart-failure events. N Engl J Med. 2009;361:1329-38.

330. Linde C, Leclercq C, Rex S, Garrigue S, Lavergne T, Cazeau S, McKennaW, Fitzgerald M, Deharo JC, Alonso C, Walker S, Braunschweig F, Bailleul C, Daubert JC. Longterm benefits of biventricular pacing in congestive heart failure: results from the MUltisite STimulation in cardiomyopathy (MUSTIC) study. J Am Coll Cardiol. 2002;40:111-8.

331. Doshi RN, Daoud EG, Fellows C, Turk K, Duran A, Hamdan MH, Pires LA, PAVE Study Group. Left ventricular-based cardiac stimulation post AV nodal ablation evaluation (the PAVE study). J Cardiovasc Electrophysiol. 2005;16:1160-5.

332. Ganesan AN, Brooks AG, Roberts-Thomson KC, Lau DH, Kalman JM, Sanders P. Role of AV nodal ablation in cardiac resynchronization in patients with coexistent atrial fibrillation and heart failure a systematic review. J Am Coll Cardiol. 2012;59:719-26

333. Gasparini M, Leclercq C, Lunati M, Landolina M, Auricchio A, Santini M, Boriani G, Lamp B, Proclemer A, Curnis A, Klersy C, Leyva F. Cardiac resynchronization therapy in patients with atrial fibrillation: the CERTIFY study (Cardiac Resynchronization Therapy in Atrial Fibrillation Patients Multinational Registry). JACC Heart Fail. 2013;1:500-7.

334. Cleland JG, Abraham WT, Linde C, Gold MR, Young JB, Claude Daubert J, Sherfesee L, Wells GA, Tang AS. An individual patient meta-analysis of five randomized trials assessing the effects of cardiac resynchronization therapy on morbidity and mortality in patients with symptomatic heart failure. Eur Heart J. 2013;34:3547-56.

335. Cleland JG, Daubert JC, Erdmann E, Freemantle N, Gras D, Kappenberger L, Tavazzi L. Longer-term effects of cardiac resynchronization therapy on mortality in heart failure [the CArdiac REsynchronization-Heart Failure (CARE-HF) trial extension phase]. Eur Heart J. 2006;27:1928-32.

336. Gold MR, Thebault C, Linde C, Abraham WT, Gerritse B, Ghio S, St John Sutton M, Daubert JC. Effect of QRS duration and morphology on cardiac resynchronization therapy outcomes in mild heart failure: results from the Resynchronization Reverses Remodeling in Systolic Left Ventricular Dysfunction (REVERSE) study. Circulation. 2012;126:822-9.

337. Cunnington C, Kwok CS, Satchithananda DK, Patwala A, Khan MA, Zaidi A, Ahmed FZ, Mamas MA. Cardiac resynchronisation therapy is not associated with a reduction in mortality or heart failure hospitalisation in patients with nonleft bundle branch block QRS morphology: meta-analysis of randomised controlled trials. Heart. 2015 Feb 12. doi:10.1136/heartjnl-2014-306811 [Epub ahead of print].

338. Magee CD, Byars LA, DeZee KJ. Limitations of subgroup analyses in meta-analysis of cardiac resynchronization therapy by QRS duration. Arch Intern Med. 2012;172:375.

339. Ruschitzka F, AbrahamWT, Singh JP, Bax JJ, Borer JS, Brugada J, Dickstein K, Ford I, Gorcsan J 3rd, Gras D, Krum H, Sogaard P, Holzmeister J, Echo CRTSG. Cardiacresynchronization therapy in heart failure with a narrow QRS complex. N Engl J Med. 2013;369:1395-405.

340. Camm AJ, Kirchhof P, Lip GY, Schotten U, Savelieva I, Ernst S, Van Gelder IC, AlAttar N, Hindricks G, Prendergast B, Heidbuchel H, Alfieri O, Angelini A, Atar D, Colonna P, De Caterina R, De Sutter J, Goette A, Gorenek B, Heldal M, Hohloser SH, Kolh P, Le Heuzey JY, Ponikowski P, Rutten FH. Guidelines for the management of atrial fibrillation: the Task Force for the Management of Atrial Fibrillation of the European Society of Cardiology (ESC). Eur Heart J. 2010;31:2369-429.

341. Deyell MW, Park KM, Han Y, Frankel DS, Dixit S, Cooper JM, Hutchinson MD, Lin D, Garcia F, Bala R, Riley MP, Gerstenfeld E, Callans DJ, Marchlinski FE. Predictors of recovery of left ventricular dysfunction after ablation of frequent ventricular premature depolarizations. Heart Rhythm. 2012;9:1465-72.

342. Baman TS, Lange DC, Ilg KJ, Gupta SK, Liu TY, Alguire C, ArmstrongW, Good E, Chugh A, Jongnarangsin K, Pelosi F Jr., Crawford T, Ebinger M, Oral H, Morady F, Bogun F. Relationship between burden of premature ventricular complexes and left ventricular function. Heart Rhythm. 2010;7:865-9.

343. Ban JE, Park HC, Park JS, Nagamoto Y, Choi JI, Lim HE, Park SW, Kim YH. Electrocardiographic and electrophysiological characteristics of premature ventricular complexes associated with left ventricular dysfunction in patients without structural heart disease. Europace. 2013;15:735-41.

344. Maggioni AP, Zuanetti G, Franzosi MG, Rovelli F, Santoro E, Staszewsky L, Tavazzi L, Tognoni G. Prevalence and prognostic significance of ventricular arrhythmias after acute myocardial infarction in the fibrinolytic era. GISSI-2 results. Circulation. 1993;87:312-22.

345. Blanck Z, Dhala A, Deshpande S, Sra J, Jazayeri M, Akhtar M. Bundle branch reentrant ventricular tachycardia: cumulative experience in 48 patients. J Cardiovasc Electrophysiol. 1993;4:253-62. 
346. Caceres J, Jazayeri M, McKinnie J, Avitall B, Denker ST, Tchou P, Akhtar M. Sustained bundle branch reentry as a mechanism of clinical tachycardia. Circulation. 1989;79:256-70.

347. Tchou P, Jazayeri M, Denker S, Dongas J, Caceres J, Akhtar M. Transcatheter electrical ablation of right bundle branch. A method of treating macroreentrant ventricular tachycardia attributed to bundle branch reentry. Circulation. 1988;78:246-57.

348. Elliott P, Andersson B, Arbustini E, Bilinska Z, Cecchi F, Charron P, Dubourg O, Kuhl U, Maisch B, McKenna WJ, Monserrat L, Pankuweit S, Rapezzi C, Seferovic P, Tavazzi L, Keren A. Classification of the cardiomyopathies: a position statement from the European Society Of Cardiology Working Group on Myocardial and Pericardial Diseases. Eur Heart J. 2008;29:270-6.

349. Taylor MR, Carniel E, Mestroni L. Familial dilated cardiomyopathy. Orphanet J Rare Dis. 2006;1:27.

350. Towbin JA, Lowe AM, Colan SD, Sleeper LA, Orav EJ, Clunie S, Messere J, Cox GF, Lurie PR, Hsu D, Canter C, Wilkinson JD, Lipshultz SE. Incidence, causes, and outcomes of dilated cardiomyopathy in children. JAMA. 2006;296:1867-76.

351. Petretta M, Pirozzi F, Sasso L, Paglia A, Bonaduce D. Review and metaanalysis of the frequency of familial dilated cardiomyopathy. Am J Cardiol. 2011;108:1171-6.

352. Haas J, Frese KS, Peil B, Kloos W, Keller A, Nietsch R, Feng Z, Muller S, Kayvanpour E, Vogel B, Sedaghat-Hamedani F, Lim WK, Zhao X, Fradkin D, Kohler D, Fischer S, Franke J, Marquart S, Barb I, Li DT, Amr A, Ehlermann P, Mereles D, Weis T, Hassel S, Kremer A, King V, Wirsz E, Isnard R, Komajda M, Serio A, Grasso M, Syrris P, Wicks E, Plagnol V, Lopes L, Gadgaard T, Eiskjaer H, Jorgensen M, GarciaGiustiniani D, Ortiz-Genga M, Crespo-Leiro MG, Deprez RH, Christiaans I, van Rijsingen IA, Wilde AA, Waldenstrom A, Bolognesi M, Bellazzi R, Morner S, Bermejo JL, Monserrat L, Villard E, Mogensen J, Pinto YM, Charron P, Elliott P, Arbustini E, Katus HA, Meder B. Atlas of the clinical genetics of human dilated cardiomyopathy. Eur Heart J. 2015;36:1123-35.

353. Hershberger RE, Lindenfeld J, Mestroni L, Seidman CE, Taylor MR, Towbin JA. Genetic evaluation of cardiomyopathy-a Heart Failure Society of America practice guideline. J Card Fail. 2009;15:83-97.

354. Strickberger SA, Hummel JD, Bartlett TG, Frumin HI, Schuger CD, Beau SL, Bitar C, Morady F, Investigators A. Amiodarone versus implantable cardioverterdefibrillator: randomized trial in patients with nonischemic dilated cardiomyopathy and asymptomatic nonsustained ventricular tachycardia-AMIOVIRT. J Am Coll Cardiol. 2003;41:1707-12.

355. Proietti R, Essebag V, Beardsall J, Hache P, Pantano A, Wulffhart Z, Juta R, Tsang B, Joza J, Nascimento T, Pegoraro V, Khaykin Y, Verma A. Substrate-guided ablation of haemodynamically tolerated and untolerated ventricular tachycardia in patients with structural heart disease: effect of cardiomyopathy type and acute success on long-term outcome. Europace. 2015;17:461-7.

356. Kober L, Torp-Pedersen C, McMurray JJ, Gotzsche O, Levy S, Crijns H, Amlie J, Carlsen J, Dronedarone Study G. Increased mortality after dronedarone therapy for severe heart failure. N Engl J Med. 2008;358:2678-87.

357. Connolly SJ, Camm AJ, Halperin JL, Joyner C, Alings M, Amerena J, Atar D, Avezum A, Blomstrom P, Borggrefe M, Budaj A, Chen SA, Ching CK, Commerford P, Dans A, Davy JM, Delacretaz E, Di Pasquale G, Diaz R, Dorian P, Flaker G, Golitsyn S, Gonzalez-Hermosillo A, Granger CB, Heidbuchel H, Kautzner J, Kim JS, Lanas F, Lewis BS, Merino JL, Morillo C, Murin J, Narasimhan C, Paolasso E, Parkhomenko A, Peters NS, Sim KH, Stiles MK, Tanomsup S, Toivonen L, Tomcsanyi J, TorpPedersen C, Tse HF, Vardas P, Vinereanu D, Xavier D, Zhu J, Zhu JR, Baret-Cormel L, Weinling E, Staiger C, Yusuf S, Chrolavicius S, Afzal R, Hohnloser SH. Dronedarone in highrisk permanent atrial fibrillation. $\mathrm{N}$ Engl J Med. 2011;365:2268-76.

358. Castelli G, Fornaro A, Ciaccheri M, Dolara A, Troiani V, Tomberli B, Olivotto I, Gensini GF. Improving survival rates of patients with idiopathic dilated cardiomyopathy in Tuscany over 3 decades: impact of evidence-based management. Circ Heart Fail. 2013;6:913-21.

359. Alexander PM, Daubeney PE, Nugent AW, Lee KJ, Turner C, Colan SD, Robertson T, Davis AM, Ramsay J, Justo R, Sholler GF, King I, Weintraub RG. Long-term outcomes of dilated cardiomyopathy diagnosed during childhood: results from a national population-based study of childhood cardiomyopathy. Circulation. 2013;128:2039-46

360. Kuruvilla S, Adenaw N, Katwal AB, Lipinski MJ, Kramer CM, Salerno M. Late gadolinium enhancement on cardiac magnetic resonance predicts adverse cardiovascular outcomes in nonischemic cardiomyopathy: a systematic review and meta-analysis. Circ Cardiovasc Imaging. 2014;7:250-8.

361. Bansch D, Antz M, Boczor S, Volkmer M, Tebbenjohanns J, Seidl K, Block M, Gietzen F, Berger J, Kuck KH. Primary prevention of sudden cardiac death in idiopathic dilated cardiomyopathy: the Cardiomyopathy Trial (CAT). Circulation. 2002;105:1453-8.

362. Roden DM. Drug-induced prolongation of the QT interval. $N$ Engl J Med. 2004;350:1013-22.

363. Chamberlain DA, Jewitt DE, Julian DG, Campbell RW, Boyle DM, Shanks RG. Oral mexiletine in high-risk patients after myocardial infarction. Lancet. 1980;2: 1324-7.

364. Elliott PM, Gimeno JR, Thaman R, Shah J, Ward D, Dickie S, Tome Esteban MT, McKenna WJ. Historical trends in reported survival rates in patients with hypertrophic cardiomyopathy. Heart. 2006;92:785-91.

365. O’Mahony C, Jichi F, Pavlou M, Monserrat L, Anastasakis A, Rapezzi C, Biagini E, Gimeno JR, Limongelli G, McKenna WJ, Omar RZ, Elliott PM. A novel clinical risk prediction model for sudden cardiac death in hypertrophic cardiomyopathy (HCM risk-SCD). Eur Heart J. 2014;35:2010-20.

366. Pelliccia A, Fagard R, Bjornstad HH, Anastassakis A, Arbustini E, Assanelli D, Biffi A, Borjesson M, Carre F, Corrado D, Delise P, Dorwarth U, Hirth A, Heidbuchel H,
Hoffmann E, Mellwig KP, Panhuyzen-Goedkoop N, Pisani A, Solberg EE, vanBuuren F, Vanhees L, Blomstrom-Lundqvist C, Deligiannis A, Dugmore D, Glikson M, Hoff PI, Hoffmann A, Horstkotte D, Nordrehaug JE, Oudhof J, McKenna WJ, Penco M, Priori S, Reybrouck T, Senden J, Spataro A. Thiene G. Recommendations for competitive sports participation in athletes with cardiovascular disease: a consensus document from the Study Group of Sports Cardiology of the Working Group of Cardiac Rehabilitation and Exercise Physiology and theWorking Group of Myocardial and Pericardial Diseases of the European Society of Cardiology. Eur Heart J. 2005;26:1422-45.

367. O’Mahony C, Tome-Esteban M, Lambiase PD, Pantazis A, Dickie S, McKenna WJ, Elliott PM. A validation study of the 2003 American College of Cardiology European Society of Cardiology and 2011 American College of Cardiology Foundation/ American Heart Association risk stratification and treatment algorithms for sudden cardiac death in patients with hypertrophic cardiomyopathy. Heart. 2013;99:534-41.

368. O’Mahony C, Lambiase PD, Quarta G, Cardona M, Calcagnino M, Tsovolas K, AlShaikh S, Rahman SM, Arnous S, Jones S, McKennaW, Elliott P. The long-term survival and the risks and benefits of implantable cardioverter defibrillators in patients with hypertrophic cardiomyopathy. Heart. 2012;98:116-25.

369. Elliott PM, Sharma S, Varnava A, Poloniecki J, Rowland E, McKenna WJ. Survival after cardiac arrest or sustained ventricular tachycardia in patients with hypertrophic cardiomyopathy. J Am Coll Cardiol. 1999;33:1596-601.

370. Cecchi F, Maron BJ, Epstein SE. Long-term outcome of patients with hypertrophic cardiomyopathy successfully resuscitated after cardiac arrest. J Am Coll Cardiol. 1989;13:1283-8.

371. Maron BJ, Spirito P, Shen WK, Haas TS, Formisano F, Link MS, Epstein AE, Almquist AK, Daubert JP, Lawrenz T, Boriani G, Estes NA 3rd, Favale S, Piccininno M, Winters SL, Santini M, Betocchi S, Arribas F, Sherrid MV, Buja G, Semsarian C, Bruzzi P. Implantable cardioverter-defibrillators and prevention of sudden cardiac death in hypertrophic cardiomyopathy. JAMA. 2007;298:405-12.

372. Syska P, Przybylski A, Chojnowska L, Lewandowski M, Sterlinski M, Maciag A Gepner K, Pytkowski M, Kowalik I, Maczynska-Mazuruk R, Ruzyllo W, Szwed H. Implantable cardioverter-defibrillator in patients with hypertrophic cardiomyopathy: efficacy and complications of the therapy in long-term followup. J Cardiovasc Electrophysiol. 2010;21:883-9.

373. Monserrat L, Elliott PM, Gimeno JR, Sharma S, Penas-Lado M, McKenna WJ. Nonsustained ventricular tachycardia in hypertrophic cardiomyopathy: an independent marker of sudden death risk in young patients. J Am Coll Cardiol. 2003;42:873-9.

374. Adabag AS, Casey SA, Kuskowski MA, Zenovich AG, Maron BJ. Spectrum and prognostic significance of arrhythmias on ambulatory Holter electrocardiogram in hypertrophic cardiomyopathy. J Am Coll Cardiol. 2005;45:697-704.

375. O'Hanlon R, Grasso A, Roughton M, Moon JC, Clark S, Wage R, Webb J, Kulkarni M, Dawson D, Sulaibeekh L, Chandrasekaran B, Bucciarelli-Ducci C, Pasquale F, Cowie MR, McKenna WJ, Sheppard MN, Elliott PM, Pennell DJ, Prasad SK. Prognostic significance of myocardial fibrosis in hypertrophic cardiomyopathy. J Am Coll Cardiol. 2010;56:867-74.

376. Gimeno JR, Tome-Esteban M, Lofiego C, Hurtado J, Pantazis A, Mist B, Lambiase P, McKenna WJ, Elliott PM. Exercise-induced ventricular arrhythmias and risk of sudden cardiac death in patients with hypertrophic cardiomyopathy. Eur Heart J. 2009;30:2599-605

377. Inada K, Seiler J, Roberts-Thomson KC, Steven D, Rosman J, John RM, Sobieszczyk P. Stevenson WG, Tedrow UB. Substrate characterization and catheter ablation for monomorphic ventricular tachycardia in patients with apical hypertrophic cardiomyopathy. J Cardiovasc Electrophysiol. 2011;22:41-8.

378. Maron BJ, McKenna WJ, Danielson GK, Kappenberger LJ, Kuhn HJ, Seidman CE Shah PM, SpencerWH3rd, Spirito P, Ten Cate FJ, Wigle ED. American College of Cardiology/European Society of Cardiology Clinical Expert Consensus Document on Hypertrophic Cardiomyopathy. A report of the American College of Cardiology Foundation Task Force on Clinical Expert Consensus Documents and the European Society of Cardiology Committee for Practice Guidelines. Eur Heart J. 2003;24:1965-91.

379. Gersh BJ, Maron BJ, Bonow RO, Dearani JA, Fifer MA, Link MS, Naidu SS, Nishimura RA, Ommen SR, Rakowski H, Seidman CE, Towbin JA, Udelson JE, Yancy CW, American College of Cardiology Foundation/American Heart Association Task Force on Practice Guidelines, American Association for Thoracic Surgery, American Society of Echocardiography, American Society of Nuclear Cardiology, Heart Failure Society of America, Heart Rhythm Society, Society for Cardiovascular Angiography and Interventions, Society of Thoracic Surgeons. 2011 ACCF/AHA guideline for the diagnosis and treatment of hypertrophic cardiomyopathy: a report of the American College of Cardiology Foundation/American Heart Association Task Force on Practice Guidelines. Circulation. 2011;124:e783-e831.

380. McKenna WJ, Oakley CM, Krikler DM, Goodwin JF. Improved survival with amiodarone in patients with hypertrophic cardiomyopathy and ventricular tachycardia. Br Heart J. 1985;53:412-6.

381. Melacini P, Maron BJ, Bobbo F, Basso C, Tokajuk B, Zucchetto M, Thiene G, Iliceto S. Evidence that pharmacological strategies lack efficacy for the prevention of sudden death in hypertrophic cardiomyopathy. Heart. 2007;93:708-10.

382. Marcus FI, McKenna WJ, Sherrill D, Basso C, Bauce B, Bluemke DA, Calkins H, Corrado D, Cox MG, Daubert JP, Fontaine G, Gear K, Hauer R, Nava A, Picard MH, Protonotarios N, Saffitz JE, Sanborn DM, Steinberg JS, Tandri H, Thiene G, Towbin JA, Tsatsopoulou A, Wichter T, Zareba W. Diagnosis of arrhythmogenic right ventricular cardiomyopathy/dysplasia: proposed modification of the task force criteria. Eur Heart J. 2010;31:806-14.

383. Basso C, Corrado D, Marcus FI, Nava A, Thiene G. Arrhythmogenic right ventricular cardiomyopathy. Lancet. 2009;373:1289-300. 
384. Sen-Chowdhry S, Syrris P, Prasad SK, Hughes SE, Merrifield R, Ward D, Pennell DJ, McKenna WJ. Left-dominant arrhythmogenic cardiomyopathy: an underrecognized clinical entity. J Am Coll Cardiol. 2008;52:2175-87.

385. Basso C, Corrado D, Thiene G. Cardiovascular causes of sudden death in young individuals including athletes. Cardiol Rev. 1999;7:127-35.

386. Tabib A, Loire R, Chalabreysse L, Meyronnet D, Miras A, Malicier D, Thivolet F, Chevalier P, Bouvagnet P. Circumstances of death and gross and microscopic observations in a series of 200 cases of sudden death associated with arrhythmogenic right ventricular cardiomyopathy and/or dysplasia. Circulation. 2003;108:3000-5.

387. Schinkel AF. Implantable cardioverter defibrillators in arrhythmogenic right ventricular dysplasia/cardiomyopathy: patient outcomes, incidence of appropriate and inappropriate interventions, and complications. Circ Arrhythm Electrophysiol. 2013;6:562-8.

388. Ruwald AC, Marcus F, Estes NA 3rd, Link M, McNitt S, Polonsky B, Calkins H Towbin JA, Moss AJ, ZarebaW. Association of competitive and recreational sport participation with cardiac events in patients with arrhythmogenic right ventricular cardiomyopathy: results from the North American multidisciplinary study of arrhythmogenic right ventricular cardiomyopathy. Eur Heart J. 2015;36:1735-43.

389. Corrado D, Leoni L, Link MS, Della Bella P, Gaita F, Curnis A, Salerno JU, Igidbashian D, Raviele A, Disertori M, Zanotto G, Verlato R, Vergara G, Delise P, Turrini P, Basso C, Naccarella F, Maddalena F, Estes NA 3rd, Buja G, Thiene G. Implantable cardioverter-defibrillator therapy for prevention of sudden death in patients with arrhythmogenic right ventricular cardiomyopathy/dysplasia. Circulation. 2003;108:3084-91.

390. Marcus GM, Glidden DV, Polonsky B, Zareba W, Smith LM, Cannom DS, EstesNA 3rd, Marcus F, Scheinman MM, Multidisciplinary Study of Right Ventricula Dysplasia Investigators. Efficacy of antiarrhythmic drugs in arrhythmogenic right ventricular cardiomyopathy: a report from the North American ARVC Registry. J Am Coll Cardiol. 2009;54:609-15.

391. Wichter T, Borggrefe M, HaverkampW, Chen X, Breithardt G. Efficacy of antiarrhythmic drugs in patients with arrhythmogenic right ventricular disease. Results in patients with inducible and noninducible ventricular tachycardia. Circulation. 1992:86:29-37.

392. Philips B, Madhavan S, James C, Tichnell C, Murray B, Dalal D, Bhonsale A, Nazarian S, Judge DP, Russell SD, Abraham T, Calkins H, Tandri H. Outcomes of catheter ablation of ventricular tachycardia in arrhythmogenic right ventricular dysplasia/cardiomyopathy. Circ Arrhythm Electrophysiol. 2012:5:499-505.

393. Dalal D, Jain R, Tandri H, Dong J, Eid SM, Prakasa K, Tichnell C, James C, Abraham T, Russell SD, Sinha S, Judge DP, Bluemke DA, Marine JE, Calkins H. Long-term efficacy of catheter ablation of ventricular tachycardia in patients with arrhythmogenic right ventricular dysplasia/cardiomyopathy. J Am Coll Cardiol. 2007;50:432-40

394. Dalal D, Molin LH, Piccini J, Tichnell C, James C, Bomma C, Prakasa K, Towbin JA Marcus FI, Spevak PJ, Bluemke DA, Abraham T, Russell SD, Calkins H, Judge DP. Clinical features of arrhythmogenic right ventricular dysplasia/cardiomyopathy associated with mutations in plakophilin-2. Circulation. 2006;113:1641-9.

395. Wichter T, Paul M, Wollmann C, Acil T, Gerdes P, Ashraf O, Tjan TD, Soeparwata R, Block M, Borggrefe $M$, Scheld HH, Breithardt G, Bocker D. Implantable cardioverter/defibrillator therapy in arrhythmogenic right ventricular cardiomyopathy: single-center experience of long-term follow-up and complications in 60 patients. Circulation. 2004:109:1503-8.

396. Nava A, Bauce B, Basso C, Muriago M, Rampazzo A, Villanova C, Daliento L, Buja G, Corrado D, Danieli GA, Thiene G. Clinical profile and long-term followup of 37 families with arrhythmogenic right ventricular cardiomyopathy. J Am Coll Cardiol. 2000;36:2226-33.

397. Nasir K, Bomma C, Tandri H, Roguin A, Dalal D, Prakasa K, Tichnell C, James C, Spevak PJ, Marcus F, Calkins H. Electrocardiographic features of arrhythmogenic right ventricular dysplasia/cardiomyopathy according to disease severity: a need to broaden diagnostic criteria. Circulation. 2004;110:1527-34.

398. Hamid MS, Norman M, Quraishi A, Firoozi S, Thaman R, Gimeno JR, Sachdev B, Rowland E, Elliott PM, McKenna WJ. Prospective evaluation of relatives for familial arrhythmogenic right ventricular cardiomyopathy/dysplasia reveals a need to broaden diagnostic criteria. J Am Coll Cardiol. 2002;40:1445-50.

399. Sen-Chowdhry S, Syrris P, Ward D, Asimaki A, Sevdalis E, McKenna WJ. Clinical and genetic characterization of families with arrhythmogenic right ventricula dysplasia/ cardiomyopathy provides novel insights into patterns of disease expression. Circulation. 2007;115:1710-20.

400. Hoffmayer KS, Machado ON, Marcus GM, Yang Y, Johnson CJ, Ermakov S, Vittinghoff E, Pandurangi U, Calkins H, Cannom D, Gear KC, Tichnell C, Park Y, Zareba W, Marcus FI, Scheinman MM. Electrocardiographic comparison of ventricular arrhythmias in patients with arrhythmogenic right ventricula cardiomyopathy and right ventricular outflow tract tachycardia. J Am Coll Cardiol. 2011;58:831-8.

401. Link MS, Laidlaw D, Polonsky B, ZarebaW, McNitt S, Gear K, Marcus F, Estes NA 3rd. Ventricular arrhythmias in the North American multidisciplinary study of ARVC: predictors, characteristics, and treatment. J Am Coll Cardiol. 2014;64: 119-25.

402. Ouyang F, Fotuhi P, Goya M, Volkmer M, Ernst S, Cappato R, Kuck K. Ventricula tachycardia around the tricuspid annulus in right ventricular dysplasia. Circulation. 2001;103:913-4

403. Heidbuchel H, Hoogsteen J, Fagard R, Vanhees L, Ector H, Willems R, Van Lierde J. High prevalence of right ventricular involvement in endurance athletes with ventricular arrhythmias. Role of an electrophysiologic study in risk stratification. Eur Heart J. 2003;24:1473-80.
404. Corrado D, Calkins H, Link MS, Leoni L, Favale S, Bevilacqua M, Basso C,Ward D, Boriani G, Ricci R, Piccini JP, Dalal D, Santini M, Buja G, Iliceto S, Estes NA 3rd, Wichter T, McKenna WJ, Thiene G, Marcus FI. Prophylactic implantable defibrillator in patients with arrhythmogenic right ventricular cardiomyopathy/ dysplasia and no prior ventricular fibrillation or sustained ventricular tachycardia. Circulation. 2010;122:1144-52.

405. Peters S. Long-term follow-up and risk assessment of arrhythmogenic right ventricular dysplasia/cardiomyopathy: personal experience from different primary and tertiary centres. J Cardiovasc Med (Hagerstown). 2007;8:521-6.

406. Lemola K, Brunckhorst C, Helfenstein U, Oechslin E, Jenni R, Duru F. Predictors of adverse outcome in patients with arrhythmogenic right ventricular dysplasia/ cardiomyopathy: long term experience of a tertiary care centre. Heart. 2005;91:1167-72

407. Rigato I, Bauce B, Rampazzo A, Zorzi A, Pilichou K, Mazzotti E, Migliore F, Marra MP, Lorenzon A, De Bortoli M, Calore M, Nava A, Daliento L, Gregori D, Iliceto S, Thiene G, Basso C, Corrado D. Compound and digenic heterozygosity predicts lifetime arrhythmic outcome and sudden cardiac death in desmosomal generelated arrhythmogenic right ventricular cardiomyopathy. Circ Cardiovasc Genet. 2013;6:533-42.

408. Kristen AV, Dengler TJ, Hegenbart U, Schonland SO, Goldschmidt H, Sack FU, Voss F, BeckerR, Katus HA, Bauer A.Prophylacticimplantation of cardioverterdefibrillator in patients with severe cardiac amyloidosis and high risk for sudden cardiac death. Heart Rhythm. 2008;5:235-40.

409. Palladini G, Malamani G, Co F, Pistorio A, Recusani F, Anesi E, Garini P, Merlini G. Holter monitoring in AL amyloidosis: prognostic implications. Pacing Clin Electrophysiol. 2001;24:1228-33.

410. Dubrey SW, Bilazarian S, LaValley M, Reisinger J, Skinner M, Falk RH. Signalaveraged electrocardiography in patients with AL (primary) amyloidosis. Am Heart J. 1997;134:994-1001.

411. Reisinger J, Dubrey SW, Lavalley M, Skinner M, Falk RH. Electrophysiologic abnormalities in AL (primary) amyloidosis with cardiac involvement. J Am Coll Cardiol. 1997;30:1046-51.

412. Ammash NM, Seward JB, Bailey KR, Edwards WD, Tajik AJ. Clinical profile and outcome of idiopathic restrictive cardiomyopathy. Circulation. 2000;101:2490-6.

413. Dubrey SW. Amyloid heart disease: a brief review of treatment options. Postgrad Med J. 2012;88:700-5.

414. Ruberg FL, Berk JL. Transthyretin (TTR) cardiac amyloidosis. Circulation. 2012;126:1286-300

415. Jaccard A, Comenzo RL, Hari P, Hawkins PN, Roussel M, Morel P, Macro M Pellegrin JL, Lazaro E, Mohty D, Mercie P, Decaux O, Gillmore J, Lavergne D, Bridoux F, Wechalekar AD, Venner CP. Efficacy of bortezomib, cyclophosphamide and dexamethasone in treatment-naive patients with high-risk cardiac AL amyloidosis (Mayo Clinic stage III). Haematologica. 2014;99:1479-85.

416. Falk RH, Rubinow A, Cohen AS. Cardiac arrhythmias in systemic amyloidosis: correlation with echocardiographic abnormalities. J Am Coll Cardiol. 1984;3: 107-13.

417. Maskatia SA, Decker JA, Spinner JA, Kim JJ, Price JF, Jefferies JL, Dreyer WJ, Smith EO, Rossano JW, Denfield SW. Restrictive physiology is associated with poor outcomes in children with hypertrophic cardiomyopathy. Pediatr Cardiol. 2012;33:141-9.

418. Rivenes SM, Kearney DL, Smith EO, Towbin JA, Denfield SW. Sudden death and cardiovascular collapse in children with restrictive cardiomyopathy. Circulation. 2000;102:876-82.

419. Lipshultz SE, Orav EJ, Wilkinson JD, Towbin JA, Messere JE, Lowe AM, Sleeper LA, Cox GF, Hsu DT, Canter CE, Hunter JA, Colan SD. Risk stratification at diagnosis for children with hypertrophic cardiomyopathy: an analysis of data from the Pediatric Cardiomyopathy Registry. Lancet. 2013;382:1889-97.

420. Webber SA, Lipshultz SE, Sleeper LA, Lu M, Wilkinson JD, Addonizio LJ, Canter CE, Colan SD, Everitt MD, Jefferies JL, Kantor PF, Lamour JM, Margossian R, Pahl E, Rusconi PG, Towbin JA. Outcomes of restrictive cardiomyopathy in childhood and the influence of phenotype: a report from the Pediatric Cardiomyopathy Registry. Circulation. 2012;126:1237-44.

421. Kaski JP, Syrris P, Burch M, Tome-Esteban MT, Fenton M, Christiansen M, Andersen PS, Sebire N, Ashworth M, Deanfield JE, McKenna WJ, Elliott PM. Idiopathic restrictive cardiomyopathy in children is caused by mutations in cardiac sarcomere protein genes. Heart. 2008;94:1478-84.

422. Bhatia NL, Tajik AJ, Wilansky S, Steidley DE, Mookadam F. Isolated noncompaction of the left ventricular myocardium in adults: a systematic overview. J Card Fail. 2011;17:771-8.

423. Oechslin E, Jenni R. Left ventricular non-compaction revisited: a distinct phenotype with genetic heterogeneity? Eur Heart J. 2011;32:1446-56.

424. Lofiego C, Biagini E, Pasquale F, Ferlito M, Rocchi G, Perugini E, Bacchi-Reggiani L, Boriani G, Leone O, Caliskan K, ten Cate FJ, Picchio FM, Branzi A, Rapezzi C. Wide spectrum of presentation and variable outcomes of isolated left ventricular noncompaction. Heart. 2007;93:65-71.

425. Murphy RT, Thaman R, Blanes JG, Ward D, Sevdalis E, Papra E, Kiotsekoglou A, Tome MT, Pellerin D, McKenna WJ, Elliott PM. Natural history and familial characteristics of isolated left ventricular non-compaction. Eur Heart J. 2005;26:187-92.

426. Muratore CA, Batista Sa LA, Chiale PA, Eloy R, Tentori MC, Escudero J, Lima AM, Medina LE, Garillo R, Maloney J. Implantable cardioverter defibrillators and Chagas' disease: results of the ICD Registry Latin America. Europace. 2009;11: 164-8.

427. Martinelli M, de Siqueira SF, Sternick EB, Rassi A Jr, Costa R, Ramires JA, Kalil Filho $\mathrm{R}$. Long-term follow-up of implantable cardioverter-defibrillator for secondary prevention in Chagas' heart disease. Am J Cardiol. 2012;110:1040-5. 
428. Cardinalli-Neto A, Bestetti RB, Cordeiro JA, Rodrigues VC. Predictors of all-cause mortality for patients with chronic Chagas' heart disease receiving implantable cardioverter defibrillator therapy. J Cardiovasc Electrophysiol. 2007;18:1236-40.

429. Barbosa MP, da Costa Rocha MO, de Oliveira AB, Lombardi F, Ribeiro AL. Efficacy and safety of implantable cardioverter-defibrillators in patients with Chagas disease. Europace. 2013;15:957-62.

430. Gali WL, Sarabanda AV, Baggio JM, Ferreira LG, Gomes GG, Marin-Neto JA Junqueira LF. Implantable cardioverter-defibrillators for treatment of sustained ventricular arrhythmias in patients with Chagas' heart disease: comparison with a control group treated with amiodarone alone. Europace. 2014;16:674-80.

431. Schwartz PJ, Moss AJ, Vincent GM, Crampton RS. Diagnostic criteria for the long QT syndrome. An update. Circulation. 1993;88:782-4.

432. Moss AJ, Schwartz PJ, Crampton RS, Tzivoni D, Locati EH, MacCluer J, Hall WJ, Weitkamp L, Vincent GM, Garson A Jr. The long QT syndrome. Prospective longitudinal study of 328 families. Circulation. 1991;84:1136-44.

433. Nguyen HL, Pieper GH, Wilders R. Andersen-Tawil syndrome: clinical and molecular aspects. Int J Cardiol. 2013;170:1-16.

434. Schwartz PJ, Priori SG, Spazzolini C, Moss AJ, Vincent GM, Napolitano C, Denjoy I, Guicheney P, Breithardt G, Keating MT, Towbin JA, Beggs AH, Brink P, Wilde AA, Toivonen L, Zareba W, Robinson JL, Timothy KW, Corfield V, Wattanasirichaigoon D, Corbett C, Haverkamp W, Schulze-Bahr E, Lehmann $\mathrm{MH}$, Schwartz K, Coumel P, Bloise R. Genotype-phenotype correlation in the long-QT syndrome: gene-specific triggers for life-threatening arrhythmias. Circulation. 2001;103:89-95.

435. Priori SG, Napolitano C, Schwartz PJ, Grillo M, Bloise R, Ronchetti E, Moncalvo C, Tulipani C, Veia A, Bottelli G, Nastoli J. Association of long QT syndrome loci and cardiac events among patients treated with beta-blockers. JAMA. 2004;292: 1341-4.

436. Moss AJ, ZarebaW, Hall WJ, Schwartz PJ, Crampton RS, Benhorin J, Vincent GM, Locati EH, Priori SG, Napolitano C, Medina A, Zhang L, Robinson JL, Timothy K, Towbin JA, Andrews ML. Effectiveness and limitations of beta-blocker therapy in congenital long-QT syndrome. Circulation. 2000;101:616-23.

437. Zareba W, Moss AJ, Daubert JP, Hall WJ, Robinson JL, Andrews M. Implantable cardioverter defibrillator in high-risk long QT syndrome patients. J Cardiovasc Electrophysiol. 2003;14:337-41.

438. Schwartz PJ, Spazzolini C, Priori SG, Crotti L, Vicentini A, Landolina M, Gasparini M, Wilde AA, Knops RE, Denjoy I, Toivonen L, Monnig G, Al-Fayyadh M, Jordaens L, Borggrefe M, Holmgren C, Brugada P, De Roy L, Hohnloser SH, Brink PA. Who are the long-QT syndrome patients who receive an implantable cardioverterdefibrillator and what happens to them?: data from the European Long-QT Syndrome Implantable Cardioverter-Defibrillator (LQTS ICD) Registry. Circulation. 2010;122:1272-82.

439. Jons C, Moss AJ, Goldenberg I, Liu J, McNitt S, ZarebaW, Qi M, Robinson JL. Risk of fatal arrhythmic events in long QT syndrome patients after syncope. J Am Coll Cardiol. 2010;55:783-8.

440. Schwartz PJ, Priori SG, Cerrone M, Spazzolini C, Odero A, Napolitano C, Bloise R, De Ferrari GM, Klersy C, Moss AJ, Zareba W, Robinson JL, Hall WJ, Brink PA, Toivonen L, Epstein AE, Li C, Hu D. Left cardiac sympathetic denervation in the management of high-risk patients affected by the long-QT syndrome. Circulation. 2004; 109:1826-33.

441. Schwartz PJ, Priori SG, Locati EH, Napolitano C, Cantu F, Towbin JA, Keating MT, Hammoude $\mathrm{H}$, Brown AM, Chen LS. Long QT syndrome patients with mutations of the SCN5A and HERG genes have differential responses to $\mathrm{Na}+$ channel blockade and to increases in heart rate. Implications for gene-specific therapy. Circulation. 1995;92:3381-6.

442. Moss AJ, Windle JR, HallWJ, Zareba W, Robinson JL, McNitt S, Severski P, Rosero S, Daubert JP, Qi M, Cieciorka M, Manalan AS. Safety and efficacy of flecainide in subjects with Long QT-3 syndrome (DeltaKPQ mutation): a randomized, doubleblind, placebo-controlled clinical trial. Ann Noninvasive Electrocardiol. 2005; 10:59-66.

443. Moss AJ, Zareba W, Schwarz KQ, Rosero S, McNitt S, Robinson JL. Ranolazine shortens repolarization in patients with sustained inward sodium current due to type-3 long-QT syndrome. J Cardiovasc Electrophysiol. 2008;19:1289-93.

444. Liu JF, Jons C, Moss AJ, McNitt S, Peterson DR, Qi M, Zareba W, Robinson JL, Barsheshet A, Ackerman MJ, Benhorin J, Kaufman ES, Locati EH, Napolitano C, Priori SG, Schwartz PJ, Towbin J, Vincent M, Zhang L, Goldenberg I. Risk factors for recurrent syncope and subsequent fatal or near-fatal events in children and adolescents with long QT syndrome. J Am Coll Cardiol. 2011;57:941-50.

445. Seth R, Moss AJ, McNitt S, Zareba W, Andrews ML, Qi M, Robinson JL, Goldenberg I, Ackerman MJ, Benhorin J, Kaufman ES, Locati EH, Napolitano C, Priori SG, Schwartz PJ, Towbin JA, Vincent GM, Zhang L. Long QT syndrome and pregnancy. J Am Coll Cardiol. 2007;49:1092-8.

446. Goldenberg I, Horr S, Moss AJ, Lopes CM, Barsheshet A, McNitt S, Zareba W, Andrews ML, Robinson JL, Locati EH, Ackerman MJ, Benhorin J, Kaufman ES, Napolitano C, Platonov PG, Priori SG, Qi M, Schwartz PJ, Shimizu W, Towbin JA, Vincent GM, Wilde AA, Zhang L. Risk for life-threatening cardiac events in patients with genotype-confirmed long-QT syndrome and normal-range corrected QT intervals. J Am Coll Cardiol. 2011;57:51-9.

447. Gaita F, Giustetto C, Bianchi F, Wolpert C, Schimpf R, Riccardi R, Grossi S, Richiardi E, Borggrefe M. Short QT syndrome: a familial cause of sudden death. Circulation. 2003;108:965-70.

448. Gaita F, Giustetto C, Bianchi F, Schimpf R, Haissaguerre M, Calo L, Brugada R, Antzelevitch C, Borggrefe M, Wolpert C. Short QT syndrome: pharmacological treatment. J Am Coll Cardiol. 2004;43:1494-9.

449. Fowler SJ, Priori SG. Clinical spectrum of patients with a Brugada ECG. Curr Opin Cardiol. 2009;24:74-81.
450. Gehi AK, Duong TD, Metz LD, Gomes JA, Mehta D. Risk stratification of individuals with the Brugada electrocardiogram: a meta-analysis. J Cardiovasc Electrophysiol. 2006; 17:577-83.

451. Priori SG, Napolitano C, Gasparini M, Pappone C, Della Bella P, Giordano U, Bloise R, Giustetto C, De Nardis R, Grillo M, Ronchetti E, Faggiano G, Nastoli J. Natural history of Brugada syndrome: insights for risk stratification and management. Circulation. 2002;105:1342-7.

452. Fauchier L, Isorni MA, Clementy N, Pierre B, Simeon E, Babuty D. Prognostic value of programmed ventricular stimulation in Brugada syndrome according to clinical presentation: an updated meta-analysis of worldwide published data. Int J Cardiol. 2013;168:3027-9.

453. Maury P, Hocini M, Haissaguerre M. Electrical storms in Brugada syndrome: review of pharmacologic and ablative therapeutic options. Indian Pacing Electrophysiol J. 2005;5:25-34.

454. Marquez MF, Bonny A, Hernandez-Castillo E, De Sisti A, Gomez-Flores J, Nava S, Hidden-Lucet F, Iturralde P, Cardenas M, Tonet J. Long-term efficacy of low doses of quinidine on malignant arrhythmias in Brugada syndrome with an implantable cardioverter-defibrillator: a case series and literature review. Heart Rhythm. 2012;9:1995-2000.

455. Nademanee K, Veerakul G, Chandanamattha P, Chaothawee L, Ariyachaipanich A Jirasirirojanakorn K, Likittanasombat K, Bhuripanyo K, Ngarmukos T. Prevention of ventricular fibrillation episodes in Brugada syndrome by catheter ablation over the anterior right ventricular outflow tract epicardium. Circulation. $2011 ; 123: 1270-9$.

456. Priori SG, Gasparini M, Napolitano C, Della Bella P, Ottonelli AG, Sassone B, Giordano U, Pappone C, Mascioli G, Rossetti G, De Nardis R, Colombo M. Risk stratification in Brugada syndrome: results of the PRELUDE (PRogrammed ELectrical stimUlation preDictive valuE) registry. J Am Coll Cardiol. 2012;59:37-45.

457. Coumel P. Catecholamine-induced severe ventricular arrhythmias with AdamsStokes syndrome in children: a report of four cases. Br Heart J. 1978;40:28-37.

458. Priori SG, Napolitano C, Memmi M, Colombi B, Drago F, Gasparini M, DeSimone L, Coltorti F, Bloise R, Keegan R, Cruz Filho FE, Vignati G, Benatar A, DeLogu A Clinical and molecular characterization of patients with catecholaminergic polymorphic ventricular tachycardia. Circulation. 2002;106:69-74.

459. Marjamaa A, Hiippala A, Arrhenius B, Lahtinen AM, Kontula K, Toivonen L, Happonen JM, Swan H. Intravenous epinephrine infusion test in diagnosis of catecholaminergic polymorphic ventricular tachycardia. J Cardiovasc Electrophysiol. 2012;23:194-9.

460. Leenhardt A, Lucet V, Denjoy I, Grau F, Ngoc DD, Coumel P. Catecholaminergic polymorphic ventricular tachycardia in children. A 7-year follow-up of 21 patients. Circulation. 1995;91:1512-9.

461. Hayashi M, Denjoy I, Extramiana F, Maltret A, Buisson NR, Lupoglazoff JM, Klug D, Takatsuki S, Villain E, Kamblock J, Messali A, Guicheney P, Lunardi J, Leenhardt A. Incidence and risk factors of arrhythmic events in catecholaminergic polymorphic ventricular tachycardia. Circulation. 2009;119:2426-34.

462. van der Werf C, Nederend I, Hofman N, van Geloven N, Ebink C, Frohn-Mulder IM Alings AM, Bosker HA, Bracke FA, van den Heuvel F, Waalewijn RA, Bikker H, van Tintelen JP, Bhuiyan ZA, van den Berg MP, Wilde AA. Familial evaluation in catecholaminergic polymorphic ventricular tachycardia: disease penetrance and expression in cardiac ryanodine receptor mutation-carrying relatives. Circ Arrhythm Electrophysiol. 2012;5:748-56.

463. Watanabe H, Chopra N, Laver D, Hwang HS, Davies SS, Roach DE, Duff HJ, Roden DM, Wilde AA, Knollmann BC. Flecainide prevents catecholaminergic polymorphic ventricular tachycardia in mice and humans. Nat Med. 2009;15:380-3.

464. Olde Nordkamp LR, Driessen AH, Odero A, Blom NA, Koolbergen DR, Schwartz PJ, Wilde AA. Left cardiac sympathetic denervation in the Netherlands for the treatment of inherited arrhythmia syndromes. Neth Heart J. 2014;22:160-6.

465. Hofferberth SC, Cecchin F, Loberman D, Fynn-Thompson F. Left thoracoscopic sympathectomy for cardiac denervation in patients with life-threatening ventricular arrhythmias. J Thorac Cardiovasc Surg. 2014;147:404-9.

466. Roses-Noguer F, Jarman JW, Clague JR, Till J. Outcomes of defibrillator therapy in catecholaminergic polymorphic ventricular tachycardia. Heart Rhythm. 2014:11:58-66.

467. Haissaguerre M, Derval N, Sacher F, Jesel L, Deisenhofer I, de Roy L, Pasquie JL, Nogami A, Babuty D, Yli-Mayry S, De Chillou C, Scanu P, Mabo P, Matsuo S, Probst V, Le Scouarnec S, Defaye P, Schlaepfer J, Rostock T, Lacroix D, Lamaison D, Lavergne T, Aizawa Y, Englund A, Anselme F, O'Neill M, Hocini M, Lim KT, Knecht S, Veenhuyzen GD, Bordachar P, Chauvin M, Jais P, Coureau G, Chene G, Klein GJ, Clementy J. Sudden cardiac arrest associated with early repolarization. N Engl J Med. 2008;358:2016-23.

468. Rosso R, Kogan E, Belhassen B, Rozovski U, Scheinman MM, Zeltser D, Halkin A Steinvil A, Heller K, Glikson M, Katz A, Viskin S. J-point elevation in survivors of primary ventricular fibrillation and matched control subjects: incidence and clinical significance. J Am Coll Cardiol. 2008;52:1231-8.

469. Paul T, Marchal C, Garson A Jr. Ventricular couplets in the young: prognosis related to underlying substrate. Am Heart J. 1990;119:577-82.

470. Beaufort-Krol GC, Dijkstra SS, Bink-Boelkens MT. Natural history of ventricular premature contractions in children with a structurally normal heart: does origin matter? Europace. 2008;10:998-1003.

471. Pfammatter JP, Paul T. Idiopathic ventricular tachycardia in infancy and childhood: a multicenter study on clinical profile and outcome.Working Group on Dysrhythmias and Electrophysiology of the Association for European Pediatric Cardiology. J Am Coll Cardiol. 1999;33:2067-72.

472. Wang S, Zhu W, Hamilton RM, Kirsh JA, Stephenson EA, Gross GJ. Diagnosisspecific characteristics of ventricular tachycardia in children with structurally normal hearts. Heart Rhythm. 2010;7:1725-31. 
473. Collins KK, Schaffer MS, Liberman L, Saarel E, Knecht M, Tanel RE, Bradley D, Dubin AM, Paul T, Salerno J, Bar-Cohen Y, Sreeram N, Sanatani S, Law IH, Blaufox A, Batra A, Moltedo JM, van Hare GF, Reed J, Ro PS, Kugler J, Anderson C, Triedman JK. Fascicular and nonfascicular left ventricular tachycardias in the young: an international multicenter study. J Cardiovasc Electrophysiol. 2013;24:640-8.

474. Schneider HE, Kriebel T, Jung K, Gravenhorst VD, Paul T. Catheter ablation of idiopathic left and right ventricular tachycardias in the pediatric population using noncontact mapping. Heart Rhythm. 2010;7:731-9.

475. Blaufox AD, Felix GL, Saul JP. Radiofrequency catheter ablation in infants $\leq 18$ months old: when is it done and how do they fare?: short-term data from the pediatric ablation registry. Circulation. 2001;104:2803-8.

476. Lapage MJ, Bradley DJ, Dick M 2nd. Verapamil in infants: an exaggerated fear? Pediatr Cardiol. 2013;34:1532-4.

477. Nagashima M, Matsushima M, Ogawa A, Ohsuga A, Kaneko T, Yazaki T, Okajima M. Cardiac arrhythmias in healthy children revealed by 24 -hour ambulatory ECG monitoring. Pediatr Cardiol. 1987;8:103-8.

478. Southall DP, Richards J, Mitchell P, Brown DJ, Johnston PG, Shinebourne EA. Study of cardiac rhythm in healthy newborn infants. Br Heart J. 1980;43:14-20.

479. Jacobsen JR, Garson A Jr, Gillette PC, McNamara DG. Premature ventricular contractions in normal children. J Pediatr. 1978;92:36-8.

480. Tsuji A, Nagashima M, Hasegawa S, Nagai N, Nishibata K, Goto M, Matsushima M. Long-term follow-up of idiopathic ventricular arrhythmias in otherwise normal children. Jpn Circ J. 1995;59:654-62.

481. Van Hare GF, Stanger P. Ventricular tachycardia and accelerated ventricular rhythm presenting in the first month of life. Am J Cardiol. 1991;67:42-5.

482. Iwamoto M, Niimura I, Shibata T, Yasui K, Takigiku K, Nishizawa T, Akaike T, Yokota S. Long-term course and clinical characteristics of ventricular tachycardia detected in children by school-based heart disease screening. Circ J. 2005;69: 273-6.

483. Roggen A, Pavlovic M, Pfammatter JP. Frequency of spontaneous ventricular tachycardia in a pediatric population. Am J Cardiol. 2008;101:852-4.

484. Garson A Jr, Smith RT Jr, Moak JP, Kearney DL, Hawkins EP, Titus JL, Cooley DA, Ott DA. Incessant ventricular tachycardia in infants: myocardial hamartomas and surgical cure. J Am Coll Cardiol. 1987;10:619-26.

485. Paul T, Bokenkamp R, Mahnert B, Trappe HJ. Coronary artery involvement early and late after radiofrequency current application in young pigs. Am Heart J. 1997; 133:436-40.

486. Khairy P, Guerra PG, Rivard L, Tanguay JF, Landry E, Guertin MC, Macle L, Thibault B, Tardif JC, Talajic M, Roy D, Dubuc M. Enlargement of catheter ablation lesions in infant hearts with cryothermal versus radiofrequency energy: an animal study. Circ Arrhythm Electrophysiol. 2011;4:211-7.

487. Saul JP, Hulse JE, Papagiannis J, Van Praagh R,Walsh EP. Late enlargement of radiofrequency lesions in infant lambs. Implications for ablation procedures in small children. Circulation. 1994;90:492-9.

488. Khairy P, Harris L, Landzberg MJ, Viswanathan S, Barlow A, Gatzoulis MA, Fernandes SM, Beauchesne L, Therrien J, Chetaille P, Gordon E, Vonder Muhll I, Cecchin F. Implantable cardioverter-defibrillators in tetralogy of Fallot. Circulation. 2008:117:363-70.

489. Khairy P, Harris L, Landzberg MJ, Fernandes SM, Barlow A, Mercier LA, Viswanathan S, Chetaille P, Gordon E, Dore A, Cecchin F. Sudden death and defibrillators in transposition of the great arteries with intra-atrial baffles: a multicenter study. Circ Arrhythm Electrophysiol. 2008;1:250-7.

490. Berul CI, Van Hare GF, Kertesz NJ, Dubin AM, Cecchin F, Collins KK, Cannon BC, Alexander ME, Triedman JK, Walsh EP, Friedman RA. Results of a multicente retrospective implantable cardioverter-defibrillator registry of pediatric and congenital heart disease patients. J Am Coll Cardiol. 2008;51:1685-91.

491. Koyak Z, de Groot JR, Van Gelder IC, Bouma BJ, van Dessel PF, Budts W, van Erven L, van Dijk AP, Wilde AA, Pieper PG, Sieswerda GT, Mulder BJ. Implantable cardioverter defibrillator therapy in adults with congenital heart disease: who is at risk of shocks? Circ Arrhythm Electrophysiol. 2012;5:101-10.

492. Zeppenfeld K, Schalij MJ, Bartelings MM, Tedrow UB, Koplan BA, Soejima K, Stevenson WG. Catheter ablation of ventricular tachycardia after repair of congenital heart disease: electroanatomic identification of the critical right ventricular isthmus. Circulation. 2007;116:2241-52.

493. Gallego P, Gonzalez AE, Sanchez-Recalde A, Peinado R, Polo L, Gomez-Rubin C Lopez-Sendon JL, Oliver JM. Incidence and predictors of sudden cardiac arrest in adults with congenital heart defects repaired before adult life. Am J Cardiol. 2012;110:109-17.

494. Ghai A, Silversides C, Harris L,Webb GD, Siu SC, Therrien J. Left ventricular dysfunction is a risk factor for sudden cardiac death in adults late after repair of tetralogy of Fallot. J Am Coll Cardiol. 2002;40:1675-80,

495. Gatzoulis MA, Balaji S, Webber SA, Siu SC, Hokanson JS, Poile C, Rosenthal M, Nakazawa M, Moller JH, Gillette PC, Webb GD, Redington AN. Risk factors for arrhythmia and sudden cardiac death late after repair of tetralogy of Fallot: a multicentre study. Lancet. 2000;356:975-81.

496. Khairy P, Landzberg MJ, Gatzoulis MA, Lucron H, Lambert J, Marcon F, Alexander ME,Walsh EP. Value of programmed ventricular stimulation after tetralogy of fallot repair: a multicenter study. Circulation. 2004;109:1994-2000.

497. Koyak Z, Harris L, de Groot JR, Silversides CK, Oechslin EN, Bouma BJ, BudtsW, Zwinderman AH, Van Gelder IC, Mulder BJ. Sudden cardiac death in adult congenital heart disease. Circulation. 2012;126:1944-54.

498. Kammeraad JA, van Deurzen CH, Sreeram N, Bink-Boelkens MT, Ottenkamp HelbingWA, Lam J, Sobotka-Plojhar MA, Daniels O, Balaji S. Predictors of sudden cardiac death after Mustard or Senning repair for transposition of the great arteries. J Am Coll Cardiol. 2004;44:1095-102.
499. van der Linde D, Konings EE, Slager MA, Witsenburg M, Helbing WA, Takkenberg JJ, Roos-Hesselink JW. Birth prevalence of congenital heart disease worldwide: a systematic review and meta-analysis. J Am Coll Cardiol. 2011;58:2241-7.

500. Marelli AJ, Mackie AS, Ionescu-Ittu R, Rahme E, Pilote L. Congenital heart disease in the general population: changing prevalence and age distribution. Circulation. 2007; 115:163-72.

501. Silka MJ, Hardy BG, Menashe VD, Morris CD. A population-based prospective evaluation of risk of sudden cardiac death after operation for common congenital heart defects. J Am Coll Cardiol. 1998;32:245-51.

502. Oechslin EN, Harrison DA, Connelly MS, Webb GD, Siu SC. Mode of death in adults with congenital heart disease. Am J Cardiol. 2000;86:1111-6.

503. Nieminen HP, Jokinen EV, Sairanen HI. Causes of late deaths after pediatric cardiac surgery: a population-based study. J Am Coll Cardiol. 2007;50:1263-71.

504. Murphy JG, Gersh BJ, Mair DD, Fuster V, McGoon MD, Ilstrup DM, McGoon DC, Kirklin JW, Danielson GK. Long-term outcome in patients undergoing surgical repair of tetralogy of Fallot. N Engl J Med. 1993;329:593-9.

505. Moons P, Gewillig M, Sluysmans T, Verhaaren H, Viart P, Massin M, Suys B, Budts W, Pasquet A, De Wolf D, Vliers A. Long term outcome up to 30 years after the Mustard or Senning operation: a nationwide multicentre study in Belgium. Heart. 2004;90:307-13.

506. Brown DW, Dipilato AE, Chong EC, Gauvreau K, McElhinney DB, Colan SD, Lock JE. Sudden unexpected death after balloon valvuloplasty for congenital aortic stenosis. J Am Coll Cardiol. 2010;56:1939-46.

507. Khairy P, Fernandes SM, Mayer JE Jr, Triedman JK, Walsh EP, Lock JE, Landzberg MJ. Long-term survival, modes of death, and predictors of mortality in patients with Fontan surgery. Circulation. 2008;117:85-92.

508. Heersche JH, Blom NA, van de Heuvel F, Blank C, Reimer AG, Clur SA, Witsenburg $\mathrm{M}$, ten Harkel AD. Implantable cardioverter defibrillator therapy for prevention of sudden cardiac death in children in the Netherlands. Pacing Clin Electrophysiol. 2010;33:179-85.

509. Silka MJ, Kron J, Dunnigan A, Dick M 2nd. Sudden cardiac death and the use of implantable cardioverter-defibrillators in pediatric patients. The Pediatric Electrophysiology Society. Circulation. 1993;87:800-7.

510. Etheridge SP, Sanatani S, Cohen MI, Albaro CA, Saarel EV, Bradley DJ. Long QT syndrome in children in the era of implantable defibrillators. J Am Coll Cardiol. 2007;50:1335-40.

511. Maron BJ, Spirito P, Ackerman MJ, Casey SA, Semsarian C, Estes NA 3rd, Shannon KM, Ashley EA, Day SM, Pacileo G, Formisano F, Devoto E, Anastasakis A, Bos JM, Woo A, Autore C, Pass RH, Boriani G, Garberich RF, Almquist AK, Russell MW, Boni L, Berger S, Maron MS, Link MS. Prevention of sudden cardiac death with implantable cardioverter-defibrillators in children and adolescents with hypertrophic cardiomyopathy. J Am Coll Cardiol. 2013;61:1527-35.

512. Radbill AE, Triedman JK, Berul CI, Fynn-Thompson F, Atallah J, Alexander ME, Walsh EP, Cecchin F. System survival of nontransvenous implantable cardioverterdefibrillators compared to transvenous implantable cardioverterdefibrillators in pediatric and congenital heart disease patients. Heart Rhythm. 2010;7:193-8.

513. Burns KM, Evans F, Kaltman JR. Pediatric ICD utilization in the United States from 1997 to 2006. Heart Rhythm. 2011;8:23-8.

514. Pahl E, Sleeper LA, Canter CE, Hsu DT, Lu M,Webber SA, Colan SD, Kantor PF, Everitt MD, Towbin JA, Jefferies JL, Kaufman BD, Wilkinson JD, Lipshultz SE, Pediatric Cardiomyopathy Registry I. Incidence of and risk factors for sudden cardiac death in children with dilated cardiomyopathy: a report from the Pediatric Cardiomyopathy Registry. J Am Coll Cardiol. 2012;59:607-15.

515. Dimas VV, Denfield SW, Friedman RA, Cannon BC, Kim JJ, Smith EO, Clunie SK, Price JF, Towbin JA, Dreyer WJ, Kertesz NJ. Frequency of cardiac death in children with idiopathic dilated cardiomyopathy. Am J Cardiol. 2009;104:1574-7.

516. Hamilton RM, Dorian P, Gow RM, Williams WG. Five-year experience with implantable defibrillators in children. Am J Cardiol. 1996;77:524-6.

517. Chatrath R, Porter CB, Ackerman MJ. Role of transvenous implantable cardioverterdefibrillators in preventing sudden cardiac death in children, adolescents, and young adults. Mayo Clin Proc. 2002;77:226-31.

518. Lawrence D, Von Bergen N, Law IH, Bradley DJ, DickM 2nd, Frias PA, Streiper MJ, Fischbach PS. Inappropriate ICD discharges in single-chamber versus dualchamber devices in the pediatric and young adult population. J Cardiovasc Electrophysiol. 2009;20:287-90.

519. Celiker A, Olgun H, Karagoz T, Ozer S, Ozkutlu S, Alehan D. Midterm experience with implantable cardioverter-defibrillators in children and young adults. Europace. 2010;12:1732-8.

520. Shah MJ. Implantable cardioverter defibrillator-related complications in the pediatric population. Pacing Clin Electrophysiol. 2009;32(Suppl 2):S71-4

521. Janson CM, Patel AR, Bonney WJ, Smoots K, Shah MJ. Implantable cardioverterdefibrillator lead failure in children and young adults: a matter of lead diameter or lead design? J Am Coll Cardiol. 2014:63:133-40.

522. Atallah J, Erickson CC, Cecchin F, Dubin AM, Law IH, Cohen MI, Lapage MJ, Cannon BC, Chun TU, Freedenberg V, Gierdalski M, Berul CI, Pediatric and Congenital Electrophysiology Society (PACES). Multi-institutional study of implantable defibrillator lead performance in children and young adults: results of the Pediatric Lead Extractability and Survival Evaluation (PLEASE) study. Circulation. 2013;127:2393-402.

523. Janousek J, Gebauer RA, Abdul-Khaliq H, Turner M, Kornyei L, Grollmuss O, Rosenthal E, Villain E, Fruh A, Paul T, Blom NA, Happonen JM, Bauersfeld U, Jacobsen JR, van den Heuvel F, Delhaas T, Papagiannis J, Trigo C,Working Group for Cardiac Dysrhythmias and Electrophysiology of the Association for European Paediatric Cardiology. Cardiac resynchronisation therapy in paediatric and congenital heart disease: differential effects in various anatomical and functional substrates. Heart. 2009;95:1165-71. 
524. van der Hulst AE, Delgado V, Blom NA, van de Veire NR, Schalij MJ, Bax JJ, Roest AA, Holman ER. Cardiac resynchronization therapy in paediatric and congenital heart disease patients. Eur Heart J. 2011;32:2236-46.

525. Morady F, Kadish AH, DiCarlo L, Kou WH, Winston S, deBuitlier M, Calkins H, Rosenheck S, Sousa J. Long-term results of catheter ablation of idiopathic right ventricular tachycardia. Circulation. 1990;82:2093-9.

526. Yamashina Y, Yagi T, Namekawa A, Ishida A, Sato H, Nakagawa T, Sakuramoto M, Sato E, Yambe T. Distribution of successful ablation sites of idiopathic right ventricular outflow tract tachycardia. Pacing Clin Electrophysiol. 2009;32:727-33.

527. Ventura R, Steven D, Klemm HU, Lutomsky B, Mullerleile K, Rostock T, Servatius $\mathrm{H}$, Risius T, Meinertz T, Kuck KH, Willems S. Decennial follow-up in patients with recurrent tachycardia originating from the right ventricular outflow tract: electrophysiologic characteristics and response to treatment. Eur Heart J. 2007;28:2338-45.

528. Krittayaphong R, Sriratanasathavorn C, Dumavibhat C, Pumprueg S, Boonyapisit W, Pooranawattanakul S, Phrudprisan S, Kangkagate C. Electrocardiographic predictors of long-term outcomes after radiofrequency ablation in patients with right-ventricular outflow tract tachycardia. Europace. 2006;8:601-6.

529. Steven D, Roberts-Thomson KC, Seiler J, Inada K, Tedrow UB, Mitchell RN, Sobieszczyk PS, Eisenhauer AC, Couper GS, Stevenson WG. Ventricular tachycardia arising from the aortomitral continuity in structural heart disease: characteristics and therapeutic considerations for an anatomically challenging area of origin. Circ Arrhythm Electrophysiol. 2009;2:660-6.

530. Hachiya H, Hirao K, Sasaki T, Higuchi K, Hayashi T, Tanaka Y, Kawabata M, Isobe M. Novel ECG predictor of difficult cases of outflow tract ventricular tachycardia: peak deflection index on an inferior lead. Circ J. 2010;74:256-61.

531. Sacher F, Roberts-Thomson K, Maury P, Tedrow U, Nault I, Steven D, Hocini M, Koplan B, Leroux L, Derval N, Seiler J, Wright MJ, Epstein L, Haissaguerre M, Jais P, Stevenson WG. Epicardial ventricular tachycardia ablation a multicenter safety study. J Am Coll Cardiol. 2010;55:2366-72.

532. Ouyang F, Mathew S, Wu S, Kamioka M, Metzner A, Xue Y, JuW, Yang B, Zhan X, Rillig A, Lin T, Rausch P, Deiss S, Lemes C, Tonnis T, Wissner E, Tilz RR, Kuck KH, Chen M. Ventricular arrhythmias arising from the left ventricular outflow tract below the aortic sinus cusps: mapping and catheter ablation via transseptal approach and electrocardiographic characteristics. Circ Arrhythm Electrophysiol. 2014;7:445-55.

533. Kamakura S, Shimizu W, Matsuo K, Taguchi A, Suyama K, Kurita T, Aihara N, Ohe T, Shimomura K. Localization of optimal ablation site of idiopathic ventricular tachycardia from right and left ventricular outflow tract by body surface ECG. Circulation. 1998;98:1525-33.

534. Callans DJ, Menz V, Schwartzman D, Gottlieb CD, Marchlinski FE. Repetitive monomorphic tachycardia from the left ventricular outflow tract: electrocardiographic patterns consistent with a left ventricular site of origin. J Am Coll Cardiol. 1997;29:1023-7.

535. Tada H, Hiratsuji T, Naito S, Kurosaki K, Ueda M, Ito S, Shinbo G, Hoshizaki H, Oshima S, Nogami A, Taniguchi K. Prevalence and characteristics of idiopathic outflow tract tachycardia with QRS alteration following catheter ablation requiring additional radiofrequency ablation at a different point in the outflow tract. Pacing Clin Electrophysiol. 2004;27:1240-9.

536. Yamada T, McElderry HT, Doppalapudi H, Murakami Y, Yoshida Y, Yoshida N, Okada T, Tsuboi N, Inden Y, Murohara T, Epstein AE, Plumb VJ, Singh SP, KayGN. Idiopathic ventricular arrhythmias originating from the aortic root prevalence, electrocardiographic and electrophysiologic characteristics, and results of radiofrequency catheter ablation. J Am Coll Cardiol. 2008;52:139-47.

537. Kanagaratnam L, Tomassoni G, Schweikert R, Pavia S, Bash D, Beheiry S, Neibauer M, SalibaW, Chung M, Tchou P, Natale A. Ventricular tachycardias arising from the aortic sinus of valsalva: an under-recognized variant of left outflow tract ventricular tachycardia. J Am Coll Cardiol. 2001;37:1408-14.

538. Ouyang F, Fotuhi P, Ho SY, Hebe J, Volkmer M, Goya M, Burns M, Antz M, Ernst S, Cappato R, Kuck KH. Repetitive monomorphic ventricular tachycardia originating from the aortic sinus cusp: electrocardiographic characterization for guiding catheter ablation. J Am Coll Cardiol. 2002;39:500-8.

539. Tada H, Nogami A, Naito S, Fukazawa H, Horie Y, Kubota S, Okamoto Y, Hoshizaki H, Oshima S, Taniguchi K. Left ventricular epicardial outflow tract tachycardia: a new distinct subgroup of outflow tract tachycardia. Jpn Circ J. 2001;65:723-30.

540. Yamada T, Litovsky SH, Kay GN. The left ventricular ostium: an anatomic concept relevant to idiopathic ventricular arrhythmias. Circ Arrhythm Electrophysiol. 2008;1:396-404.

541. Yamada T, McElderry HT, Doppalapudi H, Okada T, Murakami Y, Yoshida Y, Yoshida N, Inden Y, Murohara T, Plumb VJ, Kay GN. Idiopathic ventricular arrhythmias originating from the left ventricular summit: anatomic concepts relevant to ablation. Circ Arrhythm Electrophysiol. 2010;3:616-23.

542. Ouyang F, Bansch D, Schaumann A, Ernst S, Linder C, Falk P, Hachiya H, Kuck KH, Antz M. Catheter ablation of subepicardial ventricular tachycardia using electroanatomic mapping. Herz. 2003;28:591-7.

543. Kumagai K, Yamauchi Y, Takahashi A, Yokoyama Y, Sekiguchi Y, Watanabe J, Iesaka Y, Shirato K, Aonuma K. Idiopathic left ventricular tachycardia originating from the mitral annulus. J Cardiovasc Electrophysiol. 2005;16:1029-36.

544. Tada H, Tadokoro K, Miyaji K, Ito S, Kurosaki K, Kaseno K, Naito S, Nogami A, Oshima S, Taniguchi K. Idiopathic ventricular arrhythmias arising from the pulmonary artery: prevalence, characteristics, and topography of the arrhythmia origin. Heart Rhythm. 2008;5:419-26.

545. Sekiguchi Y, Aonuma K, Takahashi A, Yamauchi Y, Hachiya H, Yokoyama Y, Iesaka $\mathrm{Y}$, Isobe $\mathrm{M}$. Electrocardiographic and electrophysiologic characteristics of ventricular tachycardia originating within the pulmonary artery. J Am Coll Cardiol. 2005;45:887-95.
546. Timmermans C, Rodriguez LM, Crijns HJ, Moorman AF, Wellens HJ. Idiopathic left bundle-branch block-shaped ventricular tachycardia may originate above the pulmonary valve. Circulation. 2003;108:1960-7.

547. Krittayaphong R, Saiviroonporn P, Boonyasirinant T, Nakyen S, Thanapiboonpol P, Watanaprakarnchai W, Ruksakul K, Kangkagate C. Magnetic resonance imaging abnormalities in right ventricular outflow tract tachycardia and the prediction of radiofrequency ablation outcome. Pacing Clin Electrophysiol. 2006;29:837-45.

548. Proclemer A, Basadonna PT, Slavich GA, Miani D, Fresco C, Fioretti PM. Cardiac magnetic resonance imaging findings in patients with right ventricular outflow tract premature contractions. Eur Heart J. 1997;18:2002-10.

549. Lerman BB, Belardinelli L,West GA, Berne RM, DiMarco JP. Adenosine-sensitive ventricular tachycardia: evidence suggesting cyclic AMP-mediated triggered activity. Circulation. 1986;74:270-80.

550. Lerman BB. Response of nonreentrant catecholamine-mediated ventricular tachycardia to endogenous adenosine and acetylcholine. Evidence for myocardial receptor-mediated effects. Circulation. 1993;87:382-90.

551. Sung RJ, Keung EC, Nguyen NX, Huycke EC. Effects of beta-adrenergic blockade on verapamil-responsive and verapamil-irresponsive sustained ventricular tachycardias. J Clin Invest. 1988;81:688-99.

552. Wilber DJ, Baerman J, Olshansky B, Kall J, Kopp D. Adenosine-sensitive ventricular tachycardia. Clinical characteristics and response to catheter ablation. Circulation. 1993;87:126-34.

553. Marchlinski FE, Deely MP, Zado ES. Sex-specific triggers for right ventricular outflow tract tachycardia. Am Heart J. 2000;139:1009-13.

554. O'Donnell D, Cox D, Bourke J, Mitchell L, Furniss S. Clinical and electrophysiological differences between patients with arrhythmogenic right ventricular dysplasia and right ventricular outflow tract tachycardia. Eur Heart J. 2003;24:801-10.

555. Khasnis A, Jongnarangsin K, Abela G, Veerareddy S, Reddy V, Thakur R. Tachycardia-induced cardiomyopathy: a review of literature. Pacing Clin Electrophysiol. 2005;28:710-21.

556. Ho YS. Overview of cardiac anatomy relevant to catheter ablation. In: Wilber D, Packer D, Stevenson W, eds. Catheter Ablation of Cardiac Arrhythmias, 3rd edn. Cambridge, MA: Blackwell Scientific; 2008. p. 3-17.

557. McAlpine WA. Heart and Coronary Arteries. New York: Springer-Verlag; 1975.

558. Ito S, Tada H, Naito S, Kurosaki K, Ueda M, Hoshizaki H, Miyamori I, Oshima S, Taniguchi K, Nogami A. Development and validation of an ECG algorithm for identifying the optimal ablation site for idiopathic ventricular outflow tract tachycardia. J Cardiovasc Electrophysiol. 2003;14:1280-6.

559. Pons M, Beck L, Leclercq F, Ferriere M, Albat B, Davy JM. Chronic left main coronary artery occlusion: a complication of radiofrequency ablation of idiopathic left ventricular tachycardia. Pacing Clin Electrophysiol. 1997;20:1874-6.

560. Koruth JS, Aryana A, Dukkipati SR, Pak HN, Kim YH, Sosa EA, Scanavacca M, Mahapatra S, Ailawadi G, Reddy VY, d'Avila A. Unusual complications of percutaneous epicardial access and epicardial mapping and ablation of cardiac arrhythmias. Circ Arrhythm Electrophysiol. 2011;4:882-8.

561. Roberts-Thomson KC, Steven D, Seiler J, Inada K, Koplan BA, Tedrow UB, Epstein LM, Stevenson WG. Coronary artery injury due to catheter ablation in adults: presentations and outcomes. Circulation. 2009;120:1465-73.

562. Makimoto H, Zhang O. Tilz RR, Wissner E, Cuneo A, Kuck KH, Ouyang F. Aborted sudden cardiac death due to radiofrequency ablation within the coronary sinus and subsequent total occlusion of the circumflex artery. J Cardiovasc Electrophysiol. 2013;24:929-32.

563. Klein LS, Shih HT, Hackett FK, Zipes DP, Miles WM. Radiofrequency catheter ablation of ventricular tachycardia in patients without structural heart disease. Circulation. 1992;85:1666-74

564. Lin D, Hsia HH, Gerstenfeld EP, Dixit S, Callans DJ, Nayak H, Russo A, Marchlinski FE. Idiopathic fascicular left ventricular tachycardia: linear ablation lesion strategy for noninducible or nonsustained tachycardia. Heart Rhythm. 2005;2:934-9.

565. Crijns HJ, Smeets JL, Rodriguez LM, Meijer A,Wellens HJ. Cure of interfascicular reentrant ventricular tachycardia by ablation of the anterior fascicle of the left bundle branch. J Cardiovasc Electrophysiol. 1995;6:486-92.

566. Ohe T, Shimomura K, Aihara N, Kamakura S, Matsuhisa M, Sato I, Nakagawa $H$ Shimizu A. Idiopathic sustained left ventricular tachycardia: clinical and electrophysiologic characteristics. Circulation. 1988;77:560-8.

567. Ouyang F, Cappato R, Ernst S, Goya M, Volkmer M, Hebe J, Antz M, Vogtmann T, Schaumann A, Fotuhi P, Hoffmann-Riem M, Kuck KH. Electroanatomic substrate of idiopathic left ventricular tachycardia: unidirectional block and macroreentry within the Purkinje network. Circulation. 2002;105:462-9.

568. Nogami A, Naito S, Tada H, Taniguchi K, Okamoto Y, Nishimura S, Yamauchi Y Aonuma K, Goya M, Iesaka Y, Hiroe M. Demonstration of diastolic and presystolic Purkinje potentials as critical potentials in a macroreentry circuit of verapamilsensitive idiopathic left ventricular tachycardia. J Am Coll Cardiol. 2000;36:811-23.

569. Ma FS, Ma J, Tang K, Han H, Jia YH, Fang PH, Chu JM, Pu JL, Zhang S. Left posterior fascicular block: a new endpoint of ablation for verapamil-sensitive idiopathic ventricular tachycardia. Chin Med J (Engl). 2006;119:367-72.

570. Kottkamp H, Chen X, Hindricks G, Willems S, Haverkamp W, Wichter T, Breithardt $G$, Borggrefe $M$. Idiopathic left ventricular tachycardia: new insights into electrophysiological characteristics and radiofrequency catheter ablation. Pacing Clin Electrophysiol. 1995;18:1285-97.

571. Nogami A, Naito S, Tada H, Oshima S, Taniguchi K, Aonuma K, Iesaka Y. Verapamilsensitive left anterior fascicular ventricular tachycardia: results of radiofrequency ablation in six patients. J Cardiovasc Electrophysiol. 1998;9:1269-78.

572. Reithmann C, Hahnefeld A, Ulbrich M, Matis T, Steinbeck G. Different forms of ventricular tachycardia involving the left anterior fascicle in nonischemic 
cardiomyopathy: critical sites of the reentrant circuit in low-voltage areas. J Cardiovasc Electrophysiol. 2009;20:841-9.

573. Bogun F, El-Atassi R, Daoud E, Man KC, Strickberger SA, Morady F. Radiofrequency ablation of idiopathic left anterior fascicular tachycardia. J Cardiovasc Electrophysiol. 1995;6:1113-6.

574. Mizusawa Y, Sakurada H, Nishizaki M, Ueda-Tatsumoto A, Fukamizu S, Hiraoka M Characteristics of bundle branch reentrant ventricular tachycardia with a righ bundle branch block configuration: feasibility of atrial pacing. Europace. 2009;11:1208-13.

575. Nogami A. Purkinje-related arrhythmias part I: monomorphic ventricular tachycardias. Pacing Clin Electrophysiol. 2011;34:624-50.

576. Doppalapudi H, Yamada T, McElderry HT, Plumb VJ, Epstein AE, Kay GN. Ventricular tachycardia originating from the posterior papillary muscle in the left ventricle: a distinct clinical syndrome. Circ Arrhythm Electrophysiol. 2008;1: 23-9.

577. Crawford T, Mueller G, Good E, Jongnarangsin K, Chugh A, Pelosi F Jr, Ebinger M, Oral H, Morady F, Bogun F. Ventricular arrhythmias originating from papillary muscles in the right ventricle. Heart Rhythm. 2010;7:725-30.

578. Bogun F, Desjardins B, Crawford T, Good E, Jongnarangsin K, Oral H, Chugh A, Pelosi F, Morady F. Post-infarction ventricular arrhythmias originating in papillary muscles. J Am Coll Cardiol. 2008;51:1794-802.

579. Yeh SJ,Wen MS,Wang CC, Lin FC, Wu D. Adenosine-sensitive ventricular tachycardia from the anterobasal left ventricle. J Am Coll Cardiol. 1997;30:133945.

580. Kondo K, Watanabe I, Kojima T, Nakai T, Yanagawa S, Sugimura H, Shindo A Oshikawa N, Masaki R, Saito S, Ozawa Y, Kanmatsuse K. Radiofrequency catheter ablation of ventricular tachycardia from the anterobasal left ventricle. Jpn Heart J. 2000;41:215-25.

581. Tada H, Ito S, Naito S, Kurosaki K, Kubota S, Sugiyasu A, Tsuchiya T, Miyaji K, Yamada M, Kutsumi Y, Oshima S, Nogami A, Taniguchi K. Idiopathic ventricula arrhythmia arising from the mitral annulus: a distinct subgroup of idiopathic ventricular arrhythmias. J Am Coll Cardiol. 2005:45:877-86.

582. Prystowsky EN, Padanilam BJ, Joshi S, Fogel RI. Ventricular arrhythmias in the absence of structural heart disease. J Am Coll Cardiol. 2012;59:1733-44

583. Meissner MD, Lehmann MH, Steinman RT, Mosteller RD, Akhtar M, Calkins $H$ Cannom DS, Epstein AE, Fogoros RN, Liem LB, Marchlinski FE, Myerburg RJ, Veltri EP. Ventricular fibrillation in patients without significant structural heart disease: a multicenter experience with implantable cardioverter-defibrillato therapy. J Am Coll Cardiol. 1993;21:1406-12.

584. Haissaguerre M, Shah DC, Jais P, Shoda M, Kautzner J, Arentz T, Kalushe D, Kadish A, Griffith M, Gaita F, Yamane T, Garrigue S, Hocini M, Clementy J. Role of Purkinje conducting system in triggering of idiopathic ventricular fibrillation. Lancet. 2002;359:677-8

585. Bogun F, Good E, Reich S, Elmouchi D, Igic P, Tschopp D, Dey S, Wimmer A Jongnarangsin K, Oral H, Chugh A, Pelosi F, Morady F. Role of Purkinje fibers in post-infarction ventricular tachycardia. J Am Coll Cardiol. 2006;48:2500-7.

586. Knecht S, Sacher F, Wright M, Hocini M, Nogami A, Arentz T, Petit B, Franck R, De Chillou C, Lamaison D, Farre J, Lavergne T, Verbeet T, Nault I, Matsuo S, Leroux L, Weerasooriya R, Cauchemez B, Lellouche N, Derval N, Narayan SM, Jais P, Clementy J, Haissaguerre M. Long-term follow-up of idiopathic ventricula fibrillation ablation: a multicenter study. J Am Coll Cardiol. 2009;54:522-8.

587. Nogami A, Sugiyasu A, Kubota S, Kato K. Mapping and ablation of idiopathic ventricular fibrillation from the Purkinje system. Heart Rhythm. 2005;2:646-9.

588. Haissaguerre M, Shoda M, Jais P, Nogami A, Shah DC, Kautzner J, Arentz T, Kalushe D, Lamaison D, Griffith M, Cruz F, de Paola A, Gaita F, Hocini M, Garrigue S, Macle L, Weerasooriya R, Clementy J. Mapping and ablation of idiopathic ventricular fibrillation. Circulation. 2002;106:962-7.

589. Wever EF, Robles de Medina EO. Sudden death in patients without structural heart disease. J Am Coll Cardiol. 2004;43:1137-44.

590. Leenhardt A, Glaser E, Burguera M, Nurnberg M, Maison-Blanche P, Coumel P. Short-coupled variant of torsade de pointes. A new electrocardiographic entity in the spectrum of idiopathic ventricular tachyarrhythmias. Circulation. 1994:89:206-15.

591. Eisenberg SJ, Scheinman MM, Dullet NK, Finkbeiner WE, Griffin JC, Eldar M, Franz MR, Gonzalez R, Kadish AH, Lesh MD. Sudden cardiac death and polymorphous ventricular tachycardia in patients with normal QT intervals and normal systolic cardiac function. Am J Cardiol. 1995;75:687-92.

592. Van den Branden B,Wever E, Boersma L. Torsade de pointes with short coupling interval. Acta Cardiol. 2010;65:345-6.

593. Caforio AL, Pankuweit S, Arbustini E, Basso C, Gimeno-Blanes J, Felix SB, Fu M, Helio T, Heymans S, Jahns R, Klingel K, Linhart A, Maisch B, McKenna W, Mogensen J, Pinto YM, Ristic A, Schultheiss HP, Seggewiss H, Tavazzi L, Thiene G Yilmaz A, Charron P, Elliott PM. Current state of knowledge on aetiology, diagnosis, management, and therapy of myocarditis: a position statement of the European Society of Cardiology Working Group on Myocardial and Pericardial Diseases. Eur Heart J. 2013;34:2636-48.

594. JCS Joint Working Group. Guidelines for diagnosis and treatment of myocarditis (JCS 2009): digest version. Circ J. 2011;75:734-43.

595. Aoyama N, Izumi T, Hiramori K, Isobe M, Kawana M, Hiroe M, Hishida H, Kitaura Y, Imaizumi T. National survey of fulminant myocarditis in Japan: therapeutic guidelines and long-term prognosis of using percutaneous cardiopulmonary support for fulminant myocarditis (special report from a scientific committee) Circ J. 2002;66:133-44.

596. Liberman L, Anderson B, Silver ES, Singh R, Richmond ME. Incidence and characteristics of arrhythmias in pediatric patients with myocarditis: a multicenter study. J Am Coll Cardiol. 2014;63:A483.
597. Kindermann I, Kindermann M, Kandolf R, Klingel K, Bultmann B, Muller T, Lindinger A, Bohm M. Predictors of outcome in patients with suspected myocarditis. Circulation. 2008;118:639-48.

598. Prochnau D, Surber R, Kuehnert H, Heinke M, Klein HU, Figulla HR. Successful use of a wearable cardioverter-defibrillator in myocarditis with normal ejection fraction. Clin Res Cardiol. 2010;99:129-31.

599. Chung MK. The role of the wearable cardioverter defibrillator in clinical practice. Cardiol Clin. 2014;32:253-70.

600. Kandolin R, Lehtonen J, Salmenkivi K, Raisanen-Sokolowski A, Lommi J, Kupari M. Diagnosis, treatment, and outcome of giant-cell myocarditis in the era of combined immunosuppression. Circ Heart Fail. 2013;6:15-22.

601. Schumm J, Greulich S, Wagner A, Grun S, Ong P, Bentz K, Klingel K, Kandolf R, Bruder O, Schneider S, Sechtem U, Mahrholdt H. Cardiovascular magnetic resonance risk stratification in patients with clinically suspected myocarditis. J Cardiovasc Magn Reson. 2014;16:14.

602. Rosenheck S, Weiss A, Sharon Z. Therapy success and survival in patients with valvular heart disease and implantable cardioverter defibrillator. Int J Cardiol. 2010;144:103-4

603. Yang F, Shah B, Iwai S, Markowitz SM, Lerman BB, Stein KM. ICD implantation and arrhythmia-free survival in patients with depressed LV function following surgery for valvular heart disease. Pacing Clin Electrophysiol. 2008;31:1419-24.

604. Valles AG, Khawaja FJ, Gersh BJ, Enriquez-Sarano M, Friedman PA, Park SJ, Hodge DO, Cha YM. Implantable cardioverter defibrillators in patients with valvular cardiomyopathy. J Cardiovasc Electrophysiol. 2012;23:1326-32.

605. Aranki SF, Santini F, Adams DH, Rizzo RJ, Couper GS, Kinchla NM, Gildea JS, Collins JJ Jr, Cohn LH. Aortic valve endocarditis. Determinants of early survival and late morbidity. Circulation. 1994;90:II175-82.

606. Johnson LL, Sciacca RR, Ellis K, Weiss MB, Cannon PJ. Reduced left ventricular myocardial blood flow per unit mass in aortic stenosis. Circulation. 1978;57:582-90.

607. Martinez-Rubio A, Schwammenthal Y, Schwammenthal E, Block M, Reinhardt L, Garcia-Alberola A, Sierra G, Shenasa M, Haverkamp W, Scheld HH, Breithardt G, Borggrefe M. Patients with valvular heart disease presenting with sustained ventricular tachyarrhythmias or syncope: results of programmed ventricular stimulation and long-term follow-up. Circulation. 1997;96:500-8.

608. Narasimhan C, Jazayeri MR, Sra J, Dhala A, Deshpande S, Biehl M, Akhtar M, Blanck Z. Ventricular tachycardia in valvular heart disease: facilitation of sustained bundle-branch reentry by valve surgery. Circulation. 1997;96:4307-13.

609. Sagar S, Liu PP, Cooper LT Jr. Myocarditis. Lancet. 2012;379:738-47.

610. Liu QN, Reddy S, Sayre JW, Pop V, Graves MC, Fiala M. Essential role of HIV type 1-infected and cyclooxygenase 2-activated macrophages and T cells in HIV type 1 myocarditis. AIDS Res Hum Retroviruses. 2001;17:1423-33.

611. Richardson P, McKennaW, Bristow M, Maisch B, Mautner B, O'Connell J, Olsen E, Thiene G, Goodwin J, Gyarfas I, Martin I, Nordet P. Report of the 1995 World Health Organization/International Society and Federation of Cardiology Task Force on the Definition and Classification of Cardiomyopathies. Circulation. 1996;93:841-2.

612. Ukena C, Mahfoud F, Kindermann I, Kandolf R, Kindermann M, Bohm M. Prognostic electrocardiographic parameters in patients with suspected myocarditis. Eur J Heart Fail. 2011;13:398-405.

613. Kohno K, Aoyama N, Shimohama T, Yoshida M, Machida Y, Fukuda N, Aizaki T, Suzuki K, Kurosawa T, Izumi T. Resuscitation from fulminant myocarditis associated with refractory ventricular fibrillation. Jpn Circ J. 2000;64:139-43.

614. McCarthy RE 3rd, Boehmer JP, Hruban RH, Hutchins GM, Kasper EK, Hare JM, Baughman KL. Long-term outcome of fulminant myocarditis as compared with acute (nonfulminant) myocarditis. N Engl J Med. 2000;342:690-5.

615. Phillips M, Robinowitz M, Higgins JR, Boran KJ, Reed T, Virmani R. Sudden cardiac death in Air Force recruits. A 20-year review. JAMA. 1986;256:2696-9.

616. Basso C, Calabrese F, Corrado D, Thiene G. Myocarditis: an underestimated cause of sudden cardiac death. In: Aliot E, Clementy J, Prystowsky EN, eds. Fighting Sudden Cardiac Death: AWorldwide Challenge. Armonk, NY: Futura; 2000. p. 447-58.

617. Basso C, Calabrese F, Corrado D, Thiene G. Postmortem diagnosis in sudden cardiac death victims: macroscopic, microscopic and molecular findings. Cardiovasc Res. 2001;50:290-300.

618. Fabre A, Sheppard MN. Sudden adult death syndrome and other non-ischaemic causes of sudden cardiac death. Heart. 2006;92:316-20.

619. Wesslen L, Pahlson C, Lindquist O, Hjelm E, Gnarpe J, Larsson E, Baandrup U, Eriksson L, Fohlman J, Engstrand L, Linglof T, Nystrom-Rosander C, Gnarpe H, Magnius L, Rolf C, Friman G. An increase in sudden unexpected cardiac deaths among young Swedish orienteers during 1979- 1992. Eur Heart J. 1996;17:902-10.

620. D’Ambrosio A, Patti G, Manzoli A, Sinagra G, Di Lenarda A, Silvestri F, Di Sciascio G. The fate of acute myocarditis between spontaneous improvement and evolution to dilated cardiomyopathy: a review. Heart. 2001;85:499-504.

621. Kuhl U, Pauschinger M, Seeberg B, Lassner D, Noutsias M, Poller W, Schultheiss $\mathrm{HP}$. Viral persistence in the myocardium is associated with progressive cardiac dysfunction. Circulation. 2005;112:1965-70.

622. Mazzone P, Tsiachris D, Della Bella P. Epicardial management of myocarditisrelated ventricular tachycardia. Eur Heart J. 2013;34:244.

623. Wallace SM, Walton BI, Kharbanda RK, Hardy R, Wilson AP, Swanton RH. Mortality from infective endocarditis: clinical predictors of outcome. Heart. 2002;88: 53-60.

624. Kumar S, Barbhaiya C, Nagashima K, Choi EK, Epstein LM, John RM, Maytin M, Albert CM, Miller AL, Koplan BA, Michaud GF, Tedrow UB, Stevenson WC. Ventricular tachycardia in cardiac sarcoidosis: characterization of ventricular substrate and outcomes of catheter ablation. Circ Arrhythm Electrophysiol. 2015;8:87-93. 
625. Birnie DH, Sauer WH, Bogun F, Cooper JM, Culver DA, Duvernoy CS, Judson MA, Kron J, Mehta D, Cosedis Nielsen J, Patel AR, Ohe T, Raatikainen P, Soejima K. HRS expert consensus statement on the diagnosis and management of arrhythmias associated with cardiac sarcoidosis. Heart Rhythm. 2014:11:1305-23.

626. von Olshausen K, Schwarz F, Apfelbach J, Rohrig N, Kramer B, Kubler W. Determinants of the incidence and severity of ventricular arrhythmias in aortic valve disease. Am J Cardiol. 1983;51:1103-9.

627. Hochreiter C, Niles N, Devereux RB, Kligfield P, Borer JS. Mitral regurgitation: relationship of noninvasive descriptors of right and left ventricular performance to clinical and hemodynamic findings and to prognosis in medically and surgically treated patients. Circulation. 1986;73:900-12.

628. Chizner MA, Pearle DL, deLeon AC Jr. The natural history of aortic stenosis in adults. Am Heart J. 1980;99:419-24.

629. Sorgato A, Faggiano P, Aurigemma GP, Rusconi C, Gaasch WH. Ventricular arrhythmias in adult aortic stenosis: prevalence, mechanisms, and clinical relevance. Chest. 1998;113:482-91.

630. Delahaye JP, Gare JP, Viguier E, Delahaye F, De Gevigney G, Milon H. Natural history of severe mitral regurgitation. Eur Heart J. 1991;12(Suppl B):5-9.

631. Grigioni F, Enriquez-Sarano M, Ling LH, Bailey KR, Seward JB, Tajik AJ, Frye RL. Sudden death in mitral regurgitation due to flail leaflet. J Am Coll Cardiol. 1999;34:2078-85.

632. Olafiranye O, Hochreiter CA, Borer JS, Supino PG, Herrold EM, Budzikowski AS, Hai OY, Bouraad D, Kligfield PD, Girardi LN, Krieger KH, IsomOW. Nonischemic mitral regurgitation: prognostic value of nonsustained ventricular tachycardia after mitral valve surgery. Cardiology. 2013:124:108-15.

633. Groves P. Valve disease: Surgery of valve disease: late results and late complications. Heart. 2001;86:715-21.

634. Blackstone EH, Kirklin JW. Death and other time-related events after valve replacement. Circulation. 1985;72:753-67.

635. Hwang MH, Burchfiel CM, Sethi GK, Oprian C, Grover FL, Henderson WG, Hammermeister K. Comparison of the causes of late death following aortic and mitral valve replacement. VA Co-operative Study on Valvular Heart Disease. J Heart Valve Dis. 1994;3:17-24.

636. Burke AP, Farb A, Sessums L, Virmani R. Causes of sudden cardiac death in patients with replacement valves: an autopsy study. J Heart Valve Dis. 1994:3:10-6.

637. Food and Drug Administration. International Conference on Harmonisation; guidance on E14 Clinical Evaluation of QT/QTc Interval Prolongation and Proarrhythmic Potential for Non-Antiarrhythmic Drugs; availability. Notice. Fed Reg. 2005;70:61134-5.

638. Watanabe J, Suzuki Y, Fukui N, Ono S, Sugai T, Tsuneyama N, Someya T. Increased risk of antipsychotic-related QT prolongation during nighttime: a 24-hour Holter electrocardiogram recording study. J Clin Psychopharmacol. 2012;32:18-22.

639. Wu CS, Tsai YT, Tsai HJ. Antipsychotic drugs and the risk of ventricular arrhythmia and/or sudden cardiac death: a nation-wide case-crossover study. J Am Heart Assoc. 2015;4:e001568.

640. Sala M, Vicentini A, Brambilla P, Montomoli C, Jogia JR, Caverzasi E, Bonzano A, Piccinelli M, Barale F, De Ferrari GM. QT interval prolongation related to psychoactive drug treatment: a comparison of monotherapy versus polytherapy. Ann Gen Psychiatry. 2005;4:1.

641. Fanoe S, Kristensen D, Fink-Jensen A, Jensen HK, Toft E, Nielsen J, Videbech P, Pehrson S, Bundgaard H. Risk of arrhythmia induced by psychotropic medications: a proposal for clinical management. Eur Heart J. 2014;35:1306-15.

642. Girardin FR, Gex-Fabry M, Berney P, Shah D, Gaspoz JM, Dayer P. Drug-induced long QT in adult psychiatric inpatients: the 5-year cross-sectional ECG Screening Outcome in Psychiatry study. Am J Psychiatry. 2013;170:1468-76.

643. Murray-Thomas T, Jones ME, Patel D, Brunner E, Shatapathy CC, Motsko S, Van Staa TP. Risk of mortality (including sudden cardiac death) and major cardiovascular events in atypical and typical antipsychotic users: a study with the general practice research database. Cardiovasc Psychiatry Neurol. 2013;2013:247486

644. Appleby L, Thomas S, Ferrier N, Lewis G, Shaw J, Amos T. Sudden unexplained death in psychiatric in-patients. Br J Psychiatry 2000;176:405-406.

645. Roden DM, Lazzara R, Rosen M, Schwartz PJ, Towbin J, Vincent GM. Multiple mechanisms in the long-QT syndrome. Current knowledge, gaps, and future directions. The SADS Foundation Task Force on LQTS. Circulation. 1996;94:1 996-2012.

646. Ray WA, Meredith S, Thapa PB, Meador KG, Hall K, Murray KT. Antipsychotics and the risk of sudden cardiac death. Arch Gen Psychiatry. 2001;58:1161-7.

647. RayWA, Chung CP, Murray KT, Hall K, Stein CM. Atypical antipsychotic drugs and the risk of sudden cardiac death. N Engl J Med. 2009;360:225-35.

648. Haddad PM, Anderson IM. Antipsychotic-related QTc prolongation, torsade de pointes and sudden death. Drugs. 2002;62:1649-71.

649. Taylor DM. Antipsychotics and QT prolongation. Acta Psychiatr Scand. 2003;107:85-95.

650. Devinsky O. Sudden, unexpected death in epilepsy. N Engl J Med. 2011;365: 1801-11.

651. Annegers JF. United States perspective on definitions and classifications. Epilepsia. 1997;38(Suppl):S9-S12.

652. Dasheiff RM. Sudden unexpected death in epilepsy: a series from an epilepsy surgery program and speculation on the relationship to sudden cardiac death. J Clin Neurophysiol. 1991;8:216-22.

653. Donner EJ, Smith CR, Snead OC 3rd. Sudden unexplained death in children with epilepsy. Neurology. 2001;57:430-4.

654. Ficker DM, So EL, Shen WK, Annegers JF, O'Brien PC, Cascino GD, Belau PG. Population-based study of the incidence of sudden unexplained death in epilepsy. Neurology. 1998;51:1270-4.
655. Nashef L, Fish DR, Garner S, Sander JW, Shorvon SD. Sudden death in epilepsy: a study of incidence in a young cohort with epilepsy and learning difficulty. Epilepsia. 1995;36:1187-94.

656. Nilsson L, Ahlbom A, Farahmand BY, Tomson T. Mortality in a population-based cohort of epilepsy surgery patients. Epilepsia. 2003;44:575-81.

657. Sperling MR, Feldman H, Kinman J, Liporace JD, O'Connor MJ. Seizure control and mortality in epilepsy. Ann Neurol. 1999;46:45-50.

658. Tomson T, Nashef L, Ryvlin P. Sudden unexpected death in epilepsy: current knowledge and future directions. Lancet Neurol. 2008;7:1021-31.

659. Tomson T,Walczak T, Sillanpaa M, Sander JW. Sudden unexpected death in epilepsy: a review of incidence and risk factors. Epilepsia. 2005;46(Suppl 11): 54-61.

660. Walczak TS, Leppik IE, D’Amelio M, Rarick J, So E, Ahman P, Ruggles K, Cascino GD, Annegers JF, Hauser WA. Incidence and risk factors in sudden unexpected death in epilepsy: a prospective cohort study. Neurology. 2001:56:519-25

661. Sandorfi G, Clemens B, Csanadi Z. Electrical storm in the brain and in the heart: epilepsy and Brugada syndrome. Mayo Clin Proc. 2013;88:1167-73.

662. Johnson JN, Hofman N, Haglund CM, CascinoGD, Wilde AA, Ackerman MJ. Identification of a possible pathogenic link between congenital long QT syndrome and epilepsy. Neurology. 2009;72:224-31.

663. Rugg-Gunn FJ, Simister RJ, Squirrell M, Holdright DR, Duncan JS. Cardiac arrhythmias in focal epilepsy: a prospective long-term study. Lancet. 2004;364:2212-9.

664. Ryvlin P, Nashef L, Lhatoo SD, Bateman LM, Bird J, Bleasel A, Boon P, Crespel A, Dworetzky BA, Hogenhaven $\mathrm{H}$, Lerche $\mathrm{H}$, Maillard L, Malter MP, Marchal $\mathrm{C}$, Murthy JM, Nitsche M, Pataraia E, Rabben T, Rheims S, Sadzot B, Schulze-Bonhage A, Seyal M, So EL, Spitz M, Szucs A, Tan M, Tao JX, Tomson T. Incidence and mechanisms of cardiorespiratory arrests in epilepsy monitoring units (MORTEMUS): a retrospective study. Lancet Neurol. 2013;12:966-77.

665. Lund M, Diaz LJ, Ranthe MF, Petri H, Duno M, Juncker I, Eiberg H, Vissing J, Bundgaard H, Wohlfahrt J, Melbye M. Cardiac involvement in myotonic dystrophy: a nationwide cohort study. Eur Heart J. 2014;35:2158-64.

666. Groh WJ. Arrhythmias in the muscular dystrophies. Heart Rhythm. 2012;9: $1890-5$

667. Petri H, Vissing J, Witting N, Bundgaard H, Kober L. Cardiac manifestations of myotonic dystrophy type 1. Int J Cardiol. 2012;160:82-8.

668. Lallemand B, Clementy N, Bernard-Brunet A, Pierre B, Corcia P, Fauchier L, Raynaud M, Pellieux S, Babuty D. The evolution of infrahissian conduction time in myotonic dystrophy patients: clinical implications. Heart. 2012;98:291-6.

669. Groh WJ, Groh MR, Saha C, Kincaid JC, Simmons Z, Ciafaloni E, Pourmand R, Otten RF, Bhakta D, Nair GV, MarashdehMM, Zipes DP, Pascuzzi RM. Electrocardiographic abnormalities and sudden death in myotonic dystrophy type 1 . N Engl J Med. 2008; $358: 2688-97$

670. Roberts NK, Perloff JK, Kark RA. Cardiac conduction in the Kearns-Sayre syndrome (a neuromuscular disorder associated with progressive external ophthalmoplegia and pigmentary retinopathy). Report of 2 cases and review of 17 published cases. Am J Cardiol. 1979;44:1396-400.

671. Boriani G, Gallina M, Merlini L, Bonne G, Toniolo D, Amati S, Biffi M, Martignani C, Frabetti L, Bonvicini M, Rapezzi C, Branzi A. Clinical relevance of atrial fibrillation/ flutter, stroke, pacemaker implant, and heart failure in EmeryDreifuss muscular dystrophy: a long-term longitudinal study. Stroke. 2003;34:901-8.

672. Wahbi K, Meune C, Porcher R, Becane HM, Lazarus A, Laforet P, Stojkovic T, Behin A, Radvanyi-Hoffmann H, Eymard B, Duboc D. Electrophysiological study with prophylactic pacing and survival in adults with myotonic dystrophy and conduction system disease. JAMA. 2012;307:1292-301.

673. Laurent V, Pellieux S, Corcia P, Magro P, Pierre B, Fauchier L, Raynaud M, Babuty D. Mortality in myotonic dystrophy patients in the area of prophylactic pacing devices. Int J Cardiol. 2011;150:54-8.

674. Meune C, Van Berlo JH, Anselme F, Bonne G, Pinto YM, Duboc D. Primary prevention of sudden death in patients with lamin $\mathrm{A} / \mathrm{C}$ gene mutations. $\mathrm{N}$ Engl J Med. 2006;354:209-10.

675. European Society of Gynecology (ESG), Association for European Paediatric Cardiology (AEPC), German Society for Gender Medicine (DGesGM), RegitzZagrosek V, Blomstrom Lundqvist C, Borghi C, Cifkova R, Ferreira R, Foidart JM, Gibbs JS, Gohlke-Baerwolf C, Gorenek B, Iung B, Kirby M, Maas AH, Morais J, Nihoyannopoulos P, Pieper PG, Presbitero P, Roos-Hesselink JW, Schaufelberger M, Seeland U, Torracca L, ESC Committee for Practice Guidelines. ESC Guidelines on the management of cardiovascular diseases during pregnancy: the Task Force on the Management of Cardiovascular Diseases during Pregnancy of the European Society of Cardiology (ESC). Eur Heart J. 2011;32:3147-97.

676. Rashba EJ, Zareba W, Moss AJ, Hall WJ, Robinson J, Locati EH, Schwartz PJ, Andrews M. Influence of pregnancy on the risk for cardiac events in patients with hereditary long QT syndrome. LQTS Investigators. Circulation. 1998;97:451-6.

677. Task Force on the Management of Cardiovascular Diseases During Pregnancy of the European Society of Cardiology. Expert consensus document on management of cardiovascular diseases during pregnancy. Eur Heart J. 2003:24:761-81.

678. Dorian P, Cass D, Schwartz B, Cooper R, Gelaznikas R, Barr A. Amiodarone as compared with lidocaine for shock-resistant ventricular fibrillation. N Engl J Med. 2002:346:884-90.

679. Siu SC, Sermer M, Colman JM, Alvarez AN, Mercier LA, Morton BC, Kells CM, Bergin ML, Kiess MC, Marcotte F, Taylor DA, Gordon EP, Spears JC, Tam JW, Amankwah KS, Smallhorn JF, Farine D, Sorensen S. Prospective multicenter study of pregnancy outcomes in women with heart disease. Circulation. 2001;104:515-21.

680. Drenthen W, Pieper PG, Roos-Hesselink JW, van Lottum WA, Voors AA, Mulder BJ, van Dijk AP, Vliegen HW, Yap SC, Moons P, Ebels T, van Veldhuisen DJ. Outcome 
of pregnancy in women with congenital heart disease: a literature review. J Am Coll Cardiol. 2007;49:2303-11.

681. Roos-Hesselink JW, Ruys TP, Stein JI, Thilen U,Webb GD, Niwa K, Kaemmerer H, Baumgartner H, Budts W, Maggioni AP, Tavazzi L, Taha N, Johnson MR, Hall R. Outcome of pregnancy in patients with structural or ischaemic heart disease: results of a registry of the European Society of Cardiology. Eur Heart J. 2013;34:657-65.

682. Wolbrette D, Naccarelli G, Curtis A, Lehmann M, Kadish A. Gender differences in arrhythmias. Clin Cardiol. 2002;25:49-56.

683. Rodriguez-Manero M, Casado-Arroyo R, Sarkozy A, Leysen E, Sieira JA, Namdar M, Conte G, Levinstein M, Chierchia GB, de Asmundis C, Brugada P. The clinical significance of pregnancy in Brugada syndrome. Rev Esp Cardiol (Engl Ed). 2014;67:176-80.

684. Benito B, Berruezo A. Brugada syndrome and pregnancy: delving into the role of sex hormones in ion channelopathies. Rev Esp Cardiol (Engl Ed). 2014;67:165-7.

685. Shotan A, Ostrzega E, Mehra A, Johnson JV, Elkayam U. Incidence of arrhythmias in normal pregnancy and relation to palpitations, dizziness, and syncope. Am J Cardiol. 1997;79:1061-4.

686. Widerhorn J, Widerhorn AL, Rahimtoola SH, Elkayam U.WPWsyndrome during pregnancy: increased incidence of supraventricular arrhythmias. Am Heart J. 1992;123:796-8.

687. Tawam M, Levine J, Mendelson M, Goldberger J, Dyer A, Kadish A. Effect of pregnancy on paroxysmal supraventricular tachycardia. Am J Cardiol. 1993;72:838-40.

688. Lee SH, Chen SA, Wu TJ, Chiang CE, Cheng CC, Tai CT, Chiou CW, Ueng KC, Chang MS. Effects of pregnancy on first onset and symptoms of paroxysmal supraventricular tachycardia. Am J Cardiol. 1995;76:675-8

689. Brodsky M, Doria R, Allen B, Sato D, Thomas G, Sada M. New-onset ventricular tachycardia during pregnancy. Am Heart J. 1992;123:933-41.

690. Silversides CK, Harris L, Haberer K, Sermer M, Colman JM, Siu SC. Recurrence rates of arrhythmias during pregnancy in women with previous tachyarrhythmia and impact on fetal and neonatal outcomes. Am J Cardiol. 2006;97:1206-12.

691. Sharif-Kazemi MB, Emkanjoo Z, Tavoosi A, Kafi M, Kheirkhah J, Alizadeh A, SadrAmeli MA. Electrical storm in Brugada syndrome during pregnancy. Pacing Clin Electrophysiol. 2011;34:e18-e21.

692. Joglar JA, Page RL. Treatment of cardiac arrhythmias during pregnancy: safety considerations. Drug Saf. 1999;20:85-94.

693. Cox JL, Gardner MJ. Treatment of cardiac arrhythmias during pregnancy. Prog Cardiovasc Dis. 1993;36:137-78.

694. Tan HL, Lie KI. Treatment of tachyarrhythmias during pregnancy and lactation. Eur Heart J. 2001;22:458-64.

695. Abello M, Peinado R, Merino JL, Gnoatto M, Mateos M, Silvestre J, Dominguez JL. Cardioverter defibrillator implantation in a pregnant woman guided with transesophageal echocardiography. Pacing Clin Electrophysiol. 2003;26:1913-4.

696. Natale A, Davidson T, Geiger MJ, Newby K. Implantable cardioverterdefibrillators and pregnancy: a safe combination? Circulation. 1997;96:2808-12.

697. Piper JM, Berkus M, Ridgway LE 3rd. Pregnancy complicated by chronic cardiomyopathy and an automatic implantable cardioverter defibrillator. Am J Obstet Gynecol. 1992:167:506-7.

698. Sliwa K, Hilfiker-Kleiner D, Petrie MC, Mebazaa A, Pieske B, Buchmann E, RegitzZagrosek V, Schaufelberger M, Tavazzi L, van Veldhuisen DJ, Watkins H, Shah A], Seferovic PM, Elkayam U, Pankuweit S, Papp Z, Mouquet F, McMurray JJ. Current state of knowledge on aetiology, diagnosis, management, and therapy of peripartum cardiomyopathy: a position statement from the Heart Failure Association of the European Society of Cardiology Working Group on peripartum cardiomyopathy. Eur J Heart Fail. 2010;12:767-78.

699. Cooper WO, Hernandez-Diaz S, Arbogast PG, Dudley JA, Dyer S, Gideon PS, Hall K, Ray WA. Major congenital malformations after first-trimester exposure to ACE inhibitors. N Engl J Med. 2006;354:2443-51.

700. Regitz-Zagrosek V, Blomstrom Lundqvist C, Borghi C, Cifkova R, Ferreira R, Foidart JM, Gibbs JS, Gohlke-Baerwolf C, Gorenek B, lung B, Kirby M, Maas AH, Morais J, Nihoyannopoulos P, Pieper PG, Presbitero P, Roos-Hesselink JW, Schaufelberger M, Seeland U, Torracca L. ESC Guidelines on the management of cardiovascular diseases during pregnancy: the Task Force on the Management of Cardiovascular Diseases during Pregnancy of the European Society of Cardiology (ESC). Eur Heart J. 2011;32:3147-97.

701. Sliwa K, Fett J, Elkayam U. Peripartum cardiomyopathy. Lancet. 2006;368:687-93.

702. Gunderson EP, Croen LA, Chiang V, Yoshida CK,Walton D, Go AS. Epidemiology of peripartum cardiomyopathy: incidence, predictors, and outcomes. Obstet Gynecol. 2011;118:583-91.

703. Felker GM, Jaeger CJ, Klodas E, Thiemann DR, Hare JM, Hruban RH, Kasper EK, Baughman KL. Myocarditis and long-term survival in peripartum cardiomyopathy. Am Heart J. 2000;140:785-91.

704. van Spaendonck-Zwarts KY, Posafalvi A, van den Berg MP, Hilfiker-Kleiner D, Bollen IA, Sliwa K, Alders M, Almomani R, van Langen IM, van der Meer P, Sinke RJ, van der Velden J, Van Veldhuisen DJ, van Tintelen JP, Jongbloed JD. Titin gene mutations are common in families with both peripartum cardiomyopathy and dilated cardiomyopathy. Eur Heart J. 2014;35:2165-73.

705. Sliwa K, Hilfiker-Kleiner D, Mebazaa A, Petrie MC, Maggioni AP, Regitz-Zagrosek V, Schaufelberger M, Tavazzi L, van Veldhuisen DJ, Roos-Hesslink JW, Shah AJ Seferovic PM, Elkayam U, van Spaendonck-Zwarts K, Bachelier-Walenta K, Mouquet F, Kraigher-Krainer E, Hall R, Ponikowski P, McMurray JJ, Pieske B. EURObservational Research Programme: a worldwide registry on peripartum cardiomyopathy (PPCM) in conjunction with the Heart Failure Association of the European Society of Cardiology Working Group on PPCM. Eur J Heart Fail. 2014;16:583-91.
706. Gowda RM, Khan IA, Mehta NJ, Vasavada BC, Sacchi TJ. Cardiac arrhythmias in pregnancy: clinical and therapeutic considerations. Int J Cardiol. 2003;88: 129-33.

707. Schaefer C. Angiotensin II-receptor-antagonists: further evidence of fetotoxicity but not teratogenicity. Birth Defects Res A Clin Mol Teratol. 2003;67:591-4.

708. Trappe HJ, Pfitzner P. [Cardiac arrhythmias in pregnancy]. Z Kardiol. 2001;90(Suppl 4):36-44.

709. Mirshahi M, Ayani E, Nicolas C, Golestaneh N, Ferrari P, Valamanesh F, Agarwal MK. The blockade of mineralocorticoid hormone signaling provokes dramatic teratogenesis in cultured rat embryos. Int J Toxicol. 2002;21:191-9.

710. Habli M, O'Brien T, Nowack E, Khoury S, Barton JR, Sibai B. Peripartum cardiomyopathy: prognostic factors for long-term maternal outcome. Am J Obstet Gynecol. 2008;199:415.e1-415.e5.

711. Simantirakis EN, Schiza SI, Marketou ME, Chrysostomakis SI, Chlouverakis GI, Klapsinos NC, Siafakas NS, Vardas PE. Severe bradyarrhythmias in patients with sleep apnoea: the effect of continuous positive airway pressure treatment: a longterm evaluation using an insertable loop recorder. Eur Heart J. 2004;25: $1070-6$.

712. Gami AS, Olson EJ, Shen WK, Wright RS, Ballman KV, Hodge DO, Herges RM, Howard DE, Somers VK. Obstructive sleep apnea and the risk of sudden cardiac death: a longitudinal study of 10,701 adults. J Am Coll Cardiol. 2013:62:610-6.

713. Young T, Palta M, Dempsey J, Skatrud J,Weber S, Badr S. The occurrence of sleepdisordered breathing among middle-aged adults. $\mathrm{N}$ Engl J Med. 1993;328:1230-5.

714. Marshall NS, Wong KK, Liu PY, Cullen SR, KnuimanMW, Grunstein RR. Sleep apnea as an independent risk factor for all-cause mortality: the Busselton Health Study. Sleep. 2008;31:1079-85.

715. Young T, Finn L, Peppard PE, Szklo-Coxe M, Austin D, Nieto FJ, Stubbs R, Hla KM. Sleep disordered breathing and mortality: eighteen-year follow-up of the Wisconsin sleep cohort. Sleep. 2008;31:1071-8.

716. Kreuz J, Skowasch D, Horlbeck F, Atzinger C, Schrickel JW, Lorenzen H, Nickenig G, Schwab JO. Usefulness of sleep-disordered breathing to predict occurrence of appropriate and inappropriate implantable-cardioverter defibrillator therapy in patients with implantable cardioverter-defibrillator for primary prevention of sudden cardiac death. Am J Cardiol. 2013;111:1319-23.

717. Bitter T, Westerheide N, Prinz C, Hossain MS, Vogt J, Langer C, Horstkotte D, Oldenburg $\mathrm{O}$. Cheyne-Stokes respiration and obstructive sleep apnoea are independent risk factors for malignant ventricular arrhythmias requiring appropriate cardioverter-defibrillator therapies in patients with congestive heart failure. Eur Heart J. 2011;32:61-74.

718. Roche F, Xuong AN, Court-Fortune I, Costes F, Pichot V, Duverney D, Vergnon JM, Gaspoz JM, Barthelemy JC. Relationship among the severity of sleep apnea syndrome, cardiac arrhythmias, and autonomic imbalance. Pacing Clin Electrophysiol. 2003;26:669-77.

719. Guilleminault C, Connolly SJ, Winkle RA. Cardiac arrhythmia and conduction disturbances during sleep in 400 patients with sleep apnea syndrome. Am J Cardiol. 1983;52:490-4.

720. Becker HF, Koehler U, Stammnitz A, Peter JH. Heart block in patients with sleep apnoea. Thorax. 1998:53(Suppl 3):S29-S32.

721. Grimm W, Hoffmann J, Menz V, Kohler U, Heitmann J, Peter JH, Maisch B. Electrophysiologic evaluation of sinus node function and atrioventricular conduction in patients with prolonged ventricular asystole during obstructive sleep apnea. Am J Cardiol. 1996;77:1310-4.

722. Mehra R, Benjamin EJ, Shahar E, Gottlieb DJ, Nawabit R, Kirchner HL, Sahadevan J, Redline S. Association of nocturnal arrhythmias with sleep-disordered breathing: the Sleep Heart Health Study. Am J Respir Crit Care Med. 2006:173:910-6.

723. Hoffstein V, Mateika S. Cardiac arrhythmias, snoring, and sleep apnea. Chest. 1994;106:466-71.

724. Tilkian AG, Guilleminault C, Schroeder JS, Lehrman KL, Simmons FB, Dement WC. Sleep-induced apnea syndrome. Prevalence of cardiac arrhythmias and their reversal after tracheostomy. Am J Med. 1977;63:348-58.

725. Ryan CM, Usui K, Floras JS, Bradley TD. Effect of continuous positive airway pressure on ventricular ectopy in heart failure patients with obstructive sleep apnoea. Thorax. 2005;60:781-5.

726. Gami AS, Howard DE, Olson EJ, Somers VK. Day-night pattern of sudden death in obstructive sleep apnea. N Engl J Med. 2005;352:1206-14.

727. Gonzalez-Rothi RJ, Foresman GE, Block AJ. Do patients with sleep apnea die in their sleep? Chest. 1988;94:531-8.

728. Seppala T, Partinen M, Penttila A, Aspholm R, Tiainen E, Kaukianen A. Sudden death and sleeping history among Finnish men. J Intern Med. 1991:229:23-8.

729. Zeidan-Shwiri T, Aronson D, Atalla K, Blich M, Suleiman M, Marai I, Gepstein L, Lavie L, Lavie P, Boulos M. Circadian pattern of life-threatening ventricular arrhythmia in patients with sleep-disordered breathing and implantable cardioverter-defibrillators. Heart Rhythm. 2011;8:657-62.

730. Harbison J, O'Reilly P, McNicholas WT. Cardiac rhythm disturbances in the obstructive sleep apnea syndrome: effects of nasal continuous positive airway pressure therapy. Chest. 2000;118:591-5.

731. Grimm W, Koehler U, Fus E, Hoffmann J, Menz V, Funck R, Peter JH, Maisch B. Outcome of patients with sleep apnea-associated severe bradyarrhythmias after continuous positive airway pressure therapy. Am J Cardiol. 2000;86:688-92.

732. Koehler U, Fus E, GrimmW, PankowW, Schafer H, Stammnitz A, Peter JH. Heart block in patients with obstructive sleep apnoea: pathogenetic factors and effects of treatment. Eur Respir J. 1998:11:434-9.

733. Stegman SS, Burroughs JM, Henthorn RW. Asymptomatic bradyarrhythmias as a marker for sleep apnea: appropriate recognition and treatment may reduce the need for pacemaker therapy. Pacing Clin Electrophysiol. 1996;19:899-904. 
734. Garrigue S, Pepin JL, Defaye P, Murgatroyd F, Poezevara Y, Clementy J, Levy P. High prevalence of sleep apnea syndrome in patients with long-term pacing: the European Multicenter Polysomnographic Study. Circulation. 2007;115: 1703-9.

735. Doherty LS, Kiely JL, Swan V, McNicholasWT. Long-term effects of nasal continuous positive airway pressure therapy on cardiovascular outcomes in sleep apnea syndrome. Chest. 2005;127:2076-84.

736. Garrigue S, Bordier P, Jais P, Shah DC, Hocini M, Raherison C, Tunon De Lara M, Haissaguerre M, Clementy J. Benefit of atrial pacing in sleep apnea syndrome. $\mathrm{N}$ Engl J Med. 2002;346:404-12.

737. Simantirakis EN, Vardas PE. Cardiac pacing in sleep apnoea: diagnostic and therapeutic implications. Europace. 2006;8:984-7.

738. Marin JM, Carrizo SJ, Vicente E, Agusti AG. Long-term cardiovascular outcomes in men with obstructive sleep apnoea-hypopnoea with or without treatment with continuous positive airway pressure: an observational study. Lancet. 2005;365:1046-53.

739. Defaye P, de la Cruz I, Marti-Almor J, Villuendas R, Bru P, Senechal J, Tamisier R, Pepin JL. A pacemaker transthoracic impedance sensor with an advanced algorithm to identify severe sleep apnea: the DREAM European study. Heart Rhythm. 2014;11:842-8.

740. Strollo PJ Jr, Soose RJ, Maurer JT, de Vries N, Cornelius J, Froymovich O, Hanson RD, Padhya TA, Steward DL, Gillespie MB, Woodson BT, Van de Heyning PH, Goetting MG, Vanderveken OM, Feldman N, Knaack L, Strohl KP. Upper-airway stimulation for obstructive sleep apnea. N Engl J Med. 2014;370:139-49.

741. Wyse DG, Friedman PL, Brodsky MA, Beckman KJ, Carlson MD, Curtis AB, Hallstrom AP, Raitt MH, Wilkoff BL, Greene HL. Life-threatening ventricular arrhythmias due to transient or correctable causes: high risk for death in followup. J Am Coll Cardiol. 2001;38:1718-24.

742. Monnig G, Kobe J, Loher A, Wasmer K, Milberg P, Zellerhoff S, Pott C, Zumhagen S, Radu R, Scheld HH, Haverkamp W, Schulze-Bahr E, Eckardt L. Role of implantable cardioverter defibrillator therapy in patients with acquired long QT syndrome: a long-term follow-up. Europace. 2012;14:396-401.

743. Wolbrette DL. Risk of proarrhythmia with class III antiarrhythmic agents: sexbased differences and other issues. Am J Cardiol. 2003;91:39D-44D.

744. Haverkamp W, Breithardt G, Camm AJ, Janse MJ, Rosen MR, Antzelevitch C, Escande D, Franz M, Malik M, Moss A, Shah R. The potential for QT prolongation and proarrhythmia by non-antiarrhythmic drugs: clinical and regulatory implications. Report on a policy conference of the European Society of Cardiology. Eur Heart J. 2000;21:1216-31.

745. Rao GA, Mann JR, Shoaibi A, Bennett CL, Nahhas G, Sutton SS, Jacob S, Strayer SM. Azithromycin and levofloxacin use and increased risk of cardiac arrhythmia and death. Ann Fam Med. 2014;12:121-7.

746. RayWA, Murray KT, Hall K, Arbogast PG, Stein CM. Azithromycin and the risk of cardiovascular death. N Engl J Med. 2012;366:1881-90.

747. Lapi F, Wilchesky M, Kezouh A, Benisty JI, Ernst P, Suissa S. Fluoroquinolones and the risk of serious arrhythmia: a population-based study. Clin Infect Dis. 2012;55:1457-65.

748. Svanstrom H, Pasternak B, Hviid A. Use of clarithromycin and roxithromycin and risk of cardiac death: cohort study. BMJ. 2014;349:g4930.

749. Fralick M, Macdonald EM, Gomes T, Antoniou T, Hollands S, Mamdani MM, Juurlink DN, Canadian Drug Safety and Effectiveness Research Network (CDSERN). Co-trimoxazole and sudden death in patients receiving inhibitors of reninangiotensin system: population based study. BMJ. 2014;349:g6196.

750. Tada H, Sticherling C, Oral H, Morady F. Brugada syndrome mimicked by tricyclic antidepressant overdose. J Cardiovasc Electrophysiol. 2001;12:275.

751. Lipshultz SE, Lipsitz SR, Mone SM, Goorin AM, Sallan SE, Sanders SP, Orav EJ, Gelber RD, Colan SD. Female sex and drug dose as risk factors for late cardiotoxic effects of doxorubicin therapy for childhood cancer. N Engl J Med. 1995;332: 1738-43.

752. Steinherz LJ, Steinherz PG, Tan C. Cardiac failure and dysrhythmias 6-19 years after anthracycline therapy: a series of 15 patients. Med Pediatr Oncol. 1995;24:352-61.

753. Anand AJ. Fluorouracil cardiotoxicity. Ann Pharmacother. 1994;28:374-8.

754. Gorgulu S, Celik S, Tezel T. A case of coronary spasm induced by 5-fluorouracil. Acta Cardiol. 2002;57:381-3.

755. Pinter A, Dorian P, Newman D. Cesium-induced torsades de pointes. N Engl J Med. 2002;346:383-4

756. Gowda RM, Cohen RA, Khan IA. Toad venom poisoning: resemblance to digoxin toxicity and therapeutic implications. Heart. 2003;89:e14.

757. Bain RJ. Accidental digitalis poisoning due to drinking herbal tea. Br Med J (Clin Res Ed). 1985;290:1624.

758. Eddleston M, Ariaratnam CA, Sjostrom L, Jayalath S, Rajakanthan K, Rajapakse S, Colbert D, Meyer WP, Perera G, Attapattu S, Kularatne SA, Sheriff MR, Warrell DA. Acute yellow oleander (Thevetia peruviana) poisoning: cardiac arrhythmias, electrolyte disturbances, and serum cardiac glycoside concentrations on presentation to hospital. Heart. 2000;83:301-6.

759. Schnetzler B, Popova N, Collao Lamb C, Sappino AP. Coronary spasm induced by capecitabine. Ann Oncol. 2001;12:723-4.

760. Welch KM, Saiers J, Salonen R. Triptans and coronary spasm. Clin Pharmacol Ther. 2000;68:337-8.

761. Qasim A, Townend J, Davies MK. Ecstasy induced acute myocardial infarction. Heart. 2001;85:E10.

762. Tzivoni D, Banai S, Schuger C, Benhorin J, Keren A, Gottlieb S, Stern S. Treatment of torsade de pointes with magnesium sulfate. Circulation. 1988;77:392-7.

763. Hondeghem LM. Antiarrhythmic agents: modulated receptor applications. Circulation. 1987;75:514-20.
764. Siebels J, Kuck KH. Implantable cardioverter defibrillator compared with antiarrhythmic drug treatment in cardiac arrest survivors (the Cardiac Arrest Study Hamburg). Am Heart J. 1994;127:1139-44.

765. Hellestrand KJ, Burnett PJ, Milne JR, Bexton RS, Nathan AW, Camm AJ. Effect of the antiarrhythmic agent flecainide acetate on acute and chronic pacing thresholds. Pacing Clin Electrophysiol. 1983;6:892-9.

766. Echt DS, Black JN, Barbey JT, Coxe DR, Cato E. Evaluation of antiarrhythmic drugs on defibrillation energy requirements in dogs. Sodium channel block and action potential prolongation. Circulation. 1989;79:1106-17.

767. Torp-Pedersen C, Moller M, Bloch-Thomsen PE, Kober L, Sandoe E, Egstrup K, Agner E, Carlsen J, Videbaek J, Marchant B, Camm AJ. Dofetilide in patients with congestive heart failure and left ventricular dysfunction. Danish Investigations of Arrhythmia and Mortality on Dofetilide Study Group. N Engl J Med. 1999;341:857-65.

768. Lazzara R. Antiarrhythmic drugs and torsade de pointes. Eur Heart J. 1993;14(Suppl H):88-92.

769. Khan IA, Gowda RM. Novel therapeutics for treatment of long-QT syndrome and torsade de pointes. Int J Cardiol. 2004;95:1-6.

770. Barra S, Agarwal S, Begley D, Providencia R. Post-acute management of the acquired long QT syndrome. Postgrad Med J. 2014;90:348-58.

771. Borron SW, Bismuth C, Muszynski J. Advances in the management of digoxin toxicity in the older patient. Drugs Aging. 1997;10:18-33.

772. Solomon RJ. Ventricular arrhythmias in patients with myocardial infarction and ischaemia. Relationship to serum potassium and magnesium. Drugs. 1984;28(Suppl 1):66-76.

773. Sjogren A, Edvinsson L, Fallgren B. Magnesium deficiency in coronary artery disease and cardiac arrhythmias. J Intern Med. 1989;226:213-22.

774. Rasmussen HS, McNair P, Norregard P, Backer V, Lindeneg O, Balslev S. Intravenous magnesium in acute myocardial infarction. Lancet. 1986;1:234-6.

775. Abraham AS, Rosenmann D, Kramer M, Balkin J, Zion MM, Farbstien H, Eylath U. Magnesium in the prevention of lethal arrhythmias in acute myocardial infarction. Arch Intern Med. 1987;147:753-5.

776. Rajs J, Rajs E, Lundman T. Unexpected death in patients suffering from eating disorders. A medico-legal study. Acta Psychiatr Scand. 1986;74:587-96.

777. Iseri LT, Freed J, Bures AR. Magnesium deficiency and cardiac disorders. Am J Med. 1975;58:837-46.

778. Zwerling HK. Does exogenous magnesium suppress myocardial irritability and tachyarrhythmias in the nondigitalized patient? Am Heart J. 1987;113:1046-53.

779. Rosenqvist M, Beyer T, Block M, den Dulk K, Minten J, Lindemans F. Adverse events with transvenous implantable cardioverter-defibrillators: a prospective multicenter study. European 7219 Jewel ICD investigators. Circulation. 1998;98:663-70.

780. Martinez Sanchez J, Garcia Alberol A, Almendral Garrote J, Castellanos E, Perez Castellanos N, Ortiz Paton M, Sanchez Munoz JJ, Llamas Lazaro C, Ruiperez Abizanda JA, Valdes Chavarri M. [Ventricular arrhythmias induced by appropriate antibradycardia pacing in patients with implantable defibrillators]. Rev Esp Cardiol. 2001;54:845-50.

781. Callans DJ, Hook BG, Kleiman RB, Mitra RL, Flores BT, Marchlinski FE. Unique sensing errors in third-generation implantable cardioverter-defibrillators. J Am Coll Cardiol. 1993;22:1135-40.

782. Chantranuwat C, Blakey JD, Kobashigawa JA, Moriguchi JD, Laks H, Vassilakis ME Fishbein MC. Sudden, unexpected death in cardiac transplant recipients: an autopsy study. J Heart Lung Transplant. 2004;23:683-9.

783. Vakil K, Taimeh Z, Sharma A, Abidi KS, Colvin M, Luepker R, Levy WC, Adabag S. Incidence, predictors, and temporal trends of sudden cardiac death after heart transplantation. Heart Rhythm. 2014;11:1684-90.

784. Tsai VW, Cooper J, Garan H, Natale A, Ptaszek LM, Ellinor PT, Hickey K, Downey R, Zei P, Hsia H, Wang P, Hunt S, Haddad F, Al-Ahmad A. The efficacy of implantable cardioverter-defibrillators in heart transplant recipients: results from a multicenter registry. Circ Heart Fail. 2009;2:197-201.

785. Menafoglio A, Di Valentino M, Porretta AP, Foglia P, Segatto JM, Siragusa P, Pezzoli R, Maggi M, Romano GA, Moschovitis G, Gallino A. Cardiovascular evaluation of middle-aged individuals engaged in high-intensity sport activities: implications for workload, yield and economic costs. Br J Sports Med. 2014 Nov 13. doi:10.1136 bjsports-2014-093857 [Epub ahead of print]

786. Borjesson M, Serratosa L, Carre F, Corrado D, Drezner J, Dugmore DL, Heidbuchel HH, Mellwig KP, Panhuyzen-Goedkoop NM, Papadakis M, Rasmusen H, Sharma S, Solberg EE, van Buuren F, Pelliccia A, writing group on behalf of the EACPR Section of Sports Cardiology. Consensus document regarding cardiovascular safety at sports arenas: position stand from the European Association of Cardiovascular Prevention and Rehabilitation (EACPR), section of Sports Cardiology. Eur Heart J. 2011;32:2119-24.

787. Conroy RM, Pyorala K, Fitzgerald AP, Sans S, Menotti A, De Backer G, De Bacquer D, Ducimetiere P, Jousilahti P, Keil U, Njolstad I, Oganov RG, Thomsen T, TunstallPedoe H, Tverdal A, Wedel H, Whincup P, Wilhelmsen L, Graham IM, SCORE project group. Estimation of ten-year risk of fatal cardiovascular disease in Europe: the SCORE project. Eur Heart J. 2003;24:987-1003.

788. Harmon KG, Drezner JA, Wilson MG, Sharma S. Incidence of sudden cardiac death in athletes: a state-of-the-art review. Heart. 2014;100:1227-34.

789. Schmied C, Borjesson M. Sudden cardiac death in athletes. J Intern Med 2014;275:93-103.

790. Corrado D, Basso C, Pavei A, Michieli P, Schiavon M, Thiene G. Trends in sudden cardiovascular death in young competitive athletes after implementation of a preparticipation screening program. JAMA. 2006;296:1593-601.

791. Maron BJ, Araujo CG, Thompson PD, Fletcher GF, de Luna AB, Fleg JL, Pelliccia A Balady GJ, Furlanello F, Van Camp SP, Elosua R, Chaitman BR, Bazzarre TL. Recommendations for preparticipation screening and the assessment of 
cardiovascular disease in masters athletes: an advisory for healthcare professionals from the working groups of the World Heart Federation, the International Federation of Sports Medicine, and the American Heart Association Committee on Exercise, Cardiac Rehabilitation, and Prevention. Circulation. 2001;103:327-34.

792. Borjesson M, Urhausen A, Kouidi E, Dugmore D, Sharma S, Halle M, Heidbuchel H, Bjornstad HH, Gielen S, Mezzani A, Corrado D, Pelliccia A, Vanhees L. Cardiovascular evaluation of middle-aged/senior individuals engaged in leisuretime sport activities: position stand from the sections of exercise physiology and sports cardiology of the European Association of Cardiovascular Prevention and Rehabilitation. Eur J Cardiovasc Prev Rehabil. 2011;18:446-58.

793. Pappone C, Vicedomini G, Manguso F, Saviano M, Baldi M, Pappone A, Ciaccio C, Giannelli L, Ionescu B, Petretta A, Vitale R, Cuko A, Calovic Z, Fundaliotis A Moscatiello M, Tavazzi L, Santinelli V. Wolff-Parkinson-White syndrome in the era of catheter ablation: insights from a registry study of 2169 patients. Circulation. 2014;130:811-9.

794. Obeyesekere MN, Leong-Sit P, Massel D, Manlucu J, Modi S, Krahn AD, Skanes AC, Yee R, Gula LJ, Klein GJ. Risk of arrhythmia and sudden death in patients with asymptomatic preexcitation: a meta-analysis. Circulation. 2012;125:2308-15.

795. Munger TM, Packer DL, Hammill SC, Feldman BJ, Bailey KR, Ballard DJ, Holmes DR Jr Gersh BJ. A population study of the natural history ofWolff-Parkinson-White syndrome in Olmsted County, Minnesota, 1953-1989. Circulation. 1993;87:866-73.

796. Cohen MI, Triedman JK, Cannon BC, Davis AM, Drago F, Janousek J, Klein GJ, Law IH, Morady FJ, Paul T, Perry JC, Sanatani S, Tanel RE. PACES/HRS expert consensus statement on the management of the asymptomatic young patient with a WolffParkinson-White (WPW, ventricular preexcitation) electrocardiographic pattern: developed in partnership between the Pediatric and Congenital Electrophysiology Society (PACES) and the Heart Rhythm Society (HRS). Endorsed by the governing bodies of PACES, HRS, the American College of Cardiology Foundation (ACCF), the American Heart Association (AHA), the American Academy of Pediatrics (AAP), and the Canadian Heart Rhythm Society (CHRS). Heart Rhythm. 2012;9:1006-24.

797. Soumerai SB, McLaughlin TJ, Spiegelman D, Hertzmark E, Thibault G, Goldman L. Adverse outcomes of underuse of beta-blockers in elderly survivors of acute myocardial infarction. JAMA. 1997;277:115-21.

798. Kong MH, Al-Khatib SM, Sanders GD, Hasselblad V, Peterson ED. Use of implantable cardioverter-defibrillators for primary prevention in older patients: a systematic literature review and meta-analysis. Cardiol J. 2011;18:503-14.

799. Santangeli P, Di Biase L, Dello Russo A, Casella M, Bartoletti S, Santarelli P, Pelargonio G, Natale A. Meta-analysis: age and effectiveness of prophylactic implantable cardioverter-defibrillators. Ann Intern Med. 2010;153:592-9.
800. Healey JS, Hallstrom AP, Kuck KH, Nair G, Schron EP, Roberts RS, Morillo CA, Connolly SJ. Role of the implantable defibrillator among elderly patients with a history of life-threatening ventricular arrhythmias. Eur Heart J. 2007;28: 1746-9.

801. Chan PS, Nallamothu BK, Spertus JA, Masoudi FA, Bartone C, Kereiakes DJ, Chow T. Impact of age and medical comorbidity on the effectiveness of implantable cardioverter-defibrillators for primary prevention. Circ Cardiovasc Qual Outcomes. 2009;2:16-24.

802. Brullmann S, Dichtl W, Paoli U, Haegeli L, Schmied C, Steffel J, Brunckhorst C, Hintringer F, Seifert B, Duru F, Wolber T. Comparison of benefit and mortality of implantable cardioverter-defibrillator therapy in patients aged $\geq 75$ years versus those ,75 years. Am J Cardiol. 2012;109:712-7.

803. Noyes K, Corona E, Zwanziger J, Hall WJ, Zhao H, Wang H, Moss AJ, Dick AW. Health-related quality of life consequences of implantable cardioverter defibrillators: results from MADIT II. Med Care. 2007;45:377-85.

804. Lunney JR, Lynn J, Foley DJ, Lipson S, Guralnik JM. Patterns of functional decline at the end of life. JAMA. 2003;289:2387-92.

805. Padeletti L Arnar DO, Boncinelli L, Brachman J, Camm JA, Daubert JC, Hassam SK, Deliens L, Glikson M, Hayes D, Israel C, Lampert R, Lobban T, Raatikainen P, Siegal G, Vardas P, Reviewers, Kirchhof P, Becker R, Cosio F, Loh P, Cobbe S, Grace A, Morgan J. EHRA Expert Consensus Statement on the management of cardiovascular implantable electronic devices in patients nearing end of life or requesting withdrawal of therapy. Europace. 2010;12:1480-9.

806. Jaarsma T, Beattie JM, Ryder M, Rutten FH, McDonagh T, Mohacsi P, Murray SA, Grodzicki T, Bergh I, Metra M, Ekman I, Angermann C, Leventhal M, Pitsis A, Anker SD, Gavazzi A, Ponikowski P, Dickstein K, Delacretaz E, Blue L, Strasser F, McMurray J. Palliative care in heart failure: a position statement from the palliative care workshop of the Heart Failure Association of the European Society of Cardiology. Eur J Heart Fail. 2009;11:433-43.

807. Goldstein NE, Lampert R, Bradley E, Lynn J, Krumholz HM. Management of implantable cardioverter defibrillators in end-of-life care. Ann Intern Med. 2004; $141: 835-8$.

808. Wright GA, Klein GJ, Gula LJ. Ethical and legal perspective of implantable cardioverter defibrillator deactivation or implantable cardioverter defibrillator generator replacement in the elderly. Curr Opin Cardiol. 2013;28:43-9.

809. Lampert R, Hayes DL, Annas GJ, Farley MA, Goldstein NE, Hamilton RM, Kay GN, Kramer DB, Mueller PS, Padeletti L, Pozuelo L, Schoenfeld MH, Vardas PE, Wiegand DL, Zellner R. HRS Expert Consensus Statement on the Management of Cardiovascular Implantable Electronic Devices (CIEDs) in patients nearing end of life or requesting withdrawal of therapy. Heart Rhythm. 2010;7:1008-26. 